ISSN 1819-9496 (print)

ISSN 2500-0136 (online)

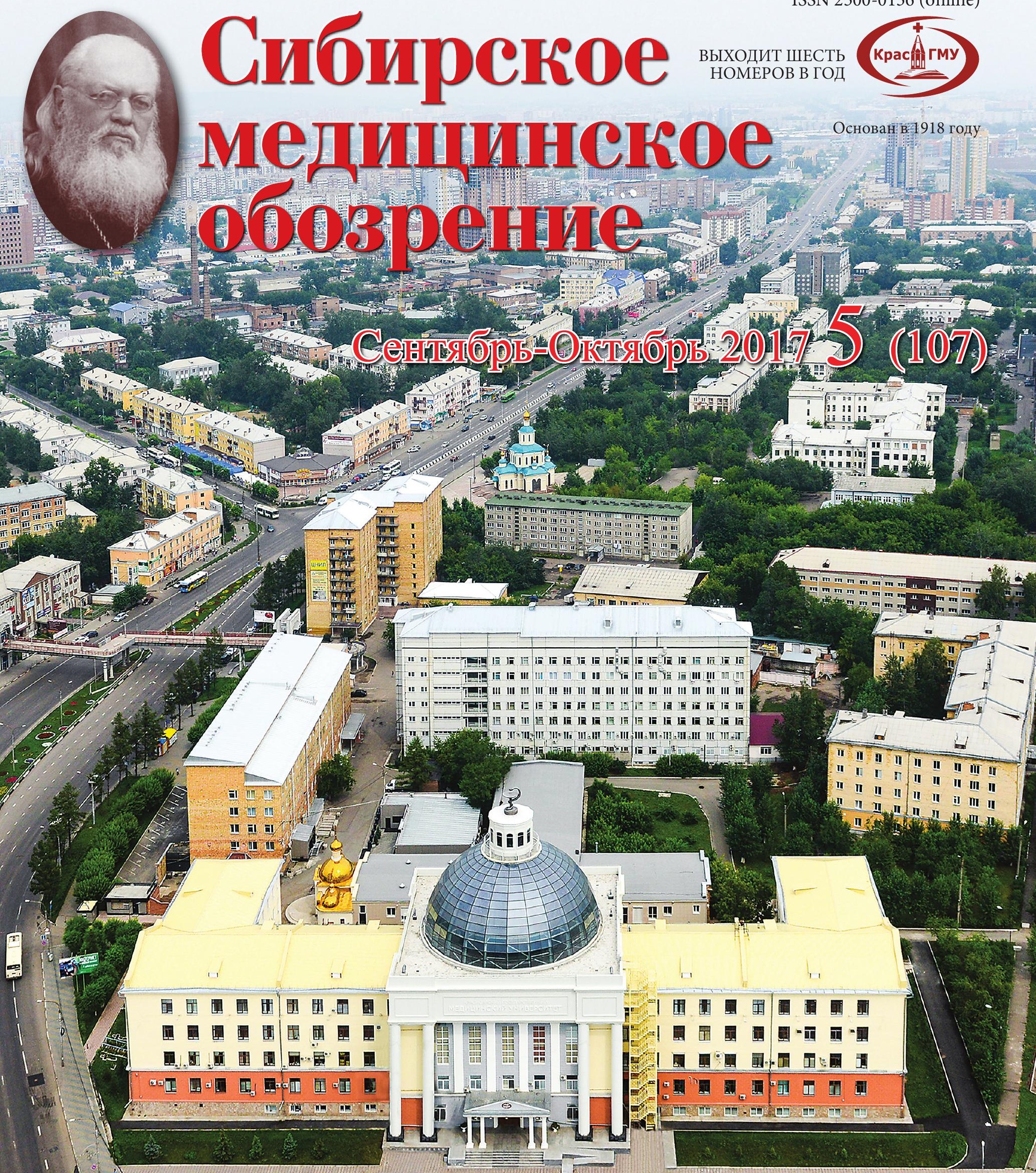

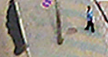




\section{Сибирское}

\section{медицинское обозрение

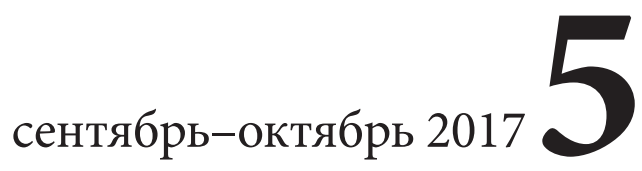

ВЫХОДИТ ШЕСТЬ НОМЕРОВ В ГОД

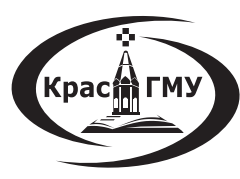

Основан в 1918 году

\section{Учредитель:}

Федеральное государственное бюджетное образовательное учреждение высшего образования «Красноярский государственный медицинский университет имени профессора

\section{В. Ф. Войно-Ясенецкого» Министерства здравоохранения Российской Федерации}

\section{Главный редактор}

д. м. н., профессор И. П. Артюхов

\section{Зам. главного редактора:}

д. м. н., профессор М. М. Петрова

к. м. н. И. А. Соловьева

\section{Выпускающий редактор:}

д. м. н., профессор И. В. Демко

Первый номер журнала «Сибирское медицинское обозрение» вышел в свет в 1918 году. Это был первый медицинский журнал в Сибири. У истоков его стояли известные деятели в области клинической медицины, общественного здоровья и здравоохранения Красноярска В. М. Крутовский, П. И. Мажаров, Р. К. Пикок, П. Н. Коновалов и другие. Журнал возрожден в 2001 году по решению Ученого совета КрасГМА.

Журнал зарегистрирован Федеральной службой по надзору в сфере связи, информационных технологий и массовых коммуникаций

ПИ № ФС77-38747 от 29 января 2010 г.

Адрес редакции:

660022, г. Красноярск, ул. Партизана Железняка, 1

Тел. 8 (391) 220-06-28, факс (391) 223-78-35

E-mail: rector@krasgmu.ru, sibmed-obozrenie@yandex.ru

Подписные индексы каталогов по Российской Федерации:

Пресса России: годовой -79794 , полугодовой -41043.

Допечатная подготовка и печать типография ООО «Знак»

Адрес: 660028, г. Красноярск, ул. Телевизорная, 1

Тел./факс (391) 220-00-90, e-mail:pkznak24@yandex.ru

Подписано в печать 24.10.2017 г. Дата выхода в свет 31.10.2017 г.

Формат 60+84/8, п.л. 9,5. Печать офсетная. Заказ № 3079. Тираж 1000 экз. Цена договорная. Производственно-практическое издание.

Фотография на 1-й стр. обложки Влада Степанова.

\section{Редакционная коллегия}

С. Н. Авдеев (Москва, Россия) - д. м. н., профессор В. В. Алямовский (Красноярск, Россия) - д. м. н., профессор А. А. Визель (Казань, респ. Татарстан) - д. м. н., профессор Ю. С. Винник (Красноярск, Россия) - д. м. н., профессор М. Ю. Галактионова (Красноярск, Россия) - д. м. н., доцент Ю. И. Гринштейн (Красноярск, Россия) - д. м. н., профессор А. И. Грицан (Красноярск, Россия) - д. м. н., профессор И. В. Демко (Красноярск, Россия) - д. м. н., профессор Т. В. Докукина (Минск, Беларусь) - д. м. н., доцент Н. В. Исаева (Красноярск, Россия) - д. м. н., профессор В. В. Козлов (Москва, Россия) - к. м. н., доцент

Г. И. Лифшиц (Новосибирск, Россия) - д. м. н., профессор В. Т. Манчук (Красноярск, Россия) - член-корр. РАН Н. Н. Медведева (Красноярск, Россия) - д. м. н., профессор А. Н. Наркевич (Красноярск, Россия) - к. м. н.

В. А. Невзорова (Владивосток, Россия) - д. м. н., профессор О. Д. Остроумова (Москва, Россия) - Д. м. н., профессор А. А. Савченко (Красноярск, Россия) - Д. м. н., профессор А. Б. Салмина (Красноярск, Россия) - д. м. н., профессор П. А. Самотёсов (Красноярск, Россия) - д. м. н., профессор Д. Б. Никитюк (Москва, Россия) - член-корр. РАН Д. В. Черданцев (Красноярск, Россия) - д. м. н., профессор Н. А. Шнайдер (Красноярск, Россия) - д. м. н., профессор А. В. Шульмин (Красноярск, Россия) - д. м. н., доцент В. Б. Цхай (Красноярск, Россия) - д. м. н., профессор

\section{Редакционный совет}

О. Л. Барбараш (Кемерово, Россия) - д. м. н., профессор A. Verkhratsky (Манчестер, Великобритания) - д. б. н., профессор М. И. Воевода (Новосибирск, Россия) - член-корр. РАН А. В. Говорин (Чита, Россия) - д. м. н., профессор А. В. Калиниченко (Новосибирск, Россия) - д. м. н., профессор Р. С. Карпов (Томск, Россия) - акад. РАН

А. Д. Куимов (Новосибирск, Россия) - д. м. н., профессор Р. Д. Курбанов (Ташкент, Узбекистан) - д. м. н., профессор И. О. Маринкин (Новосибирск, Россия) - д. м. н., профессор В. А. Марков (Томск, Россия) - д. м. н., профессор А. А. Модестов (Москва, Россия) - д. м. Н., профессор Р. Г. Оганов (Москва, Россия) - акад. РАН

В. П. Пузырев (Томск, Россия) - акад. РАН

А. В. Черных (Воронеж, Россия) - член-корр. РАН

А. Г. Чучалин (Москва, Россия) - акад. РАН

А . Ebert (Берлин, Германия) - д. м. н., профессор 


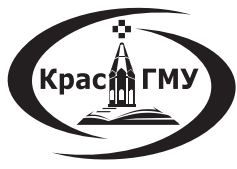

Was founded in 1918

\section{The founders:}

\section{Prof. V. F. Voino-Yasenetsky Krasnoyarsk State Medical University}

\section{Editor in Chief}

Doctor of Medical Science, Professor I. P. Artyukhov

Deputy Chief Editors:

Doctor of Medical Science, Professor M. M. Petrova Candidate of Medical Sciences I. A. Soloveva

\section{Issue Editor:}

Doctor of Medical Science, Professor I.V. Demko

The first issue of the journal "Siberian Medical Review" was published in 1918. It was the first medical journal in Siberia. At the beginnings of the journal were well-known persons of the clinical medicine, public health in Krasnoyarsk - V. M. Krutovsky, P. I. Mazharov, R. K. Peacock, P. N. Konovalov and others. The journal was revived in 2001 by the decision of the KrasSMA Academic Council.

The Journal is registered by the Federal Service for Supervision in the Sphere of Communications, Information Technologies and Mass Communications PI No. FS 77-38747 dated January 29, 2010.

The editorial office:

1, Partizan Zheleznyak Str., Krasnoyarsk, Russia, 660022

Phone + 7391 220-06-28, fax + 7391 223-78-35

E-mail: rector@krasgmu.ru, sibmed-obozrenie@yandex.ru Subscription indexes in catalogs of the Russian Federation: Media of Russia: annual - 79794, half-yearly - 41043. Prepress and Printed in the workshops «Znak, LTD» Address: 1, Televizornaya Str., Krasnoyarsk, Russia, 660028 Phone/fax:+7 391 220-00-90, e-mail: pkznak24@yandex.ru Signed in printing 24.10.2017. Format 60+84/8, p.p. 9,5. Offset printing. Ordering № 3079. Print run 1000 copies. The price is negotiable. Production and Practical Edition. Photo on the front cover Vyacheslav Stepanov

\section{Editorial Board}

S. N. Avdeev (Moscow, Russia) - Dr. Med. Sci., Professor V. V. Alyamovskiy (Krasnoyarsk, Russia) - Dr. Med. Sci., Professor A. A. Vizel (Kazan, Republic of Tatarstan) - Dr. Med. Sci., Professor Yu. S. Vinnik (Krasnoyarsk, Russia) - Dr. Med. Sci., Professor M. Yu. Galaktionova (Krasnoyarsk, Russia) - Dr. Med. Sci., Associate Professor Yu. I. Grinshtein (Krasnoyarsk, Russia) - Dr. Med. Sci., Professor A. I. Gritsan (Krasnoyarsk, Russia) - Dr. Med. Sci., Professor I. V. Demko (Krasnoyarsk, Russia) - Dr. Med. Sci., Professor T. V. Dokukina (Minsk, Belarus) - Dr. Med. Sci., Associate Professor N. V. Isaeva (Krasnoyarsk, Russia) - Dr. Med. Sci., Professor V. V. Kozlov (Moscow, Russia) - Cand. Med. Sci., Associate Professor G. I. Lifshits (Novosibirsk, Russia) - Dr. Med. Sci., Professor V. T. Manchuk (Krasnoyarsk, Russia) - Corresponding Member of RAS N. N. Medvedeva (Krasnoyarsk, Russia) - Dr. Med. Sci., Professor A. N. Narkevich (Krasnoyarsk, Russia) - Cand. Med.Sci.

V. A. Nevzorova (Vladivostok, Russia) - Dr. Med. Sci., Professor O. D. Ostroumova (Moscow, Russia) - Dr. Med. Sci., Professor A. A. Savchenko (Krasnoyarsk, Russia) - Dr. Med. Sci., Professor A. B. Salmina (Krasnoyarsk, Russia) - Dr. Med. Sci., Professor P. A. Samotyosov (Krasnoyarsk, Russia) - Dr. Med. Sci., Professor D. B. Nikityuk (Moscow, Russia) - Corresponding Member of RAS D. V. Cherdantsev (Krasnoyarsk, Russia) - Dr. Med. Sci., Professor N. A. Shnayder (Krasnoyarsk, Russia) - Dr. Med. Sci., Professor A. V. Shulmin (Krasnoyarsk, Russia) - Dr. Med. Sci., Associate Professor V. B. Tskhay (Krasnoyarsk, Russia) - Dr. Med. Sci., Professor

\section{Editorial Advisory Board}

O. L. Barbarash (Kemerovo, Russia) - Dr. Med. Sci., Professor A. Verkhratsky (Manchester, Great Britain) - Dr. Med. Sci., Professor M. I. Voevoda (Novosibirsk, Russia) - Corresponding Member of RAS A. V. Govorin (Chita, Russia) - Dr. Med. Sci., Professor A. V. Kalinichenko (Novosibirsk, Russia) - Dr. Med. Sci., Professor R. S. Karpov (Tomsk, Russia) - Acad. of RAS A. D. Kuimov (Novosibirsk, Russia)- Dr. Med. Sci., Professor R. D. Kurbanov (Tashkent, Uzbekistan) - Dr. Med. Sci., Professor I. O. Marinkin (Novosibirsk, Russia) - Dr. Med. Sci., Professor V. A. Markov (Tomsk, Russia) - Dr. Med. Sci., Professor

A. A. Modestov (Moscow, Russia) - Dr. Med. Sci., Professor R. G. Oganov (Moscow, Russia) - Acad. of RAS V. P. Puzyrev (Tomsk, Russia) - Acad. of RAS A. V. Chernyh (Voronezh, Russia) - Corresponding Member of RAS A. G. Chuchalin (Moscow, Russia) - Acad. of RAS

A. Ebert (Berlin, Germany) - Dr. Med. Sci., Professor 


\section{СОДЕРЖАНИЕ}

Артюхов И. П. Обращение к читателям . 5

\section{ПЕРЕДОВАЯ СТАТЬЯ}

Артюхов И. П., Шульмин А. В., Обухов А. А., Тихонова Н. В. Живая память о Святителе Луке (Войно-Ясенецком) 6

\section{НАУЧНЫЕ ОБЗОРЫ}

Кобякова О. С., Деев И. А., Куликов Е. С., Пименов И. Д., Тюбилин Д. С. Естественное течение бронхиальной астмы: факторы, не позволяющие достичь контроля в долгосрочной перспективе

Коростовиева Л. С., Вареницына С. Ю., Бочкарев М. В., Семенов А. П., Свиряев Ю. В. Брадиаритмии при синдроме обструктивного апноэ во время сна: тактика ведения.

\section{ОРИГИНАЛЬНЫЕ ИССЛЕДОВАНИЯ}

Овчаренко С. И., Галеикайте Я. К., Волель Б. А. Лёгочная реабилитация больных хронической обструктивной болезнью тегких с учётом типа реагирования на заболевание.

Антонов В. Н. Этиологические и клинические аспекты манифестации различных вариантов течения хронической обструктивной болезни легких ......

Визель А. А., Вафина А. Р., Визель И. Ю., Салахова И. Н., Дьякова Е. В., Кудрявиева Э. З. Характеристика больных бронхиальной астмой, поступивших в стационары города Казани .

Сергеева И. В., Демко И. В., Корчагин Е. Е. Клинико-лабораторная характеристика больных внебольничными пневмониями на фоне гриппа A(H1N1)PDM09.

Наркевич А. Н., Виноградов К. А., Кореикая Н. М. Параметризация объектов на цифровых микроскопических изображениях мокроты, окрашенной по методу Циля-Нильсена .

Савченко А. А., Гринитейн Ю. И., Гринитейн И. Ю., Гвоздев И. И., Петрова М. М. Зависимость метаболизма тромбоцитов от хемилюминесцентной активности нейтрофилов при остром коронарном синдроме

Шимохина Н. Ю., Петрова М. М., Савченко А. А. Показатели тредмил-теста у больных острым коронарным синдромом и тревожно-депрессивными расстройствами ..

Павлюкова Е. Н., Кужель Д. А., Матюшин Г. В., Яковлев Е. И., Новоселов О. В. Корреляционный анализ скручивания левого желудочка при блокаде левой ножки пучка Гиса.

Припачкина Е. А., Филёв А. П., Говорин А. В., Муха Н. В., Василенко П. В., Соколова Н. А. Особенности вариабельности ритма сердца у беременных с идиопатической желудочковой экстрасистолией

Дочкина Е. С., Устинова А. В., Таранущенко Т. Е. Особенности анамнеза детей с детским церебральным параличом. .85

\section{ПРАКТИЧЕСКАЯ МЕДИЦИНА}

Безденежных А. В., Сумин А. Н. Оценка риска сердечно-сосудистых осложнений при внесердечных оперативных вмешательствах: коморбидность и применение шкал клинической оценки.

\section{МНЕНИЕ ПО ПРОБЛЕМЕ}

Кох Н. В., Слепухина А. А., Лифшии Г. И. Подходы к профилактике и лечению метаболического синдрома: нутригенетика 105

Кондрикова Н. В., Помешкина С. А., Барбараш О. Л. Пациент после коронарного шунтирования: фокус на восстановление трудоспособности..

\section{ЗАЩИЩЕННЫЕ ДИССЕРТАЦИИ}

Штарик С. Ю. Обзор тематики диссертаций, рассмотренных в 2016 году советом по защите диссертаций на соискание ученой степени кандидата наук, на соискание ученой степени доктора наук Д 208.037.01 по специальности 14.01.08 - педиатрия ............115 


\section{CONTENTS}

Artyukhov I. P. The appeal to readers 5

\section{LEADING ARTICLE}

Artyukhov I. P., Shulmin A. V., Obukhov A. A., Tihonova N. V. Live memory of the Saint Luka (Voino-Yasenetsky). 6

\section{SCIENTIFIC REVIEWS}

Kobyakova O. S., Deev I. A., Kulikov E. S., Pimenov I. D., Tyuflin D. S. Natural course of bronchial asthma: factors that don't allow to achieve the control in a long-term perspective.

Korostovtseva L. S., Varenitsyna S. Yu., Bochkarev M. V., Semenov A. P., Sviryaev Yu. V. Bradyarrhythmias in the obstructive sleep apnea syndrome: treatment tactics.

\section{ORIGINAL RESEARCH}

Ovcharenko S. I., Galetskayte Y. K., Volel B. A. Pulmonary rehabilitation of patients with chronic obstructive pulmonary disease and the type of disease-related response.

Antonov V. N. Etiological and clinical aspects of manifestation the various variants of chronic obstructive pulmonary disease course........ 35

Vizel A. A., Vafina A. R., Vizel I. Yu., Salakhova I. N., Dyakova E. V., Kudryavtseva E. Z. Characteristics of patients with bronchial asthma have admitted to the stationares of the city of Kazan..

Sergeeva I. V., Demko I. V., Korchagin E. E. Clinical-laboratory characteristics of patients with extramural pneumonia against the background of FLU A(H1N1)pdm09.. 47

Narkevich A. N., Vinogradov K. A., Koretskaya N. M. Parameterization of objects on digital microscopic images of sputum, stained by the Ziehl-Neelsen method..

Savchenko A. A., Grinshtein Yu. I., Grinshtein I. Yu., Gvozdev I. I., Petrova M. M. Dependence of thrombocytes metabolism from the chemiluminesent activity of neutrophils in patients with different sensitivity to acetylsalicylic acid in acute coronary syndrome. .........59 Shimohina N. Yu., Petrova M. M., Savchenko A. A. Treadmill test indicators in patients with acute coronary syndrome and anxiety-depressive disorders.

Pavlyukova E. N., Kuzhel D. A., Matyushin G. V., Yakovlev E. I., Novoselov O. V. Correlation analysis of left ventricle twisting at blockade of ventriculonector left leg.

Pripachkina E. A., Filev A. P., Govorin A. V., Mukha N. V., Vasilenko P. V., Socolova N. A. Peculiarities of variability of heart rhythm in pregnant women with idiopathic ventricular extrasystole..

Dochkina E. S., Ustinova A. V., Taranushenko T. E. Peculiarities of anamnesis in children with infantile cerebral palsy... 85

\section{PROBLEMS OF PRACTICAL HEALTH CARE}

Bezdenezhnykh A. V., Sumin A. N. Evaluation of cardiac-vascular complications risk in out-of-cardiac surgery: comorbidity and use of clinical evaluation scale.

\section{OPINION ABOUT THE PROBLEM}

Kokh N. V., Slepukhina A. A., Lifshits G.I. Approaches to prevention and treatment of metabolic syndrome: nutrigenetics.. 105

Kondrikova N. V., Pomeshkina S. A., Barbarash O. L. Patient after coroary artery bypass grafting. 109

\section{DISSERTATIONS}

Shtarik S. Yu. Review of dissertation topics that were submitted in 2016 by the Committee of Dissertation defense for the degree of candidate of science, for the degree of doctor of science D 208.037.01 in specialty 14.01.08 - pediatrics. 


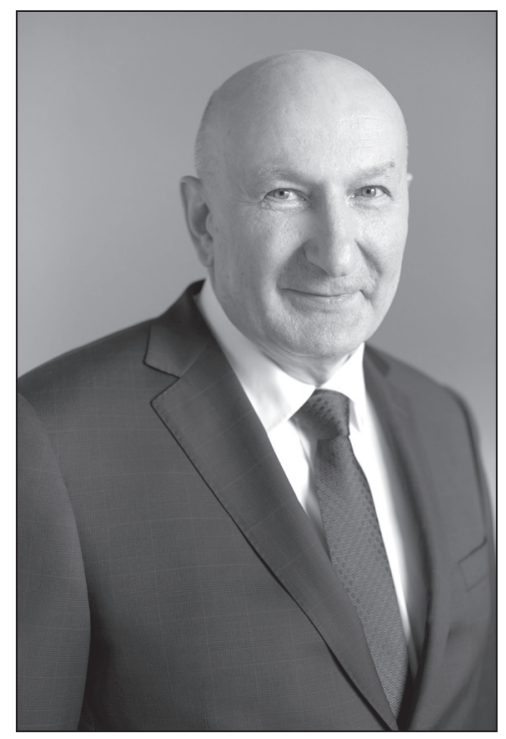

\section{Дорогие друзвя!}

Вы держите в руках журнал, у истоков которого стояли известные деятели в области клинической медицины, общественного здоровья и здравоохранения Красноярска - это был первый медицинский журнал в Сибири. И, видимо, глубоко символичен тот факт, что сегодня его номер посвящен нашему университету, отмечающему в эти дни свое 75-летие - вклад КрасГМУ в развитие здравоохранения Сибири, да и России в целом, неоценим.

За время своего существования Красноярский государственный медицинский университет им. проф. В. Ф. Войно-Ясенецкого подготовил около сорока тысяч высококлассных специалистов различного профиля, многие из которых стали выдающимися организаторами практического здравоохранения, известными на всю страну преподавателями, учеными с мировым именем. И сейчас в нашем коллективе трудится более полутора сотен докторов и почти четыреста кандидатов медицинских наук, почти у каждого из них свои ученики, своя школа.

Эта преемственность поколений - фундаментальная основа нашего коллектива. У нас одно из лучших в стране студенческих научных обществ, и у нас работают ученые - лауреаты правительственных премий и престижных научных грантов. КрасГМУ соавтор более трех десятков договоров о международном сотрудничестве с ведущими университетами мира, а на его площадях успешно работают несколько научных лабораторий и научных центров с международным участием.

Все это, безусловно, является отличной питательной средой для занятия наукой, что, в свою очередь, отражается и на страницах журнала «Сибирское медицинское обозрение» - одной из главных наших научных площадок. И 75-летний юбилей КрасГМУ - это наш общий праздник. Это праздник и тех, кто в суровые годы войны закладывал основы нашего вуза - мы бережно храним о них память, и тех, кто, продолжая традиции, упорно продолжает бороться за укрепление здоровья нации и будущее России.

Вместе мы победим!

С праздником, дорогие друзъя!

Иван АРТЮХОВ,

ректор Красноярского государственного медицинского университета им. проф. В. Ф. Войно-Ясенецкого, профессор, д.м.н. 


\section{Передовая статья / Leading article}

( ) АРТЮХОВ И. П., ШУЛЬМИН А. В., ОБУХОВ А. А., ТИХОНОВА Н. В.

УДК 617(092)ВОЙНО-ЯСЕНЕЦКИЙ В.Ф.

DOI: $10.20333 / 2500136-2017-5-6-9$.

\section{ЖИВАЯ ПАМЯТЬ О СВЯТИТЕЛЕ ЛУКЕ (ВОЙНО-ЯСЕНЕЦКОМ)}

И. П. Артюхов ${ }^{1}$ А. В. Шульмин ${ }^{1}$, А. А. Обухов ${ }^{2}$ Н. В. Тихонова ${ }^{1}$

${ }^{1}$ Красноярский государственный медицинский университет им. проф. В. Ф. Войно-Ясенецкого, Красноярск 660022, Российская Федерация

${ }^{2}$ Красноярская митрополия русской православной церкви, Красноярск, Советский район Храм во имя святителя Луки, архиепископа

Красноярского. Красноярск 660022, Российская Федерация

Резюме. Исследование жизни высоко-духовных людей, таких как Святитель Лука (Войно-Ясенецкий), позволяют находить факты, знакомство с которыми вносят вклад в формирование целостной гуманной личности будущего медицинского работника и гражданина страны.

Ключевые слова: смысл жизни, нравственность, судьба, служение, совесть, профессия врача.

Для цитирования: Артюхов ИП, Шульмин АВ, Обухов АА, Тихонова НВ. Живая память о святителе Луке (Войно-Ясенецком). Сибирское медииинское обозрение. 2017;(5): 6-9. DOI: 10.20333/2500136-2017-5-6-9.

\section{LIVE MEMORY OF THE SAINT LUKA (VOINO-YASENETSKY)}

I. P.Artyukhov' ${ }^{1}$ A. V. Shul'min 1 , A. A. Obukhov' ${ }^{2}$ N. V. Tihonova ${ }^{1}$

${ }^{1}$ Professor V. F. Voino-Yasenetsky Krasnoyarsk State Medical University; Krasnoyarsk 660022, Russian Federation

${ }^{2}$ Krasnoyarsk Orthodox Metropolis of the Russian Orthodox Church, Krasnoyarsk, Sovetskiy district The temple named after St. Luke, Archbishop of

Krasnoyarsk, Krasnoyarsk 660022, Russian Federation

Abstract. The study of the life of high-spiritual people, such as St. Luka (Voino-Yasenetsky), allows us to find the facts that make contribution to the formation of a holistic humane personality of the future medical specialist and citizen of the country.

Key words: meaning of life, morality, destiny, service, conscience, profession of doctor.

Citation: Artyukhov IP, Shul'min AV, Obukhov AA, Tihonova NV. Live memory of the Saint Luka (Voino-Yasenetsky). Siberian Medical Review. 2017; (5): 6-9. DOI: 10.20333/2500136-2017-5-6-9.

\section{Введение}

При освоении профессии врача возникает много вопросов и общефилософской направленности и морально-нравственного содержания. Тогда и возникает необходимость обращения к опыту людей, жизнь и смерть которых содержат ответы на эти сложные вопросы, которые задает нам жизнь. Рождаясь, человек открывается миру как чистый лист и дальнейшая его судьба во многом зависит от того, что будет вписано в его книгу памяти. Индивидуальное сознание, вливаясь в социум, начинает взаимодействовать с другими людьми. Качество взаимоотношений человека будет во много определяться, что к этому моменту он усвоил и освоил. Совесть, сострадание, любовь должны как можно раньше войти в стратегию смысла жизни человека и закрепиться в его памяти. Взрослея, homo sapiens задает себе трудные вопросы «зачем я живу», «что будет со мной после смерти», но ответы на них он готов принять только от тех, кто заслуживает доверия.

Бывает так, что хорошими уроками для нас являются отдельные эпизоды из жизни людей. Но иногда в мир приходят люди, житие которых становится особым примером познания премудрости выбора в поступках, в формировании мироощущения. Еще более редко слу- чается так, что жизнь человека сияет гранями многих добродетелей в служении Богу и людям. Таким является житие свт. Луки проф. В. Ф. Войно-Ясенецкого [1, 2, $3,4,5]$. Это именно тот случай, когда мы видим, как практически наш современник восходил путем проб, ошибок, страданий не только к профессиональному признанию, но и к святости.

Святитель Лука (проф. В. Ф. Войно-Ясенецкий) чтится церковью, научным сообществом и врачами. Его именем названы десятки храмов, медицинских организаций, ВУЗов, общественных организаций. Очень важно, чтобы все, кто встречаются с его именем, имели правильное представление о житие этого великого целителя телесных и душевных недугов людей.

Обращаясь к памяти о Святителе Луке, следует не забывать о том, что также как человек не сразу становится профессионалом, так и не сразу человек духовный становится на духовно-нравственную ступень, когда его причисляют к лику Святых. Иногда на предложение в поиске ответов на проблемы жизни воспользоваться опытом или советом человека высокого жития звучит контраргумент: «так это же святой, а я человек грешный и слабый». Другой стороной медали является сетование: «Какой же он профессионал если 
сам пишет, что допускал ошибки» или «Какой же он святой если грешил». На что можно ответить - только поверхностный взгляд или нежелание изменить себя рождает такое суждение, поскольку даже если немного вникнуть в жизнь В. Ф. Войно-Ясенецкого, мы увидим путь сомнений, ошибок и даже падений, но мы увидим и способность преодолевать сомнения, исправлять ошибки и подниматься после падений, основанных на собственных усилиях, сопряженных с помощью Бога.

Первое чему можно научиться из жизни Валентина Феликсовича - это подход к выбору профессии. Движимый желанием помогать людям юный Валентин выбирает между реализацией таланта художника и профессией врача. Вот цитата из его воспоминаний о выборе профессии врача: «Это соответствовало моим стремлениям быть полезным для крестьян, так плохо обеспеченных медицинской помощью, но поперек дороги стояло мое почти отвращение к естественным наукам. Я все-таки преодолел это отвращение и поступил на медицинский факультет Киевского университета» [2].Это совершенно не значит, что профессия художника не может служить людям или все должны выбирать профессии, где есть возможность непосредственно помогать страждущим людям, но это урок обретения целостности и смысла жизни. Для студентов, которые оставляют или прерывают обучение из-за трудности освоения некоторых дисциплин, будет полезно ознакомиться с еще одной цитатой из воспоминаний будущего профессора и лауреата главной премии за научные достижения в нашей стране в то время: «Когда я изучал физику, химию, минералогию, у меня было почти физическое ощущение, что я насильно заставляю мозг работать над тем, что ему чуждо. Мозг, точно сжатый резиновый шар, стремился вытолкнуть чуждое ему содержание. Тем не менее, я учился на одни пятерки и неожиданно чрезвычайно заинтересовался анатомией» [2].

Чем ближе окончание ВУЗа, тем острее стоит вопрос выбора специальности и нарастает конфликт между желаниями и возможностями. Валентин Феликсович остается верным своему мироощущению и, закончив обучение с отличием, неожиданно для всех выбирает путь земского врача. Тогда как многие сегодня воспринимают работу участковым терапевтом фактически как «наказание». Следует отметить, что это не значит, что врачи должны мириться с плохой организацией труда или низкими зарплатами, но все-таки очень значимо, когда на первом месте стоит желание помогать людям. Именно на этой почве вырастают такие профессионалы как Н. И. Пирогов, В. П. Филатов, С. П. Боткин, Е. С. Боткин (причисленный к лику святых), и многие другие отечественные и зарубежные светила медицины.

Профессия врача сопряжена с ошибками, о которых вспоминал и Валентин Феликсович и все из ранее

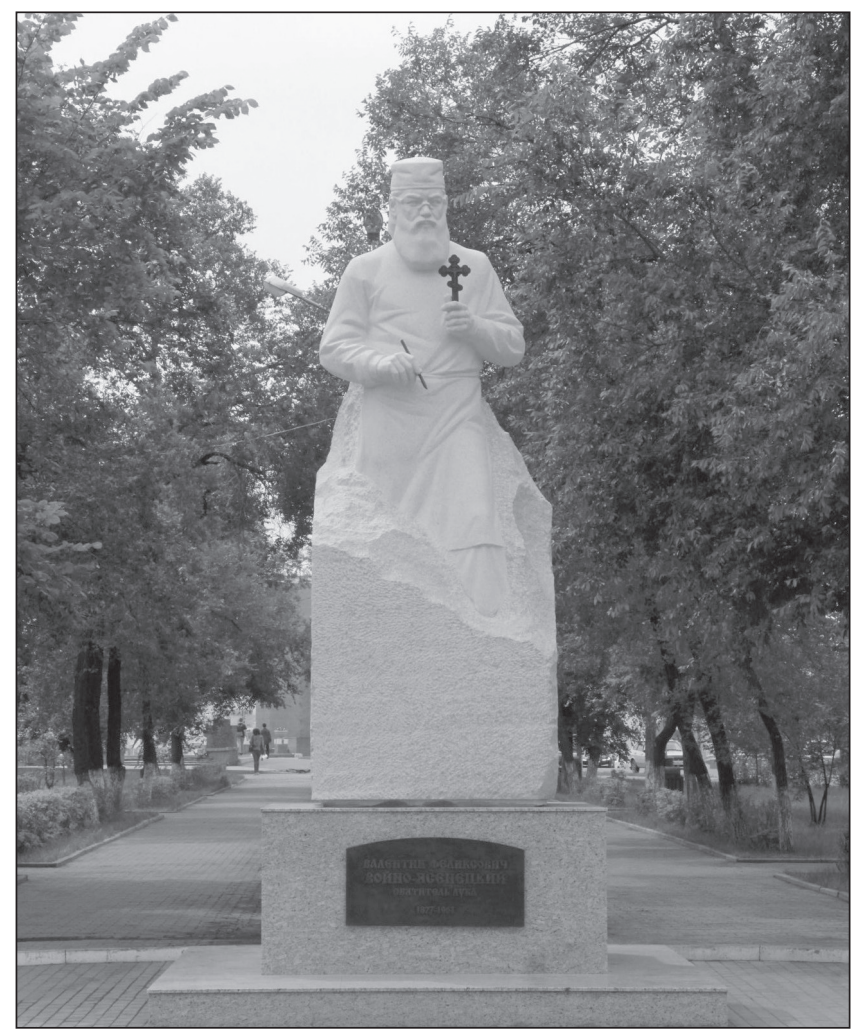

Фото 1. «Памятник профессору В. Ф. Войно-Ясенецкому, Святителю Луке».

перечисленных великих врачей нашей эпохи, и каждый такой случай глубоко переживался ими, но не вводил в отчаяние, а помогал в будущем повышать качество работы. «Тяжело переживаю смерть больных после операции, - писал епископ Лука сыну. - Было три смерти в операционной, и они меня положительно подкосили. Тебе как теоретику неведомы эти мучения, а я переношу их все тяжелее и тяжелее... Молился об умерших дома, храма в Красноярске нет...» [2].

Высокие нагрузки на врачей, конечно, нежелательны из-за увеличения вероятности ошибок, возрастающих рисков профессионального и эмоционального выгорания. Неоднократно с этой проблемой пришлось столкнуться и доктору В. Ф. Войно-Ясенецкому. О своей работе в годы Великой Отечественной войны он пишет: «1942 год...Уже четыре недели я не работаю вследствие очень тяжелого переутомления, главным образом, мозгового. Три недели пролежал в больнице крайкома, теперь лежу у себя на квартире. Врачи говорят, что по выздоровлении я не должен работать больше четырех часов и не делать больше двух операций. А до сих пор я работал до восьми-девяти часов и делал четырепять операций» [3], но поддерживаемый молитвами и сильной волей к помощи страждущим он продолжает работать столько сколько позволяют его силы.

Наградой для врача являются не только его заработная плата, но и видение плодов своего труда. Из воспоминаний Святителя Луки: «Раненые офицеры и солдаты очень любили меня. Когда я обходил палаты 
по утрам, меня радостно приветствовали раненые. Некоторые из них, безуспешно оперированные в других госпиталях по поводу ранения в больших суставах, излеченные мною, неизменно салютовали мне высоко поднятыми прямыми ногами» [2].

К сожалению, сегодня не редко мы видим не только неблагодарность пациентов, но участившиеся случаи нападения на врачей. Не миновала сия чаша и доктора Войно-Ясенецкого. О чем свидетельствует данный фрагмент его автобиографии: «В огромных, превращенных в палаты маршировальных залах высшего кадетского корпуса, разгулявшаяся на фронтах братва без просыпу пила самогон, курила махру, а по временам и «баловалась девочками». Тут же рядом лежали тяжело раненные. Но на их мольбы о тишине и покое легко раненные не обращали никакого внимания. Однажды, во время профессорского обхода, ординатор Беньяминович доложила об очередной оргии в палате. Валентин Феликсович приказал вызвать дебоширов к нему. Но едва он поднялся на второй этаж в свой кабинет, как снизу по лестнице целая орава пьяных красноармейцев полезла «бить попа». Доктор Беньяминович успела запереться в операционной, а профессора избили. Били жестоко, пинали ногами и костылями. После этих побоев заведующий клиникой на несколько дней был прикован к постели». Исходя из вышесказанного, необходимо особо отметить, что в настоящее время государство и руководство медицинских организаций должно прилагать достаточно усилий к проблеме защиты врача, поскольку сама по себе проблема, как мы видим, существовала во все времена и не исчезнет сама по себе.

Не озлобили его и несправедливые гонения, ссылки, тюрьмы и жестокие пытки со стороны богоборческой власти. Понимая то, что его опыт и знания, в годы Великой Отечественной войны, могут пригодится в исцелении раненых воинов, он пишет письмо с прошением временно освободить его из заключения и дать возможность работать военным врачом, с последующим отбыванием срока в полном объеме.

Еще одной гранью его жизни является научная работа. Его докторская диссертация по вопросам регионарной анестезии заслужила самых высоких, а порой и восторженных оценок от современников. Работу по гнойной хирургии, которая получила еще более высокую оценку как среди коллег, так и от руководства страны, профессор В. Ф. Войно-Ясенецкий зачастую выполнял в тяжелых условиях заключения - в тюрьмах и лагерях.

Из воспоминаний Святителя Луки (23 ноября 1937 г. по 6 января 1938 г. время, когда он был в тюремном заключении): «Из Ташкента мне прислали очень много историй болезней из гнойного отделения ташкентской больницы, и я имел возможность благодаря этому написать много глав своей книги “Очерки гнойной хирургии” [3].

В письме из Большой Мурты к сыну Михаилу от 20 июля 1941 г. Валентин Феликсович пишет: «...Я очень порывался послать заявление о предоставлении мне работы по лечению раненых, но потом решил подождать с этим до окончания моей книги... а мне остается два-два с половиной месяца работы над ней...» [4]. Или другой фрагмент из письма, направленного сыну Михаилу 30 сентября 1941 г., в связи с переездом из Большой Мурты в Красноярск: «...Прервалась на время моя работа над последней главой об абсцессе легкого, но я взял с собой материалы и надеюсь писать здесь...» [4].

Ученым, которые сетуют на тяжелые условия для выполнения своей научной работы, после прочтения некоторых моментов автобиографии профессора В. Ф. Войно-Ясенецкого станет намного легче воспринимать личные неурядицы.

Семейная жизнь Святителя Луки стала для него особым крестом, который под силу далеко не каждому. Его не сломили ни ранняя смерть супруги, ни необходимость практически отказаться от возможности лично воспитывать своих детей, ни даже то, что идеологическая машина настраивала его детей против него, вызывая у них не только непонимание, но и осуждение. Но мы видим, сколько любви, терпения и понимания проявляет Валентин Феликсович в своих попытках объяснить им тот смысл жизни и смерти, который он не может предать.

Когда человечество хочет, как можно дольше сохранить память о достойных своих сынах, то называет их именами города, улицы, скверы. Так и решение о праве носить имя профессора В. Ф. Войно-Ясенецкого является знаковым для Красноярского Государственного медицинского университета и это не только честь, но и большая ответственность. Именно поэтому необходимо доносить до сознания всех трудящихся и учащихся в ВУЗе быть сопричастным к делам милосердия в медицине и социальном служении, чему мы можем учиться у Святителя Луки.

Более 10 лет в КрасГМУ действует университетский храм им. Святителя Луки, где находится икона с его мощами. В 2017 году на площади перед главным корпусом КрасГМУ установлен памятник Святителю Луке, который каждый день встречает и провожает всех, кто приходит в наш ВУЗ. Чрезвычайно важно, чтобы у студентов и преподавателей взгляд на Святого воскрешал мысли и образы созидающие, утешающие, изменяющие мир к лучшему.

С этой целью в ВУЗе реализуется единая комплексная воспитательная работа и информационная деятельность в рамках корпоративной политики университета. Реализуются современные педагогические подходы в образовательной деятельности через информирова- 
ние студентов на лекциях и практических занятиях по истории медицины, библиотечные выставки, ежегодные «Лукинские чтения». К 140-летнему юбилею рождения Святителя Луки проведена всероссийская научно-практическая конференция «Медицинское и духовное наследие проф. В. Ф. Войно-Ясенецкого (Святителя Луки)».

В завершение еще раз, хотелось бы подчеркнуть, что очень важно иметь в памяти людей, которые смотрят на икону или памятник Святителя Луки, полноценное представление о житии этого Великого сына России. Именно в ней врачи могут обрести знания для врачебного искусства, черпать опыт милосердия и стойкости к трудностям профессии. Страждущие же нашли бы утешение в проповедях Святителя Луки и исцеление по молитвам о благополучном завершении лечения перед его образом и мощами.

\section{Литература}

1. Лисичкин ВА. Лука, врач возлюбленный. М.: Издательский Совет Русской Православной Церкви; 2009: 313-326.

2. Лука (Войно-Ясенецкий). «Я полюбил страдание...». Автобиография. М.: Русский хронограф; 1995. 205 c.

3. Поповский МА. Жизнь и житие Войно-Ясенецкого, архиепископа и хирурга. М.: Пик; 2001. 476 с.

4. Круглова ЕИ. «Святитель Лука (Войно Ясенецкий)». М.: Благовест; 2014. 21 с.

5. Митрополит Ташкентский, Владимир Среднеазиатский. Святитель Лука, архиепископ Симферопольский и Крымский. М.: Сибирская Благозвонница; 2007. 768 с.

\section{References}

1. Lisichkin VA. Luka, beloved physician. M.: Publishing Council of the Russian Orthodox Church; 2009:313-326 p.
2. Luka (Voino-Yasenetsky). «I fell in love with suffering... ». Autobiography. M.: «Russian Chronograph»; 1995. 205 p.

3. Popovsky MA. Life and existence of Voino-Yasenetsky, Archbishop and Surgeon. M.: The peak; 2001. 476 p.

4. Kruglova EI. «St. Luke (Voino Jasenetzky)». M.: The Blagovest.; 2014. 21 p.

5. Metropolitan Tashkentsky, Vladimir Sredneazyatsky. St. Luke, Archbishop of Simferopol and the Crimea. M.: Siberian Blagozvonnitsa; 2007. 768 p.

\section{Сведения об авторах}

Артюхов Иван Павлович, Красноярский государственный медицинский университет им. проб. В. Ф. Войно-Ясенеикого; адрес: Российская Федерация, 6600221, г. Красноярск, ул. Партизана Железняка, д. 1; тел.: +7 (391) 2201395; e-mail: rector@krasgmu.ru

Шульмин Андрей Владимирович, Красноярский государственный медицинский университет им. проф. В. Ф. Войно-Ясенецкого; адрес: Российская Федерация, 6600221, 2. Красноярск, ул. Партизана Железняка, д. 1; тел.: +7 (391) 2201396; e-mail: gydwin@bk.ru

Обухов Анатолий Аркадьевич, Красноярская митрополия русской православной иеркви, Красноярск, Советский район Храм во имя святителя Луки, архиепископа Красноярского; адрес: Российская Федеращия, 6600221, Красноярск, ул. Партизана Железняка, д. 1; Красноярский государственный медииинский университет имени профессора В.Ф. Войно-Ясенеикого; адрес: Российская Федерация, 6600221, Красноярск, ул. Партизана Железняка, д. 1; тел.: +7(902)9245781; e-mail: svt-Luka@mail.ru

Тихонова Наталья Владимировна, Красноярский государственный медицинский университет имени профессора В.Ф. Войно-Ясенеиякого; адрес: Российская Федеращия, 660022, 2. Красноярск, ул. Партизана Железняка, д. 1; тел.: +7(913)1839211; e-mail:nvt24@таil.ru

\section{Information about the authors}

Artyukhov Ivan P., Professor V. F. Voino-Yasenetsky Krasnoyarsk State Medical University; Address: 1, Partizan Zhelezhyak str., Krasnoyarsk, 660022, Russian Federation; Phone: +7(391) 2201395; e-mail: rector@krasgmu.ru

Shul'min Andrey V., Professor V. F. Voino-Yasenetsky Krasnoyarsk State Medical University; Address: 1, Partizan Zhelezhyak str., Krasnoyarsk 660022, Russian Federation; Phone: +7(391) 2201396; e-mail: gydwin@bk.ru

Obukhov Anatoly A., Krasnoyarsk Orthodox Metropolis of the Russian Orthodox Church, The temple in the name of St. Luke, Archbishop of Krasnoyarsk; Address: Krasnoyarsk, 660022, Russian Federation; Phone: +7(902)9245781; e-mail: svt-Luka@mail.ru

Tihonova Natalia V., Professor V. F. Voino-Yasenetsky Krasnoyarsk State Medical University; Address: 1, Partizan Zhelezhyak str., Krasnoyarsk 660022, Russian Federation; Phone: +7(391)2209825; e-mail: nvt24@mail.ru

\section{Научные обзоры / Scientific reviews}

\section{ЕСТЕСТВЕННОЕ ТЕЧЕНИЕ БРОНХИАЛЬНОЙ АСТМЫ: ФАКТОРЫ, НЕ ПОЗВОЛЯЮЩИЕ ДОСТИЧЬ КОНТРОЛЯ В ДОЛГОСРОЧНОЙ ПЕРСПЕКТИВЕ}

О. С. Кобякова, И. А. Деев, Е. С. Куликов, И. Д. Пименов, Д. С. Тюфилин

Сибирский государственный медицинский университет, Томск 634050, Российская Федерация

\footnotetext{
Резюме. Бронхиальная астма занимает лидирующие позиции по распространенности среди нозологий респираторной системы, при этом является социально значимым заболеванием. По данным контролируемых исследований, регулярное применение базисной противовоспалительной терапии обеспечивает достижение контроля в 40-70 \% случаев уже в первые 6 месяцев лечения, при этом уровень текущего контроля астмы в популяции не превышает 23 \%. Несоответствие этих данных может свидетельствовать о наличии факторов, ограничивающих достижение контроля в условиях реальной клинической практики. В данном обзоре представлены результаты исследований, посвященных естественному течению бронхиальной астмы в контексте факторов, ассоциированных с изменением контроля данной патологии в долгосрочной перспективе.
} 
Ключевые слова: бронхиальная астма, естественное течение астмы, контроль астмы, избыточный вес, курение, гендерные различия, возрастные изменения.

Для ицтирования: Кобякова ОС, Деев ИА, Куликов ЕС, Пименов ИД, Тюфилин ДС. Естественное течение бронхиальной астмы: факторы, не позволяющие достичь контроля в долгосрочной перспективе. Сибирское медииинское обозрение. 2017;(5): 9-18 . DOI: 10.20333/2500136-2017-5-9-18.

\title{
NATURAL COURSE OF BRONCHIAL ASTHMA: FACTORS THAT DON'T ALLOW TO ACHIEVE THE CONTROL IN A LONG-TERM PERSPECTIVE
}

\author{
O. S. Kobyakova, I. A. Deev, E. S. Kulikov, I. D. Pimenov, D. S. Tyufilin
}

Siberian State Medical University, Tomsk 634050, Russian Federation

Abstract. Bronchial asthma has the leading position in prevalence among the nosologies of the respiratory system, and is a socially significant disease. According to controlled studies, regular use of basic anti-inflammatory therapy ensures control in 40-70\% of cases already in the first 6 months of treatment, while the level of current control of asthma in the population does not exceed 23\%. The discrepancy of these data may indicate the presence of factors limiting the achievement of control in the conditions of real clinical practice. This review presents the results of studies devoted to the natural course of bronchial asthma in the context of factors associated with a change in the control of this pathology in the long term perspective.

Key words: bronchial asthma, natural course of asthma, asthma control, overweight, smoking, gender differences, age changes.

Citation: Kobyakova OS, Deev IA, Kulikov ES, Pimenov ID, Tyufilin DS. Natural course of bronchial asthma: factors that don't allow to achieve the control in a long-term perspective. Siberian Medical Review. 2017;(5): 9-18. DOI: 10.20333/2500136-2017-5-9-18.

\section{Введение}

Бронхиальная астма (БА) остается одной из самых распространенных нозологий респираторной системы и, по данным Всемирной организации здравоохранения, является причиной более 350 млн. смертей в год [1], при этом, несмотря на успехи в понимании механизмов и факторов риска формирования данного заболевания, а также прогресс в области фармакотерапии, уровень текущего контроля астмы в популяции, по данным крупных эпидемиологических исследований, не превышает 5-23 \% [2].

В тоже время, результаты контролируемых исследований демонстрируют, что регулярное применение базисной терапии обеспечивает контроль в 40-70\% случаев в первые 6 месяцев лечения [2]. Подобное расхождение диктует необходимость изучения естественного течения БА и факторов, оказывающих на него влияние. Так, ряд отечественных и зарубежных исследований демонстрируют зависимость изменения контроля БА и объема фармакотерапии от ряда факторов, что указывает на актуальность их учета при определении подхода к лечению астмы.

В этой связи целью данного обзора является обобщение результатов исследований, посвященных естественному течению бронхиальной астмы в контексте факторов, ассоциированных с изменением контроля данной патологии.

Избыточный вес и естественное течение астмы

Ассоциация ожирения с распространенностью, заболеваемостью и контролем БА показана некоторыми научными коллективами: так, С. А. Jr. Camargo et al. (1999) продемонстрировали в проспективном исследовании прямую связь между высоким индексом массы тела (ИМТ) и риском начала БА у женщин. В исследовании приняли участие 85911 пациенток в возрасте от 26 до 46 лет, у которых за 5-летний период было выявлено 1596 случаев БА. В многофакторной модели относительный риск развития БА для различных категорий ИМТ в первый год исследования составил 0,9 (ИМТ <20,0); 1,0 (ИМТ 20,0-22,4); 1,1 (ИМТ 22,5-24,9); 1,6 (ИМТ 25,027,4); 1,7 (ИМТ 27,5-29,9); 2,7 (ИМТ >30,0) (р<0,001). В ряде других исследований установлено, что женщины, набравшие вес после 18 лет, имели повышенный риск развития БА в течение 4-летнего периода наблюдения, а также показана ассоциация высокого ИМТ у взрослых с повышенной распространенностью БА $[3,4]$.

В разрезе эволюции БА остается вопрос: как изменение массы тела влияет на контроль астмы. Коллектив B. Stenius Aarniala et al. (2000), провели исследование в двух группах (лечебная и группа контроля, $\mathrm{n}=38$ ), в которые включались пациенты с ИМТ от 30 до 42 и подтвержденным диагнозом БА. Лечебная группа приняла участие в программе по снижению веса, по результатам которой в конце курса участники потеряли в среднем 14,5 \% от первоначального веса (против 0,3 \% в контрольной группе). После 8-недельного периода диеты разница в объёме форсированного выдоха за первую секунду $\left(\mathrm{O} Ф \mathrm{~B}_{1}\right)$ в лечебной и контрольной группах составила 7,2 \% (p=0,009), разница в форсированной жизненной ёмкости легких (ФЖЕЛ) - 8,6 \% (p<0,0001). Через год различия в двух группах оставались статистически значимыми: 7,6 \% для ОФВ $(\mathrm{p}=0,02)$ и 7,6 \% для ФЖЕЛ ( $\mathrm{p}=0,001)$, кроме того, было отмечено снижение количества обострений БА в группе похудевших $(\mathrm{p}=0,001)[5]$.

По данным исследования, проведенного в 2004 году, с участием 58 женщин, у 24 из которых диагностирована БА, на каждые 10 \% снижения веса, приходилось увеличение ФЖЕЛ в среднем на 92 мл $(\mathrm{p}=0,05), \mathrm{OФВ}_{1}$ на 73 мл $(\mathrm{p}=0,04)[6]$.

В исследовании P. Saint-Pierre et al. (2005) влияние ИМТ на эволюцию контроля астмы $(\mathrm{n}=406)$ оцени- 
валось с помощью модели Маркова (статистический метод, позволяющий строить модели заболевания как последовательность переходов между состояниями здоровья с течением времени) [7]. Установлено, что пациенты с избыточным весом имели более низкий риск перехода в группу приемлемого контроля БА (относительный риск $(\mathrm{OP})=0,45, \mathrm{p}<0,01)$, однако влияние веса оставалось значительным (OP=0,53, $\mathrm{p}<0,01)$ в многомерной модели, куда включались другие коварианты (тяжесть астмы, текущее лечение пероральными стероидами и история использования пероральных стероидов в течение последнего года). В другом исследовании (2007 г.) в группе пациентов, страдающих БА и ожирением, после проведения коррекции веса, отмечалось достоверное увеличение контроля по опроснику ACT (Asthma control test - тест по контролю над астмой) с 18,7 до 22,2 (p<0,001), в то же время оценка по АСТ оставалась неизменной в группе контроля (от 18,8 до 18,6; p=0,73), а также уменьшение симптомов БА (одышки) и снижение частоты использования препаратов первой помощи (для обоих параметров $\mathrm{p}<0,05$ ) [8].

Кроме того, влияние увеличения массы тела на контроль БА продемонстрировано в работе Т. Haselkorn et al. (2009), в которой испытуемые, набравшие 2,7 и более килограммов в течение года, сообщили об ухудшении контроля над астмой (отношение шансов (ОШ) = 1,22; 95-ти \% доверительный интервал (ДИ95 \%) 1,01-1,49, $\mathrm{p}=0,04)$, качества жизни $(\mathrm{p}=0,003)$, а также о более частом использовании пероральных стероидов (ОШ 1,31; ДИ95 \% 1,04-1,66, p=0,02) по сравнению с пациентами, у которых вес не изменился или снизился [9].

\section{Курение}

Курение является фактором, ассоциированным с неконтролируемой БА в долгосрочной перспективе, кроме того, оно потенцирует снижение ОФВ при естественном течении данной патологии [10]. Так, в исследовании 2005 года $(\mathrm{n}=122)$, было показано, что долгосрочные эффекты ингаляционных глюкокортикостероидов (ИГКС) на течение БА, менее выражены у курильщиков: по результатам наблюдения, длившегося в среднем 23 года, показано, что у мужчин, со стажем курения меньше 5 пачка-лет, ОФВ 1 снижался в среднем с 54,4 (29,5-79,2) мл/год до 17,7 (6,5-28,7) мл/год после начала терапии ИГКС ( $\mathrm{p}=0,0097)$, при этом у женщин аналогичный параметр изменялся статистически незначимо - с 27,3 (7,6-46,9) мл/год до 26,5 (15,8-37,1) мл/ год. Данный положительный эффект не наблюдался у людей со стажем курения более 5 пачка-лет: так, снижение ОФВ до и после использования ИГКС составляло 27,8 и 16,1 мл/год для мужчин, а для женщин - 24,5 и 11,6 мл/год [11].

Еще в одном исследовании, проведенном Р. Kauppi et al. (2014), при наблюдении 344 пациентов с БА в период с 1995 по 2006 год, 34 \% из них хотя бы раз обращались в отделение скорой помощи с обострением БА, при этом независимыми факторами риска обострения являлись курение в анамнезе (OP=1,9; ДИ95 \% 1,3-3,1), а также в настоящее время (OP=3,6; ДИ95 \% 1,6-8,2), низкая оценка по опроснику HRQoL (Health-related Quality of life - опросник качества жизни), обусловленного здоровьем (OP=2,5; ДИ95 \% 1,3-3,7) и снижение ОФВ1 (ОФВ1 < 65 \%, ОР=2,2, ДИ95 \% 1,3 -3,7) [12].

Однако не все исследования демонстрируют взаимосвязь между курением и тяжелым или неконтролируемым течением БА. Например, в масштабном проспективном исследовании Z. Ali et al. (2013) пациенты с БА (n=1075) включались с 1974 по 1990 гг. и наблюдались до конца 2011 г.; за время проведения исследования в изучаемой когорте был зафиксирован 261 случай смерти по причине БА, при этом учеными не было обнаружено существенной ассоциации между курением и последующей смертью от астмы [13].

\section{Предьдущие обострения}

Популяционные исследования БА показали, что у пациентов с недавним обострением астмы существует значительный риск рецидивов. Например, в исследовании C. L. Emerman et al. (1999), были выявлены факторы, связанные с рецидивом обострения БА у взрослых пациентов после лечения в отделении неотложной помощи. Было установлено, что пациенты, перенесшие рецидив заболевания, с большей вероятностью обращались за неотложной помощью в приемное отделение (ОШ 1,3; ДИ95 \% 1,1-1,5, на 5 посещений) или клинику (ОШ 1,4; ДИ95 \% 1,1-1,7, на 5 посещений), а также жаловались на более длительную продолжительность симптомов (ОШ 2,5; ДИ95 \% 1,2-5,2) [14].

Схожие результаты получили M. McCarren et al. (1998) при оценке обострений через 8 недель после обращения больных БА за неотложной помощью $(\mathrm{n}=284)$. По результатам проспективного наблюдения выяснилось, что в течение первых 10 дней только у 8 \% пациентов регистрировался рецидив заболевания, а к концу 8 недели их количество увеличилось до 45 \%, при этом 3 фактора оказались независимо связаны с обострением: обращение в отделение неотложной помощи за предыдущие 6 месяцев (ОР 2,3; ДИ95 \% 1,6-3,4), затруднение профессиональной или другой деятельности за 4 недели до обострения (ОР 2,7; ДИ95 \% 1,6-4,3), а также прекращение назначенного лечения обострений в течение 24 часов без достижения по крайней мере 50 \% от прогнозируемой максимальной скорости выдоха (OP 2,6; ДИ95 \% 1,6-4,1) [15]. Связь между обострениями и повторными обращениями также была продемонстрирована и другими исследователями на меньших выборках [16-18].

Другая масштабная работа была проведена в рамках уже упомянутого нами исследования TENOR, в котором период наблюдения составил 1,5 года. Исследовате- 
ли показали, что у пациентов с недавним обострением определялся повышенный риск ухудшения контроля в будущем (ОШ 6,33; ДИ95 \% 4,57-8,76), в том числе после корректировки на демографические и клинические факторы (ОШ 3,77; ДИ95 \% 2,62-5,43), на тяжесть астмы по оценке врача (ОШ 5,62; ДИ95 \% 4,03-7,83), тяжесть БА согласно NAEPP (National Asthma Education and Prevention Program - национальная программа обучения и профилактики БА; ОШ 5,07; ДИ95 \% 3,62-7,11), GINA (Global Initiative for Asthma - глобальная стратегия лечения и профилактики бронхиальной астмы; ОШ 5,32; ДИ95 \% 3,80-7,47) и контроль астмы (ОШ 3,90; ДИ95 \% 2,77-5,50) [19].

Исследование, проведенное M. Schatz et al. (2014), показало, что количество обострений у пациентов с астмой в условиях реальной практики остаются относительно постоянными с течением времени, а высокая интенсивность лечения не связана с существенно меньшим риском обострения.

По данным ретроспективного когортного анализа, в который были включены пациенты (n=2543), получавшие высокие дозы ИГКС, было показано, что за первый год исследования (2007) у 28 \% пациентов были зарегистрированы обострения, а к 2011 году данный показатель составил уже 25 \%, т.е. вероятность обострения показала небольшое, но статистически значимое снижение со временем (ОШ 0,96; ДИ95 \% 0,94-0,99), при этом риск обострения в течение последующего периода увеличился почти в 8 раз, если у пациента регистрировалось обострение в предыдущем году (ОШ 7,80; ДИ95 \% 7,07-8,61) [20].

\section{Социально-экономический статус, медицинская} грамотность и расовая принадлежность

По мнению многих исследователей низкий социально-экономический статус пациента является фактором риска для более частого развития обострений БА [21, 22]. Так, при изучении вопроса смертности от БА в штате Филадельфия (США) с 1969 по 1991 гг. показано, что данный параметр выше среди людей с низким уровнем дохода ( $<<0,001)$ [23], а исследование, проведенное М. D. Eisner et al. (2001), выявило ассоциацию низкого экономического статуса с риском госпитализации по поводу БА [24].

Возможным объяснением плохого контроля среди пациентов с низким социоэкономическим статусом может быть недостаточная медицинская грамотность в данной группе [25]. Например, существуют исследования, которые показывают связь между невысокой грамотностью в области медицины и низким уровнем знаний о медикаментозной терапии астмы и применением дозированных ингаляторов [26]. Исследователи под руководством R. J. Adams et al. (2009) показали, что пациенты $(\mathrm{n}=385)$ с астмой и недостаточной медицинской грамотностью чаще сообщают о ночных пробуждениях в связи с обострениям БА и о частых госпитализациях [27].

Также в когортном исследовании, проведенном L. M. Curtis et al. (2012), продемонстрировано, что пациенты $(n=353)$ с невысокой грамотностью в вопросах здоровья сообщали о более частых обращениях в отделения неотложной помощи (ОР 1,67; ДИ95 \% 1,27-2,18, p<0,001), госпитализациях (ОР 2,10; ДИ95 \% 1,16-3,82, p=0,01) и худшем контроле астмы (ОР 0,49; ДИ95 \% 0,34-0,71, $\mathrm{p}<0,001)$. Кроме того, у лиц с более низким уровнем образования и доходом отмечались более тяжелые исходы БА [28].

Ряд авторов указывает на различия в естественном течении бронхиальной астмы среди представителей разных рас. Так в исследовании, проведенном A. Javed et al. (2013), одним из факторов, ассоциированных с достижением ремиссии БА (более 3 лет), являлась принадлежность к европеоидной расе $(\mathrm{p}=0,039)$, при этом не было найдено статистической разницы для остальных изучаемых показателей [29].

\section{Возраст}

Среди пожилых пациентов ( $\geq 65$ лет) с астмой наблюдаются более высокие показатели смертности [30], частота госпитализаций и осложнений, связанных с астмой по сравнению с более молодыми пациентами $[31,32]$. Причинами этого может быть специфически протекающее воспаление у пожилых (Inflamm-aging), снижение функции легких вследствие снижения эластической тяги легких и силы дыхательных мышц [33-38].

По результатам статистического анализа К. М. Hardaker et al. (2011) оказалось, что для пожилых пациентов с астмой предикторами гиперчувствительности являются феномен воздушной ловушки, диффузионная вентиляция $\left(\mathrm{S}_{\text {acin }}\right)$ и обструкция дыхательных путей $\left(\mathrm{r}^{2}=0,57, \mathrm{p}<0,0001\right)$, в то время как для молодых пациентов предикторами гиперчувствительности, на ряду с обструкцией дыхательных путей, были фракция выдыхаемого NO и проводящая вентиляция $\mathrm{S}_{\text {cond }}\left(\mathrm{r}^{2}=0,51\right.$, $\mathrm{p}<0,0001$ ) [39].

Ученые из США в 2011 году сравнивали уровень контроля у пожилых (старше 65 лет, $\mathrm{n}=398$ ) и молодых $(\mathrm{n}=2557)$ пациентов с БА. Многофакторный анализ выявил достоверно худший контроль БА у пожилых пациентов, при этом оказалось, что пожилые пациенты хуже осведомлены как справляться с приступами астмы $(\mathrm{p}<0,05)$, а также реже пользуются письменным планом действий при БА $(\mathrm{p}<0,05)[40]$.

Существует ряд работ, результаты которых говорят о достаточном контроле БА среди возрастных пациентов. Исследователи группы TENOR (2006) в ходе проспективного исследования сравнили использование специфической терапии, контроль астмы и качество жизни у пожилых ( $\geq 65$ лет, $\mathrm{n}=566$ ) и молодых (18-64 лет, 
n=2912) пациентов. Хотя у пожилых отмечалась худшая функция легких по данным ОФВ

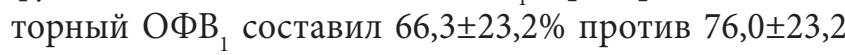
$\%$ у молодых пациентов, $\mathrm{p}<0,001$; постбронходилата-

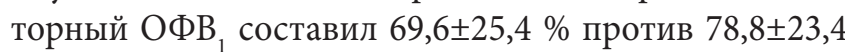
$\%, \mathrm{p}<0,001)$, они достоверно меньше обращались за неотложной помощью $(\mathrm{p}<0,01)$, реже совершали незапланированные визиты к пульмонологу $(p<0,001)$ и пользовались пероральными стероидами $(\mathrm{p}<0,009)$ [41].

Исследователи под руководством E. V. Ponte et al. (2014) попытались оценить связь возраста с контролем астмы в когорте пациентов, получающих надлежащее лечение. В проспективное исследование с периодом наблюдения в один год были включены пациенты (n=401) с неконтролируемой астмой, не имеющие опыта использования ИГКС. Было показано, что возраст >55 лет на начало исследования был связан с достоверно меньшим числом обращений за неотложной помощью (ОШ 1,6; ДИ 95 \% 1,1-2,4) и уровнем ОФВ $<60 \%$ (ОШ 1,8; ДИ95 \% 1,1-3,3) [42]. Тем не менее, исследование, проведенное в 2002 году G. B. Diette et al., также продемонстрировало, что пожилой возраст не является прогностическим фактором для будущей госпитализации (ОШ 1,05; ДИ 95 \% 0,68-1,61), при этом, предикторами, независимо связанными с госпитализацией, оказались принадлежность к женскому полу или не европейской расе, низкий уровень образования, плохое физическое состояние и более частые симптомы астмы [43].

По мнению некоторых исследователей, основным фактором, определяющим тяжесть заболевания, является не возраст, а стаж заболевания. Так, ученые S. A. Quadrelli и A. J. Roncoroni (1998) провели сравнение между пациентами с БА двух возрастов - 65 лет и старше $(\mathrm{n}=50)$ и <40 лет $(\mathrm{n}=99)$, и попытались определить влияние длительности заболевания, для этого сравнивались пациенты с ранним началом (начало до 40 лет, $\mathrm{n}=22$ ) и респонденты с поздним началом БА (начало после 40 лет, $\mathrm{n}=22$ ). Оказалось, что у молодых пациентов достоверно чаще определялась эозинофилия $(\mathrm{p}<0,05)$ и значение $\operatorname{IgE} \geq 100 \mathrm{ME} /$ л $(\mathrm{p}<0,001)$. Для пациентов старше 65 лет оказались характерны короткие (менее 3 месяцев) бессимптомные периоды (78,5 \% vs $45,4 \%, \mathrm{p}<0,001)$, достоверно меньший ОФВ $(54,4 \pm 17,3$ $\%$ vs $71,8 \pm 18,5 \%, \mathrm{p}<0,001)$, потребность в системных стероидах была также выше в данной группе $(27,5 \%$ vs $4,5 \%$, p<0,001). Однако проведение статистического анализа ANOVA при сравнении трех групп (моложе 40 лет и двух групп с возрастом $\geq 65$ лет с ранним и поздним началом астмы) показало, что респонденты старше 65 лет с ранним началом астмы достоверно чаще обращались за неотложной помощью и принимали системные стероиды, имели низкий ОФВ 1 и достоверно более короткие промежуточные периоды без симптомов по сравнению с группой моложе 40 лет
[44]. Схожий вывод сделали M. Zureik и J. Orehek (2002) по результатам описательного исследования, в котором приняли участие 1485 пожилых пациента ( $\geq 65$ лет) с БА. Так, среднее значение ОФВ у пациентов с диагнозом астмы, выставленным в возрасте младше 20 лет, составило $58,1 \pm 19,5 \%$ vs $60,5 \pm 20,4 \%$ (участники, которым диагноз БА был выставлен в промежутке от 20 до 50 лет) vs $62,5 \pm 19,4$ \% (участники с диагнозом БА, установленном в промежутке между 50 и 65 годами), в то время как у пациентов, которым астму диагностировали после 65 лет, ОФВ составил 67,1 $21,4 \%(\mathrm{p}<0,001)$ [45].

Общеизвестным является тот факт, что бронхиальная астма характеризуется длительным течением с изменением уровня контроля и степени тяжести. При этом в условиях реальной клинической практики врач контактирует с пациентом относительно короткий промежуток времени и оценивает уровень этих параметров только на текущий момент и/или в краткосрочной перспективе (годы), а в течение жизни каждого пациента, как правило, наблюдают несколько специалистов, кроме того, пациенты переходят из педиатрической амбулаторно-поликлинической сети во взрослую, меняются и подходы к лечению БА.

Данный обзор демонстрирует, что для достижения контроля БА недостаточно использование рациональной базисной фармакотерапии, необходимо учитывать ряд немодифицируемых факторов, к которым, по данным зарубежной литературы, следует отнести женский пол, расовую принадлежность и стаж заболевания.

Большую группу предикторов также составляют модифицируемые факторы, имеющие доказанное влияние на естественное течение БА - курение и избыточный вес, а также низкие социально-экономический статус и медицинская грамотность пациентов с астмой. Указанные факторы могут стать точкой приложения интервенционных программ, направленных на достижение оптимального контроля в популяции и снижение случаев обострения БА, однако стоит отметить, что результаты зарубежных исследований не всегда получается полностью экстраполировать на ситуацию в России. В этой связи для реализации подобных программ является актуальным изучение и получение структурированных данных о естественном течении БА в условиях реальной клинической практики в России, а также определение факторов, связанных с изменением контроля и степени тяжести указанной патологии.

\section{Литература}

1. Asthma fact sheet [Интернет]. Доступно: http:// www.who.int/mediacentre/factsheets/fs307/en/ (дата обращения 27.08.2017)

2. Куликов ЕС, Огородова ЛМ, Белевский АС, Петровский ФИ, Чучалин АГ. Эффективность 
стратегий достижения и поддержания контроля над бронхиальной астмой в условиях реальной клинической практики: данные многоцентрового исследования СТРЕЛА-АСТ. Пульмонология. 2010;1:80-6.

3. Camargo CA Jr, Weiss ST, Zhang S, Willett WC, Speizer FE. Prospective study of body mass index, weight change, and risk of adult-onset asthma in women. Archives of internal medicine. 1999;159(21):2582-8. DOI: 10.1001/ archinte.159.21.2582.

4. Shaheen SO, Sterne JA, Montgomery SM, Azima $\mathrm{H}$. Birth weight, body mass index and asthma in young adults. Thorax. 1999;54(5):396-402.

5. Stenius-Aarniala B, Poussa T, Kvarnström J, Grönlund EL, Ylikahri M, Mustajoki P. Immediate and long term effects of weight reduction in obese people with asthma: randomised controlled study. BMJ: British medical journal / British Medical Association. 2000;320(7238):827-32.

6. Aaron SD, Fergusson D, Dent R, Chen Y, Vandemheen KL, Dales RE. Effect of weight reduction on respiratory function and airway reactivity in obese women. Chest. 2004;125(6):2046-52.

7. Saint-Pierre P, Bourdin A, Chanez P, Daures JP, Godard P. Are overweight asthmatics more difficult to control? Allergy. 2006;61(1):79-84. DOI: 10.1111/j.13989995.2005.00953.x

8. Maniscalco M, Zedda A, Faraone S, Cerbone MR, Cristiano S, Giardiello C, Sofia M. Weight loss and asthma control in severely obese asthmatic females. Respiratory medicine. 2008;102(1):102-8. DOI: 10.1016/j. rmed.2007.07.029.

9. Haselkorn T, Fish JE, Chipps BE, Miller DP, Chen $\mathrm{H}$, Weiss ST. Effect of weight change on asthma-related health outcomes in patients with severe or difficult-totreat asthma. Respiratory medicine. 2009;103(2):27483. DOI: 10.1016/j.rmed.2008.08.010. DOI: 10.1016/J. rmed.2008.08.010.

10. Lange P, Parner J, Vestbo J, Schnohr P, Jensen G. A 15-year follow-up study of ventilatory function in adults with asthma. The New England journal of medicine. 1998;339:1194-200. DOI: 10.1056/ NEJM199810223391703.

11. Dijkstra A, Vonk JM, Jongepier H, Koppelman GH, Schouten JP, ten Hacken NH, Timens W, Postma DS. Lung function decline in asthma: association with inhaled corticosteroids, smoking and sex. Thorax. 2006;61(2):10510. DOI: $10.1136 /$ thx.2004.039271.

12. Kauppi P, Kupiainen H, Lindqvist A, Haahtela T, Laitinen $\mathrm{T}$. Long-term smoking increases the need for acute care among asthma patients: a case control study. BMC pulmonary medicine. 2014;14:119. [Internet] DOI. 10.1186/1471-2466-14-119. URL: https://www.ncbi. nlm. nih.gov/pmc/articles/PMC4108236/

13. Ali Z, Dirks CG, Ulrik CS. Long-term mortality among adults with asthma: a 25-year follow-up of 1,075 outpatients with asthma. Chest. 2013;143(6):1649-1655. DOI: $10.1378 /$ chest.12-2289.

14. Emerman CL, Woodruff PG, Cydulka RK, Gibbs MA, Pollack CV Jr, Camargo CA Jr. Prospective multicenter study of relapse following treatment for acute asthma among adults presenting to the emergency department. MARC investigators. Multicenter Asthma Research Collaboration. Chest. 1999;115(4):919-27. DOI: http:// dx.doi.org/10.1378/chest.12-2289.

15. McCarren M, McDermott MF, Zalenski RJ, Jovanovic B, Marder D, Murphy DG, Kampe LM, Misiewicz VM, Rydman RJ. Prediction of relapse within eight weeks after an acute asthma exacerbation in adults. Journal of clinical epidemiology. 1998;51(2):107-18. DOI: http://dx.doi. org/10.1016/S0895-4356(97)00246-1.

16. Adams RJ, Smith BJ, Ruffin RE. Factors associated with hospital admissions and repeat emergency department visits for adults with asthma. Thorax. 2000;55(7):566-73. DOI: $10.1136 /$ thorax.55.7.566.

17. Turner MO, Noertjojo K, Vedal S, Bai T, Crump S, Fitzgerald JM. Risk factors for near-fatal asthma. A case-control study in hospitalized patients with asthma. American journal of respiratory and critical care medicine. 1998;157(6Pt1):1804-9. DOI: 10.1164/ ajrccm.157.6.9708092.

18. Crane J, Pearce N, Burgess C, Woodman K, Robson B, Beasley R. Markers of risk of asthma death or readmission in the 12 months following a hospital admission for asthma. International journal of epidemiology. 1992;21(4):737-44.

19. Miller MK, Lee JH, Miller DP, Wenzel SE; TENOR Study Group. Recent asthma exacerbations: a key predictor of future exacerbations. Respiratory medicine. 2007;101(3):481-9. DOI: 10.1016/j.rmed.2006.07.005.

20. Schatz M, Meckley LM, Kim M, Stockwell BT, Castro M. Asthma exacerbation rates in adults are unchanged over a 5-year period despite high-intensity therapy. The journal of allergy and clinical immunology. In practice. 2014;2(5):570-4.e1. DOI: 10.1016/j.jaip.2014.05.002.

21. Sturdy PM, Victor CR, Anderson HR, Bland JM, Butland BK, Harrison BD, Peckitt C, Taylor JC; Mortality and Severe Morbidity Working Group of the National Asthma Task Force. Psychological, social and health behaviour risk factors for deaths certified as asthma: a national case-control study. Thorax. 2002;57(12):1034-9. DOI: 10.1136/thorax.57.12.1034.

22. Wissow LS, Gittelsohn AM, Szklo M, Starfield B, Mussman M. Poverty, race, and hospitalization for childhood asthma. American journal of public health. 1988;78(7):777-82.

23. Lang DM, Polansky M. Patterns of asthma mortality in Philadelphia from 1969 to 1991. The New England journal of medicine. 1994;331(23):1542-6. DOI: 10.1056/ NEJM199412083312302. 
24. Eisner MD, Katz PP, Yelin EH, Shiboski SC, Blanc PD. Risk factors for hospitalization among adults with asthma: the influence of sociodemographic factors and asthma severity. Respiratory research. 2001;2(1):53-60. DOI: $10.1186 / \mathrm{rr} 37$.

25. Apter AJ, Wan F, Reisine S, Bender B, Rand C, Bogen DK, Bennett IM, Bryant-Stephens T, Roy J, Gonzalez R, Priolo C, Have TT, Morales KH. The association of health literacy with adherence and outcomes in moderate-severe asthma. The Journal of allergy and clinical immunology. 2013;132(2):321-7. DOI: 10.1016/j.jaci.2013.02.014.

26. Paasche-Orlow MK, Riekert KA, Bilderback A, Chanmugam A, Hill P, Rand CS, Brancati FL, Krishnan JA. Tailored education may reduce health literacy disparities in asthma self-management. American journal of respiratory and critical care medicine. 2005;172(8):980-6. DOI: $10.1164 / \mathrm{rccm} .200409-1291$ OC.

27. Adams RJ, Appleton SL, Hill CL, Ruffin RE, Wilson $\mathrm{DH}$. Inadequate health literacy is associated with increased asthma morbidity in a population sample. The Journal of allergy and clinical immunology. 2009;124(3):601-3. DOI: 10.1016/j.jaci.2009.05.035.

28. Curtis LM, Wolf MS, Weiss KB, Grammer LC. The impact of health literacy and socioeconomic status on asthma disparities. The Journal of asthma : official journal of the Association for the Care of Asthma. 2012;49(2):17883. DOI: 10.3109/02770903.2011.648297.

29. Javed A, Yoo KH, Agarwal K, Jacobson RM, Li X, Juhn YJ. Characteristics of children with asthma who achieved remission of asthma. The Journal of asthma: official journal of the Association for the Care of Asthma. 2013;50(5):472-9. DOI: 10.3109/02770903.2013.787625.

30. Boulet LP. Is asthma control really more difficult to achieve in the elderly patient? International archives of allergy and immunology. 2014;165(3):149-51. DOI: 10.1159/000368966.

31. Griswold SK, Nordstrom CR, Clark S, Gaeta TJ, Price ML, Camargo CA Jr. Asthma exacerbations in North American adults: who are the "frequent fliers» in the emergency department? Chest. 2005;127(5):1579-86. DOI: 10.1378/chest.127.5.1579.

32. Banerji A, Clark S, Afilalo M, Blanda MP, Cydulka RK, Camargo CA Jr. Prospective multicenter study of acute asthma in younger versus older adults presenting to the emergency department. Journal of the American Geriatrics Society. 2006;54(1):48-55. DOI: 10.1111/j.15325415.2005.00563.x

33. Sharma G, Goodwin J. Effect of aging on respiratory system physiology and immunology. Clinical interventions in aging. 2006;1(3):253-60.

34. Boulet LP. Asthma in the elderly patient. Asthma research and practice. 2016;2:3. DOI: 10.1186/s40733015-0015-1.

35. Xia S, Zhang X, Zheng S, Khanabdali R, Kalionis
B, Wu J, Wan W, Tai X. An Update on Inflamm-Aging: Mechanisms, Prevention, and Treatment. Journal of immunology research. 2016;2016:8426874. DOI: $10.1155 / 2016 / 8426874$.

36. Turner JM, Mead J, Wohl ME. Elasticity of human lungs in relation to age. Journal of applied physiology. 1968;25(6):664-71.

37. Brooks CR, Gibson PG, Douwes J, Van Dalen CJ, Simpson JL. Relationship between airway neutrophilia and ageing in asthmatics and non-asthmatics. Asian Pacific Society of Respirology. 2013;18(5):857-65.

38. Chotirmall SH, Burke CM. Aging and the microbiome: implications for asthma in the elderly? Expert Review of Respiratory Medicine. 2015;9(2):125-8. DOI:10. 1586/17476348.2015.1002473.

39. Hardaker KM, Downie SR, Kermode JA, Farah CS, Brown NJ, Berend N, King GG, Salome CM. Predictors of airway hyperresponsiveness differ between old and young patients with asthma. Chest. 2011;139(6):1395-1401. DOI: 10.1378/chest.10-1839. Epub 2011 Mar 31.

40. Talreja N, Baptist AP. Effect of age on asthma control: results from the National Asthma Survey. Annals of allergy, asthma and immunology: official publication of the American College of Allergy, Asthma, and Immunology. 2011;106(1):24-9. DOI: 10.1016/j.anai.2010.10.017.

41. Slavin RG, Haselkorn T, Lee JH, Zheng B, Deniz Y, Wenzel SE; TENOR Study Group. Asthma in older adults: observations from the epidemiology and natural history of asthma: outcomes and treatment regimens (TENOR) study. Annals of allergy, asthma and immunology : official publication of the American College of Allergy, Asthma, and Immunology. 2006;96(3):406-14.

42. Ponte EV, Stelmach R, Franco R, Souza-Machado C, Souza-Machado A, Cruz AA. Age is not associated with hospital admission or uncontrolled symptoms of asthma if proper treatment is offered. International archives of allergy and immunology. 2014;165(1):61-7. DOI: $10.1159 / 000367924$.

43. Diette GB, Krishnan JA, Dominici F, Haponik E, Skinner EA, Steinwachs D, Wu AW. Asthma in older patients: factors associated with hospitalization. Archives of internal medicine. 2002;162(10):1123-32.

44. Quadrelli SA, Roncoroni AJ. Is asthma in the elderly really different? Respiration; international review of thoracic diseases. 1998;65(5):347-53.

45. Zureik M, Orehek J. Diagnosis and severity of asthma in the elderly: results of a large survey in 1,485 asthmatics recruited by lung specialists. Respiration; international review of thoracic diseases. 2002;69(3):223-8.

\section{References}

1. Asthma fact sheet [Internet]. Available: http:// www.who.int/mediacentre/factsheets/fs307/en/ (cited 27.08.2017) 
2. Kulikov ES, Ogorodova LM, Belevskiy AS, Petrovskiy FI, Chuchalin AG. The effectiveness of strategies for achieving and maintaining control over bronchial asthma in conditions of real clinical practice: data from a multicenter study of STRELA-ACT. Pulmonologiya. 2010;1:80-6. (In Russian)

3. Camargo CA Jr, Weiss ST, Zhang S, Willett WC, Speizer FE. Prospective study of body mass index, weight change, and risk of adult-onset asthma in women. Archives of internal medicine. 1999;159(21):2582-8. DOI: 10.1001/ archinte.159.21.2582.

4. Shaheen SO, Sterne JA, Montgomery SM, Azima $\mathrm{H}$. Birth weight, body mass index and asthma in young adults. Thorax. 1999;54(5):396-402.

5. Stenius-Aarniala B, Poussa T, Kvarnström J, Grönlund EL, Ylikahri M, Mustajoki P. Immediate and long term effects of weight reduction in obese people with asthma: randomised controlled study. BMJ: British medical journal / British Medical Association. 2000;320(7238):827-32.

6. Aaron SD, Fergusson D, Dent R, Chen Y, Vandemheen KL, Dales RE. Effect of weight reduction on respiratory function and airway reactivity in obese women. Chest. 2004;125(6):2046-52.

7. Saint-Pierre P, Bourdin A, Chanez P, Daures JP, Godard P. Are overweight asthmatics more difficult to control? Allergy. 2006;61(1):79-84. DOI: 10.1111/j.13989995.2005.00953.x

8. Maniscalco M, Zedda A, Faraone S, Cerbone MR, Cristiano S, Giardiello C, Sofia M. Weight loss and asthma control in severely obese asthmatic females. Respiratory medicine. 2008;102(1):102-8. DOI: 10.1016/j. rmed.2007.07.029.

9. Haselkorn T, Fish JE, Chipps BE, Miller DP, Chen $\mathrm{H}$, Weiss ST. Effect of weight change on asthma-related health outcomes in patients with severe or difficult-totreat asthma. Respiratory medicine. 2009;103(2):27483. DOI: $10.1016 /$ j.rmed.2008.08.010. DOI: $10.1016 /$ j. rmed.2008.08.010.

10. Lange P, Parner J, Vestbo J, Schnohr P, Jensen G. A 15-year follow-up study of ventilatory function in adults with asthma. The New England journal of medicine. 1998;339:1194-200. DOI: 10.1056/ NEJM199810223391703.

11. Dijkstra A, Vonk JM, Jongepier H, Koppelman GH, Schouten JP, ten Hacken NH, Timens W, Postma DS. Lung function decline in asthma: association with inhaled corticosteroids, smoking and sex. Thorax. 2006;61(2):10510. DOI: $10.1136 /$ thx.2004.039271.

12. Kauppi P, Kupiainen H, Lindqvist A, Haahtela T, Laitinen T. Long-term smoking increases the need for acute care among asthma patients: a case control study. BMC pulmonary medicine. 2014;14:119. [Internet] DOI. 10.1186/1471-2466-14-119. URL: https://www.ncbi. nlm. nih.gov/pmc/articles/PMC4108236/
13. Ali Z, Dirks CG, Ulrik CS. Long-term mortality among adults with asthma: a 25-year follow-up of 1,075 outpatients with asthma. Chest. 2013;143(6):1649-1655. DOI: 10.1378/chest.12-2289.

14. Emerman CL, Woodruff PG, Cydulka RK, Gibbs MA, Pollack CV Jr, Camargo CA Jr. Prospective multicenter study of relapse following treatment for acute asthma among adults presenting to the emergency department. MARC investigators. Multicenter Asthma Research Collaboration. Chest. 1999;115(4):919-27. DOI: http://dx.doi. org/10.1378/chest.12-2289.

15. McCarren M, McDermott MF, Zalenski RJ, Jovanovic B, Marder D, Murphy DG, Kampe LM, Misiewicz VM, Rydman RJ. Prediction of relapse within eight weeks after an acute asthma exacerbation in adults. Journal of clinical epidemiology. 1998;51(2):107-18. DOI: http://dx.doi. org/10.1016/S0895-4356(97)00246-1.

16. Adams RJ, Smith BJ, Ruffin RE. Factors associated with hospital admissions and repeat emergency department visits for adults with asthma. Thorax. 2000;55(7):56673. DOI: 10.1136/thorax.55.7.566.

17. Turner MO, Noertjojo K, Vedal S, Bai T, Crump S, Fitzgerald JM. Risk factors for near-fatal asthma. A case-control study in hospitalized patients with asthma. American journal of respiratory and critical care medicine. 1998;157(6Pt1):1804-9. DOI: 10.1164/ajrccm.157.6.9708092.

18. Crane J, Pearce N, Burgess C, Woodman K, Robson B, Beasley R. Markers of risk of asthma death or readmission in the 12 months following a hospital admission for asthma. International journal of epidemiology. 1992;21(4):737-44.

19. Miller MK, Lee JH, Miller DP, Wenzel SE; TENOR Study Group. Recent asthma exacerbations: a key predictor of future exacerbations. Respiratory medicine. 2007; 101(3):481-9. DOI: 10.1016/j.rmed.2006.07.005.

20. Schatz M, Meckley LM, Kim M, Stockwell BT, Castro M. Asthma exacerbation rates in adults are unchanged over a 5-year period despite high-intensity therapy. The journal of allergy and clinical immunology. In practice. 2014;2(5):570-4.e1. DOI: 10.1016/j.jaip.2014.05.002.

21. Sturdy PM, Victor CR, Anderson HR, Bland JM, Butland BK, Harrison BD, Peckitt C, Taylor JC; Mortality and Severe Morbidity Working Group of the National Asthma Task Force. Psychological, social and health behaviour risk factors for deaths certified as asthma: a national casecontrol study. Thorax. 2002;57(12):1034-9. DOI: 10.1136/ thorax.57.12.1034.

22. Wissow LS, Gittelsohn AM, Szklo M, Starfield B, Mussman M. Poverty, race, and hospitalization for childhood asthma. American journal of public health. 1988;78(7):777-82.

23. Lang DM, Polansky M. Patterns of asthma mortality in Philadelphia from 1969 to 1991. The New England 
journal of medicine. 1994;331(23):1542-6. DOI: 10.1056/ NEJM199412083312302.

24. Eisner MD, Katz PP, Yelin EH, Shiboski SC, Blanc PD. Risk factors for hospitalization among adults with asthma: the influence of sociodemographic factors and asthma severity. Respiratory research. 2001;2(1):53-60. DOI: $10.1186 / \mathrm{rr} 37$.

25. Apter AJ, Wan F, Reisine S, Bender B, Rand C, Bogen DK, Bennett IM, Bryant-Stephens T, Roy J, Gonzalez R, Priolo C, Have TT, Morales KH. The association of health literacy with adherence and outcomes in moderate-severe asthma. The Journal of allergy and clinical immunology. 2013;132(2):321-7. DOI: 10.1016/j.jaci.2013.02.014.

26. Paasche-Orlow MK, Riekert KA, Bilderback A, Chanmugam A, Hill P, Rand CS, Brancati FL, Krishnan JA. Tailored education may reduce health literacy disparities in asthma self-management. American journal of respiratory and critical care medicine. 2005;172(8):980-6. DOI: 10.1164/rccm.200409-1291OC.

27. Adams RJ, Appleton SL, Hill CL, Ruffin RE, Wilson $\mathrm{DH}$. Inadequate health literacy is associated with increased asthma morbidity in a population sample. The Journal of allergy and clinical immunology. 2009;124(3):601-3. DOI: 10.1016/j.jaci.2009.05.035.

28. Curtis LM, Wolf MS, Weiss KB, Grammer LC. The impact of health literacy and socioeconomic status on asthma disparities. The Journal of asthma : official journal of the Association for the Care of Asthma. 2012;49(2):17883. DOI: 10.3109/02770903.2011.648297.

29. Javed A, Yoo KH, Agarwal K, Jacobson RM, Li X, Juhn YJ. Characteristics of children with asthma who achieved remission of asthma. The Journal of asthma: official journal of the Association for the Care of Asthma. 2013;50(5):472-9. DOI: 10.3109/02770903.2013.787625.

30. Boulet LP. Is asthma control really more difficult to achieve in the elderly patient? International archives of allergy and immunology. 2014;165(3):149-51. DOI: $10.1159 / 000368966$.

31. Griswold SK, Nordstrom CR, Clark S, Gaeta TJ, Price ML, Camargo CA Jr. Asthma exacerbations in North American adults: who are the «frequent fliers» in the emergency department? Chest. 2005;127(5):1579-86. DOI: 10.1378/chest.127.5.1579.

32. Banerji A, Clark S, Afilalo M, Blanda MP, Cydulka RK, Camargo CA Jr. Prospective multicenter study of acute asthma in younger versus older adults presenting to the emergency department. Journal of the American Geriatrics Society. 2006;54(1):48-55. DOI: 10.1111/j.15325415.2005.00563.x

33. Sharma G, Goodwin J. Effect of aging on respiratory system physiology and immunology. Clinical interventions in aging. 2006;1(3):253-60.

34. Boulet LP. Asthma in the elderly patient. Asthma research and practice. 2016;2:3. DOI: 10.1186/s40733-0150015-1.
35. Xia S, Zhang X, Zheng S, Khanabdali R, Kalionis B, Wu J, Wan W, Tai X. An Update on Inflamm-Aging: Mechanisms, Prevention, and Treatment. Journal of immunology research. 2016;2016:8426874. DOI: 10.1155/2016/8426874.

36. Turner JM, Mead J, Wohl ME. Elasticity of human lungs in relation to age. Journal of applied physiology. 1968;25(6):664-71.

37. Brooks CR, Gibson PG, Douwes J, Van Dalen CJ, Simpson JL. Relationship between airway neutrophilia and ageing in asthmatics and non-asthmatics. Asian $\mathrm{Pa}$ cific Society of Respirology. 2013;18(5):857-65.

38. Chotirmall SH, Burke CM. Aging and the microbiome: implications for asthma in the elderly? Expert Review of Respiratory Medicine. 2015;9(2):125-8. DOI:10.1586/17 476348.2015.1002473.

39. Hardaker KM, Downie SR, Kermode JA, Farah CS, Brown NJ, Berend N, King GG, Salome CM. Predictors of airway hyperresponsiveness differ between old and young patients with asthma. Chest. 2011;139(6):1395-1401. DOI: 10.1378/chest.10-1839. Epub 2011 Mar 31.

40. Talreja N, Baptist AP. Effect of age on asthma control: results from the National Asthma Survey. Annals of allergy, asthma and immunology: official publication of the American College of Allergy, Asthma, and Immunology. 2011;106(1):24-9. DOI: 10.1016/j.anai.2010.10.017.

41. Slavin RG, Haselkorn T, Lee JH, Zheng B, Deniz Y, Wenzel SE; TENOR Study Group. Asthma in older adults: observations from the epidemiology and natural history of asthma: outcomes and treatment regimens (TENOR) study. Annals of allergy, asthma and immunology: official publication of the American College of Allergy, Asthma, and Immunology. 2006;96(3):406-14.

42. Ponte EV, Stelmach R, Franco R, Souza-Machado C, Souza-Machado A, Cruz AA. Age is not associated with hospital admission or uncontrolled symptoms of asthma if proper treatment is offered. International archives of allergy and immunology. 2014;165(1):61-7. DOI: $10.1159 / 000367924$.

43. Diette GB, Krishnan JA, Dominici F, Haponik E, Skinner EA, Steinwachs D, Wu AW. Asthma in older patients: factors associated with hospitalization. Archives of internal medicine. 2002;162(10):1123-32.

44. Quadrelli SA, Roncoroni AJ. Is asthma in the elderly really different? Respiration; international review of thoracic diseases. 1998;65(5):347-53.

45. Zureik M, Orehek J. Diagnosis and severity of asthma in the elderly: results of a large survey in 1,485 asthmatics recruited by lung specialists. Respiration; international review of thoracic diseases. 2002;69(3):223-8.

\section{Сведения об авторах}

Кобякова Ольга Сергеевна, Сибирский государственный медицинский университет; адрес: Российская Федерация, 634050, г. Томск, ул. Московский тракт, д. 2; тел.: +7(3822)530423; e-mail: olga_kobyakova@rambler.ru

Деев Иван Анатольевич, Сибирский государственный медииинский 
университет; адрес: Российская Федерация, 634050, г. Томск, ул. Московский тракm, д. 2; тел.: +7(3822)901101\#1503; e-mail: ivandeyev@yandex.ru

Куликов Евгений Сергеевич, Сибирский государственный медицинский университет; адрес: Российская Федерация, 634050, г. Томск, ул. Московскии тракт, д. 2; тел.: +7(3822)901101 \#1528; e-mail: evgeny.s.kulikov@gmail.com

Пименов Игорь Дмитриевич, Сибирский государственный медииинский университет; адрес: Российская Федераиия, 634050, г. Томск, ул. Московский тракт, д. 2; тел.: +7(3822)901101\#1619; e-mail: igor.d.pimenov@gmail.com

Тюбилин Денис Сергеевич, Сибирский государственньй медицинский университет; адрес: Российская Федераиия, 634050, г. Томск, ул. Московскии тракт, д. 2; тел.: +7(3822)901101 \#1571; e-mail: dtufilin@gmail.com

\section{Information about the authors}

Kobyakova Olga S., Siberian State Medical University; Address: 2, Moskovsky trakt, Tomsk Russian Federation 634050; Phone: +7(3822)530423 e-mail: olga_kobyakova@rambler.ru
Deev Ivan A., Siberian State Medical University; Address: 2, Moskovsky trakt, Tomsk Russian Federation 634050; Phone: +7(3822)901101 \#1503. e-mail:ivandeyev@yandex.ru

Kulikov Evgeny S., Siberian State Medical University; Address: 2, Moskovsky trakt, Tomsk Russian Federation 634050; Phone: +7(3822)901101 \#1528; e-mail: evgeny.s.kulikov@gmail.com

Pimenov Igor D., Siberian State Medical University; Address: 2, Moskovsky trakt, Tomsk Russian Federation 634050; Phone: +7(3822)901101 \#1619; e-mail: igor.d.pimenov@gmail.com

Tyufilin Denis. S., Siberian State Medical University; Address: 2, Moskovsky trakt, Tomsk Russian Federation 634050; Phone: +7(3822)901101 \#1571; e-mail: dtufilin@gmail.com

Поступила 29.07.2017 2 Принята к печати 13.09.2017 г.

๑ КОРОСТОВЦЕВА Л. С., ВАРЕНИЦЫНА С. Ю., БОЧКАРЕВ М. В., СЕМЕНОВ А. П., СВИРЯЕВ Ю. В.

УДК 616.12-008.313:616.24-008.444

DOI: $10.20333 / 2500136-2017-5-18-28$.

\section{БРАДИАРИТМИИ ПРИ СИНДРОМЕ ОБСТРУКТИВНОГО АПНОЭ ВО ВРЕМЯ СНА: ТАКТИКА ВЕДЕНИЯ}

Л. С. Коростовцева ${ }^{1}$, С. Ю. Вареницына ${ }^{1}$, М. В. Бочкарев ${ }^{1}$, А. П. Семенов ${ }^{1}$ Ю. В. Свиряев ${ }^{1,2}$

${ }^{1}$ Северо-Западный федеральный медицинский исследовательский центр имени В. А. Алмазова, Санкт-Петербург 197341, Российская Федерация ${ }^{2}$ Институт эволюционной физиологии и биохимии имени И. М. Сеченова Российской академии наук, Санкт-Петербург 194223,

Российская Федерация

Резюме. Синдром обструктивного апноэ во время сна (СОАС) является широко распространенной патологией с доказанной связью с сердечнососудистыми заболеваниями, включая артериальную гипертензию, ишемическую болезнь сердца, нарушения сердечного ритма и проводимости. В представленной лекции акцент сделан на брадиаритмиях, ассоциированных с нарушениями дыхания во время сна. Помимо общих сведений о встречаемости нарушений проводимости сердца у лиц с СОАС и лежащих в основе их развития патогенетических механизмах, обсуждаются подходы к диагностике и возможные трудности, связанные с выявлением причинно-следственных связей между нарушениями дыхания во время сна и нарушениями ритма сердца. Предложен алгоритм по тактике ведения пациентов с брадиаритмиями в ночное время и риском нарушений дыхания во время сна.

Ключевые слова: синдром обструктивного апноэ во время сна, нарушения дыхания во время сна, сердечно-сосудистая смертность и заболеваемость, брадиаритмии, синус-арест, атриовентрикулярная блокада.

Для иитирования: Коростовцева ЛС, Вареницына СЮ, Бочкарев МВ, Семенов АП, Свиряев ЮВ. Брадиаритмии при синдроме обструктивного апноэ во время сна: тактика ведения. Сибирское медищинское обозрение. 2017;(5): 18-28. DOI: 10.20333/2500136-2017-5-18-28.

\section{BRADYARRHYTHMIAS IN THE OBSTRUCTIVE SLEEP APNEA SYNDROME: TREATMENT TACTICS}

L. S. Korostovtseva ${ }^{1}$, S. Yu. Varenitsyna', M. V. Bochkarev' ${ }^{1}$, A. P. Semenov ${ }^{1}$, Yu. V. Sviryaev', ${ }^{1}$

${ }^{1}$ V. A. Almazov Federal North-West Medical Research Centre, St. Petersburg 197341, Russian Federation

${ }^{2}$ Sechenov Institution of the Evolutionary Physiology and Biochemistry of the Russian Academy of Sciences, St. Petersburg 194223, Russian Federation

Abstract. The syndrome of obstructive sleep apnea (SOSA) is a common pathology with a proven connection with cardiovascular diseases, including arterial hypertension, coronary heart disease, cardiac rhythm and conduction disorders. In the lecture the emphasis is on bradyarrhythmias, associated with breathing disorders during sleep. In addition to general information on the occurrence of cardiac conduction disorders in persons with SOSA and pathogenetic mechanisms, approaches to diagnosis and possible difficulties, associated with the identification of cause-effect relationships between respiratory disturbances during sleep and heart rhythm disturbances are discussed. It is suggested the algorithm for the tactics of treatment the patients with bradyarrhythmias at night and the risk of breathing disorders during sleep.

Key words: obstructive sleep apnea syndrome, breathing disorders during sleep, cardiovascular mortality and morbidity, bradyarrhythmias, sinus arrest, atrioventricular blockade.

Citation: Korostovtseva LS, Varenitsyna SYu, Bochkarev MV, Semenov AP, Sviryaev YuV. Bradyarrhythmias in the obstructive sleep apnea syndrome: treatment tactics. Siberian Medical Review. 2017; (5): 18-28. DOI: 10.20333/2500136-2017-5-18-28. 
Синдром обструктивного апноэ во время сна (СОАС) с учетом доказанной связи с сердечно-сосудистыми заболеваниями (прежде всего артериальной гипертензии) и высокой частотой в популяции представляет серьезную проблему современного здравоохранения. СОАС характеризуется повторяющимися эпизодами обструкции верхних дыхательных путей во время сна, которые сопровождаются развитием гипоксии, гипоксемии, гиперкапнии, частыми ночными пробуждениями, приводящими к снижению качества сна и нарушению функционирования в дневное время (в частности, из-за дневной сонливости). Доказано, что СОАС является независимым фактором риска развития сердечно-сосудистых осложнений $[1,2]$. В ходе метаанализа X. Ge и соавторов (2013), в который были включены 6 исследований с общей численностью обследованных 11932 человека, выявлено, что наличие СОАС средне-тяжелой степени ассоциировано с повышением риска летальных исходов от любых причин (вероятный риск 1,67; 95 $\%$ доверительный интервал (ДИ) $1,25-2,23 ; \mathrm{p}=0,001$ ), a СОАС тяжёлой степени - с еще более высоким риском (1,9 (95 \% ДИ 1,29-2,81, p=0,001). При анализе предикторов сердечно-сосудистой смертности оказалось, что СОАС средне-тяжелой степени ассоциирован с повышенным риском фатальных сердечно-сосудистых осложнений (вероятный риск 2,21; 95 \% ДИ 1,61-3,04; p $<0,001)$, риск ещё большей степени выявлен при анализе подгруппы с СОАС тяжёлой степени (вероятный риск 2,65 (95\% ДИ 1,82-3,85, p<0,001) [3].

Среди возможных причин повышения риска фатальных сердечно-сосудистых событий у лиц с СОАС обсуждаются нарушения сердечного ритма и проводимости [4-6]. В данной статье мы коснемся преимущественно аспектов, касающихся брадиаритмий у пациентов с обструктивными нарушениями дыхания во время сна (НДС). Брадиаритмии выявляются в среднем у 7 \% пациентов с СОАС [7, 8], асистолия во время сна встречается у 5-10 \% пациентов с СОАС $[8,9]$. Продолжительность эпизодов асистолии при СОАС может достигать десятков секунд. Описаны асистолии длительностью до 15 и даже 22 секунд, которые зачастую протекают бессимптомно [10] и обычно обусловлены синоатриальной (СА-блокады) и атриовентрикулярной (АВ-блокады) блокадами высоких градаций $[11,12]$.

Выраженность апноэ-ассоциированной брадикардии обычно повышается пропорционально степени тяжести COAC [13]. Зачастую у больных COAC регистрируется феномен циклической вариации ЧСС (ЦВЧСС) [13-15], для которой типичны чередующиеся эпизоды выраженного замедления и учащения ритма сердца: прогрессирующая брадикардия, возникающая в момент начала эпизода апноэ (при этом снижение ЧСС пропорционально степени гипоксемии), и тахикардия при восстановлении дыхания. В основе развития ЦВЧСС и брадикардии (брадиаритмий) лежат изменения тонуса вегетативной нервной системы (с периодическим повышением вагального тонуса, в частности, в ответ на колебания внутригрудного давления), влияние интермиттирующей гипоксемии-гиперкапнии, нарушение хеморецепторной и барорефлекторной чувствительности $[4,13,15$, $16]$.

Несмотря на данные обсервационных исследований и описанные патогенетические механизмы, встречаются противоречивые результаты исследований о взаимосвязи СОАС и брадиаритмий. В исследовании A. Velasco et al. (2014) частота брадиаритмий (включая дисфункцию синусового узла и АВ-блокаду) не отличалась у лиц с высоким и низким риском СОАС $(\mathrm{n}=190)$. Однако результат может быть обусловлен тем, что для оценки риска НДС авторы применяли субъективную оценку по Берлинскому опроснику, а объективное подтверждение (полисомнографическое исследование) получено не было [17]. Меньшую вероятность выявления брадикардии и нарушений проводимости в дневное время у пациентов с подтвержденным СОАС средне-тяжелой степени, чем у лиц без НДС, выявила американская группа ученых по результатам субанализа исследования «Исходы нарушений сна у пожилых мужчин» (Outcomes of Sleep Disorders in Older Men, MrOS Sleep). Однако в этом исследовании не проводилось длительное мониторирование ЭКГ, а выполнялась оценка лишь 10-секундной 12-канальной ЭКГ в покое [18].

Подходы к диагностике

Брадиаритмия, связанная с обструктивным апноэ, возникает только во время сна. Однако при возникновении нарушений сердечного ритма и проводимости в период предполагаемого бодрствования у лиц с выраженной сонливостью необходим особо тщательный анализ и сбор анамнеза для дифференциальной диагностики и постановки правильного диагноза (так как непродолжительное засыпание в дневное время пациенты могут описывать как приступы кратковременного «отключения сознания»). С другой стороны, при выраженной дневной сонливости на фоне кратковременных эпизодов сна, могут развиваться нарушения в проводящей системе сердца (вплоть до синус-ареста и AB-блокады II степени и выше), которые при мониторировании ЭКГ могут быть отнесены к периоду бодрствования, если дневник пациента заполнен небрежно, а доктор не провел соответствующего прицельного опроса [19].

Во время бодрствования в большинстве случаев пациенты с СОАС (в особенности с ожирением) склонны к тахикардии и по данным электрофизиологического 
исследования нарушения проводимости сердца у них не выявляются. Тем не менее, нередки случаи, когда неправильная трактовка причины нарушения проводимости приводит к необоснованной имплантации постоянного электрокардиостимулятора (ПЭКС) [20].

В ряде случаев генез пресинкопальных и синкопальных состояний у одного и того же пациента может быть многофакторным, что требует мультидисциплинарного подхода и разностороннего обследования. Так, описаны случаи эпилептических приступов, сопровождающихся развитием выраженной брадикардии, возникающих после эпизодов апноэ во время сна [21]. В одном исследовании показана высокая частота дыхательных нарушений, ассоциированных с эпизодами гипоксемии и брадикардии, у взрослых пациентов с верифицированной эпилепсией [22], что указывает на необходимость проведения комплексного диагностического обследования для выявления НДС у этой категории больных. В то же время, причинно-следственная связь между НДС и эпиприступами в таких случаях требует более детального анализа и дальнейшего изучения.

Стандартом в диагностике синдрома обструктивного апноэ во время сна является полисомнографическое исследование, которое включает в себя регистрацию электроэнцефалограммы, электроокулограммы, электромиограммы, дыхательных параметров (ороназального потока воздуха, сатурации кислорода, дыхательных движений (брюшной стенки и грудной клетки), электрокардиограммы (ЭКГ), двигательной активности и других показателей [23]. Полисомнографическое исследование является достаточно трудоемким и дорогостоящим методом, в связи с чем широко внедряются более простые и дешевые методы, однако их информативность по сравнению с ПСГ не всегда оптимальна $[24,25]$. При выявлении клинически значимых брадиаритмий у пациента с СОАС необходимо точно определить связаны ли нарушения проводимости со сном и бодрствованием, что может обеспечить лишь полное полисомнографическое исследование.

Скрининговые методы могут быть полезны для предварительного обследования (особенно в группах риска). Так, в ходе автоматического анализа результатов суточного мониторирования ЭКГ, основанного на оценке вариабельности частоты сердечных сокращений (ЧСС) и определении эпизодов тахи-брадикардии, характерных для пациентов с СОАС, дают возможность оценить вероятность обструктивных нарушений дыхания во время сна, а также с достаточно высокой точностью установить степень их тяжести [26, 27].

В целом холтеровское мониторирование ЭКГ с одновременной регистрацией дыхательных параметров (так называемое кардиреспираторное мониторирова- ние, включающее запись индукционной реоплетизмографии/пневмографии, пульсоксиметрии) является одним из многообещающих направлений в диагностике НДС. В России подобный прибор был разработан компанией «Инкарт» (Санкт-Петербург). Он позволяет регистрировать 12-канальную ЭКГ, носовое дыхание, храп, пульсоксиметрию. Дополнительно был разработан алгоритм для оценки дисперсии ЧСС в ночное время (частые смены эпизодов тахи- и брадикардии) по 10-секундному тренду ЧСС, что позволяет судить о степени тяжести апноэ во время сна $[23,28]$.

Сучетом вышеописанных сложностей дифференциальной диагностики эпизодов выраженной дневной сонливости и пресинкопальных состояний, ассоциированных с нарушениями проводимости ритма сердца, при проведении ХМ ЭКГ/кардиореспираторного мониторирования у пациентов с СОАС, необходимо обращать их внимание на правильное и тщательное заполнение дневника с регистрацией всех периодов сна (включая кратковременные эпизоды - как днем, так и ночью), а также отмечать те временные промежутки, когда у пациента высока вероятность заснуть (например, просмотр телевизора, послеобеденный отдых и т.д.). Как указывалось ранее, кардиореспираторное мониторирование может быть полезно в сочетании с ЭЭГ-видеомониторированием в неврологической практике [22].

Необходимо отметить, что частое сочетание брадиаритмий и СОАС заставило разработчиков ПЭКС внедрить алгоритм оценки нарушения дыхания во время сна с помощью трансторакальной импедансометрии в приборы ПЭКС (исследование DREAM), что позволяет не только диагностировать СОАС, но и осуществлять длительное мониторирование с оценкой динамики ИАГ [29].

\section{Тактика ведения}

Согласно рекомендациям Европейского общества кардиологов, постоянная электрокардиостимуляция (ПЭКС) не показана лицам с потенциально обратимыми причинами брадиаритмий, к числу которых может быть отнесен и СОАС [30]. Эксперты Американской ассоциации сердца в рекомендациях 2008 года выделили раздел, посвященный вопросам электрокардиостимуляции у лиц с нарушениями проводимости сердца при наличии НДС, в котором подчеркивается, что имплантация ПЭКС не показана в случае бессимптомных нарушений ритма и проводимости и возможности устранения основной причины этих нарушений [31].

Эффективность неинвазивной вентиляции легких (СРАР-терапии) в устранении значимых брадиаритмий у лиц с СОАС, включая асистолию более 10 секунд, подтверждается данными отдельных клинических наблюдений $[2,12,19,32-35]$ и результатами 
клинических исследований $[7,36,37]$. В то же время СРАР-терапия неэффективна в отношении ночных эпизодов асистолии у лиц без СОАС. Это подтверждает патогенетическую обоснованность применения метода создания положительного давления в верхних дыхательных путях для лечения брадикардий у пациентов с обструктивными НДС [38]. Более того, по результатам проспективного исследования Doherty et al. неинвазивная вентиляция легких обладает протективным действием в отношении летальных исходов от сердечно-сосудистой патологии, в том числе и вследствие нарушений ритма (14,8 и 1,9 \% в группе с СРАР-терапией и без нее соответственно, $\mathrm{p}<0,009)$ [39].

Описаны случаи имплантации ПЭКС в связи с СССУ пациентам без предварительной диагностики НДС, у которых активация искусственного водителя ритма отмечалась сотни раз только в ночное время до того, как была назначена СРАР-терапия $[40,41]$. Однако целесообразность имплантации ПЭКС пациентам с СОАС и нарушениями проводимости сердца в ночное время до сих пор вызывает споры [42].

Данные о риске развития осложнений лечения скорее говорят в пользу СРАР-терапии, при которой нежелательные явления (сухость во рту, аллергические кожные реакции, вазомоторные реакции, заложенность носа, носовые кровотечения и другие) регистрируются примерно в $13 \%$ случаев [43], в то время как встречаемость ранних и поздних послеоперационных осложнений ПЭКС (включая диспозицию электрода, перфорацию миокарда, кровотечения, пневмоторакс, инфекционные осложнения, дисфункцию и дислокацию электродов и другие) составляет до 10-35 \% [30, $44,45,46]$. Однако нельзя не учитывать тот факт, что основными проблемами (до 30-50 \%) при проведении неинвазивной вентиляции легких являются частая непереносимость и низкая приверженность к терапии (отказ от терапии, использование приборов менее 4 часов за ночь, на протяжении менее $70 \%$ ночей), что становится основным препятствием к долгосрочному лечению [43, 47].

В 2002 году было опубликовано небольшое исследование ( $\mathrm{n}=15)$, которое, казалось, открыло перспективу для проведения ПЭКС пациентам с НДС и брадиаритмиями: по результатам этого исследования предсердная ПЭКС приводила к уменьшению частоты эпизодов как центральных, так и обструктивных апноэ [48]. Среди возможных механизмов рассматривалось рефлекторное повышение тонуса верхних дыхательных путей и изменение структуры сна под действием ПЭКС $[48,49]$. Однако впоследствии появились работы, опровергшие влияние ПЭКС на выраженность СОАС $[50,51,52]$, а сравнительные исследования и метаанализ доказали неоспоримое преимущество
СРАР-терапии в лечении НДС [53, 54]. Правда, возможность применения ПЭКС для лечения центральных апноэ до сих пор обсуждается ввиду возможного улучшения сердечного выброса, сопровождающегося уменьшением времени циркуляции крови в малом и большом кругах кровообращения и приводящего к стабилизации дыхания и предотвращению гипервентиляции [55].

С другой стороны, если предположить, что замедление ЧСС на фоне апноэ является механизмом, обладающим защитным действием и обеспечивающим сохранение энергии в условиях дефицита кислорода, то искусственная стимуляция миокарда (в частности, ПЭКС) может негативно сказаться на работе сердца [29]. Более того, в условиях гипоксемии выше вероятность развития ишемии миокарда, что подтверждается результатами клинических наблюдений эпизодов депрессии сегмента ST в ночное время у лиц с СОАС тяжелой степени [56]. В таких случаях необоснованная электрокардиостимуляция (при отсутствии структурных изменений проводящей системы сердца) может усугубить ишемию и/или спровоцировать нарушения ритма [57].

Медикаментозные подходы к лечению пациентов с СОАС и брадиаритмиями в настоящее время малоизучены. Описаны отдельные случаи успешного медикаментозного лечения пациентов с синоатриальной блокадой на фоне НДС. В частности, у больного с пресинкопальными состояниями на фоне синус-ареста и СОАС тяжелой степени (ИАГ более 50 в час), который отказался как от проведения СРАР-терапии, так и от имплантации ПЭКС, терапия аденозинергическим препаратом - теофиллином 200 мг/сут - привела к полному устранению эпизодов нарушений ритма в ходе почти трехлетнего наблюдения [58].

Ввиду хронической симпатикотонии (в течение суток) у пациентов с СОАС, назначение препаратов, обладающих симпатолитической активностью, представляется целесообразным, однако назначение бетаблокаторов лицам с брадиаритмиями обычно ограничено. Необходимо отметить, что согласно результатам исследования J. Wolf et al. (2016) назначение бета-блокаторов (применялись бисопролол, метопролол, бетаксолол, карведилол) пациентам с СОАС средне-тяжелой степени без сопутствующей бронхолегочной патологии не сопровождалось изменением брадикардического ответа (выраженность брадикардии не возрастала) или ухудшением нарушений проводимости. В то же время тахикардический ответ изменялся - снижалась выраженность тахикардии, ассоциированной с окончанием эпизодов апноэ/гипопноэ [59]. Результаты этого исследования позволяют рекомендовать (по крайней мере не отменять) назначение бета-блокаторов лицам с СОАС и брадикардией. 
В целом медикаментозное лечение пациентов может рассматриваться лишь в отдельных случаях и не является оптимальным подходом для лечения брадиаритмий.

Ввиду вышесказанного можно предложить следующий алгоритм при выборе тактики ведения пациентов с СОАС и брадиаритмиями:

- У пациентов с брадиаритмиями преимущественно в ночное время/во время сна следует проводить полное полисомнографическое исследование (при невозможности - кардиореспираторное мониторирование) для исключения НДС [25]. При выявлении СОАС у таких пациентов целесообразно выполнение чреспищеводного электрофизиологического исследования для оценки функции проводящей системы сердца. Также в ряде случаев для оценки связи эпизодов брадиаритмии с НДС (например, в отсутствие возможности выполнения полисомнографического исследования) может быть рекомендована оценка реакции ЧСС в пробе Мюллера (симуляция вдоха при закрытых верхних дыхательных путях): развитие выраженной брадикардии в конце пробы характерно для лиц с синдромом апноэ во время сна [60].

- У пациентов с диагностированным СОАС и брадиаритмиями, регистрирующимися преимущественно в ночное время (или во время сна), терапию следует начинать с неинвазивной вентиляции легких. СРАР-терапия на сегодня самый эффективный метод лечения СОАС, однако, влияние на прогноз кардиоваскулярной патологии при длительном ее применении остается до конца неясным и требует дальнейших исследований [61]. Возможно применение и других методов лечения СОАС - использование внутриротовых приспособлений, позиционное лечение, лечение патологии ЛОР-органов и других - при обязательном контроле их эффективности [25].

- У пациентов с СОАС и брадиаритмиями с учетом высокого риска ишемии миокарда на фоне выраженной гипоксемии целесообразно проводить дополнительные исследования (нагрузочные тесты, коронарографию, компьютерную томографию сердца в ангиорежиме и пр.) для исключения мало-/бессимптомного атеросклеротического поражения миокарда с целью медикаментозного и/или хирургического лечения [56, 57].

- Вопрос об имплантации ПЭКС целесообразно обсуждать при непереносимости неинвазивной вентиляции легких и/или категорическом отказе пациента от применения СРАР-терапии, при недостаточной продолжительности и/или эффективности (в частности, при сохранении апноэ и/или нарушений проводимости сердца на фоне СРАР-терапии) использования этого метода лечения в течение ночи (в силу субъективных или объективных причин).
- При определении тактики лечения вопрос следует решать в пользу имплантации ПЭКС при наличии признаков нарушений проводящей системы сердца по данным электрофизиологического исследования, при наличии симптомов в дневное время (например, пресинкопе и синкопе) и признаков, не корригируемых другими методами сердечно-сосудистых заболеваний (в частности, ишемическая болезнь сердца, кардиосклероз на фоне перенесенного миокардита и пр.) [62].

- Вопросы медикаментозного лечения лиц с СОАС и брадиаритмиями требуют дальнейшего изучения [58, 59]. Назначение бета-блокаторов при апноэ-ассоциированной брадикардии можно считать безопасным и потенциально может снижать риск внезапной сердечной смерти у пациентов с сопутствующей сердечнососудистой патологией [59].

\section{Заключение}

В последние годы ведется активная работа о возможностях применения СРАР-терапии у больных с тяжелыми брадиаритмиями, которые связаны с COAC. Имеющийся опыт, а также результаты исследований, показывают, что у немалой доли пациентов, имеющих доказанную связь развития тяжелой брадиаритмии или периодов длительной асистолии с эпизодами остановки дыхания во время сна, применение СРАР-терапии позволяет избежать имплантации ПЭКС, в том числе и при наличии абсолютных, с точки зрения степени выраженности брадикардии, показаний к такому виду вмешательства.

Неинвазивная вентиляция легких неэффективна в отношении ночных эпизодов асистолии у лиц без COAC, однако приводит к устранению нарушений ритма, ассоциированных с апноэ. Это подтверждает патогенетическую обоснованность применения метода создания положительного давления в верхних дыхательных путях для лечения брадикардий у пациентов с обструктивными нарушениями дыхания во время сна.

\section{Литература}

1.Lacedonia D, Carpagnano GE, Sabato R, lo Storto MM, Palmiotti GA, Capozzi V, Pia Foschino Barbaro M, Gallo C. Characterization of obstructive sleep apnea-hypopnea syndrome (OSA) population by means of cluster analysis. Journal of Sleep Research. 2016:25(6):724-30. DOI: $10.1111 /$ jsr.12429.

2.Płatek AE, Karpiński G, Szymański FM. Can continuous positive airway pressure therapy have antiarrhythmic properties? Kardiologia Polska. 2015;73(8):671. DOI: 10.5603/KP.2015.0155.

3.Ge X, Han F, Huang Y, Zhang Y, Yang T, Bai C, Guo X. Is obstructive sleep apnea associated with cardiovascular and all-cause mortality? PLoS One. 2013;8(7):e69432. 
4.Padeletti M, Zacà V, Mondillo S, Jelic S. Sleep-disordered breathing increases the risk of arrhythmias. Journal of Cardiovascular Medicine (Hagerstown). 2014;15(5):4116. DOI: 10.2459/JCM.0000000000000019.

5.Gami AS, Olson EJ, Shen WK, Wright RS, Ballman KV, Hodge DO, Herges RM, Howard DE, Somers VK. Obstructive sleep apnea and the risk of sudden cardiac death: a longitudinal study of 10,701 adults. Journal of the American College of Cardiology. 2013;62(7):610-6. DOI: 10.1016/j.jacc.2013.04.080.

6.Gami AS, Somers VK. Implications of obstructive sleep apnea for atrial fibrillation and sudden cardiac death. JournalofCardiovascularElectrophysiology.2008;19(9):9971003. DOI: $10.1111 / j .1540-8167.2008 .01136 . x$.

7.Koehler U, Fus E, Grimm W, Pankow W, Schäfer H, Stammnitz A, Peter JH. Heart block in patients with obstructive sleep apnoea: pathogenetic factors and effects of treatment. European Respiratory Journal. 1998;11(2):434-9.

8.Guilleminault C, Connolly SJ, Winkle RA. Cardiac arrhythmia and conduction disturbances during sleep in 400 patients with sleep apnea syndrome. American Journal of Cardiology. 1983;52(5):490-4.

9. Roche F, Xuong AN, Court-Fortune I, Costes F, Pichot V, Duverney D, Vergnon JM, Gaspoz JM, Barthélémy JC. Relationship among the severity of sleep apnea syndrome, cardiac arrhythmias, and autonomic imbalance. Pacing and Clinical Electrophysiology. 2003;26(3):669-77

10.Martí Almor J, Félez Flor M, Balcells E, Cladellas M, Broquetas J, Bruguera J. Prevalence of obstructive sleep apnea syndrome in patients with sick sinus syndrome. Revista Espanola of Cardiologia. 2006;59(1):28-32.

11.Guilleminault C, Eldridge F, Dement W. Insomnia with sleep apnea: a new syndrome. Science; 1973;181:856858.

12.Korostovtseva L, Sviryaev Y, Zvartau N, Druzhkova T, Tikhonenko V, Konradi A. New insights into the management of rhythm and conduction disorders after acute myocardial infarction. American Journal of Case Reports. 2014;15:159-162. DOI:10.12659/AJCR.890357.

13.Shepard Jr JW. Hypertension, cardiac arrhythmias, myocardial infarction, and stroke in relation to obstructive sleep apnea. Clinical Chest Medicine. 1992;13:437-8.

14.Guilleminault C, Pool P, Motta J, Gillis AM. Sinus arrest during REM sleep in young adults. New England Journal of Medicine. 1984;311(16):1006-10. DOI: 10.1056/ nejm198410183111602.

15.Dyavanapalli J, Jameson H, Dergacheva O, Jain V, Alhusayyen M, Mendelowitz D. Chronic intermittent hypoxia-hypercapnia blunts heart rate responses and alters neurotransmission to cardiac vagal neurons. Journal of Physiology. 2014;592(13):2799-811. DOI: 10.1113.

16.Holty J-E C, Guilleminault C. REM-related bradyarrhythmia syndrome. Sleep Medical Reviews. 2011;15(3):143-51. DOI: 10.1016/j.smrv.2010.09.001.
17.Velasco A, Hall C, Perez-Verdia A, Nugent K. Association of high-risk scores for obstructive sleep apnea with symptomatic bradyarrhythmias. Journal of Cardiovascular Medicine. 2014, 15:407-10. DOI: 10.2459/ JCM.0b013e3283630d07.

18.Kwon Y, Picel K, Adabag S, Vo T, Taylor BC, Redline S, Stone K, Mehra R, Ancoli-Israel S, Ensrud KE. Osteoporotic fractures in men (MrOS) Study Group. Sleep Breathing. 2016;20(4):1161-68. DOI:10.1007/s11325-0161326-z.

19.Lotze U, Rothhagen B, Neubauer K, Mäder I. Dizziness and near syncope due to sinus bradycardia and sinoatrial block associated with obesity and daytime tiredness. A clear indication for pacemaker implantation? Herz. 2008;33:455-9. DOI 10.1007/s00059-008-3096-2.

20.Serafini A, Dolso P, Gigli GL, Fratticci L, Cancelli I, Facchin D, Gigli M, Valente M. Rem sleep brady-arrhythmias: An indication to pacemaker implantation? Sleep Medicine. 2012;13(6):759-62. DOI: 10.1016.

21.Nishimura Y, Saito Y, Kondo N, Matsuda E, Fujiyama M, Morizane R, Maegaki Y. Ictal central apnea and bradycardia in temporal lobe epilepsy complicated by obstructive sleep apnea syndrome. Epilepsy and Behavior Case Reports. 2015;4:41-4. DOI:10.1016/j.ebcr.2015.05.001.

22.Pavlova M, Abdennadher M, Singh K, Katz E, Llewellyn N, Zarowsly M, White DP, Dworetzky BA, Kothare SV. Advantages of respiratory monitoring during video-EEG evaluation to differentiate epileptic seizures from other events. Epilepsy and Behavior. 2014;32:142-44. DOI:10.1016/j.yebeh.2013.12.031.

23.Блоцкий АА, Медведева ИП, Крамаренко ОА. Кардиореспираторное холтеровское мониторирование в диагностике синдрома обструктивного апноэ. Материалы межрегиональной научно-практической конференции оториноларингологов Сибири и Дальнего Востока с международным участием «Актуальные вопросы оториноларингологии». 2016:40-51.

24.Hayano J, Watanabe E, Saito Y., Sasaki F, Fujimoto K, Nomiyama T, Kawai K, Kodama I, Sakakibara. Screening for obstructive sleep apnea by cyclic variation of heart rate. Circulation: Arrhythmia and Electrophysiology. 2011;4(1):64-72.

25.Parati G, Lombardi C, Hedner J, Bonsignore MR, Grote L, Tkacova R, Lйvy P, Riha R, Bassetti C, Narkiewicz K, Mancia G, McNicholas WT; EU COST Action B26 members. Recommendations for the management of patients with obstructive sleep apnoea and hypertension. European Respiratory Journal. 2013;41(3):523-38. DOI: 10.1183/09031936.00226711.

26.Беленков ЮН, Пальман АД. Синдром обструктивного апноэ сна и нарушения сердечного ритма. Эффективная фармакотерапия. 2015;53:56-63.

27.Heneghan C, de Chazal P, Ryan S, Chua CP, Doherty L, Boyle P, Nolan P, McNicholas WT. Electrocardiogram 
recording as a screening tool for sleep disordered breathing. Journal of Clinical Sleep Medicine. 2008;4(3):223-28.

28.Kwon Y, Picel K, Adabag S, Vo T, Taylor BC, Redline S, Stone K, Mehra R, Ancoli-Israel S, Ensrud KE, for the Osteoporotic Fractures in Men (MrOS) Study Group. Sleepdisordered breathing and daytime cardiac conduction abnormalities on 12-lead electrocardiogram in communitydwelling older men. Sleep Breathing. 2016;20(4):1161-68. DOI:10.1007/s11325-016-1326-z.

29.Defaye P, de la Cruz I, Marti-Almor J, Villuendas R, Bru P, Sunuchal J, Tamisier R, Pepin JL. Heart Rhythm pacemaker transthoracic impedance sensor with an advanced algorithm to identify severe sleep apnea: the DREAM. European study. 2014;11(5):842-8. DOI:10.1016/j.hrthm.2014.02.011.

30.2013 ESC Guidelines on cardiac pacing and cardiac resynchronization therapy / The Task Force on cardiac pacing and resynchronization therapy of the European Society of Cardiology (ESC). Developed in collaboration with the European Heart Rhythm Association (EHRA). European Heart Journal. 2013;34:2281-329. DOI:10.1093/ eurheartj/eht150.

31.ACC/AHA/HRS 2008 Guidelines for Device-Based Therapy of Cardiac Rhythm Abnormalities /A Report of the American College of Cardiology/American Heart Association Task Force on Practice Guidelines (Writing Committee to Revise the ACC/AHA/NASPE 2002 Guideline Update for Implantation of Cardiac Pacemakers and Antiarrhythmia Devices). Circulation. 2008;117:e350e408. DOI: 10.1161/CIRCUALTION AHA.108.189742

32.Яковлев АВ, Бузунов РВ, Андрюшина НА, Туров АН, Яковлева НФ. Успешное лечение брадиаритмии, ассоциированной с синдромом обструктивного апноэ сна, методом создания постоянного положительного давления в дыхательных путях. Кардиология. 2013;53(8):93-96.

33.Pataka A, Daskalopoulou E, Papastefanou S, Baltatzi C, Aggelopulos P, Vlachogiannis E. Multiple heart pauses during sleep in a patient with obstructive sleep apnoea syndrome. Sleep Breathing. 2013;17:19-23. DOI 10.1007/ s11325-012-0648-8.

34.Maeno K, Kasai A, Setsuda M, Nishiyama A, Sakabe S, Ohnishi T, Saito K, Nishikawa H. Advanced atrioventricular block induced by obstructive sleep apnea before oxygen desaturation. Heart Vessels. 2009;24:236-40. DOI 10.1007/s00380-008-1113-2

35. Mataciuniene D, Masaitiene R, Mameniskiene R, Budrys VA. Heavy snorer with multiple prolonged asystoles during the night - reversably CPAP therapy. Sleep Breathing. 2013;17:25-8. DOI: 10.1007/s11325-012-0690-6.

36.Voigt L, Saul BI, Lombardo G, Reddy CV, Kassotis J. Correction of AV-nodal block in a 27-year-old man with severe obstructive sleep apnea - a case report. Angiology. 2003;54(3):363-7. DOI:10.1177/000331970305400314.
37.Becker H, Brandenburg U, Peter JH, Von Wichert P. Reversal of sinus arrest and atrioventricular conduction block in patients with sleep apnea during nasal continuous positive airway pressure. American Journal of Respiratory and Critical Care Medicine. 1995;151(1):215-8. DOI:10.1164/ajrccm.151.1.7812557.

38.Литвин АЮ, Певзнер АВ, Голицын ПВ, Галяви РА, Мазыгула ЕП, Нестеренко ЛЮ, Чазова ИЕ, Голицын СП. Новые подходы к лечению брадиаритмий у больных с синдромом обструктивного апноэ во сне. Терапевтический архив. 2006;8:41-7.

39.Doherty LS, Kiely JL, Swan V, McNicholas WT. Longterm effects of nasal continuous positive airway pressure therapy on cardiovascular outcomes in sleep apnea syndrome. Chest. 2005;127(6):2076-84. DOI: 10.1378/ chest.127.6.2076.

40.Белов АМ, Каллистов ДЮ, Воронин ИМ, Молашенко НП, Чучалин АГ. Кардиологические проявления синдрома обструктивного апноэ во время сна. Клинические случаи. Терапевтический архив. 1998;70(3):44-9

41.Bradley TD, Shapiro CM. ABC of sleep disorders. Unexpected presentations of sleep apnoea: use of CPAP in treatment. British Medical Journal. 1993;306(6887):1260-62.

42.Sahadevan J, Srinivasan D. Treatment of obstructive sleep apnea in patients with cardiac arrhythmias. Current Treatment Options in Cardiovascular Medicine. 2012;14:520-28.

43.Somiah M, Taxin Z, Keating J, Mooney AM, Norman RG, Rapoport DM, Ayappa I. Sleep quality, short-term and long-term CPAP adherence. Journal of Clinical Sleep Medicine. 2012;8(5):489-500. DOI: 10.5664/jcsm.2138.

44.Opić P, van Kranenburg M, Yap SC, van Dijk A. Complications of pacemaker therapy in adults with congenital heart disease: a multicenter study. International Journal of Cardiology. 2013;168:3212-216. DOI: 10.1016/j. ijcard.2013.04.114.

45.Aizawa Y, Kunitomi A, Nakajima K, Kashimura S, Katsumata Y, Nishiyama T, Kimura T, Nishiyama N, Tanimoto Y, Kohsaka S, Takatsuki S, Fukuda K. Risk factors for early replacement of cardiovascular implantable electronic devices. International Journal of Cardiology. 2015;178:99-101.

46. Belvin D, Hirschl D, Vineet R.J., Godelman A, Marjorie WS, Jay NG, Linda $\mathrm{BH}$. Chest radiographs are valuable in demonstrating clinically significant pacemaker complications that require reoperation. Canadian Association of Radiologists Journal. 2011:62:288e295.DOI:10.1016/j. carj.2010.04.016.

47.Wolkove N, Baltzan M, Kamel H, Dabrusin R, Palayew M. Long-term compliance with continuous positive airway pressure in patients with obstructive sleep apnea. Canadian Respiratory Journal. 2008;15(7):365-69.

48.Garrigue S, Bordier P, Jaïs P, Shah DC, Hocini M, Raherison C, Tunon De LM, Haïssaguerre M, Clementy 
J. Benefit of atrial pacing in sleep apnea syndrome. New England Journal of Medicine. 2002;346(6):404-12. DOI: 10.1056/NEJMoa011919.

49.Floras JS, Bradley T.D. Atrial overdrive pacing for sleep apnea: a door now closed. American Journal of Respiratory and Critical Care Medicine. 2005;172(1):1-3.

50.Krahn AD, Yee R, Erickson MK, Markowitz T, Gula LJ, Klein GJ, Skanes AC, George CF, Ferguson KA. Physiologic pacing in patients with obstructive sleep apnea: a prospective, randomized crossover trial. Journal of the American College of Cardiology. 2006;47(2):379-83. DOI:10.1016/j.jacc.2005.09.026.

51.Pépin JL, Defaye P, Garrigue S, Poezevara Y, Lévy P. Overdrive atrial pacing does not improve obstructive sleep apnoea syndrome. European Respiratory Journal. 2005;25(2):343-7. DOI:10.1183/09031936.05.00132703

52.Unterberg C, Lüthje L, Szych J, Vollmann D, Hasenfuss G, Andreas S. Atrial overdrive pacing compared to CPAP in patients with obstructive sleep apnoea syndrome. European Heart Journal. 2005;26(23):2568-75. DOI:10.1093/eurheartj/ehi448.

53.Simantirakis EN, Schiza SE, Chrysostomakis SI, Chlouverakis GI, Klapsinos NC, Siafakas NM, Vardas PE. Atrial overdrive pacing for the obstructive sleep apneahypopnea syndrome. New England Journal of Medicine. 2005;353(24):2568-77. DOI:10.1056/NEJMoa050610.

54.Baranchuk A, Jeff SH, Christopher SS, Damian PR, Carlos AM, Stuart JC, Fitzpatrick M. Atrial overdrive pacing in sleepapnoea: a meta-analysis. Europace. 2009;11:1037-40. DOI:10.1093/europace/eup165. DOI:10.1093/europace/eup165.

55.Simantirakis EN, Vardas PE. Cardiac pacing in sleep apnoea: diagnostic and therapeutic implications. Europace. 2006;8(11):984-7.

56.Peled N, Abinader EG, Pillar G, Sharif D, Lavie P. Nocturnal ischemic events in patients with obstructive sleep apnea syndrome and ischemic heart disease: effects of continuous positive air pressure treatment. Journal of the American College of Cardiology. 1999;34(6):1744-9.

57.Chow AW, Segal OR, Davies DW, Peters NS. Mechanism of pacing-induced ventricular fibrillation in the infarcted human heart. Circulation. 2004;110(13):1725-30. DOI:10.1161/01.CIR.0000143043.65045.CF.

58.Daoulah A, Ocheltree S, Al-Faifi SM, Ahmed W, Alsheikh-Ali AA, Asrar F, Lotfi A. Sleep apnea and severe bradyarrhythmia - an alternative treatment option: a case report. Journal of Medical Case Reports. 2015;9:113. DOI:10.1186/s13256-015-0596-6.

59.Wolf J, Drozdowski J, Czechowiczi K, Winklewski P, Jassem E, Kara T, Somers VK, Narkiewicz K. Effect of beta-blocker therapy on heart rate response in patients with hypertension and newly diagnosed untreated obstructive sleep apnea syndrome. International Journal of Cardiology. 2016;202:67-72. DOI:10.1016/j.ijcard.2015.08.139.
60.Huettner M, Koehler U, Nell C, Kesper K, Hildebrandt $\mathrm{O}$, Grimm W. Heart rate response to simulated obstructive apnea while awake predicts bradycardia during spontaneous obstructive sleep apnea. International Journal of Cardiology. 2015;186:216-8. DOI: 10.1016/j.ijcard.2015.03.245.

61.Куликов АН, Кучмин АН, Казаченко АА, Галактионов ДА, Уманская ЕП. Кардиологические маски синдрома обструктивного апноэ во время сна. Артериальная гипертензия. 2015;21(3):309-18.

62.Suda S, Kasai T, Kato M, Kawana F, Kato T, Ichikawa R, Hayashi H, Kawata T, Sekita G, Itoh S, Daida H. Bradyarrhythmias may induce central sleep apnea in a patient with obstructive sleep apnea. Heart Vessels. 2015;30(4):554-7. DOI: 10.1007/s00380-014-0511-x.

\section{References}

1. Lacedonia D, Carpagnano GE, Sabato R, lo Storto MM, Palmiotti GA, Capozzi V, Pia Foschino Barbaro M, Gallo C. Characterization of obstructive sleep apnea-hypopnea syndrome (OSA) population by means of cluster analysis. Journal of Sleep Research. 2016:25(6):724-30. DOI: $10.1111 /$ jsr.12429.

2. Płatek AE, Karpiński G, Szymański FM. Can continuous positive airway pressure therapy have antiarrhythmic properties? Kardiologia Polska. 2015;73(8):671. DOI: 10.5603/KP.2015.0155.

3. Ge X, Han F, Huang Y, Zhang Y, Yang T, Bai C, Guo X. Is obstructive sleep apnea associated with cardiovascular and all-cause mortality? PLoS One. 2013;8(7):e69432.

4. Padeletti M, Zacà V, Mondillo S, Jelic S. Sleep-disordered breathing increases the risk of arrhythmias. Journal of Cardiovascular Medicine (Hagerstown). 2014;15(5):4116. DOI: $10.2459 /$ JCM.0000000000000019.

5. Gami AS, Olson EJ, Shen WK, Wright RS, Ballman KV, Hodge DO, Herges RM, Howard DE, Somers VK. Obstructive sleep apnea and the risk of sudden cardiac death: a longitudinal study of 10,701 adults. Journal of the American College of Cardiology. 2013;62(7):610-6. DOI: 10.1016/j.jacc.2013.04.080

6. Gami AS, Somers VK. Implications of obstructive sleep apnea for atrial fibrillation and sudden cardiac death. Journal ofCardiovascularElectrophysiology. 2008;19(9):9971003. DOI: 10.1111/j.1540-8167.2008.01136.x.

7. Koehler U, Fus E, Grimm W, Pankow W, Schäfer H, Stammnitz A, Peter JH. Heart block in patients with obstructive sleep apnoea: pathogenetic factors and effects of treatment. European Respiratory Journal. 1998;11(2): 434-9.

8. Guilleminault C, Connolly SJ, Winkle RA. Cardiac arrhythmia and conduction disturbances during sleep in 400 patients with sleep apnea syndrome. American Journal of Cardiology. 1983;52(5):490-4.

9. Roche F, Xuong AN, Court-Fortune I, Costes F, Pichot V, Duverney D, Vergnon JM, Gaspoz JM, Barthélémy JC. 
Relationship among the severity of sleep apnea syndrome, cardiac arrhythmias, and autonomic imbalance. Pacing and Clinical Electrophysiology. 2003;26(3):669-77

10. Martí Almor J, Félez Flor M, Balcells E, Cladellas M, Broquetas J, Bruguera J. Prevalence of obstructive sleep apnea syndrome in patients with sick sinus syndrome. Revista Espanola of Cardiologia. 2006;59(1):28-32.

11. Guilleminault C, Eldridge F, Dement W. Insomnia with sleep apnea: a new syndrome. Science. 1973;181:856858.

12. Korostovtseva L, Sviryaev Y, Zvartau N, Druzhkova T, Tikhonenko V, Konradi A. New insights into the management of rhythm and conduction disorders after acute myocardial infarction. American Journal of Case Reports. 2014;15:159-162. DOI:10.12659/AJCR.890357.

13. Shepard Jr JW. Hypertension, cardiac arrhythmias, myocardial infarction, and stroke in relation to obstructive sleep apnea. Clinical Chest Medicine. 1992;13:437-8.

14. Guilleminault C, Pool P, Motta J, Gillis AM. Sinus arrest during REM sleep in young adults. New England Journal of Medicine. 1984;311(16):1006-10. DOI: 10.1056/ nejm198410183111602.

15. Dyavanapalli J, Jameson H, Dergacheva O, Jain V, Alhusayyen M, Mendelowitz D. Chronic intermittent hypoxia-hypercapnia blunts heart rate responses and alters neurotransmission to cardiac vagal neurons. Journal of Physiology. 2014;592(13):2799-811. DOI: 10.1113.

16. Holty J-E C, Guilleminault C. REM-related bradyarrhythmia syndrome. Sleep Medical Reviews. 2011;15(3):143-51. DOI: 10.1016/j.smrv.2010.09.001.

17. Velasco A, Hall C, Perez-Verdia A, Nugent K. Association of high-risk scores for obstructive sleep apnea with symptomatic bradyarrhythmias. Journal of Cardiovascular Medicine. 2014,15:407-10. DOI: 10.2459/ JCM.0b013e3283630d07.

18. Kwon Y, Picel K, Adabag S, Vo T, Taylor BC, Redline S, Stone K, Mehra R, Ancoli-Israel S, Ensrud KE. Osteoporotic fractures in men (MrOS) Study Group. Sleep Breathing. 2016;20(4):1161-68. DOI:10.1007/s11325-0161326-z.

19. Lotze U, Rothhagen B, Neubauer K, Mäder I. Dizziness and near syncope due to sinus bradycardia and sinoatrial block associated with obesity and daytime tiredness. A clear indication for pacemaker implantation? Herz. 2008;33:455-9. DOI 10.1007/s00059-008-3096-2.

20. Serafini A, Dolso P, Gigli GL, Fratticci L, Cancelli I, Facchin D, Gigli M, Valente M. Rem sleep brady-arrhythmias: An indication to pacemaker implantation? Sleep Medicine. 2012;13(6):759-62. DOI: 10.1016.

21. Nishimura Y, Saito Y, Kondo N, Matsuda E, Fujiyama M, Morizane R, Maegaki Y. Ictal central apnea and bradycardia in temporal lobe epilepsy complicated by obstructive sleep apnea syndrome. Epilepsy and Behavior Case Reports. 2015;4:41-4. DOI:10.1016/j.ebcr.2015.05.001.
22. Pavlova M, Abdennadher M, Singh K, Katz E, Llewellyn N, Zarowsly M, White DP, Dworetzky BA, Kothare SV. Advantages of respiratory monitoring during video-EEG evaluation to differentiate epileptic seizures from other events. Epilepsy and Behavior. 2014;32:142-44. DOI:10.1016/j.yebeh.2013.12.031.

23. Blotskiy AA, Medvedeva IP, Kramarenko OA. Cardiorespiratory monitoring for obstructive sleep apnea diagnostics. Interregional Conference of ENt specialists from Siberia and Far East "Relevant issues of otorhinolaryngology". 2016: 40-51. (In Russian)

24. Hayano J, Watanabe E, Saito Y., Sasaki F, Fujimoto K, Nomiyama T, Kawai K, Kodama I, Sakakibara. Screening for obstructive sleep apnea by cyclic variation of heart rate. Circulation: Arrhythmia and Electrophysiology. 2011;4(1):64-72.

25. Parati G, Lombardi C, Hedner J, Bonsignore MR, Grote L, Tkacova R, Lйvy P, Riha R, Bassetti C, Narkiewicz K, Mancia G, McNicholas WT; EU COST Action B26 members. Recommendations for the management of patients with obstructive sleep apnoea and hypertension. European Respiratory Journal. 2013;41(3):523-38. DOI: 10.1183/09031936.00226711.

26. Belenkov YuN, Palman AD. Obstructive sleep apnea syndrome and heart rhythm disorders. Effective Pharmacotherapy. 2015;53:56-63. (In Russian)

27. Heneghan C, de Chazal P, Ryan S, Chua CP, Doherty L, Boyle P, Nolan P, McNicholas WT. Electrocardiogram recording as a screening tool for sleep disordered breathing. Journal of Clinical Sleep Medicine. 2008;4(3):223-28.

28. Kwon Y, Picel K, Adabag S, Vo T, Taylor BC, Redline S, Stone K, Mehra R, Ancoli-Israel S, Ensrud KE, for the Osteoporotic Fractures in Men (MrOS) Study Group. Sleepdisordered breathing and daytime cardiac conduction abnormalities on 12-lead electrocardiogram in communitydwelling older men. Sleep Breathing. 2016;20(4):1161-68. DOI:10.1007/s11325-016-1326-z.

29. Defaye P, de la Cruz I, Marti-Almor J, Villuendas R, Bru P, Sunuchal J, Tamisier R, Pepin JL. Heart Rhythm pacemaker transthoracic impedance sensor with an advanced algorithm to identify severe sleep apnea: the DREAM. European study. 2014;11(5):842-8. DOI:10.1016/j.hrthm.2014.02.011.

30. 2013 ESC Guidelines on cardiac pacing and cardiac resynchronization therapy / The Task Force on cardiac pacing and resynchronization therapy of the European Society of Cardiology (ESC). Developed in collaboration with the European Heart Rhythm Association (EHRA). European Heart Journal. 2013;34:2281-329. DOI:10.1093/ eurheartj/eht150.

31. ACC/AHA/HRS 2008 Guidelines for Device-Based Therapy of Cardiac Rhythm Abnormalities /A Report of the American College of Cardiology/American Heart Association Task Force on Practice Guidelines (Writing 
Committee to Revise the ACC/AHA/NASPE 2002 Guideline Update for Implantation of Cardiac Pacemakers and Antiarrhythmia Devices). Circulation. 2008;117:e350e408. DOI: 10.1161/CIRCUALTION AHA.108.189742.

32. Yakovlev AV, Buzunov RV, Andryushina NA, Turov AN, Yakovleva NF. Successful treatment of bradyarrhythmias associated with obstructive sleep apnea syndrome, by the method of creating of continuous positive airway pressure. Kardiologiia. 2013;53(8):93-6. (In Russian)

33. Pataka A, Daskalopoulou E, Papastefanou S, Baltatzi C, Aggelopulos P, Vlachogiannis E. Multiple heart pauses during sleep in a patient with obstructive sleep apnoea syndrome. Sleep Breathing. 2013;17:19-23. DOI 10.1007/ s11325-012-0648-8.

34. Maeno K, Kasai A, Setsuda M, Nishiyama A, Sakabe S, Ohnishi T, Saito K, Nishikawa H. Advanced atrioventricular block induced by obstructive sleep apnea before oxygen desaturation. Heart Vessels. 2009;24:236-40. DOI 10.1007/s00380-008-1113-2

35. Mataciuniene D, Masaitiene R, Mameniskiene R, Budrys VA. Heavy snorer with multiple prolonged asystoles during the night - reversably CPAP therapy. Sleep Breathing. 2013;17:25-8. DOI: 10.1007/s11325-012-0690-6.

36. Voigt L, Saul BI, Lombardo G, Reddy CV, Kassotis J. Correction of AV-nodal block in a 27-year-old man with severe obstructive sleep apnea - a case report. Angiology. 2003;54(3):363-7. DOI:10.1177/000331970305400314 .

37. Becker H, Brandenburg U, Peter JH, Von Wichert P. Reversal of sinus arrest and atrioventricular conduction block in patients with sleep apnea during nasal continuous positive airway pressure. American Journal of Respiratory and Critical Care Medicine. 1995;151(1):215-8. DOI:10.1164/ajrccm.151.1.7812557.

38. Litvin AYu, Pevzner AV, Golitsyn PV, Galyavi RA, Mazygula EP, Nesterenko LYu, Chazova IE, Golitsyn SP. New approaches to the treatment of bradyarrhythmias in patients with obstructive sleep apnea syndrome. Therapeutic Archive. 2006;8:41-7. (In Russian)

39. Doherty LS, Kiely JL, Swan V, McNicholas WT. Long-term effects of nasal continuous positive airway pressure therapy on cardiovascular outcomes in sleep apnea syndrome. Chest. 2005;127(6):2076-84. DOI: 10.1378/ chest.127.6.2076 .

40. Belov AM, Callistov DYu, Voronin IM, Molashenko NP, Chuchalin AG. Cardiac manifestations of obstructive sleep apnea syndrome. Clinical cases. Therapeutic archive. 1998;70(3):44-9. (In Russian)

41. Bradley TD, Shapiro CM. ABC of sleep disorders. Unexpected presentations of sleep apnoea: use of CPAP in treatment. British Medical Journal. 1993;306(6887):1260-62.

42. Sahadevan J, Srinivasan D. Treatment of obstructive sleep apnea in patients with cardiac arrhythmias. Current Treatment Options in Cardiovascular Medicine. 2012;14:520-28.
43. Somiah M, Taxin Z, Keating J, Mooney AM, Norman RG, Rapoport DM, Ayappa I. Sleep quality, short-term and long-term CPAP adherence. Journal of Clinical Sleep Medicine. 2012;8(5):489-500. DOI: 10.5664/jcsm.2138.

44. Opić P, van Kranenburg M, Yap SC, van Dijk A. Complications of pacemaker therapy in adults with congenital heart disease: a multicenter study. International Journal of Cardiology. 2013;168:3212-216. DOI: 10.1016/j. ijcard.2013.04.114.

45. Aizawa Y, Kunitomi A, Nakajima K, Kashimura S, Katsumata Y, Nishiyama T, Kimura T, Nishiyama N, Tanimoto Y, Kohsaka S, Takatsuki S, Fukuda K. Risk factors for early replacement of cardiovascular implantable electronic devices. International Journal of Cardiology. 2015;178:99-101.

46. Belvin D, Hirschl D, Vineet R.J., Godelman A, Marjorie WS, Jay NG, Linda $\mathrm{BH}$. Chest radiographs are valuable in demonstrating clinically significant pacemaker complications that require reoperation. Canadian Association of Radiologists Journal. 2011:62:288e295.DOI:10.1016/j. carj.2010.04.016.

47. Wolkove N, Baltzan M, Kamel H, Dabrusin R, Palayew M. Long-term compliance with continuous positive airway pressure in patients with obstructive sleep apnea. Canadian Respiratory Journal. 2008;15(7):365-69.

48. Garrigue S, Bordier P, Jaïs P, Shah DC, Hocini M, Raherison C, Tunon De LM, Haïssaguerre M, Clementy $\mathrm{J}$. Benefit of atrial pacing in sleep apnea syndrome. New England Journal of Medicine. 2002;346(6):404-12. DOI: 10.1056/NEJMoa011919.

49. Floras JS, Bradley T.D. Atrial overdrive pacing for sleep apnea: a door now closed. American Journal of Respiratory and Critical Care Medicine. 2005;172(1):1-3.

50. Krahn AD, Yee R, Erickson MK, Markowitz T, Gula LJ, Klein GJ, Skanes AC, George CF, Ferguson KA. Physiologic pacing in patients with obstructive sleep apnea: a prospective, randomized crossover trial. Journal of the American College of Cardiology. 2006;47(2):379-83. DOI:10.1016/j.jacc.2005.09.026.

51. Pépin JL, Defaye P, Garrigue S, Poezevara Y, Lévy P. Overdrive atrial pacing does not improve obstructive sleep apnoea syndrome. European Respiratory Journal. 2005;25(2):343-7. DOI:10.1183/09031936.05.00132703.

52. Unterberg C, Lüthje L, Szych J, Vollmann D, Hasenfuss G, Andreas S. Atrial overdrive pacing compared to CPAP in patients with obstructive sleep apnoea syndrome. European Heart Journal. 2005;26(23):2568-75. DOI:10.1093/eurheartj/ehi448

53. Simantirakis EN, Schiza SE, Chrysostomakis SI, Chlouverakis GI, Klapsinos NC, Siafakas NM, Vardas PE. Atrial overdrive pacing for the obstructive sleep apneahypopnea syndrome. New England Journal of Medicine. 2005;353(24):2568-77. DOI:10.1056/NEJMoa050610.

54. Baranchuk A, Jeff SH, Christopher SS, Damian PR, Carlos AM, Stuart JC, Fitzpatrick M. Atrial over- 
drive pacing in sleepapnoea: a meta-analysis. Europace. 2009;11:1037-40. DOI:10.1093/europace/eup165. DOI:10.1093/europace/eup165.

55. Simantirakis EN, Vardas PE. Cardiac pacing in sleep apnoea: diagnostic and therapeutic implications. Europace. 2006;8(11):984-7.

56. Peled N, Abinader EG, Pillar G, Sharif D, Lavie P. Nocturnal ischemic events in patients with obstructive sleep apnea syndrome and ischemic heart disease: effects of continuous positive air pressure treatment. Journal of the American College of Cardiology. 1999;34(6):1744-9.

57. Chow AW, Segal OR, Davies DW, Peters NS. Mechanism of pacing-induced ventricular fibrillation in the infarcted human heart. Circulation. 2004;110(13):1725-30. DOI:10.1161/01.CIR.0000143043.65045.CF.

58. Daoulah A, Ocheltree S, Al-Faifi SM, Ahmed W, Alsheikh-Ali AA, Asrar F, Lotfi A. Sleep apnea and severe bradyarrhythmia - an alternative treatment option: a case report. Journal of Medical Case Reports. 2015;9:113. DOI:10.1186/s13256-015-0596-6.

59. Wolf J, Drozdowski J, Czechowiczi K, Winklewski P, Jassem E, Kara T, Somers VK, Narkiewicz K. Effect of beta-blocker therapy on heart rate response in patients with hypertension and newly diagnosed untreated obstructive sleep apnea syndrome. International Journal of Cardiology. 2016;202:67-72. DOI:10.1016/j.ijcard.2015.08.139.

60. Huettner M, Koehler U, Nell C, Kesper K, Hildebrandt $\mathrm{O}$, Grimm W. Heart rate response to simulated obstructive apnea while awake predicts bradycardia during spontaneous obstructive sleep apnea. International Journal of Cardiology. 2015;186:216-8. DOI: 10.1016/j.ijcard.2015.03.245.

61. Kulikov AN, Kuchmin AN, Kazachenko AA, Galaktionov DA, Umanskaya EP. Cardiovascular-like obstructive sleep apnea syndrome. Arterialnaya Gipertenziya $=$ Arterial Hypertension. 2015;21(3):309-18. (In Russian)
62. Suda S, Kasai T, Kato M, Kawana F, Kato T, Ichikawa R, Hayashi H, Kawata T, Sekita G, Itoh S, Daida H. Bradyarrhythmias may induce central sleep apnea in a patient with obstructive sleep apnea. Heart Vessels. 2015;30(4):554-7. DOI: $10.1007 / \mathrm{s} 00380-014-0511-\mathrm{x}$

\section{Сведения об авторах}

Коростовиева Людмила Сергеевна, Северо-Западный федеральный медииинский исследовательский иентр имени В.А. Алмазова; адрес: Российская Федераиия, 197341, 2. Санкт-Петербург, ул. Аккуратова, д. 2.; тел.: +7(921)7873548; e-mail: korostovtseva_ls@ almazovcentre.ru

Вареницына Светлана Юрьевна, Северо-Западный федеральный медицинский исследовательский иентр имени В.А. Алмазова; адрес: Российская Федеращия, 197341, СанктПетербург, ул. Аккуратова, д. 2.; тел.:+7(821)7026810; e-mail: somnology@almazovcentre.ru

Бочкарев Михаил Викторович, Северо-Западный федеральный медицинкий исследовательский иентр имени В.А. Алмазова; адрес: Российская Федерация, 197341, Санкт-Петербург, ул. Аккуратова, д. 2.; тел.: +7(821)7026810; e-mail: bochkarev_mv@ almazovcentre.ru

Семенов Андрей Петрович, Северо-Западный федеральный медицинский исследовательский центр имени В.А. Алмазова; адрес: Российская Федераиия, 197341, Санкт-Петербург, ул. Аккуратова, д. 2.; тел.: +7(821)7026810; e-mail: somnology@almazovcentre.ru

Свиряев Юрий Владимирович, Северо-Западный федеральный медииинский исстедовательский центр имени В.А. Алмазова; адрес: Российская Федерация, 197341, СанктПетербург, ул. Аккуратова, д. 2.; тел.+7(821)7026810; e-mail: somnology@almazovcentre.ru

\section{Information about the authors}

Korostovtseva Lyudmila S., V. A. Almazov Federal North-West Medical Research Centre; Address: 2, Akkuratov st., St Petersburg, Russian Federation, 197341; Phone: +7(921)7873548; e-mail:korostovtseva_ls@almazovcentre.ru

Varenitsyna Svetlana Y. V., A. Almazov Federal North-West Medical Research Centre; Address: 2, Akkuratov st., St Petersburg, Russian Federation, 197341; Phone: $+7(821) 7026810$ e-mail: somnology@almazovcentre.ru

Bochkarev Mikhail. V. V., A. Almazov Federal North-West Medical Research Centre; Address: 2, Akkuratov st., St Petersburg, Russian Federation, 197341; Phone: $+7(821) 7026810$; e-mail:bochkarev_mv@almazovcentre.ru

Semenov Andrey P. V., A. Almazov Federal North-West Medical Research Centre; Address: 2, Akkuratov st., St Petersburg, Russian Federation, 197341; Phone: +7(821)7026810; e-mail: somnology@almazovcentre.ru

Sviryaev Yurii V. V., A. Almazov Federal North-West Medical Research Centre; Address: 2, Akkuratov st., St Petersburg, Russian Federation, 197341; Phone: $+7(821) 7026810$; e-mail: somnology@almazovcentre.ru

\section{Оригинальные исследования / Original research}

( О ОВЧАРЕНКО С. И., ГАЛЕЦКАЙТЕ Я. К., ВОЛЕЛЬ Б. А.

УДК 616.24-036:616-084. 12-06.

DOI: $10.20333 / 2500136-2017-5-28-35$.

\section{ЛЁГОЧНАЯ РЕАБИЛИТАЦИЯ БОЛЬНЫХ ХРОНИЧЕСКОЙ ОБСТРУКТИВНОЙ БОЛЕЗНЬЮ ЛЕГКИХ С УЧЁТОМ ТИПА РЕАГИРОВАНИЯ НА ЗАБОЛЕВАНИЕ}

\section{С. И. Овчаренко, Я. К. Галецкайте, Б. А. Волель}

Первый Московский государственный медицинский университет имени И. М. Сеченова, Москва 119991, Российская Федерация

Цель исследования. Разработать, применить и оценить эффективность программ лёгочной реабилитации (ЛР), адаптированных с учетом типов реагирования на заболевание (тревоги о болезни/депрессии и гипонозогнозии), у больных хронической обструктивной болезнью лёгких (ХОБЛ). Материал и методы. В исследование для участия в разработанных дифференцированных 3-недельных программах лёгочной реабилитации было включено 30 пациентов с ХОБЛ (Группа А - 20 больных с тревогой о болезни или депрессией; Группа В - 10 пациентов с гипонозогнозией). Курс ЛР состоял из сессий по формированию мотивации к участию, типовых физических тренировок, индивидуальных и групповых дифферен- 
цированных обучающих занятий, а также психотерапевтических методик, направленных как на создание стратегии селф-менеджмента, так и на коррекцию дезадаптивного типа реагирования на заболевание; психофармакотерапии (в случае необходимости). Всем пациентам исходно, сразу после завершения программы, через 1, 3, 6 месяцев после окончания курса ЛР проводилась оценка ФВД, 6-MT, CAT, mMRC, SF-36, SGRQ, ypoвня знаний о ХОБЛ, уровня депрессии по шкале Бека.

Результаты. Уже на этапе набора пациентов установлена сложность формирования мотивации у больных с гипонозогнозией. У пациентов обеих групп дифференцированные программы ЛР показали свою эффективность в отношении ОФВ1, 6-MT, САТ, mMRС, физического компонента SF-36, всех шкал SGRQ, знаний о заболевании, BDI. Однако улучшение показателей сохранялось более длительное время в группе A.

Заключение. Дифференцированные в зависимости от типа реагирования на заболевание программы ЛР эффективны при всех типах реагирования на заболевание. В то же время пациенты с гипонозогнозией требуют больших усилий по созданию мотивации, поддержанию достигнутых улучшений, а также, возможно, дополнительных мероприятий в период после прохождения программы ЛР и раннего повторения курса.

Ключевые слова: хроническая обструктивная болезнь лёгких (ХОБЛ), лёгочная реабилитация, совладание с болезнью, типы реагирования на заболевание, тревога о болезни, депрессия, гипонозогнозия, дезадаптивное отрицание физического неблагополучия.

Для ицтирования: Овчаренко СИ, Галецкайте ЯК, Волель БА. Легочная реабилитация больных хронической обструктивной болезнью легких с учётом реагирования на заболевание. Сибирское медищинское обозрение. 2017;(5): 28-35. DOI: 10.20333/2500136-2017-5-28-35

\title{
PULMONARY REHABILITATION OF PATIENTS WITH CHRONIC OBSTRUCTIVE PULMONARY DISEASE AND THE TYPE OF DISEASE-RELATED RESPONSE
}

\author{
S. I. Ovcharenko, Y. K. Galetskayte, B. A. Vole
}

\author{
I. M. Sechenov First Moscow State Medical University, Moscow 119991, Russian Federation
}

The aim of the research. To develop, apply and evaluate the effectiveness of pulmonary rehabilitation (PR) programs adapted to the types of response to the disease (anxiety about disease/ depression and hyponosognosia) in patients with chronic obstructive pulmonary disease (COPD).

Material and methods. The study included 30 patients with COPD (Group A - 20 patients with anxiety about the disease or depression, Group B - 10 patients with hyponosognosia) to participate in the developed differentiated 3-week programs of pulmonary rehabilitation. The course of the PR consisted of sessions on the formation of motivation for participation, typical physical training, individual and group differentiated training sessions, as well as psychotherapeutic techniques aimed both at creating a strategy of self-management, and on correcting a disadaptive type of response to the disease; psychopharmacotherapy (if necessary). All patients immediately after the completion of the program, at 1, 3,6 months after the end of the course of PR, were initially evaluated FVD, 6-MT, CAT, mMRC, SF-36, SGRQ, level of knowledge of COPD, depression level on the Beck scale.

Results. At the stage of patient recruitment, the complexity of the formation of motivation in patients with hyponosognosia was established. In patients of both groups differentiated PR programs showed their effectiveness in relation to FEV1, 6-MT, CAT, mMRC, physical component of SF-36, all SGRQ scales, knowledge of the disease, BDI. However, the improvement in indices persisted for a longer time in group A.

The conclusion. Differentiated depending on the type of response to the disease of the PR program are effective for all types of response to the disease. At the same time, patients with hyponosognosia require more efforts to create motivation, to maintain the improvements achieved, and, possibly, additional activities in the period after the passage of the PR program and the early repetition of the course.

Key words: chronic obstructive pulmonary disease (COPD), pulmonary rehabilitation, coping with the disease, types of response to the disease, anxiety about the disease, depression, hypnosognosia, disadaptive denial of physical well-being.

Citation: Ovcharenko SI, Galetskayte YK, Volel BA. Pulmonary rehabilitation of patients with chronic obstructive pulmonary disease and the type of diseaserelated response. Siberian Medical Review. 2017; (5): 28-35. DOI: 10.20333/2500136-2017-5-28-35.

\section{Введение}

Лёгочная реабилитация (ЛР) является методом, обладающим самым благоприятным соотношением «затраты - эффективность», наряду с вакцинацией против гриппа и отказом от курения [1]. Под ЛР понимают комплексную программу мероприятий, основанную на пациент-ориентированную терапию и включающую в себя помимо физических тренировок, образовательные и психосоциальные методики, созданные для улучшения физического и эмоционального состояния больных и обеспечения длительной приверженности пациента к поведению, направленному на сохранение здоровья $[2,3,4]$.

Учитывая ранее изученные нами, освещённые в предшествующих публикациях $[5,6,7,8,9]$ особенности пациентов с различными типами реагирования, мы разработали и применили программы ЛР, основанные на дифференцированных подходах для боль- ных с гипонозогнозией и пациентов с тревогой о болезни и депрессией. Под гипонозогнозией (аберрантной ипохондрией) понимается тип реагирования на заболевание, при котором отсутствует минимальная эмоциональная реакция на возникшую соматическую патологию (ХОБЛ), что сопровождается неадекватным медицинским поведением [10].

Целью нашего исследования было разработать, применить и оценить эффективность программ лёгочной реабилитации, адаптированных с учетом типов реагирования на заболевание, у больных ХОБЛ.

В соответствии с рекомендациями полноценная программа легочной реабилитации должна продолжаться в течение 8 - 12 недель (не менее 12 занятий) [11]. Основные разделы ЛР включают: физическое тренировки, коррекцию нутритивного статуса, обучение пациентов, психососциальные мероприятия. В каждом из этих разделов выделяется ряд компонен- 
тов, в который входят: оптимальная лекарственная терапия, кислородная поддержка, отказ от курения, образовательные программы, физические тренировки, тренировки дыхательной мускулатуры, техники для улучшения дренажа бронхов, психосоциальное консультирование, выработка навыков управления заболеванием при обострении, нутритивная поддержка, силовые тренировки, техника сохранения энергии, изменения поведения больных, ходьба вне дома в сопровождении, а также вопросы ухода из жизни [2, 3]. Кратность проведения - минимум 2 раза в неделю, длительность - 30 минут и больше [12, 13, 14].

\section{Материал и методы}

Для реализации поставленной цели, отбирались больные в возрасте 40-80 лет с подтвержденным диагнозом ХОБЛ лёгкого, среднетяжёлого, тяжёлого и крайне тяжёлого течения (GOLD 2008) с длительностью течения ХОБЛ более 2 лет (установленный временной промежуток является минимальным адекватным для формирования типа реагирования на заболевание).

Bce больные подвергались полноценному физическому и лабораторно-инструментальному обследованию по общепринятой схеме ведения пациентов с ХОБЛ. После получения согласия пациента, проводилось психиатрическое (в том числе с применением психометрических шкал и опросников) обследование, при котором определялся тип реагирования на ХОБЛ.

Перед прохождением курса реабилитации, по его окончании и через 1,3 и 6 месяцев после окончания курса каждому пациенту были проведены оценка симптомов ХОБЛ (по шкалам Modified British Medical Research Council (mMRC), COPD assessment test (CAT), визуально-аналоговой шкалы (ВАШ)) и частоты обострений, функциональные исследования (спирография, тест с 6-минутной ходьбой (6MT)), оценка уровня основных знаний о ХОБЛ по авторскому вопроснику, оценка качества жизни (КЖ) больных по общему вопроснику Short Form Medical Outcomes Study (SF-36) и специальному вопроснику St. George's Respiratory Questionnaire (SGRQ), при диагностированной психиатром депрессии - оценка симптомов депрессии (Beck Depression Inventory шкала Бека).

Всего в программы ЛР удалось включить только 30 пациентов, согласившихся на участие. Уже на этапе набора пациентов для реабилитационных мероприятий определялись обусловленные типами реагирования отличия: из базы больных с тревогой о болезни и депрессией приняли участие в программе 48,8 \% пациентов (20 из 41), и они составили группу А. Из базы больных с гипонозогнозией удалось отобрать лишь 10 из 44 человек - всего 22,7 \%, что вполне объяснимо низкой степенью приверженности и сотрудничества больных с гипонозогнозией и сложностью формирования у этой категории пациентов мотивации к участию в ЛР. Все больные, участвовавшие в программе ЛР, были мужчинами (средний возраст 64,5 $\pm 9,0$ года) с длительностью течения ХОБЛ 5,7士3,3 года. 14 больных (46,7 \%) были инвалидами. Индекс курящего человека (ИКЧ) составлял в среднем 46,8土16,6 пачкалет $(42,3$ [37,8; 52,5] пачка-лет).

При исходной оценке отмечались сниженные показатели переносимости физической нагрузки, а также качества жизни по всем шкалам на основании опросников SF-36 и SGRQ.

Среди пациентов, согласившихся на участие в программе ЛР, отмечались различные уровни приверженности: высокая (12 больных - 40,0 \%), низкая (8 пациентов - 26,7 \%) и средняя (10 больных - 33,3 \%). На момент начала ЛР большая часть больных не выполняла ни пикфлуометрии (19 пациентов - 63,3 \%) ни дыхательной гимнастики (23 пациента - 76,7 \%). Исходно знания о заболевании ХОБЛ в среднем

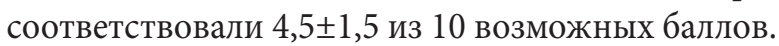

Больные группы тревоги о болезни и депрессии (группы А) и гипонозогнозии (группы В) были сопоставимы по характеристикам тяжести основного заболевания и всем им проводилась адекватная их состоянию медикаментозная терапия, которая не менялась на протяжении исследования.

Дифберенцированные подходы к легочной реабилитации с учётом типов реагирования на заболевание

При разработке программ были использованы международные и отечественные рекомендаций по ЛР с адаптацией в зависимости от типов реагирования на заболевание $[2,3,4,10]$.

Длительность программ составляла 3 недели. Для всех пациентов программа реабилитации включала в себя следующие компоненты:

1. Физические тренировки (2 сессии в день, по 20 40 минут)

- Интервальные тренировки на велоэргометре

- Развитие мышц верхних и нижних конечностей (сила, выносливость), улучшение функции суставов

- Дыхательные упражнения (дыхательные тренажеры, оптимизация работы дыхательной мускулатуры - изменение паттерна дыхания, диафрагмальное дыхание)

2. Психосоциальная реабилитация (психофармакотерапия применялась у 13 больных)

3. Обучение (3 - 4 занятия по 1 - 1,5 часа)

4. Коррекция питательного статуса в рамках обучающих мероприятий

Роль и направление базового корректирующего воздействия каждой из составных частей программы определялись именно типом реагирования на болезнь 
(например, при гипонозогнозии - важнейшей составляющей было обучение и поддержание мотивации с акцентом на формирование картины болезни, при тревоге и депрессии - обучение совладанию с симптомами). Программы отличались друг от друга и формами организации: индивидуальные и групповые, амбулаторные и стационарные. Для больных с тревогой о болезни и депрессией, в связи с их высокой приверженностью, было возможно проведение занятий как во время нахождения их в стационаре, так и в амбулаторных условиях. Обучение проходило в малых группах (3 - 4 человека), которые одновременно играли и роль групп поддержки (особенно важно при тревожно-депрессивных расстройствах).

Так, у больных с тревогой о болезни и депрессией, обращалось внимание на положительное влияние тренировок на настроение, адаптацию к одышке и возможность справляться с ней. При обучении пациентов с тревогой о болезни и депрессией особое внимание уделялось побочным эффектам терапии (подробный рассказ об их безопасности и обсуждение нежелательных явлений). В группе больных с тревогой о болезни и депрессией проводились беседы с родственниками с целью их поддержки и информирования о способах психо-эмоциональной помощи пациенту.

У пациентов с гипонозогнозией занятия проходили исключительно в условиях стационара и в индивидуальном порядке в связи с необходимостью формирования адекватной состоянию и восприятию пациента внутренней картины болезни. Занятия с такими пациентами строились в форме диалога, позволяющего оценивать имеющиеся представления о ХОБЛ и ее симптомах, направлять и указывать (в том числе и на примере специально провоцируемых симптомов, например, одышки) на проявления заболевания и предвестников их возникновения в ходе нагрузки. Следует отметить, что важным этапом реабилитационных программ выступает процесс формирования мотивации у больного. Оценка и дальнейшее формирование мотивации к участию в программе является краеугольным камнем в процессе реабилитации этой категории пациентов. При гипонозогнозии проводились отдельные мотивационные беседы-занятия еще до начала физических тренировок и обучения, в них проводилось информирование об эффектах ЛР, обсуждались возможные сложности с участием и предпринимались попытки к их преодолению.

При необходимости к процессу формирования мотивации у пациентов с гипонозогнозией подключались и родственники больных. Их участие практически на всех этапах реабилитации и жизни больного с гипонозогнозией невозможно переооценить. Обучение и информирование родственников пациентов проводилось для последующего с их стороны постреабилитационного контроля за выполнением рекомендаций врача и дополнительного укрепления мотивации пациента.

При проведении мероприятий по отказу от курения в группе гипонозогнозии (как правило, «злостные курильщики»), целесообразно направление пациентов в специализированные центры помощи в отказе от курения либо раннее назначение специальных лекарственных препаратов (варениклин, никотинсодержащие препараты).

Специфической дифференцировки физических тренировок не проводилось, однако, продолжалось следование общим принципам работы с больными с различными типами реагирования, использовались элементы обучения и поведенческой терапии.

Основные отличительные характеристики разработанных дифференцированных в зависимости от типов реагирования на ХОБЛ программ представлены в таблице.

Таблииа

\section{Основнье принципь программ легочной реабилитации, дифференцированньх в зависимости от типов реагирования}

\begin{tabular}{|c|c|}
\hline $\begin{array}{c}\text { Пациенты с тревогой } \\
\text { о болезни и депрессией }\end{array}$ & $\begin{array}{c}\text { Пациенты } \\
\text { с гипонозогнозией }\end{array}$ \\
\hline $\begin{array}{c}\text { Групповые занятия, } \\
\text { играющие роль групп } \\
\text { поддержки }\end{array}$ & Только индивидуальные занятия \\
\hline $\begin{array}{c}\text { Возможно проведение } \\
\text { в амбулаторных условиях }\end{array}$ & $\begin{array}{l}\text { Проведение программ исключи- } \\
\text { тельно в условиях стационара }\end{array}$ \\
\hline $\begin{array}{c}\text { Обучение разграничению между } \\
\text { симптомами ХОБЛ и знаками пси- } \\
\text { хологического неблагополучия }\end{array}$ & $\begin{array}{c}\text { Дополнительные занятия по } \\
\text { формированию мотивации, пред- } \\
\text { варяющие основной курс ЛР }\end{array}$ \\
\hline $\begin{array}{c}\text { Обучение техникам } \\
\text { совладания с симптомами ХОБл }\end{array}$ & $\begin{array}{c}\text { Создание образа болезни и } \\
\text { собственного тела }\end{array}$ \\
\hline \multirow[t]{2}{*}{$\begin{array}{c}\text { Работа с родственниками, } \\
\text { направленная на обучение } \\
\text { психо-эмоциональной поддержке } \\
\text { и обеспечение этой поддержкой } \\
\text { самим родственникам }\end{array}$} & $\begin{array}{c}\text { Привлечение родственников для } \\
\text { поддержания мотивации и } \\
\text { контроля выполнения } \\
\text { пациентом врачебных } \\
\text { рекомендаций }\end{array}$ \\
\hline & $\begin{array}{c}\text { Задания для самостоятельного } \\
\text { обдумывания }\end{array}$ \\
\hline
\end{tabular}

Статистический анализ данных проводился с использованием пакета программ SPSS Statistics v17.0, Microsoft Excel. В случае нормального распределения для описания использовались среднее значение и стандартное отклонение. При непараметрическом распределении - «медиана [25 процентиль; 75 процентиль]». Для оценки различий двух зависимых 
количественных переменных непараметрическими методами использовался критерий Фридмана и Вилкоксона, двух независимых переменных - U-тест по методу Манна-Уитни. Различия считались достоверными при $\mathrm{p}<0,05$; различия расценивались как тенденции при $0,05<\mathrm{p}<0,1$.

\section{Результаты и обсуждение}

На фоне проведения ЛР в обеих группах отмечено улучшение показателей оценки эффективности. Так, впервые у пациентов с ХОБЛ выявлен статистически значимый рост показателей бронхиальной проходимости по данным изменения ОФВ (рис. 1). Такая ди-

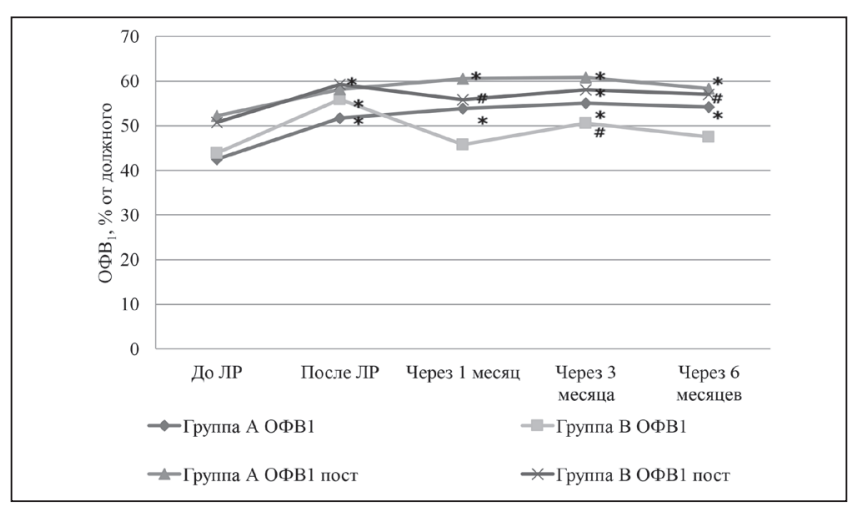

Рисунок 1. Динамика на фоне ЛР ОФВ и постбронходилатационного ОФВ1 в группе А и группе $B$.

Примечание: ${ }^{*}-p<0,05$; \# - 0,05<p<0,1.

намика наблюдалась в обеих группах ( $\mathrm{p} \leq 0,001$ в группе $\mathrm{A} ; \mathrm{p}=0,003$ и $\mathrm{p}=0,034$ в группе $\mathrm{B})$, однако у пациентов с гипонозогнозией этот показатель снижался уже к концу первого месяца после окончания курса ( $\mathrm{p}<$ 0,001). В группе тревоги о болезни и депрессии $О Ф \mathrm{~B}_{1}$, напротив, увеличивался вплоть до 6 месяца $(\mathrm{p}<0,05)$. Вероятнее всего, это связано с более чётким выполнением назначений врача после курса реабилитации.

В динамике у больных с тревогой о болезни и депрессией как и у пациентов с гипонозогнозией, реабилитация достоверно положительно влияла на расстояние, проходимое во время 6-МТ ( $\mathrm{p}<0,001$ и $\mathrm{p}$ $=0,008$, соответственно). Следует отметить, что различия были значимы как статистически, так и клинически (установленное по данным многоцентровых исследований и обзоров различие - 48 метров [28]). В группе пациентов с тревогой о болезни и депрессией отмечалось дальнейшее улучшение показателей 6-MT через 1 и 6 месяцев. В группе же больных с гипонозогнозией значимый дальнейший рост показателя наблюдался только через 1 месяц, а в последующие месяцы выявлена тенденция к уменьшению проходимой дистанции (рис. 2). В то же время ее величина сохраняла значительные отличия от исходного уровня $(\mathrm{p}<0,05)$.

В обеих группах на фоне мероприятий реабилитации и на протяжении последующих 6 месяцев отмечено

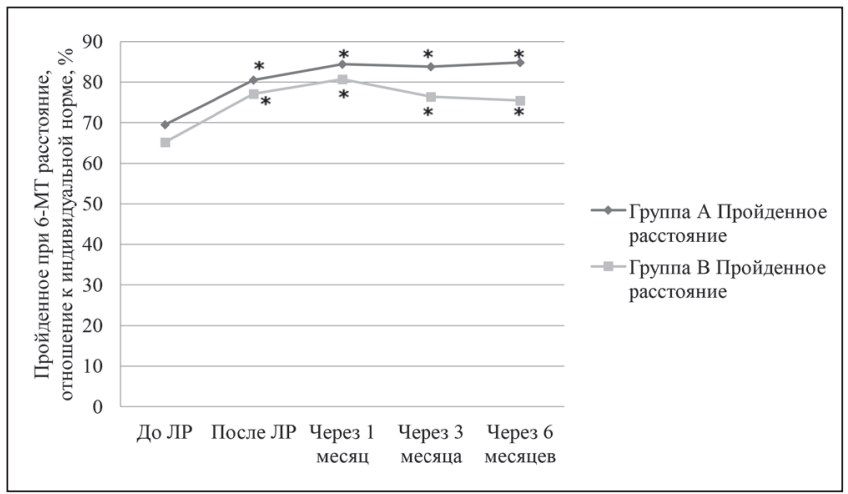

Рисунок 2. Динамика на фоне ЛР отношения пройденного расстояния при 6-МТ к индивидуальным нормальным значениям в группе $A$ и группе $B$.

Примечание: ${ }^{*}-p<0,05$.

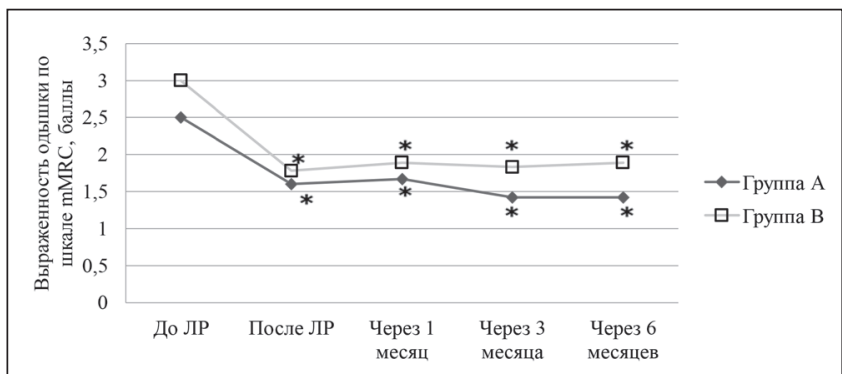

Рисунок 3. Динамика на фоне ЛР влияния симптомов на повседневную активность по шкале $\mathrm{mMRC}$ в группе $\mathrm{A} u$ spynne $B$.

Примечание: ${ }^{*}-p<0,05$.

достоверное и устойчивое снижение выраженности одышки по шкале mMRC ( $<$ 0,05) (рис. 3).

При сравнении динамики баллов опросника CAT после достоверного улучшения этого параметра на фоне реабилитации ( $\mathrm{p}<0,001$ и $\mathrm{p}=0,003$, соответственно) в группе тревоги о болезни и депрессии наблюдалось поддержание достигнутого уровня и скачкообразное увеличение его уже на 1 месяце в группе гипонозогнозии (рис. 4).

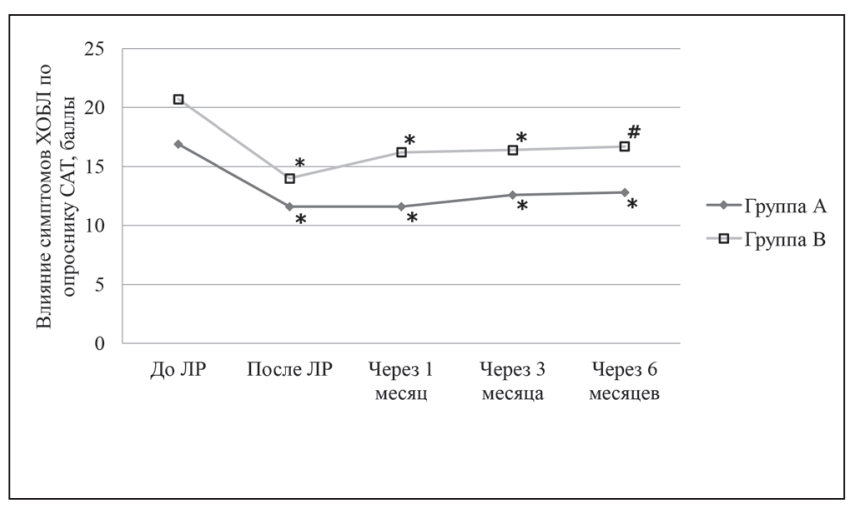

Рисунок 4. Динамика на фоне ЛР влияния симптомов на повседневную активность по опроснику САТ в группе А и групnе B.

Примечание: ${ }^{*}-p<0,05 ; \#-0,05<p<0,1$.

Соответственно изменениям объективных функциональных показателей выявлена и динамика в уровне 
качества жизни. Так, независимо от типа реагирования на ХОБЛ возросли показатели физического компонента КЖ вопросника SF-36 (физическое функционирование - PF, общее состояние здоровья - GH) (p < 0,05). На фоне реабилитационных мероприятий отмечался значимый устойчивый рост показателей психического компонента здоровья (психическое здоровье - MH, ролевое функционирование, обусловленное эмоциональным состоянием - RE, социальное функционирование - SF) в группе тревоги о болезни и депрессии $(\mathrm{p}<0,05)$ и отсутствие изменений исходно относительно высоких значений данных параметров в группе гипонозогнозии.

При анализе КЖ по SGRQ в группе тревоги о болезни и депрессии все показатели постепенно улучшались на протяжении 6 месяцев наблюдения $(\mathrm{p}<0,05)$. В группе же гипонозогнозии, несмотря на существенный первоначальный эффект, по всем 4 шкалам (симптомы, активность, влияние, сумма), выраженность этих изменений снижалась при дальнейшем наблюдении.

Обучающие мероприятия также показали одинаковую эффективность в двух группах ( $<<0,001)$. Тем не менее, в группе гипонозогнозии продолжала наблюдаться тенденция к быстрому снижению достигнутых значений, однако уровень знаний, превосходящий первоначальный, сохранялся (рис. 5).

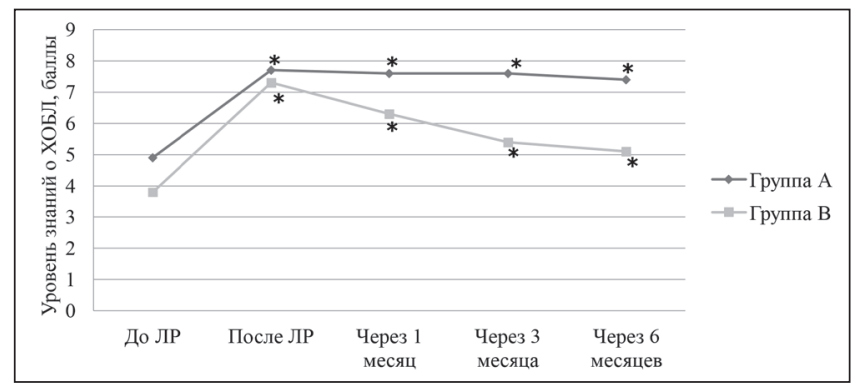

Рисунок 5. Динамика на фоне ЛР уровня знаний о ХОБЛ в spynne A u spynne $B$.

Примечание: ${ }^{\star}-p<0,05$.

\section{Заключение}

Нами была проведена оптимизация программ лёгочной реабилитации, в основе которой лежат дифференцированные, в зависимости от типов реагирования на заболевание подходы. Показана одинаково высокая эффективность созданных программ как у больных с тревогой о болезни и депрессией, так и с гипонозогнозией. Однако у пациентов с гипонозогнозией достигаемые улучшения имеют тенденцию к более быстрому сокращению после окончания мероприятий ЛР, в то время как в группе больных с тревогой о болезни и депрессией даже при отсутствии достоверных изменений сразу после реабилитации, уже через 1 месяц определяется устойчивое, на протяжении полугода, улучшение показателей.
В ходе проведённого исследования в очередной раз была подтверждена важность мотивации и обеспечения информированности о мероприятиях ЛР, в особенности для больных с гипонозогнозией (даже с учётом этих условий и кропотливой работы в данном направлении, доля больных, согласившихся на участие в программе, составила всего 25\%). Положения о ЛР занимают существенное место в международных рекомендациях, включающих основной документ - программу GOLD [16].

\section{Литература}

1. Rochester CL, Vogiatzis I, Holland AE, Lareau SC, Marciniuk DD, Puhan MA, Spruit MA, et al. An Official American Thoracic Society/European Respiratory Society Policy Statement: Enhancing Implementation, Use, and Delivery of Pulmonary Rehabilitation. American Journal of Respiratory and Critical Care Medicine. 2015;192(11):137386. DOI:10.1164/rccm.201510-1966ST.

2. Федеральные клинические рекомендации по диагностике и лечению хронической обструктивной болезни лёгких. Российское респираторное общество, 2014. [Интернет]. Доступно: http://www.pulmonology. ru/download/COPD2014may.doc.

3. Spruit MA, Singh SJ, Garvey C, ZuWallack R, Nici L, Rochester C, Hill K, Holland A, Lareau S, Man WD-C, Pitta F, et al. An official American Thoracic Society/European Respiratory Society statement: key concepts and advances in pulmonary rehabilitation. American Journal of Respiratory and Critical Care Medicine. 2013;188:e13-e64. DOI:10.1164/rccm.201309-1634st.

4. Bolton CE, Bevan-Smith EF, Blakey JD, Crowe P, Elkin SL, Garrod, NJ Greening NJ, Heslop K, Hull JH, D-C Man W, Morgan MD, Proud D, Roberts CM, Sewell L, Singh SJ, Walker PP, Walmsley S. British Thoracic Society guideline on pulmonary rehabilitation in adults. Thorax. 2013;68:ii1-ii30. DOI:10.1136/thoraxjnl-2013-203808.

5. Овчаренко СИ, Галецкайте ЯК, Волель БА, Пушкарев ДФ, Лас ЕА. Типы реагирования на хроническое заболевание у пациентов с хронической обструктивной болезнью лёгких и ревматоидным артритом. Клиницист. 2013;1:21-29.

6. Овчаренко СИ, Галецкайте ЯК, Волель БА, Пушкарев ДФ, Лас ЕА. Типология расстройств личности и реагирования на заболевание при хронической обструктивной болезни лёгких. Пульмонология. 2013;2:74-80.

7. Cafarella PA, Effing TW, Barton C, Ahmed D, Frith PA. Management of depression and anxiety in COPD. European Respiratory Monograph. 2013;59:144-163. DOI:10.1183/1025448x.10012112.

8. Овчаренко СИ, Галецкайте ЯК, Волель БА. Предикторы дезадаптивного поведения в болезни пациентов с хронической обструктивной болезнью лёгких. Пульмонология. 2014;2:60-68. 
9. Пушкарев ДФ, Волель БА, Овчаренко СИ, Галецкайте ЯК, Лас ЕА. Расстройства личности и хроническая соматическая патология на модели ревматоидного артрита и хронической обструктивной болезни лёгких. Психические расстройства в общей медииине. 2012;3:7-15.

10. Смулевич АБ, Волель БА. Расстройства личности и соматическая болезнь (проблема ипохондрического развития личности). Журнал неврологии и психиатрии им. С.С. Корсакова. 2008;5:4-12.

11. Beauchamp MK, Janaudis-Ferreira T, Goldstein RS, Brooks D. Optimal duration of pulmonary rehabilitation for individuals with chronic obstructive pulmonary disease - a systematic review. Chronic Respiratory Disease. 2011;8:129-140. DOI:10.1177/1479972311404256.

12. Ries AL, Bauldoff GS, Carlin BW, Casaburi R, Emery CF, Mahler DA, Make B, Rochester CL, Zuwallack R, Herrerias C. Pulmonary rehabilitation: Joint ACCP/ AACVPR evidence-based clinical practice guidelines. Chest. 2007;131(5):4-42. DOI:10.1378/chest.06-2418.

13. Pitta F, Troosters T, Probst VS, Langer D, Decramer M, Gosselink R Are patients with COPD more active after pulmonary rehabilitation? Chest. 2008;134:273-280. DOI:10.1378/chest.07-2655.

14. Rossi G, Florini F, Romagnoli M, Bellantone T, Lucic S, Lugli D, Clini E. Length and clinical effectiveness of pulmonary rehabilitation in outpatients with chronic airway obstruction. Chest. 2005;127:105-109. DOI:10.1378/ chest.127.1.105.

15. Redelmeier DA, Bayoumi AM, Goldstein RS, Guyatt $\mathrm{GH}$. Interpreting small differences in functional status: the six minute walk test in chronic lung disease patients. American Journal of Respiratory and Critical Care Medicine. 1997;155:1278-1282. DOI:10.1164/ajrccm.155.4.9105067.

16. Global Strategy for the Diagnosis, Management and Prevention of COPD, Global Initiative for Chronic Obstructive Lung Disease (GOLD) 2017 [Интернет]. Доступно: http:/goldcopd.org/gold-2017-global-strategy-diagnosis-management-prevention-copd/.

\section{References}

1. Rochester CL, Vogiatzis I, Holland AE, Lareau SC, Marciniuk DD, Puhan MA, Spruit MA, et al. An Official American Thoracic Society/European Respiratory Society Policy Statement: Enhancing Implementation, Use, and Delivery of Pulmonary Rehabilitation. American Journal of Respiratory and Critical Care Medicine. 2015;192(11):137386. DOI:10.1164/rccm.201510-1966ST.

2. Federal clinical guidelines on diagnosis and treatment of chronic obstructive pulmonary disease. Russian respiratory society, 2014. [Internet]. Available at: http:// www.pulmonology.ru/download/COPD2014may.doc. Accessed August 30, 2017. (In Russian)

3. Spruit MA, Singh SJ, Garvey C, ZuWallack R, Nici L,
Rochester C, Hill K, Holland A, Lareau S, Man WD-C, Pitta F, et al. An official American Thoracic Society/European Respiratory Society statement: key concepts and advances in pulmonary rehabilitation. American Journal of Respiratory and Critical Care Medicine. 2013;188:e13-e64. DOI:10.1164/rccm.201309-1634st.

4. Bolton CE, Bevan-Smith EF, Blakey JD, Crowe P, Elkin SL, Garrod, NJ Greening NJ, Heslop K, Hull JH, D-C Man W, Morgan MD, Proud D, Roberts CM, Sewell L, Singh SJ, Walker PP, Walmsley S. British Thoracic Society guideline on pulmonary rehabilitation in adults. Thorax. 2013;68:ii1-ii30. DOI:10.1136/thoraxjnl-2013-203808.

5. Ovcharenko SI, Galetskayte YaK, Volel' BA, Pushkarev DF, Las EA. Disease coping styles in patients with chronic obstructive pulmonary disease or rheumatoid arthritis. Clinicist. 2013;1:21-29.(In Russian)

6. Ovcharenko SI, Galetskayte YaK, Volel' BA, Pushkarev DF, Las EA. Patterns of personality disorders and disease-related responses in patients with chronic obstructive pulmonary disease. Pulmonology. 2013;2:74-80.(In Russian)

7. Cafarella PA, Effing TW, Barton C, Ahmed D, Frith PA. Management of depression and anxiety in COPD. European Respiratory Monograph. 2013;59:144-163. DOI:10.1183/1025448x.10012112.

8. Ovcharenko SI, Galetskayte YaK, Volel' BA. Predictors of disadaptive disorders in patients with chronic obstructive pulmonary disease. Pulmonology. 2014;2:60-68. (In Russian)

9. Pushkarev DF, Volel' BA, Ovcharenko SI, Galetskayte YaK, Las EA. Personality disorders and chronic medical disease: a comparative analysis of rheumatoid arthritis and chronic obstructive pulmonary disease. Psychic Disorders in General Medicine. 2012;3:7-15.(In Russian)

10. Smulevich AB, Volel' BA. Personality disordres and somatic disease (hypohondriac personality development problem). Neuroscience and Behavioral Physiology. 2008;5:4-12.(In Russian)

11. Beauchamp MK, Janaudis-Ferreira T, Goldstein RS, Brooks D. Optimal duration of pulmonary rehabilitation for individuals with chronic obstructive pulmonary disease - a systematic review. Chronic Respiratory Disease. 2011;8:129-140. DOI:10.1177/1479972311404256.

12. Ries AL, Bauldoff GS, Carlin BW, Casaburi R, Emery CF, Mahler DA, Make B, Rochester CL, Zuwallack R, Herrerias C. Pulmonary rehabilitation: Joint ACCP/ AACVPR evidence-based clinical practice guidelines. Chest. 2007;131(5):4-42. DOI:10.1378/chest.06-2418.

13. Pitta F, Troosters T, Probst VS, Langer D, Decramer M, Gosselink R Are patients with COPD more active after pulmonary rehabilitation? Chest. 2008;134:273-280. DOI:10.1378/chest.07-2655.

14. Rossi G, Florini F, Romagnoli M, Bellantone T, Lucic S, Lugli D, Clini E. Length and clinical effectiveness of 
pulmonary rehabilitation in outpatients with chronic airway obstruction. Chest. 2005;127:105-109. DOI:10.1378/ chest.127.1.105.

15. Redelmeier DA, Bayoumi AM, Goldstein RS, Guyatt GH. Interpreting small differences in functional status: the six minute walk test in chronic lung disease patients. American Journal of Respiratory and Critical Care Medicine. 1997;155:1278-1282. DOI:10.1164/ajrccm.155.4.9105067.

16. Global Strategy for the Diagnosis, Management and Prevention of COPD, Global Initiative for Chronic Obstructive Lung Disease (GOLD) 2017 [Internet]. Available at: http://goldcopd.org/gold-2017-global-strategy-diagnosis-management-prevention-copd/.

\section{Сведения об авторах}

Овчаренко Светлана Ивановна, Первый Московский государственный медицинский университет имени И. М. Сеченова; адрес: Российская Федеращия, 119991, г. Москва, ул. Трубецикая, д. 8, стр. 2; тел.: +7(916)4066778; e-mail: svetffk@mail.ru

Галецкайте Янина Казисовна, Первьй Московский государственный медицинский университет имени И. М. Сеченова; адрес: Российская Федеращия, 119991, г. Москва, ул. Трубеикая, д. 8, стр. 2; тел.: +7(903)7944775; e-mail: galetskayte@gmail.com

Волель Беатриса Альбертовна, Первый Московский государственный медищинский университет имени И. М. Сеченова; адрес: Российская Федеращия, 119991, г. Москва, ул. Трубецкая, д. 8, стр. 2; тел.: +7(916)6160760; e-mail: beatrice.volel@gmail.com

\section{Information about authors}

Ovcharenko Svetlana I., I. M. Sechenov First Moscow State Medical University; Address: 8-2 Trubetskaya st., Moscow 119991, Russian Federation; Phone: +7(916)4066778; e-mail: svetffk@ mail.ru

Galetskayte Yanina K., I. M. Sechenov First Moscow State Medical University; Address: 8-2 Trubetskaya st., Moscow 119991, Russian Federation; Phone: +7(903)7944775; e-mail: galetskayte@gmail.com

Volel Beatrisa A., I. M. Sechenov First Moscow State Medical University; Address: 8-2 Trubetskaya st., Moscow 119991, Russian Federation; Phone: +7(916)6160760; e-mail: beatrice. volel@gmail.com

(c) АНТОНОВ В. Н.

УДК 616.233-002

DOI: $10.20333 / 2500136-2017-5-35-40$.

\title{
ЭТИОЛОГИЧЕСКИЕ И КЛИНИЧЕСКИЕ АСПЕКТЫ МАНИФЕСТАЦИИ РАЗЛИЧНЫХ ВАРИАНТОВ ТЕЧЕНИЯ ХРОНИЧЕСКОЙ ОБСТРУКТИВНОЙ БОЛЕЗНИ ЛЕГКИХ
}

\author{
В. Н. Антонов \\ Южно-Уральский государственный медицинский университет, Челябинск 454092, Российская Федерация
}

\begin{abstract}
Цель исследования. В статье обсуждаются проблемы ранней манифестации клинических проявлений ХОБЛ в зависимости от воздействия этиологических факторов, в частности табакокурения.

Материал и методы. Обследовано 249 пациентов с изолированной ХОБЛ и 250 больных с сочетанным течением ХОБЛ и ИБС. Всем больным было проведено комплексное клиническое обследование. Проанализированы выявленные факторы риска развития ИБС и ХОБЛ, в частности, оценивался факт табакокурения, стаж и индекс курящего человека. Оценены следующие показатели: возраст появления первых симптомов ХОБЛ, продолжительность заболевания, кашлевой анамнез. Функциональные показатели: объем форсированного выдоха в первую секунду $\left(О Ф B_{1}\right)$, отношение ОФВ к форсированной жизненной емкости легких (ФЖЕЛ).

Результаты. Индекс курящего человека в обеих группах превышал 200 единиц. В группе ХОБЛ+ИБС индекс курящего человека достоверно превышал этот показатель по сравнению с пациентами с изолированной ХОБЛ на 9 \% ( $<<0,05)$.

Заключение. Степень тяжести пациентов с сочетанным течением ХОБЛ и ИБС зависит от стажа курения и его интенсивности, особенно у пациентов с GOLD 3 и GOLD 4 по классификации ХОБЛ 2011 года. У пациентов с коморбидным течением ХОБЛ и ИБС основные клинические проявления заболевания регистрируются раньше, чем у больных с изолированной ХОБЛ и ассоциируются с меньшим стажем курения. У больных с ХОБЛ и ИБС функциональные показатели респираторной системы достоверно ниже таковых, чем у пациентов с изолированной ХОБЛ.

Ключевые слова: ХОБЛ, ИБС, коморбидность, факторы риска, табакокурение, индекс курящего человека.

Для цитирования: Антонов ВН. Этиологические и клинические аспекты манифестации различных вариантов течения хронической обструктивной болезни легких. Сибирское медииинское обозрение. 2017;(5): 35-40. DOI: 10.20333/2500136-2017-5-35-40.
\end{abstract}

\section{ETIOLOGICAL AND CLINICAL ASPECTS OF MANIFESTATION THE VARIOUS VARIANTS OF CHRONIC OBSTRUCTIVE PULMONARY DISEASE COURSE}

V. N. Antonov

South Ural State Medical University, Chelyabinsk 454092, Russian Federation

The aim of the research. The article discusses the problems of early manifestation of clinical development of COPD depending on the effect of etiological factors, in particular tobacco smoking.

Material and methods. 249 patients with isolated COPD and 250 patients with combined course of COPD and IHD were examined. All patients had complex clinical examination. The revealed risk factors for the development of IHD and COPD were analyzed, in particular, the fact of smoking, the length of time and 
the index of the smoker was estimated. The following indices are estimated: age of appearance of the first symptoms of COPD, duration of the disease, cough anamnesis. Functional indices: volume of forced expiration in the first second (FEV1), ratio of FEV1 to forced vital capacity of lungs (FVC).

Results. The index of the smoker in both groups exceeded 200 units. In the COPD + IHD group, the smokers' index significantly exceeded this figure compared to patients with isolated COPD by $9 \%(\mathrm{p}<0.05)$

The conclusion. The severity of patients with combined course of COPD and IHD depends on the length of smoking and its intensity, especially in patients with GOLD 3 and GOLD 4 according to the COPD classification of 2011. In patients with comorbid course of COPD and IHD, the main clinical manifestations of the disease are registered earlier than in patients with isolated COPD and associated with a shorter smoking experience. In patients with COPD and IHD, the functional parameters of the respiratory system are significantly lower than those of patients with isolated COPD.

Key words: COPD, IHD, comorbidity, risk factors, smoking, smoker index.

Citation: Antonov VN. Etiological and clinical aspects of manifestation the various variants of chronic obstructive pulmonary disease course. Siberian Medical Review. 2017; (5): 35-40. DOI: 10.20333/2500136-2017-5-35-40.

\section{Введение}

Согласно эпидемиологическим данным, изложенным в обновленной версии глобальной стратегии по диагностике, управлению, профилактике хронической обструктивной болезни легких (ХОБЛ) (GOLD 2017), распространенность в мире данной нозологии остается достаточно высокой, и имеет тенденцию к росту [1]. С увеличением числа больных с симптомами бронхиальной обструкции растет и смертность от ХОБЛ. По данным ВОЗ, сегодня ХОБЛ является 3-й лидирующей причиной смерти в мире, ежегодно от ХОБЛ умирает около 2,8 млн человек, что составляет $4,8 \%$ всех причин смерти [2].

Течение ХОБЛ отличается значительным полиморфизмом. Гетерогенная природа заболевания рассматривается в различных аспектах - клиническом, функциональном, патоморфологическом. С момента появления самого понятия ХОБЛ были предприняты попытки описать и систематизировать данную неоднородность. Первое разделение больных ХОБЛ на фенотипы принадлежит A. Dornhorst, который более 50 лет назад описал два разных подтипа больных с дыхательной недостаточностью: больных с эмфиземой, одышкой, без цианоза, со сниженной массой тела («розовые пыхтельщики») и больных с хроническим бронхитом, цианозом и отеками, признаками правожелудочковой сердечной недостаточности («синие отечники») [3]. Затем, B. Burrows et al. в 1966 г. описали две подгруппы больных ХОБЛ, которые отличались между собой по клинической, функциональной, рентгенологической и морфологической картине, и назвали эти подгруппы эмфизематозным и бронхитическим фенотипами хронической обструкции дыхательных путей [4]. Кроме вышеперечисленных в настоящее время выделяют и иные фенотипы заболевания: сочетание ХОБЛ и БА, фенотип с частыми обострениями, фенотип пульмонологической кахексии, фенотипы системной воспалительной реакции $[1,2]$.

В зарубежной и отечественной литературе, особенно в последние годы, особое внимание уделяется сочетанному варианту течения ХОБЛ и ишемической болезни сердца (ИБС) $[5,6]$. Данную проблему мож- но рассматривать с нескольких позиций. Во-первых, респираторные и сердечно-сосудистые заболевания имеют общие факторы риска - курение, урбанизацию, низкую физическую активность, старение популяции, генетическую предрасположенность [6]. Крайне опасным фактором риска признано курение. По некоторым оценкам в индустриальных странах курение вносит вклад в смертность около 80 \% мужчин и $60 \%$ женщин, в то время как в развивающихся странах - у $45 \%$ мужчин и $20 \%$ женщин [7]. Таким образом, один и тот же фактор является определяющим в развитии $2-x$ заболеваний. Во-вторых, ИБС и ХОБЛ имеют общий механизм в виде формирования системного воспаления. Предполагается, что усиление локального воспаления в бронхах, легочной паренхиме и сосудах оказывает системное воздействие и способствует прогрессированию ХОБЛ, развитию атеросклероза и сердечной патологии у данных пациентов [7]. Известно, что снижение ОФВ на 10 \% увеличивает риск сердечно-сосудистой смертности на $28 \%$, а не фатальных коронарных событий - на 20 \% [8, 9]. В третьих, ХОБЛ и ИБС являются социально значимыми заболеваниями, имеющие колоссальный вклад в структуру заболеваемости и смертности $[1,2]$.

Исходя из вышеизложенного, остается чрезвычайно актуальным дальнейшее изучение связи этиологических и патогенетических аспектов различных вариантов развития ХОБЛ, и в частности коморбидного течения ХОБЛ и ИБС.

Цель исследования: оценка влияния табакокурения на основные клинико-функциональные показатели у больных с коморбидным течением ХОБЛ и ИБС.

Задачи исследования:

1. Проанализировать воздействие курения на степень тяжести ХОБЛ и ИБС.

2. Оценить соотношение сроков появления основных респираторных симптомов у пациентов с ХОБЛ и ИБС в зависимости от стажа курения и индекса курящего человека.

3. Показать влияние индекса курящего человека на основные показатели функционального состояния респираторной системы. 


\section{Материал и методы}

Проведен анализ историй болезни пациентов с изолированной ХОБЛ, коморбидным течением ХОБЛ и ИБС, проходивших лечение в пульмонологическом и кардиологическом отделениях ОКБ №4 в 2014-2016гг. Диагноз ХОБЛ выставлялся на основании критериев постановки диагноза GOLD-2011 [10]. Диагноз ИБС соответствовал критериям нозологии согласно рекомендациям Европейского общества кардиологов (2006 г.) и Всероссийского научного общества кардиологов (2008 г.) [11]. В исследование были включены 499 пациентов. Условием включения было наличие
WINDOWS 13. Данные представлены в виде доверительного интервала ДИ 95 \%. Использовался t-test, с неравными дисперсиями, 3-х хвостовой. При анализе связей внутри групп применялся линейный парный коэффициент корреляции К. Пирсона.

\section{Результаты и обсуждение}

Группы были сопоставимы по количеству пациентов, возрасту, основным клиническим характеристикам. Основные результаты анализа анамнеза курения у обследованных пациентов представлены в таблице 1.

Курение выступает в качестве триггера и поддерживающего фактора риска развития воспаления у паци-

Анамнестические данные по группам

Таблииа 1

\begin{tabular}{|c|c|c|c|c|c|c|}
\hline Группа & $\begin{array}{c}\text { Количество } \\
\text { человек }\end{array}$ & $\begin{array}{c}\text { Стаж курения } \\
\text { (годы) }\end{array}$ & ИКч & $\begin{array}{c}\text { Начало } \\
\text { заболевания, } \\
\text { возраст в годах }\end{array}$ & $\begin{array}{c}\text { Продолжительность } \\
\text { заболевания } \\
\text { ХОБл }\end{array}$ & $\begin{array}{c}\text { Кашлевой } \\
\text { анамнез } \\
\text { в годах }\end{array}$ \\
\hline ХОБЛ & 249 & $\begin{array}{c}21,29 \\
{[11,75 ; 30,84]}\end{array}$ & $\begin{array}{c}244,3 \\
{[196,7 ; 291,9]}\end{array}$ & $\begin{array}{c}59,77 \\
{[50,29 ; 69,25]}\end{array}$ & $\begin{array}{c}11,89 \\
{[5,67 ; 18,12]}\end{array}$ & $\begin{array}{c}11,34 \\
{[6,87 ; 15,82]}\end{array}$ \\
\hline ХОБЛ+ИБС & 250 & $\begin{array}{c}17,31 \\
{[9,86 ; 24,76]}\end{array}$ & $\begin{array}{c}262,6 * \\
{[206,6 ; 318,6]}\end{array}$ & $\begin{array}{c}55,16 \\
{[49,15 ; 61,17]}\end{array}$ & $\begin{array}{c}13,86 \\
{[7,89 ; 19,84]}\end{array}$ & $\begin{array}{c}16,22 \\
{[11,25 ; 21,19]}\end{array}$ \\
\hline
\end{tabular}

факта курения у пациента минимум 5 лет. Группы стратифицированы по количеству, возрасту, стажу курения.

После подтверждения диагнозов ХОБЛ и ИБС пациенты были разделены на две группы: 1. Больные с ХОБЛ, n=250, средний возраст 59,9 (52,1;67,6) лет; 2. ХОБЛ и ИБС, n=249, средний возраст $61,5(54,7 ; 68,3)$ лет.

Всем больным было проведено комплексное клиническое обследование, которое включало клиническую оценку, жалобы, анамнез, физикальное, лабораторное и инструментальные исследования. Проведена пульсоксиметрия; оценка функции внешнего дыхания (ФВД): спирография на аппарате Microlab (Англия), общая бодиплетизмография на приборе Master Screen Body (Jaeger, Германия). Проведен анализ выявленных факторов риска развития ИБС и ХОБЛ, в частности, оценивался факт табакокурения, стаж курения и рассчитывался индекс курящего человека (ИКЧ) по формуле - количество выкуриваемых сигарет, умноженное на 12. При этом принималось, что если результат превышал 120, то рассматривали пациента как имеющего фактор риска ХОБЛ и ИБС, свыше 200 - злостный курильщик. Оценены следующие показатели: возраст появления первых симптомов ХОБЛ, продолжительность заболевания, кашлевой анамнез. Функциональные показатели: объем форсированного выдоха в первую секунду $\left(O \Phi B_{1}\right)$, отношение $О Ф \mathrm{~B}_{1}$ к форсированной жизненной емкости легких (ФЖЕЛ). Для статистической обработки полученных результатов использовалась программа STATISTICA для ентов с ХОБЛ. Основными моментами в отрицательном влиянии табакокурения являются продолжительность экспозиции, то есть стаж курения, и интенсивность воздействия, или количество выкуриваемых сигарет в день. Индекс курящего человека отражает именно эти две составляющие, и является наиболее оптимальным ориентиром при оценке вклада табакокурения при рассмотрении этиологической составляющей течения заболевания в каждом конкретном случае. При анализе связи продолжительности курения и появления первых симптомов заболевания в исследуемой когорте пациентов выявлено, что у пациентов с сочетанным течением ХОБЛ и ИБС наблюдается менее продолжительный стаж курения, по сравнению с больными с изолированной ХОБЛ (таблица 1). При этом индекс курящего человека в обеих группах превышал 200 единиц (245,1 и 264,8 соответственно), указывая на неоспоримый вклад факта курения в генез и ХОБЛ и ИБС. В группе ХОБЛ+ИБС индекс курящего человека достоверно превышал этот показатель по сравнению с пациентами с изолированной ХОБЛ на $9 \%($ p $<0,05)$. Пациенты с сочетанной патологией хоть и имели меньший стаж курения, в тоже время у них констатировано более интенсивное воздействие на пациента за счет увеличенного количества выкуриваемых сигарет. Обращает внимание возраст наступления первых симптомов заболевания. Пациенты в обеих группах были сопоставимы по возрасту, однако клинические проявления бронхиальной обструкции у больных с коморбидным течением ХОБЛ и ИБС наступили на 4,61 года раньше, нежели у пациентов с 
ХОБЛ без сопутствующей патологии. Таким образом, менее продолжительная по времени, но большая по интенсивности экспозиция неблагоприятных этиологических факторов, в частности курения, являются триггером более раннего развития основных элементов воспалительного процесса у пациентов с коморбидным течением ХОБЛ и ИБС.

Следующим интересующим вопросом явилось изучение влияния продолжительности курения на структуру исследуемых групп пациентов. Время экспозиции табачного дыма, как известно, влияет на морфологические проявления повреждения легочной ткани у пациентов с ХОБЛ. Чем большая продолжительность курения, тем более распространённые изменения в респираторной системе, глубина и вовлеченность легочной ткани в воспалительный процесс. В эпидемиологических исследованиях показано, что при стаже курения до 10 лет, как правило, преобладают в основном изменения по одному из возможных типов - или бронхитическому, или эмфизематозному [12]. С увеличением стажа курения более 10-15 лет наблюдаются уже смешанные, как бронхитические, так и эмфизематозные изменения, что приводит к утяжелению клинической картины и ухудшению прогноза жизни пациента [4]. Результаты анализа распределения больных по стажу курения в исследуемой когорте представлены в таблице 2 . наблюдается прямая зависимость - при увеличении стажа курения растет и степень тяжести пациента. В ряде исследований установлено, что ХОБЛ приводит к инвалидности в среднем через 10 лет после установления диагноза и более чем в половине случаев (58 \%) - это лица моложе 50 лет [13]. С увеличением степени тяжести уменьшается и продолжительность жизни, так у пациентов с тяжелыми обструктивными изменениями, при ОФВ 1 менее 30 \% от должных величин, и частыми обострениями риск летальных исходов увеличивается на $30 \%[1,2]$.

При этом как в общем, так и отдельно по различной продолжительности курения, статистически значимо ИКЧ превалировал у пациентов с сочетанным течением ХОБЛ и ИБС. У пациентов с ХОБЛ и ИБС наблюдается более интенсивное этиологическое воздействие, обеспечивая, по всей видимости, более раннюю манифестацию клинических проявлений.

Основные клинико-функциональные показатели, обуславливающие проявления бронхиальной обструкции - ОФВ и степень одышки, оцененная в баллах, выглядели следующим образом: у пациентов с ХОБЛ ОФВ составил 51,46 $(46,55 ; 56,37) \%$, у больных с ХОБЛ и ИБС - 40,96 $(35,9 ; 46,02) \%$. Констатируется достоверность статистических различий $(\mathrm{p}<0,05)$. Индекс одышки по mMRC в группе с изолированной ХОБЛ составил $3,34(2,71 ; 3,98)$ балла, у пациентов с

Таблииа 2

Структура больньх по стажу курения

\begin{tabular}{|c|c|c|c|c|c|c|c|c|c|}
\hline & \multirow{2}{*}{$\mathrm{n}$} & \multirow{2}{*}{$\%$} & \multicolumn{6}{|c|}{ Стаж курения } & \multirow{2}{*}{ ИКЧ (средний) } \\
\hline & & & До 10 лет & $\%$ & 10-15 лет & $\%$ & Более 15 лет & $\%$ & \\
\hline ХОБЛ & 249 & 49,8 & 49 & 20 & 87 & 35 & 113 & 45 & \multirow{2}{*}{$\begin{array}{c}244,3 \\
{[196,7 ; 291,9]}\end{array}$} \\
\hline ИКЧ & & & $\begin{array}{c}201,2 \\
{[196,7 ; 205,7]}\end{array}$ & & $\begin{array}{c}248,6 \\
{[244,9 ; 252,3]}\end{array}$ & & $\begin{array}{c}285,5 \\
{[279,1 ; 291,9]}\end{array}$ & & \\
\hline 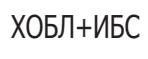 & 250 & 50,2 & 43 & 17 & 92 & 37 & 115 & 46 & \multirow{2}{*}{$\begin{array}{c}262,6 \\
{[206,6 ; 318,6]}\end{array}$} \\
\hline ИКЧ & & & $\begin{array}{c}212,8 \\
{[206,6 ; 219,0]}\end{array}$ & & $\begin{array}{c}269,9 \\
{[262,0 ; 277,4]}\end{array}$ & & $\begin{array}{c}311,8 \\
{[305,0 ; 318,6]}\end{array}$ & & \\
\hline \multirow[t]{2}{*}{ Всего } & 499 & 100 & 92 & 18 & 179 & 36,1 & 228 & 45,9 & $\begin{array}{c}257,6 \\
{[196,7 ; 318,6]}\end{array}$ \\
\hline & & & $\mathrm{p} 1-2<0,05$ & & p1-2<0,05 & & p1-2<0,05 & & \\
\hline
\end{tabular}

Как видно из представленного материала, подавляющее количество пациентов имело стаж курения более 10 лет. В общем по группам стаж курения в 45,9 \% превышал 15 лет, в 36,1 \% случаев стаж составил от 10 до 15 лет, и в 18 \% пациенты курили менее 10 лет. При сопоставлении продолжительности курения и тяжести клинических проявлений, выявлено, что
ХОБЛ и ИБС - 3,59 (3,19;4,00), без статистически значимых различий.

У пациентов с коморбидным течением ХОБЛ и ИБС наблюдается более выраженная бронхиальная обструкция, обуславливающая тяжесть заболевания у данной группы больных. Кроме того, как было указано выше, более низкие показатели ОФВ 1 являются 
и прогностически неблагоприятным фактором $[8,9]$. Учитывая этот факт, проведен анализ влияния ИКЧ на тяжесть клинических проявлений ХОБЛ, в соответствие с классификацией GOLD 2011, который представлен в таблицах 3 и 4.

Таблииа 3

Влияние ИКЧ на тяжесть клинических проявлений у пациентов с ХОБЛ и ИБС

\begin{tabular}{|c|c|c|c|}
\hline $\begin{array}{c}\text { Группа ХОБЛ } \\
\text { по GOLD }\end{array}$ & $\mathrm{n}$ & $\begin{array}{c}\text { ИКЧ, } \\
\text { средний }\end{array}$ & $\begin{array}{c}\text { Коэффициент } \\
\text { корреляции, } \mathrm{r}\end{array}$ \\
\hline GOLD 2 & 57 & $\begin{array}{c}211,8 \\
{[206,6 ; 217,1]}\end{array}$ & 0,192 \\
\hline GOLD 3 & 91 & $\begin{array}{c}248,8 \\
{[242,4 ; 255,1]}\end{array}$ & 0,684 \\
\hline GOLD 4 & 102 & $\begin{array}{c}312,5 \\
{[306,4 ; 318,6]}\end{array}$ & 0,811 \\
\hline
\end{tabular}

Влияние ИКЧ на тяжесть клинических проявлений Таблииа 4 у пащиентов с изолированной ХОБЛ

\begin{tabular}{|c|c|c|c|}
\hline $\begin{array}{c}\text { Группа XОБЛ } \\
\text { по GOLD }\end{array}$ & $\mathrm{n}$ & $\begin{array}{c}\text { ИКЧ, } \\
\text { средний }\end{array}$ & $\begin{array}{c}\text { Коэффициент } \\
\text { корреляции, } \mathrm{r}\end{array}$ \\
\hline GOLD 2 & 63 & $\begin{array}{c}201,9 \\
{[196,7 ; 207,1]}\end{array}$ & 0,212 \\
\hline GOLD 3 & 90 & $\begin{array}{c}256,7 \\
{[250,6 ; 262,8]}\end{array}$ & 0,821 \\
\hline GOLD 4 & 96 & $\begin{array}{c}286,7 \\
{[281,5 ; 291,9]}\end{array}$ & 0,714 \\
\hline
\end{tabular}

Как вытекает из полученных результатов, в структуре курящих больных с ХОБЛ преобладают пациенты с тяжелой степенью тяжести. Кроме того, выявлена корреляционная зависимость между степенью тяжестью и ИКЧ у больных с тяжелой $(\mathrm{r}=0,82, \mathrm{p}<0,05)$ и крайне тяжелой степенью тяжести ХОБЛ ( $\mathrm{r}=0,71, \mathrm{p}<0,05)$.

Подобная же закономерность констатирована и у пациентов с сочетанным течением ХОБЛ и ИБС, только со статистически значимым преобладанием ИКЧ у пациентов с GOLD 2 и GOLD 4.

\section{Заключение}

1. Степень тяжести пациентов с сочетанным течением ХОБЛ и ИБС зависит от стажа курения и интенсивности, особенно у пациентов с GOLD 3 и GOLD 4 по классификации ХОБЛ 2011 года.

2. У пациентов с коморбидным течением ХОБЛ и ИБС основные клинические проявления заболевания регистрируются раньше, чем у больных с изолированной ХОБЛ и ассоциируются с меньшим стажем курения.

3. У больных с ХОБЛ и ИБС функциональные показатели респираторной системы достоверно ниже таковых, чем у пациентов с изолированной ХОБЛ.

\section{Литература}

1. Global Strategy for the Diagnosis, Management and Prevention of COPD, Global Initiative for Chronic Obstructive Lung Disease (GOLD) 2016. [Internet] Available from: http://goldcopd.org/.

2. Айсанов 3Р, Авдеев СН, Архипов ВВ, Белевский АС, Лещенко ИВ, Овчаренко СИ, Шмелев ЕИ, Чучалин АГ. Национальные клинические рекомендации по диагностике и лечению хронической обструктивной болезни легких: алгоритм принятия клинических решений. Пульмонология. 2017;27(1):13-20. DOI:10.18093/08690189-2017-27-1-13-20.

3. Авдеев СН. Фенотипы хронической обструктивной болезни легких: особенности терапии. Болезни органов дыхания. Консилиум (прил.). 2010;1:23-8.

4. Pistolesi M, Bigazzi F, Cestelli L, Paoletti M, Camiciottoli G. ХОБЛ: комплексное заболевание: Фенотипы хронической обструктивной болезни легких. [Интернет]. Доступно: https://medi.ru/info/4869 (обращение 28.07.2017).

5. Куценко МА, Чучалин АГ. Парадигма коморбидности: синтропия ХОБЛ и ИБС. РМЖ. 2014;5:389.

6. Боев СС, Доценко НЯ, Шехунова ИА, Дедова ВО. Сочетание хронической обструктивной болезни легких и ишемической болезни сердца. Вопросы раииональной терапии. [Интернет]. Доступно: http:// therapia.ua/therapia/2015-/2-95. (обращение 28.07.2017).

7. Коррейа ЛЛ, Лебедев ТЮ, Ефремова ОА. Проблема полиморбидности при сочетании хронической обструктивной болезни легких и некоторых сердечно-сосудистых заболеваний. Научные ведомости Белгородского государственного университета. 2013;4(147):12-17.

8. Sin DD, Wu L, Man SF. The relationship between reduced lung function and cardiovascular mortality. Chest. 2005;127:1952-9. DOI: http://dx.doi.org/10.1378/ chest.127.6.1952.

9. Sin DD, Man SF. Chronic obstructive pulmonary disease as a risk factor for cardiovascular morbidity and mortality. Proceedings of the American Thoracic Society. 2005;2(1):8-11. DOI:http://dx.doi.org/10.1513/ pats.200404-032ms.

10. Глобальная стратегия диагностики, лечения и профилактики хронической обструктивной болезни легких (пересмотр 2011 г.) / Пер. с англ. под ред. А.С. Белевского. М.: Российское респираторное общество; 2012. 80 c.

11. Национальные рекомендации по диагностике и лечению стабильной стенокардии. Кардиоваскулярная терапия и пробилактика. 2008;7(6):37.

12. Айсанов 3Р, Кокосов АН, Овчаренко СИ, Хмелькова НГ, Цой АН, Чучалин АГ, Шмелев ЕИ. Хронические обструктивные болезни легких. Федеральная программа. РМЖ. 2001;1:9. 
13. Овчаренко СИ Противовоспалительная терапия хронического бронхита. РМЖ. 2001;5:201.

\section{References}

Global Strategy for the Diagnosis, Management and Prevention of COPD, Global Initiative for Chronic Obstructive Lung Disease (GOLD) 2016. [Internet] Available from: http://goldcopd.org/.

2. Aisanov ZR, Avdeev SN, Arkhipov VV, Belevsky AS, Leschenko IV, Ovcharenko SI, Shmelev EI, Chuchalin AG National clinical guidelines for the diagnosis and treatment of chronic obstructive pulmonary disease: an algorithm for making clinical decisions. Pulmonology. 2017;27(1):13-20. DOI:10.18093/0869-0189-2017-27-1 13-20 (In Russian)

3. Avdeev SN. Phenotypes of chronic obstructive pulmonary disease: features of therapy. Diseases of the respiratory system. Consilium (adj.). 2010;1:23-8. (In Russian)

4. Pistolesi M, Bigazzi F, Cestelli L, Paoletti M, Camiciottoli G. COPD: Complex disease: Phenotypes of chronic obstructive pulmonary disease. [Internet]. Available at https://medi.ru/info/4869 (reference 28.07.2017)

5. Kutsenko MA, Chuchalin AG The paradigm of comorbidity: the syndrome of COPD and IHD. RMJ. 2014;5:389. (In Russian)

6. Boev SS, Dotsenko N.Ya., Shehunova IA, Dedova V.O. Combination of chronic obstructive pulmonary disease and coronary heart disease. Issues of rational therapy. [Internet]. Available at http://therapia.ua/therapia/2015-/2-95. (reference July 28, 2017). (In Russian)

7. Correia LL, Lebedev TYu, Efremova OA. The problem of polymorbidity in a combination of chronic obstructive pulmonary disease and certain cardiovascular diseases. Scientific Bulletin of Belgorod State University. 2013;4(147):12-17. (In Russian)

8. Sin DD, Wu L, Man SF. The relationship between reduced lung function and cardiovascular mortality. Chest. 2005;127:1952-9. DOI:http://dx.doi.org/10.1378/ chest.127.6.1952

9. Sin DD, Man SF. Chronic obstructive pulmonary disease as a risk factor for cardiovascular morbidity and mortality. Proceedings of the American Thoracic Society. 2005;2(1):8-11. DOI:http://dx.doi.org/10.1513/ pats.200404-032ms.

10. Global strategy for diagnosis, treatment and prevention of chronic obstructive pulmonary disease (2011 revision). M: Russian Respiratory Society, 2012. 80 p. (In Russian)

11. National guidelines for the diagnosis and treatment of stable angina pectoris. Cardiovascular therapy and prevention. 2008;7(6): 37. (In Russian)

12. Aisanov ZR, Kokosov AN, Ovcharenko SI, Khmelkova NG, Tsoi AN, Chuchalin AG, Shmelev EI Chronic obstructive pulmonary disease. The federal program. RM1. 2001;1:9 (In Russian)

13. Ovcharenko S.I. Anti-inflammatory therapy of chronic bronchitis. RM2. 2001;5:201. (In Russian)

\section{Сведения об авторах}

Антонов Владимир Николаевич, Южно-Уральский государственный медииинский университет; адрес: Российская Федерация, 454092, г. Челябинск, ул. Воровского 64; тел.: +7(351) 2327371; e-mail:ant-vn@yandex.ru

\section{Information about the authors}

Antonov Vladimir N., South Ural State Medical University; address: Russian Federation, 454092 Chelyabinsk, ul. Vorovsky 64; Phone: +7 (351) 2327371; e-mail: ant-vn@yandex.ru

\title{
ХАРАКТЕРИСТИКА БОЛЬНЫХ БРОНХИАЛЬНОЙ АСТМОЙ, ПОСТУПИВШИХ В СТАЦИОНАРЫ ГОРОДА КАЗАНИ
}

\author{
А. А. Визель ${ }^{1}$ А. Р. Вафина ${ }^{1}$, И. Ю. Визель ${ }^{1}$, И. Н.Салахова ${ }^{1}$, Е. В. Дьякова ${ }^{2}$, Э. 3. Кудрявцева ${ }^{3}$ \\ ${ }^{1}$ Казанский государственный медицинский университет, Казань 420012, Российская Федерация \\ ${ }^{2}$ Республиканская клиническая больница, Казань 420064, Российская Федерация \\ ${ }^{3} 16$-я городская клиническая больница, Казань 420039, Российская Федерация
}

Цель исследования. Изучение клинических проявлений, особенностей лечения, предпочтений больных бронхиальной астмой (БА) и соответствия оказания помощи этим больным клиническим рекомендациям.

Материал и методы. Проведён опрос, клиническое, лабораторное и функциональное обследование 100 больных БА, поступивших в стационары города Казани до июля 2017 года. База данных создана и обработана программой SPSS-18.

Результаты. В соответствии с GINA 2017 у 96 \% больных БА была неконтролируемой и у 4 \% - частично контролируемой; по результатам применения вопросника ACQ у 94\% больных была плохо контролируемая БА. Пациенты назвали худшим временем суток вечер и ночь, а также сообщили, что утренние симптомы негативно влияли на дневную активность. Наиболее эффективными и удобными устройствами больные назвали дозирующие порошковые ингаляторы. Наиболее эффективной комбинацией пациенты назвали будесонид с формотеролом. Лечение, проводимое на амбулаторном этапе и в стационаре, соответствовало отечественным и зарубежным клиническим рекомендациям по диагностике и лечению БА. Однако только 43 \% больных имели адекватное терапевтическое сотрудничество, а 20 \% - не были достаточно обучены применению 
средств доставки аэрозолей. Модификация и усиление терапии при госпитализации также соответствовали отечественным и международным рекомендациям.

Заключение. Проведённая работа показала, что уровень оказания помощи больным БА в Казани соответствует современным требованиям. Среди назначаемых препаратов значительную часть стали занимать генерики. Работа показала, что имеются возможности дальнейшего совершенствования лечения БА путем повышения комплаентности больных, более полного обучения и регулярного контроля техники применения различных ингаляционных препаратов.

Ключевые слова: бронхиальная астма, контроль, вопросники, лечение, ингаляторы, бронхолитики, ингаляционные кортикостероиды, терапевтическое сотрудничество.

Для цитирования: Визель АА, Вафина АР, Визель ИЮ, Салахова ИН, Дьякова ЕВ, Кудрявцева ЭЗ. Характеристика больных бронхиальной астмой, поступивших в стационары города Казани. Сибирское медиинское обозрение. 2017;(5): 40-47. DOI: 10.20333/2500136-2017-5-40-47.

\section{CHARACTERISTICS OF PATIENTS WITH BRONCHIAL ASTHMA HAVE ADMITTED TO THE STATIONARES OF THE CITY OF KAZAN}

A. A. Vizel', A. R. Vafina', I. Yu. Vizel', I. N. Salakhova ${ }^{1}$, E. V. Dyakova ${ }^{2}$, E. Z. Kudryavtseva ${ }^{3}$

${ }^{1}$ Kazan State Medical University, Kazan 420012, Russian Federation

${ }^{2}$ Republican Clinical Hospital, Kazan 420064, Russian Federation

${ }^{3} 16$-city Clinical Hospital, Kazan 420039, Russian Federation

The aim of the research. To study the clinical manifestations, peculiarities of treatment, preferences of patients with bronchial asthma (BA) and compliance of care for these patients with clinical recommendations.

Material and methods. It was conducted the survey, clinical, laboratory and functional examination of 100 patients with asthma, that have admitted to the hospitals in Kazan until July 2017. The database was created and processed by the SPSS-18 program.

Results. According to GINA 2017, 96\% of patients had uncontrolled asthma and 4\% had partially controlled; according to the results of the ACQ questionnaire, $94 \%$ of patients had poorly controlled BA. Patients said the worst time of the day evening and night, and also reported that morning symptoms had a negative effect on daytime activity.

The most effective and convenient devices were called metered dose powder inhalers. The most effective combination the patients named budesonide with formoterol. Treatment, conducted at the outpatient and inpatient, corresponded to domestic and foreign clinical recommendations for diagnosis and treatment of asthma.

However, only $43 \%$ of patients had adequate therapeutic cooperation, and 20\% - were not sufficiently trained in the use of aerosol delivery. Modification and strengthening of therapy during hospitalization also corresponded to domestic and international recommendations.

The conclusion. The work showed that the level of care for patients with BA in Kazan is up-to-date. Among the prescribed drugs, a significant proportion began to occupy the generics. The work showed that there are opportunities to further development the treatment of asthma by improving patient compliance, more complete training and regular monitoring of the technique of using various inhalation drugs.

Key words: bronchial asthma, control, questionnaires, treatment, inhalers, bronchodilators, inhaled corticosteroids, therapeutic cooperation.

Citation: Vizel AA, Vafina AR, Vizel IYu, Salakhova IN, Dyakova EV, Kudryavtseva EZ. Characteristics of patients with bronchial asthma have admitted to the stationares of the city of Kazan. Siberian Medical Review. 2017; (5): 40-47. DOI: 10.20333/2500136-2017-5-40-47.

\section{Введение}

Бронхиальная астма (БА) - это гетерогенное заболевание, характеризующееся хроническим воспалением дыхательных путей, наличием респираторных симптомов, таких как свистящие хрипы, одышка, заложенность в груди и кашель, которые варьируют по времени и интенсивности и проявляются вместе с вариабельной обструкцией дыхательных путей. Гетерогенность БА проявляется различными фенотипами заболевания, многие из которых возможно выделить в обычной клинической практике $[1,2,3]$, а рост заболеваемости БА отмечается во многих регионах России $[4,5]$. Это увеличивает расходы системы здравоохранения [6]. В Республике Татарстан заболеваемость БА увеличилась за последние 20 лет до 895,4 (+184,4 \%), тогда как смертность снизилась с 11,8 до 2,19 (-81,4 $\%)$, а летальность с 0,59 \% до 0,18 \% (-69,4 \%) [7]. В то же время существующие методы лечения позволяют достичь контроля над БА, продолжается совершенствование её терапии $[8,9]$. Примерном успешной оптимизации терапии БА служит анализ ситуации в г. Омске, где было отмечено сокращение потребления симптоматических препаратов и увеличение комбинаций ингаляционных глюкокортикостероидов (ИГКС) и бета-2 адреномиметиков длительного действия (ДДБА) [10]. Серьёзные аналитические исследования оказания помощи больным БА проводятся в Оренбурге и Красноярске $[11,12]$. Неоднородность заболевания и динамика эпидемиологических показателей делают актуальным изучение клинических проявлений, структуры заболевших по тяжести течения и контролю над БА, фармакоэпидемиологии в разных регионах России в разные периоды времени. В связи с этим целью данной работы было изучение клиниче- 
ских проявлений, особенностей лечения больных БА, поступивших в стационары города Казани.

\section{Материал и методы}

В проспективное инициативное, не интервенционное, наблюдательное исследование было включено 100 больных бронхиальной астмой (67 женщин и 33 мужчины) в возрасте от 19 до 87 лет $(59,2 \pm 1,4(14,1)$ года), находившихся в стационарах г. Казани с 17.02.2016 по 13.07.2017 года (83 - в Республиканской клинической больнице, 12 - в 16-й городской клинической больнице, 4 - в ОАО «12-я городская клиническая больница» и 1 - в госпитале Медико-санитарной части МВД РФ по РТ). Наряду с традиционным сбором анамнеза был использован классический вопросник ACQ из 5 вопросов, рекомендованный к применению глобальной инициативой GINA [1] и национальными клиническими рекомендациями по БА [2]. Функция внешнего дыхания была исследована на спирометре открытого типа Spirobank (MIR, Италия, одобрен ATS, сертифицирован для применения в России) с первичной обработкой данных программой WinspiroPRO. Результаты лабораторных исследований были заимствованы из медицинских карт стационарных больных. Bсе данные были собраны и обработаны в базах данных прикладной статистической программы SPSS-18. При представлении средних величин результаты выражались как M \pm SE (SD) - среднее значение, ошибка средней, стандартное отклонение. Во всех случаях пациентов курировал врач-пульмонолог. 51\% больных были в возрасте 60 лет и моложе. Среди обследованных было 20 мужчин трудоспособного возраста (60 лет и моложе - 66,7\% мужчин) и 24 женщины трудоспособного возраста (55 лет и моложе - 35,8\% женщин). Все больные были опрошены и обследованы исследователями в период пребывания в стационаре. Только у 2 пациентов данная госпитализация была первой за последние 12 месяцев. Среднее число госпитализаций в течение последнего года составило $1,64 \pm 0,12(1,20)$ (61 \% - 1 обострение, $23 \%$ - 2 обострения, $7 \%-3$ обострения и $7 \%-4$ и более обострений) госпитализации (от 0 до 7), среднее число обострений, потребовавших изменения терапии, за последний год было $5,14 \pm 0,45(4,54)$. У 12 пациентов данное обострение было первым за последние 12 месяцев.

\section{Результаты и обсуждение}

Согласно критериям GINA 2017, у 96 \% больных БА была неконтролируемой и у $4 \%$ - частично контролируемой. Средний балл вопросника ACQ составил $3,72 \pm 0,12(1,18)$, от 0 до 5,8. В соответствии с градациями, указанными в GINA, в интервале 0-0,75 балла (хороший контроль БА) результаты опроса были только у 2 больных (2 \%), в интервале 0,75-1,50 («серая зона») - у 4 пациентов (4 \%), а у остальных $94 \%$ - более 1,5 баллов (плохо контролируемая БА).
Среди обследованных больных БА 82,0 \% больных никогда не курили, 13,0 \% - курили в прошлом и только 5 больных (5 \%) - курили на момент обследования. Все 18 бывших и настоящих курильщиков курили сигареты. Медиана стажа курения была равна нулю, поскольку 82 \% пациентов не курили никогда. 1 больной курил первый год, а еще 17 курили 5 и более лет. $62 \%$ пациентов не употребляли алкоголь, $35 \%$ редко, 3 \% - периодически. У 41 \% больных наряду с БА были клинические проявления ринита, 56 \% больных имели отягощённый аллергологический анамнез. Наиболее частыми сопутствующими заболеваниями были гипертоническая болезнь (64 \%), ишемическая болезнь сердца (41\%), хроническая сердечная недостаточность (32\%), гастроэзофагеальная рефлюксная болезнь (32 \%), сахарный диабет (15\%).

При опросе пациентов было установлено, что главной жалобой пациенты назвали одышку (88 \%), хотя 75 \% подтвердили у них наличие кашля, но значимость его для них была не высокой (только 2 \% больных отметили кашель, как основную жалобу). 95 \% больных сообщили о ночных пробуждениях, 73 \% пользовались ингаляторами в ночное время. Среди всех нарушений сна чаще всего встречалось преждевременное утреннее пробуждение (82 \%). Хуже всего пациенты себя чувствовали вечером (23\%), ночью (19\%) или утром (17\%), а $33 \%$ не смогли определить это время суток. Наилучшим для состояния временем суток эти больные назвали день (46\%), тогда как 30 \% не смогли определить это время суток. Тем не менее, нарушение своей привычной дневной активности отметили 82 \% больных, при этом 76 \% пациентов связывали это с утренними симптомами, которые снижали качество жизни в течение дня.

Результаты спирометрии больных БА широко варьировались. Среднее значение ФЖЕЛ составило $2,43 \pm 0,11(1,08)$ л $(77,7 \pm 2,4(24,2) \%$ от должных значений), ФЖЕЛ была ниже $80 \%$ от должной у $10 \%$ пациентов. Среднее значение ОФВ 1 было $1,58 \pm 0,08(0,83)$ л $(61,0 \pm 2,4(23,7) \%$ от должных величин), ОФВ1 был ниже $80 \%$ от должного у $32 \%$ больных. Отношение ОФВ $/$ /ФЖЕЛ варьировало от $27,2 \%$ до $96 \%$ и составило в среднем $64,9 \pm 1,6(16,4) \%$. У $61 \%$ пациентов это отношение было ниже 70 \%. Ёмкость вдоха была в среднем $2,82 \pm 0,62(6,24)$ л или $97,5 \pm 2,7(21,1) \%$ от должных величин). 69 больным в стационаре была проведена проба с сальбутамолом. Прирост ОФВ составил в среднем $18,38 \pm 1,68(14,0) \%$ или $326 \pm 29$ (245) мл. Средние значения сатурации $\left(\mathrm{SaO}_{2}\right)$ были $96,2 \pm 0,24(2,4) \%$ (от 84 \% до 99 \%). Согласно данным пульсоксиметрии дыхательная недостаточность (ДН) 1-й степени наблюдалась у 7 \%, ДН2 - у 4 \%. Частота

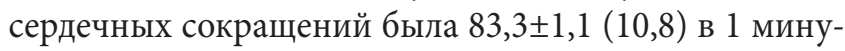
ту (от 64 до 116 в минуту). 
Лейкоцитарная формула характеризовалась следующими показателями: палочкоядерные нейтрофи-

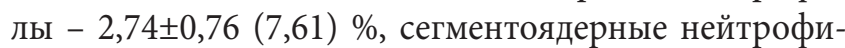

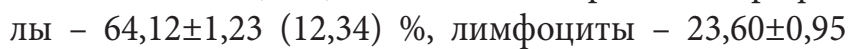

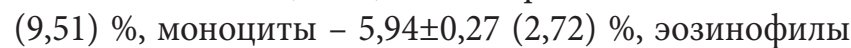

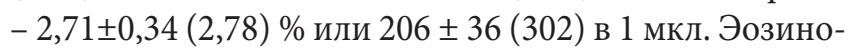
филия 5 \% и более была у $11,6 \%$ больных БА.

Пациенты были опрошены относительно проводимой им повседневной терапии. В ответ на вопрос: «Какое лекарство Вы считаете для себя наиболее эффективным?» 67 \% больных назвали сочетание ИГКС/ ДДБА. Из них 49 \% пациентов лучшей назвали комбинацию будесонид/формотерол (при этом только в $19 \%$ это была фиксированная комбинация), а $18 \%$ - флутиказон/салметерол. 20 \% больных наилучший эффект отметили при применении бронхолитиков короткого действия (12\% - фенотерол/ипратропий).

На вопрос о кратности применения препаратов в течение суток $49 \%$ хотели бы пользоваться 1 раз в сутки, $24 \%$ - 2 раза в сутки, $25 \%$ - ситуационно, по потребности, и только 2 \% сказали, что им безразлично.

Рисунок 1 отражает влияние типа устройств на удобство и оценку эффективности, а также реальную частоту применения этих устройств в данной группе больных БА. Больные БА предпочитали дозирующие порошковые ингаляторы (ДПИ), они им чаще помо-

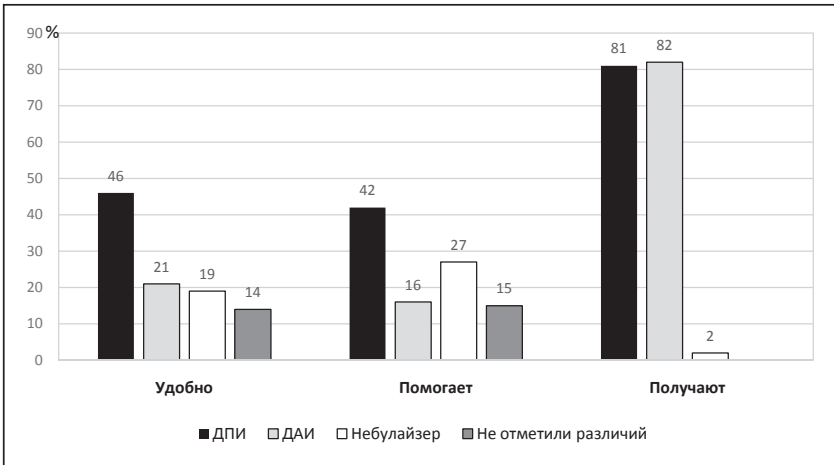

Рисунок 1. Частота удобства средств доставки для больных, восприятия эфбекта препаратов и фактической частоты их применения $(n=100)$.

гали (различия достоверны, $\mathrm{p}<0,05)$, вероятно по той причине, что именно ДПИ применялись для доставки ИГКС/ДДБА. Однако на практике ДПИ были назначены столь же часто, как и дозирующие аэрозольные ингаляторы (ДАИ), посредством которых доставляли бронхолитики короткого действия (различий в частоте не было).

80 \% больных сообщили, что уже на первом визите медработник хорошо обучил их пользованию ингалятором, но только у 40 \% техника была проверена на повторном визите, и только у 9 \% технику ингаляций врач проверял регулярно.

Распределение препаратов, которые получали пациенты перед поступлением в стационары, представлено на рисунке 2.
Бронхолитки короткого действия

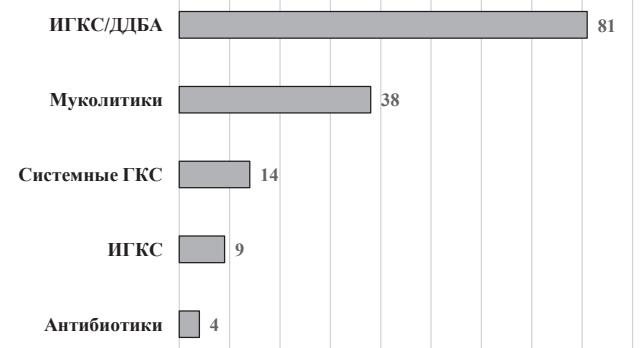

Рисунок 2. Частота назначения препаратов разных классов больным БА $(n=100)$.

Среди бронходилататоров короткого действия чаще всего (64 \%) была назначена фиксированная комбинация коротко действующего бета-2 адреномиметика (КДБА) и коротко действующего антихолинергика (КДАХ) - фенотерол/ипратропий - посредством ДАИ (61 \% - оригинальный препарат и $3 \%$ - генерик). Сальбутамол получали 11 \% больных (1\% - оригинальный препарат и $10 \%$ - генерик). 7 \% пациентов ингалировали оригинальный фенотерол. Среди них 78 \% получали эти препараты по льготному лекарственному обеспечению.

Только 9 \% больных получали ИГКС без ДДБА (7 $\%$ - беклометазона дипропионат генерический ДАИ, 2 \% - оригинальный будесонид ДПИ). 88,9 \% имели льготное лекарственное обеспечение.

Все комбинации ИГКС/ДДБА были оригинальными. Среди них в 88,9 \% случаев препарат был получен по льготе. 58 \% больных БА получали будесонид/ формотерол (33 \% - раздельно, $25 \%$ - фиксированная комбинация) и 23 \% - фиксированную комбинацию флутиказона пропионат/салметерол. 6 \% больных в качестве третьего ингалятора получали длительно действующий антихолинергический бронхолитик (ДДАХ) - тиотропия бромид (оригинальный), в 3 случаях с помощью ДПИ Хандихалер и в 2 - через устройство Респимат; в одним случае тиотропий был в комбинации с ДДБА - олодатеролом через устройство Респимат.

14 \% пациентов получали системные оральные глюкокортикостероиды (ГКС) - 13 \% преднизолон и $1 \%$ - метилпреднизолон. В 78,6 \% получали их по льготному лекарственному обеспечению.

38 \% больных самостоятельно приобретали муколитические препараты $(22 \%-\mathrm{N}$-ацетилцистеин, $15 \%$ - амброксола гидрохлорид и 1 \% - бромгексин/ гвайфенезин/сальбутамол). 4 \% перед госпитализацией принимали антибиотики (3 больных азитромицин и 1 - левофлоксацин).

Частота назначения различных препаратов представлена в таблице 1 , а распределение лекарственных средств по группам отражает рисунок 3. 
Характеристика терапии, которую получали пациенты до госпитализации (n=100)

\begin{tabular}{|c|c|}
\hline Схемы лечения & Частоты \% \\
\hline Ипратропий+Фенотерол+Будесонид+Формотерол & 8,0 \\
\hline Будесонид+Формотерол & 7,0 \\
\hline Ипратропий+Фенотерол+Будесонид+Формотерол+N-ацетилцистеин & 5,0 \\
\hline Ипратропий+Фенотерол+Будесонид+Формотерол+Амброксол & 4,0 \\
\hline Ипратропий+Фенотерол+Будесонид+Формотерол+Преднизолон & 4,0 \\
\hline Ипратропий+Фенотерол & 3,0 \\
\hline Ипратропий+Фенотерол+Беклометазон & 3,0 \\
\hline Ипратропий+Фенотерол+Флутиказон+Салметерол & 3,0 \\
\hline Ипратропий+Фенотерол+Флутиказон+Салметерол+Амброксол & 3,0 \\
\hline Сальбутамол+N-ацетилцистеин & 2,0 \\
\hline Будесонид+Формотерол+Преднизолон & 2,0 \\
\hline Фенотерол+Флутиказон+Салметерол & 2,0 \\
\hline Сальбутамол+Флутиказон+Салметерол & 2,0 \\
\hline Фенотерол+Будесонид+Формотерол+N-ацетилцистеин & 2,0 \\
\hline Ипратропий+Фенотерол+Будесонид+Формотерол+Преднизолон+N-ацетилцистеин & 2,0 \\
\hline Ипратропий+Фенотерол+Флутиказон+Салметерол+Преднизолон & 2,0 \\
\hline Сальбутамол & 1,0 \\
\hline Беклометазон & 1,0 \\
\hline Сальбутамол+Беклометазон & 1,0 \\
\hline Сальбутамол+Будесонид & 1,0 \\
\hline Флутиказон+Сальметерол & 1,0 \\
\hline Будесонид+Формотерол+N-ацетилцистеин & 1,0 \\
\hline Ипратропий+Фенотерол+N-ацетилцистеин & 1,0 \\
\hline Сальбутамол+Будесонид+Формотерол & 1,0 \\
\hline Тиотропий+Флутиказон+Сальметерол & 1,0 \\
\hline Фенотерол+Будесонид+Формотерол & 1,0 \\
\hline Фенотерол+Будесонид+Формотерол+Амброксол & 1,0 \\
\hline Фенотерол+Флутиказон+Салметерол+Амброксол & 1,0 \\
\hline Ипратропий+Фенотерол+Беклометазон+Преднизолон & 1,0 \\
\hline Сальбутамол+Флутиказон+Салметерол+Амброксол & 1,0 \\
\hline Ипратропий+Фенотерол+Беклометазон+Будесонид+Формотерол & 1,0 \\
\hline Ипратропий+Фенотерол+Будесонид+Формотерол+Метилпреднизолон & 1,0 \\
\hline Ипратропий+Фенотерол+Будесонид+Формотерол+Преднизолон+Амброксол & 1,0 \\
\hline Ипратропий+Фенотерол+Тиотропий+Будесонид+Флутиказон+Салметерол+Амброксол & 1,0 \\
\hline Ипратропий+Фенотерол+Тиотропий+Будесонид+Формотерол+Амброксол & 1,0 \\
\hline Ипратропий+Фенотерол+Тиотропий+Флуимуцил & 1,0 \\
\hline Ипратропий+Фенотерол+Тиотропий+Флутиказон+Салметерол+N-ацетилцистеин & 1,0 \\
\hline Ипратропий+Фенотерол+Флутиказон+Салметерол+N-ацетилцистеин +Левофлоксацин & 1,0 \\
\hline Сальбутамол+Будесонид+Формотерол+Преднизолон+Гвайфенезин+Бромгексин & 1,0 \\
\hline Сальбутамол+Тиотропий+Олодатерол+Будесонид+Формотерол+Амброксол & 1,0 \\
\hline Не получали перед госпитализацией & 4,0 \\
\hline
\end{tabular}




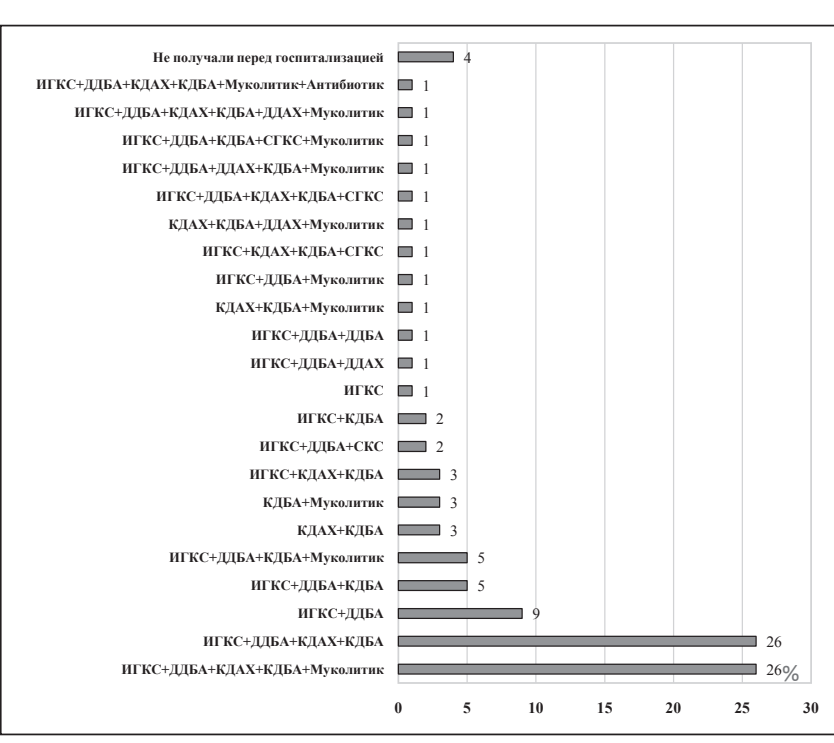

Рисунок 3. Распределение текарственных средств, которые получали больные БА до госпитализачии, по фармакотогическим группам $(n=100)$. Сокращения в тексте.

Большинство пациентов получали вполне адекватную терапию, тем не менее были госпитализированы с обострением. Возможным объяснением этого факта стал результат проведения теста комплаентности Мориски-Грина, согласно которому только 42 \% имели адекватное терапевтическое сотрудничество (таблица 2). Чаще всего ( 45 \%) пациенты просто забывали вдохнуть препарат.

Таблииа 2

Тест комплаентности Мориски-Грина (n=100)

\begin{tabular}{|l|c|}
\hline Были комплаентными больными & $42 \%$ \\
\hline Забывали принять препараты & $45 \%$ \\
\hline Не использовали препарат в назначенное время & $37 \%$ \\
\hline $\begin{array}{l}\text { Пропускает приём препарата, если хорошо себя } \\
\text { чувствует }\end{array}$ & $33 \%$ \\
\hline $\begin{array}{l}\text { Если чувствует себя плохо, после приёма лекарства, } \\
\text { пропускает следующий приём }\end{array}$ & $16 \%$ \\
\hline
\end{tabular}

В стационаре лечение больных было модифицировано и усилено. 70 \% получали бронхолитики короткого действия через небулайзер (14\% - оригинальный сальбутамол, $53 \%$ - ипратропий/фенотерол (30 \% оригинальный и $23 \%$ - генерический) и $3 \%$ - генерический ипратропий/сальбутамол. Одному больному 69 лет со стажем курения 60 пачка-лет была назначена оригинальная фиксированная комбинация индакатерола и гликопиррония через ДПИ. В 68 \% случаев больным внутривенно вводили раствор эуфиллина отечественного производства. Системные ГКС были назначены 83 \% пациентов (70 \% - преднизолон, $12 \%$ - дексаметазон и $1 \%$ - метилпреднизолон). Ингаля- ционные ГКС получали 76 \% больных (53 \% - будесонид (45\% оригинальный, $8 \%$ - генерический), 13 $\%$ - генерический беклометазона дипропионат), 43 \% - через небулайзер, 13 \% - через ДАИ, 20 \% - через ДПИ. 23 \% больным при госпитализации были назначены антибиотики: цефалоспорины III генерации - 10 $\%$, макролиды - $8 \%$, фторхинолоны II генерации - 3 $\%$, тетрациклины - $2 \%$. Все препараты были не оригинальными.

Полученные данные согласуются с работами других отечественных авторов. Так, ранее было показано, что ДН при БА определяется не сатурацией, а состоянием вентиляционной способности лёгких [13]. В нашем исследовании ОФВ 1 была снижена у 32 \% пациентов, тогда как снижение насыщения крови кислородом было только у 11 \% больных. В большинстве случаев проводимая терапия соответствовала современным представлениям о лечении БА $[14,15]$.

\section{Заключение}

Представленный анализ 100 больных БА, последовательно поступавших в стационары г. Казани, показал, что во всех случаях госпитализация была обоснованной, поскольку была связана с обострением. Состояние больных оставалось неоднородным в течение суток. Назначенная до госпитализации терапия была в большинстве случаев адекватна состоянию больных, значительная часть пациентов получали льготное лекарственное обеспечение, однако только $42 \%$ из них имели хорошее терапевтическое сотрудничество перед поступлением. Кроме того, 20 $\%$ больных не были в достаточной степени обучены технике применения ингаляционных лекарственных средств, и только $9 \%$ отметили, что контроль техники ингаляций медработники регулярно проверяли и корректировали. Модификация и усиление терапии при госпитализации также соответствовали отечественным и международным рекомендациям. Проведённая работа показала, с одной стороны, что амбулаторная и стационарная помощь больным БА, поступающим в стационары г. Казани, адекватна современным положениям медицины. Значительную часть препаратов стали составлять генерические лекарственные средства, без снижения эффективности терапии. В то же время выявлены возможные пути улучшения контроля над БА, которые состоят в повышении образования больных в вопросах терапии, необходимости регулярной базисной терапии (повышения комплаентности), а также в обучении и регулярном контроле техники ингаляции из различных устройств.

\section{Литература}

1. Global Strategy for Asthma Management and Prevention. Global Initiative for Asthma (GINA). Updated 2017 [Internet]. Available: http://ginasthma.org. 
2. Чучалин АГ, Айсанов 3Р, Белевский АС, Бушманов АЮ, Васильева ОС, Волков ИК, Геппе НА, Княжеская НП, Кондюрина ЕГ, Колосова НГ, Мазитова НН, Малахов АБ, Мещерякова НН, Ненашева НМ, Ревякина ВА, Шубин ИВ Российское респираторное общество. Федеральные клинические рекомендации по диагностике и лечению бронхиальной астмы, 2016 [Интернет]. Доступно: http: // www.spulmo.ru.

3. Федосеев ГБ, Трофимов ВИ, Шайлиева ВГ, Елисеева МВ, Крякунов КН Многоликая бронхиальная астма - фенотипы и клинико-патогенетические варианты. Российский аллергологический журнал. 2012;1:50-7.

4. Овсянникова ЛВ, Петров ДВ Бронхиальная астма в Омской области: динамика показателей заболеваемости и распространённости. Омский научный вестник. 2015;1(138):18-20.

5. Титова ОН, Куликов ВД Динамика показателей заболеваемости бронхиальной астмой взрослого населения Санкт-Петербурга. Медищинский альянс. 2017;1:59-67.

6. Хабриев РУ, Аринина ЕЕ, Рашид МА. Эпидемиологическое бремя хронической обструктивной болезни лёгких и бронхиальной астмы в РФ. Современная организачия текарственного обеспечения. 2015;4:1931.

7. Вафин АЮ, Визель АА, Шерпутовский ВГ, Лысенко ГВ, Колгин РА, Визель ИЮ, Шаймуратов РИ, Амиров НБ. Заболевания органов дыхания в Республике Татарстан: многолетний эпидемиологический анализ. Вестник современной клинической медицины. 2016;9(1):24-31.

8. Чучалин АГ. Бронхиальная астма: новые перспективы в терапии. Казанский медицинский журнал. 2011;92(5):676-84.

9. Невзорова ВА, Майстровская ЮВ, Коновалова ЕН, Лукьянов ПА, Чикаловец ИВ. Современные технологии в лечении и реабилитации больных бронхиальной астмой. Тихоокеанский медицинский журнал. 2001;1:25-37.

10. Овсянников НВ, Антонов НС, Ляпин ВА, Шукиль ЛВ. Бронхиальная астма в промышленном регионе: фармакоэпидемиологические аспекты. Фармаиия. 2012;6:31-4.

11. Кулбаисов АМ, Полумордвинцев ТВ, Жестков AВ. Фармакотерпия больных бронхиальной астмой: проблемы и возможные пути их решения. Вестник современной клинической медииины. 2017;10(3):18-23. DOI: 10.20969/VSKM.2017.10(3).18-23.

12. Демко ИВ, Гордеева НВ, Бочанова ЕН, Крапошина АЮ, Соловьева ИА, Гайгольник ТВ. Анализ лекарственного обеспечения больных бронхиальной астмой в Красноярском крае. Современные проблемы науки и образования. 2016;5:167-72.

13. Анисимов ДА, Гончарова ЛН, Дьячкова АА. Ана- лиз диагностических параметров дыхательной недостаточности у больных бронхиальной астмой. Самарский научный вестник. 2015;2(11):10-12.

14. Лещенко ИВ, Эсаулова НА. Бронхиальная астма: современные вопросы базисной терапии (в помощь практическому врачу). РМЖ. 2015;18:1074-79.

15. Лещенко ИВ, Баранова ИИ. Выбор базисной терапии бронхиальной астмы в реальной клинической практике. Терапевтический архив. 2015;3:92-97.

\section{References}

1. Global Strategy for Asthma Management and Prevention. Global Initiative for Asthma (GINA). Updated 2017 [Internet]. Available: http://www.ginasthma.org

2. Chuchalin AG, Aisanov ZR, Belevskiy AS, Bushmanov AYu, Vasileva OS, Volkov IK, Geppe NA, Knyazheskaya NP, Kondyurina EG, Kolosova NG, Mazitova NN, Malakhov AB, Meshcheryakova NN, Nenasheva NM, Revyakina VA, Shubin IV Russian respiratory society. Federal clinical recommendations for diagnosis and treatment of bronchial asthma, 2016 [Internet]. Available: http:// spulmo.ru. (In Russian).

3. Fedoseev GB, Trofimov VI, Shaylieva VG, Eliseeva MV, Kryakunov KN The many faces of asthma-phenotypes and clinical pathogenetic variants. Rossijskij allergologicheskij zhurnal. 2012;1:50-5. (In Russian)

4. Ovsyannikova LV, Petrov DV Bronchial asthma in the Omsk region: Dynamics of morbidity and prevalence. Omskij nauchnyj vestnik. 2015;1(138):18-20. (In Russian).

5. Titova ON, Kulikov VD Trends of incidence of bronchial asthma in the adult population of St. Petersburg. Medicinskij al'jans. 2017;1:59-67. (In Russian)

6. Habriev RU, Arinina EE, Rashid MA. Epidemiological burden of chronic obstructive pulmonary diseases and bronchial asthma in RF. Sovremennaja organizacija lekarstvennogo obespechenija. 2015;4:19-31. (In Russian)

7. Vafin AJu, Vizel' AA, Sherputovskiy VG, Lysenko GV, Kolgin RA, Vizel' IYu, Shaymuratov RI, Amirov NB Respiratory diseases in the Republic of Tatarstan: longterm epidemiological analysis. Vestnik Sovremennoi Klinicheskoi Mediciny [The Bulletin of Contemporary Clinical Medicine]. 2016;9(1):24-31. (In Russian)

8. Chuchalin AG Bronchial asthma: new perspectives in therapy. Kazan Medical Journal. 2011;92(5):676-684. (In Russian)

9. Nevzorova VA, Maystrovskaya YuV, Konovalova EN, Luk'yanov PA, Chikalovets IV. Modern technologies in the treatment and rehabilitation of patients with bronchial asthma. Tihookeanskij medicinskij zhurnal. 2001;1:25-37. (In Russian)

10. Ovsyannikov NV, Antonov NS, Lyapin VA, Shukil' LV. Bronchial asthma in the industrial region: pharmacoepidemiological aspects. 2012;6:31-4. (In Russian)

11. Kulbaisov AM, Polumordvintsev TV, Zhestkov AV. 
Pharmacotherapy of the patients with bronchial asthma: problems and possible solutions. Vestnik Sovremennoi Klinicheskoi Mediciny [The Bulletin of Contemporary Clinical Medicine]. 2017;10(3):18-23. DOI: 10.20969/ VSKM.2017.10(3).18-23. (In Russian)

12. Demko IV, Gordeeva NV, Bochanova EN, Kraposhina AYu, Solovieva IA, Gaygol'nik TV. Analysis of drug supply patients with bronchial asthma in Krasnoyarsk region. Sovremennye problemy nauki i obrazovanija. 2016; 5:167-72. (In Russian)

13. Anisimov DA, Goncharova LN, D'yachkova AA. Analysis of diagnostic parameters of respiratory failure in patients with bronchial asthma. Samarskij nauchnyj vestnik. 2015;2(11):10-12. (In Russian)

14. Leshchenko IV, Esaulova NA. Bronchial asthma: current issues of basic therapy (to help the practical doctor). RMJ. 2015;18:1074-1079. (In Russian)

15. Leshchenko IV, Baranova II. The choice of the basic therapy of bronchial asthma in real clinical practice. Terapevticheskij arhiv. 2015;3:92-7. (In Russian)

\section{Сведения об авторах}

Визель Александр Андреевич, Казанский государственный медииинский университет; адрес: Российская Федерация, 420012, г. Казань, ул. Бутлерова, 49; тел.: +7(843)2360652; e-mail:lordara@inbox.ru
Вафина Аделя Рустемовна, Казанский государственный медииинский университет; адрес: Российская Федеращия, 420012, г. Казань, ул. Бутлерова, 49; тел.: +7(843)2360652; e-mail: adelyavafina@gmail.com

Визель Ирина Юрвевна, Казанский государственный медицинский университет; адрес: Российская Федеращия, 420012, г. Казань, ул. Бутлерова, 49; тел.: +7(843)2360652; e-mail: tatpulmo@mail.ru

Салахова Ирина Николаевна, Казанский государственный медииинский университет; адрес: Российская Федеращия, 420012, г. Казань, ул. Бутлерова, 49; тел.: +7(843)2360652; e-mail: iboroznova@gmail.com

Дьякова Екатерина Валерьевна, Республиканская клиническая больница; адрес: Российская Федеращия, 420064, г. Казань, Оренбургский тракт, 138; тел.: +7(843)2312158; e-mail:vrkaty.dyakowa@yandex.ru

Кудрявиева Эльвира Зуферовна, 16-я городская клиническая больниия; адрес: Российская Федеращия, 420039, г. Казань, ул. Гагарина, 121; тел.: +7(843)5426612; e-mail:elk-a@inbox.ru

\section{Information about the authors}

Vizel Alexander A., Kazan State Medical University; Address: 49, Butlerov str., Kazan, Russian Federation, 420012; Phone: +7(843)2360652; e-mail: lordara@inbox.ru

Vafina Adelia R., Kazan State Medical University; Address: 49, Butlerov str., Kazan, Russian Federation, 420012; Phone: +7(843)2360652; e-mail:adelyavafina@gmail.com

Vizel Irina Yu., Kazan State Medical University; Address: 49, Butlerov str., Kazan, Russian Federation, 420012; Phone:+7(843)2360652; e-mail: tatpulmo@mail.ru

Salakhova Irina N., Kazan State Medical University; Address: 49, Butlerov str., Kazan, Russian Federation, 420012; Phone: +7(843)2360652; e-mail: iboroznova@gmail.com

Dyakova Ekaterina V., Republican Clinical Hospital; Address: 138, Orenburgskyi trakt, Kazan, Russian Federation, 420064; Phone: +7(843)2312158; e-mail: vrkaty.dyakowa@yandex.ru

Kudryavtseva Elvira Z., 16-city Clinical Hospital; Address: 121, Gagarin str., Kazan, Russian Federation, 420039; Phone: +7(843)5426612; e-mail: elk-a@inbox.ru

Поступила 22.08.2017 2. Принята к печати 13.09.2017 2.

( С СЕРГЕЕВА И. В, ДЕМКО И. В., КОРЧАГИН Е. Е.

DOI: 10.20333/2500136-2017-5-47-53.

УДК 616.24-002.14

\section{КЛИНИКО-ЛАБОРАТОРНАЯ ХАРАКТЕРИСТИКА БОЛЬНЫХ ВНЕБОЛЬНИЧНЫМИ ПНЕВМОНИЯМИ НА ФОНЕ ГРИППА А(Н1N1)PDМ09}

\section{И. В. Сергеева ${ }^{1}$, И. В. Демко ${ }^{12}$, Е. Е. Корчагин ${ }^{12}$}

${ }^{1}$ Красноярский государственный медицинский университет имени профессора В.Ф. Войно-Ясенецкого, Красноярск 660022, Российская Федерация

${ }^{2}$ Краевая клиническая больница, Красноярск 660022, Российская Федерация

Цель исследования. Изучить клинико-лабораторные особенности течения внебольничной пневмонии на фоне гриппа A(H1N1)pdm09.

Материал и методы. В статье приведены особенности течения внебольничных пневмоний на фоне гриппа A(H1N1)pdm09 у 169 больны в период с 2009 по 2016 гг., в возрасте от 18 до 85 лет. Диагноз внебольничной пневмонии верифицировался на основании клинико-эпидемиологических данных в момент поступления в стационар; рентгенологических и лабораторных методов диагностики. Критериями тяжести течения являлись: степень дыхательной недостаточности, выраженность интоксикационного синдрома, объем воспалительной инфильтрации, наличие осложнений, декомпенсация сопутствующих заболеваний.

Результаты. У 96 (56,8 \%) больных регистрировалась тяжелая внебольничная пневмония, у 73 больных (43,2\%) - нетяжелая внебольничная пневмония. Течение внебольничных пневмоний на фоне гриппа A(H1N1)pdm09 у обследованных нами больных характеризовалось острым началом, проявлялось выраженным интоксикационным синдромом и поражением дыхательных путей, степень проявления которого зависела от тяжести заболевания. В 56,8 \% случаях пневмонии протекали с тяжелым течением, преимущественно у молодых людей 18-29 лет, имеющих отягощенный преморбидный фон с преобладанием метаболического синдрома, что и определило ведущую роль в развитии тяжелого течения пневмонии на фоне гриппа A(H1N1)pdm09. По данным рентгенологического обследования у больных с тяжелыми пневмониями чаще диагностировались двусторонние пневмонии (64,6 \%) с тотальным и долевым поражением, в группе больных с нетяжелым течением пневмонии преобладали односторонние пневмонии (83,5 \%), с преимущественной локализацией в правом легком (68,5 \%).Особенностью гематологических параметров при тяжелом течение пневмонии был незначительный лейкоцитоз с тромбоцитопенией, которые нарастали в зависимости от дня поступления в стационар. В биохимических параметрах при тяжелой пневмонии отмечалось повышение СРБ, креатинина, АсТ, КФК, снижение общего белка, что расценивалось как проявление полиорганной недостаточности на фоне эндогенной интоксикации. 
Заключение. Таким образом, внебольничные пневмонии на фоне гриппа $\mathrm{A}(\mathrm{H} 1 \mathrm{~N} 1) \mathrm{pdm} 09$ протекают в тяжелой форме, в основе которой лежит синдром выраженного системного воспалительного ответа.

Ключевые слова: грипп A(H1N1)pdm09, внебольничная пневмония, пациенты, тяжесть течения, преморбидный фон, лабораторные методы диагностики.

Для иитирования: Сергеева ИВ, Демко ИВ, Корчагин ЕЕ. Клинико-лабораторная характеристика больных внебольничными пневмониями на фоне гриппа A(H1N1)pdm09. Сибирское медицинское обозрение. 2017;(5): 47-53. DOI: 10.20333/2500136-2017-5-47-53.

\section{CLINICAL-LABORATORY CHARACTERISTICS OF PATIENTS WITH EXTRAMURAL PNEUMONIA AGAINST THE BACKGROUND OF FLU A(H1N1)PDM09}

I. V. Sergeeva ${ }^{1}$ I. V. Demko ${ }^{12}$, E. E. Korchagin ${ }^{12}$

${ }^{1}$ Professor V. F. Voino-Yasenetsky Krasnoyarsk State Medical University, Krasnoyarsk 660022, Russian Federation

${ }^{2}$ Krasnoyarsk Regional Clinical Hospital, Krasnoyarsk 660022, Russian Federation

The aim of the research. To study the clinical and laboratory features of the course of community-acquired pneumonia against the background of flu $\mathrm{A}(\mathrm{H} 1 \mathrm{~N} 1) \mathrm{pdm} 09$.

Material and methods. The article presents the features of the course of community-acquired pneumonia against the background of influenza $\mathrm{A}(\mathrm{H} 1 \mathrm{N1})$ pdm09 in 169 patients between 2009 and 2016, aged 18 to 85 years old. The diagnosis of community-acquired pneumonia was verified on the basis of clinical and epidemiological data at the time of admission to the hospital; X-ray and laboratory diagnostic methods. Criteria for the severity were: the degree of respiratory failure, the severity of the intoxication syndrome, the volume of inflammatory infiltration, the presence of complications, the decompensation of concomitant diseases.

Results. In 96 (56.8\%) patients, severe community-acquired pneumonia was registered, 73 patients (43.2\%) had non-severe community-acquired pneumonia. The course of community-acquired pneumonia on the background of influenza A(H1N1)pdm09 in the patients examined by us was characterized by an acute onset, manifested by a severe intoxication syndrome and lesions of the respiratory tract, the degree of manifestation of which was depended on the severity of the disease. In $56.8 \%$ of cases, pneumonia occurred with severe course, mainly in young people aged 18-29 years old with a burdened premorbid background with a predominance of metabolic syndrome, which determined the leading role in the development of severe pneumonia with influenza A (H1N1) pdm09. According to the X-ray examination in patients with severe pneumonia, bilateral pneumonia was more often diagnosed (64.6\%) with total and fractional lesion, unilateral pneumonia prevailed in the group of patients with moderate pneumonia (83.5\%), with predominant localization in the right lung (68 , 5\%). A feature of hematological parameters in severe pneumonia was a slight leukocytosis with thrombocytopenia, which increased depending on the day of admission to the hospital. In biochemical parameters in severe pneumonia, there was an increase in CRP, creatinine, AsT, CPC, a decrease in total protein, which was regarded as a manifestation of multiple organ failure in the context of endogenous intoxication.

The conclusion. Thus, out-of-hospital pneumonia against the background of influenza A (H1N1) pdm09 occurs in severe form, which is based on the syndrome of a pronounced systemic inflammatory response.

Key words: influenza A(H1N1)pdm09, extramural pneumonia, patients, severity of the course, premorbid background, laboratory diagnostic methods. Citation: Sergeeva IV, Demko IV, Korchagin EE. Clinical-laboratory characteristics of patients with extramural pneumonia against the background of FLU A(H1N1)pdm09. Siberian Medical Review. 2017; (5): 47-53. DOI: 10.20333/2500136-2017-5-47-53.

\section{Введение}

Эпидемия гриппа в 2009г., вызванная новым вирусом гриппа A(H1N1)pdm09, отличалась от предыдущих эпидемий ранним началом (октябрь месяц), значительной интенсификацией и продолжительностью эпидемического процесса $[1,2]$. Тип гриппа A(H1N1)pdm09 был обнаружен у 40,7 \% больных [1, 2]. Учитывая изменения в структурном белке гемагглютинина вируса гриппа A(H1N1)pdm09 и отсутствие у населения иммунитета к этому типу вируса, наблюдалось пандемическое распространение инфекции $[1,2]$. Грипп A(H1N1)pdm09, кроме своей высокой контагиозности, отличается от сезонного гриппа повышенным развитием осложненных форм, среди которых преобладают внебольничная пневмония и острая дыхательная недостаточность [3-6]. Внебольничная пневмония при гриппе составляет до 65 \% всех осложнений [7-9]. Пандемический вирус гриппа A(H1N1) pdm09 отличается по своей патогенности от сезонного способностью инфицировать нижние дыхательные пути и вызывать быстропрогрессирующую пневмонию, особенно у лиц молодого возраста [10-13]. Учитывая эти особенности, в диагностике поражения легочной ткани при гриппе имеют большое значение лучевые методы исследования $[14,15]$.

\section{Материал и методы}

Методом проспективного наблюдения в исследование были включены 169 больных в возрасте от 18 до 85 лет с верифицированным гриппом A(H1N1)pdm09, течение которого осложнилось пневмонией с 2009 по 2016 гг. Обследование и лечение проводилось на базах инфекционного и пульмонологических отделений КГБУЗ «Красноярская межрайонная клиническая больница скорой медицинской помощи имени Н.С. Карповича» и КГБУЗ «Краевая клиническая больница» г. Красноярска. Обяза- 
тельным критерием включения являлось отсутствие вторичного инфицирования другими вирусами гриппа.

Диагноз внебольничной вирусно-бактериальной пневмонии верифицировался на основании клинико-эпидемиологических данных в момент поступления в стационар; рентгенологических и лабораторных методов диагностики. Критериями тяжести течения являлись: степень дыхательной недостаточности, выраженность интоксикационного синдрома, объем воспалительной инфильтрации, наличие осложнений, декомпенсация сопутствующих заболеваний.

Лабораторная диагностика гриппа проводилась молекулярно-биологическим (ПЦР) методом.

В ходе обследования, согласно тяжести течения Заболевания, были определены следующие группы больных:

1 группа - 96 (56,8+3,8 \%) больных с тяжелыми внебольничными пневмониями на фоне гриппа A(H1N1)pdm09,

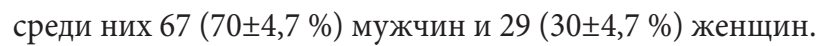

2 группа - 73 (43,2 $\pm 3,8 \%$ ) больных с внебольничной пневмонией, средней степени тяжести на фоне гриппа $\mathrm{A}(\mathrm{H} 1 \mathrm{~N} 1)$ pdm09, среди них $45(61,6 \pm 5,7 \%)$ мужчин и $28(38,4 \pm 5,7 \%)$ женщин.

Статистическую обработку полученных результатов проводили с использованием программы Statistica 6.0 (StatSoft Inc., США) в соответствии с принципами доказательной медицины. Проверка данных на нормальность распределения производилась визуально по гистограмме и с использованием теста Колмогорова-Смирнова. Количественные параметры при нормальном распределении приведены в виде средней арифметической $(\mathrm{M})$ и средней ошибки средней $(\mathrm{m})$. Для анализа различий при нормальном распределении данных применяли критерий $\mathrm{t}$ Стьюдента. Если распределение существенно отличалось от нормального, использовали непараметрические методы: для сравнения независимых выборок - критерий Манна-Уитни. Значимость различий качественных показателей определяли с помощью критерия $\chi 2$. Различия считали достоверными при вероятности $\mathrm{p}<0,05$ ( $>95 \%)$.

\section{Результаты и обсуждение}

Из общего числа наблюдаемых подавляющее большинство

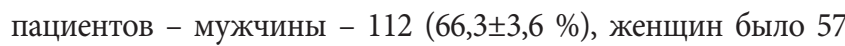
$(33,7 \pm 3,6 \%)$. Как среди мужчин, так и среди женщин, в группе обследованных преобладали лица молодого возраста - от 18 до 29 лет - 88 (52 $\pm 3,8 \%)$.

Среди обследованных вакцинированных от гриппа не было.

При сборе анамнеза жизни подавляющее большинство пациентов 1-й группы отмечали частые ОРВИ (более 4 раз за год), хронические тонзиллиты с обострением (более 2

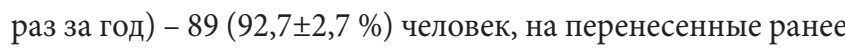
пневмонии указали 23 (24 4,4 \% пациентов), а во 2-й группе таких пациентов было $11(15 \pm 4,2 \%)$ человек.

У $128(75,7 \pm 3,3$ \%) обследованных пациентов выявлен отягощенный преморбидный фон. Наиболее часто встречались: метаболический синдром, бронхолегочная и сердечно-сосудистая патология. Значимого влияния премор- бидного фона на тяжесть течения внебольничной пневмонии выявлено не было, за исключением ожирения. Следует отметить, что ожирение регистрировалось у 61 (63,5 $\pm 4,9 \%)$ пациента с тяжелым течением пневмонии и у $13,7 \pm 4,0$ \% пациентов 2-й группы ( $<<0,05)$.

При анализе длительности заболевания, обращает внимание позднее поступление в стационар. Так, независимо от тяжести течения пневмонии пациенты были госпитализированы на 5,6 $\pm 2,3$ день.

Из анамнеза известно, что у всех пациентов заболевание начиналось остро с повышения температуры тела, симптомов интоксикации (озноб, головная боль, головокружения, боли в глазах, «ломота в теле») и катаральных явлений (сухой надсадный кашель, заложенность носа и (или) насморк, першение в горле и боль при глотании).

Анализ характера и частоты клинических признаков показал, что жалобы в обследуемых группах носят схожий характер, но достоверно различаются по степени выраженности. Так, жалобы на повышение температуры предъявляли все обследуемые пациенты. При этом у пациентов 1-й группы преобладала гипертермическая лихорадка (54,2 $\pm 5,1$ \%). В группе нетяжелой пневмонии одинаково часто наблю-

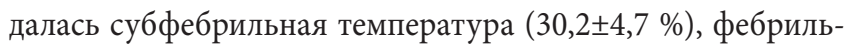
ная температура $(34,2 \pm 4,8 \%)$ и гипертермическая лихорадка $(35,6 \pm 4,9 \%)$. Длительность лихорадки у больных 1 -й группы (тяжелое течение пневмонии) составляла 6,07 $\pm 0,41$ суток, а у пациентов 2-й группы (нетяжелое течение пнев-

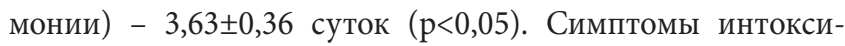
кации (общая слабость, головокружение, головная боль)

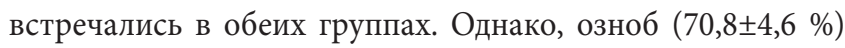
достоверно чаще выявлялся при тяжелом течении вирусно-бактериальной пневмонии $(\mathrm{p}<0,05)$. Жалобы на кашель предъявляли все обследуемые пациенты. Непродуктивный кашель регистрировался в группе нетяжелой пневмонии у $61(83,6 \pm 4,3$ \%) пациента. На продуктивный кашель жаловались 52 (54 $55,1 \%)$ больных в группе с 1-й группе. При наличии продуктивного кашля у пациентов обеих групп преобладало выделение мокроты слизистого и слизисто-гнойного характера. Однако количество пациентов со слизистой мокротой достоверно больше было в группе с нетяжелым течением вирусно-бактериальной пневмонии - 35 (48 $\pm 5,8$ $\%)$ человек, чем в группе с тяжелым течением - $21(22 \pm 4,8$ $\%)$ человек $(\mathrm{p}<0,05)$. Слизисто-гнойная и гнойная мокрота достоверно чаще выявлялась у пациентов с тяжелым течением $(38(39,6 \pm 5,0 \%)$ и $15(15,6 \pm 3,7 \%)$ больных против 14 $(19 \pm 4,6 \%)$ и $3(4,2 \pm 2,3 \%)$ человек с пневмонией средней степени тяжести соответственно, $\mathrm{p}<0,05)$. Кровохарканье определялись только у больных с тяжелой пневмонией -8 $(8,2 \pm 2,8 \%)$ человек.

Особенностью перкуссии и аускультации пациентов с тяжелым течением пневмонии в сравнении с группой нетяжелых пневмоний явилось более часто определяемое укорочение перкуторного звука (65,6 $\pm 4,8 \%$ против $38,3 \pm 5,7$ $\%$; $<<0,05)$, жесткое дыхание $(73,9 \pm 4,5$ \% против $41 \pm 5,8$ \%; 
$\mathrm{p}<0,05)$ и крепитация $(18,7 \pm 4,0 \%$ против $5,5 \pm 2,7 \%$; $<<0,05)$.

Всем больным при поступлении в стационар выполнялась микроскопическое и бактериологическое исследование мокроты. У больных с пневмониями тяжелого течения отмечалось увеличение содержания в мокроте лейкоцитов и альвеолярных макрофагов в сравнении с группой нетяжелых пневмоний. При бактериоскопии мокроты микрофлора была обнаружена чаще у пациентов с тяжелым течением пневмонии (76 $\pm 4,4$ \% случаев) в сравнении с группой пациентов с нетяжелым течением - у 54,8 $\pm 5,8 \%$ ( $<<0,05)$. При этом верификация возбудителя была в концентрации от $10^{6}$ до $10^{8} \mathrm{KOE} /$ мл. Этиологически значимым возбудителем у пациентов в обеих группах был Streptococcus pneumoniae $(32,4 \pm 4,8 \%$ и $31,5 \pm 5,4 \%$ случаев, соответственно). Вторым по частоте регистрировался возбудитель Staphylococcus aureus (15,5 $\pm 3,7 \%$ и 9,7 $\pm 3,5 \%$, соответственно), реже определялся Streptococcus pyogenies - 8,3 $\pm 2,8 \%$ и 6,8 $22,9 \%$, соответственно. Ассоциация микроорганизмов (Streptococcus pneumoniae + Staphylococcus aureus) выявлялась чаще у пациентов с тяжелым течением пневмонии (19,8 $\pm 4,1 \%$ случаев против 6,8 2,9 \% случаев во 2-й группе, $\mathrm{p}<0,05)$. Следует отметить, что проведенный нами бактериологический анализ подтвердил доминирующую роль Streptococcus pneumoniae в развитии внебольничной пневмонии. Кроме этого, по результатам нашего исследования, выявлено увеличение роли ассоциация микроорганизмов (Streptococcus pneumoniae + Staphylococcus aureus) в развитии тяжелого течения пневмонии. Результаты исследования мокроты на антибиотикограмму показали чувствительность к оксациллинам $(98,6 \pm 0,9 \%)$, цефалоспоринам III-IV поколений $(91,3 \pm 2,2 \%)$, карбапенемам $(95,9 \pm 1,5 \%)$.

По данным рентгенологического обследования выявлены различия в локализации и характере поражения легочной ткани в обследуемых группах. У пациентов 1-й группы диагностировались двусторонние пневмонии - 62 (64,6士4,9 $\%)$ пациентов. Объем инфильтрации легочной ткани в этой группе характеризовался преобладанием долевой пневмонии - 56,2 $\pm 5,1 \%$ случаев $(\mathrm{p}<0,05)$. У пациентов с нетяжелым течением пневмонии, достоверно чаще выявлялись односторонние пневмонии - 94,5 $\pm 2,7$ \% случаев $(\mathrm{p}<0,05)$. Поражение правого легкого выявлены у 42 (57,5 $\pm 5,8$ \%) па-

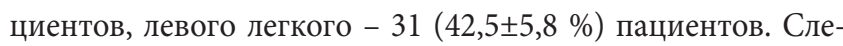
дует отметить, что в группе с нетяжелым течением преобладали полисегментарные пневмонии - 49 (67+5,5 \%) пациентов. Длительность разрешения инфильтрации в группе тяжелых пневмоний составила 18,0 $\pm 0,65$ дней, что было достоверно дольше, чем в группе нетяжелых пневмоний $(13,5 \pm 0,58$ день $)(\mathrm{p}<0,05)$.

При поступлении в стационар у обследуемых пациентов регистрировалась тахикардия. Частота сердечных сокращений, как один из признаков комплексной оценки тяжести течения пневмонии, у пациентов с тяжелым течением пнев-

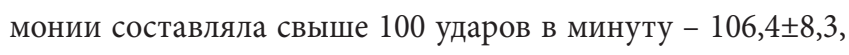
тогда как в группе с нетяжелой пневмонией - до 100 ударов в минуту $(93,2 \pm 4,6)$. Кроме этого, у пациентов с тяжелым течением пневмонии при поступлении в стационар наблюдалось тахипноэ $(29,5 \pm 4,2$ в мин) со снижением сатурации крови кислородом $(78,5 \%)$. Следует отметить, что уровень сатурации кислорода в крови косвенно отражает объем поражения легочной ткани, не участвующей в газообменных процессах.

Следует отметить, что у всех пациентов с тяжелым течением внебольничной пневмонии регистрировались осложнения, наиболее часто встречались: острая дыхательная недостаточность (ОДН) (74 \%) и острый респираторный дистресс-синдром (ОРДС) (65,6 \%). Частота развившихся осложнений у пациентов 1-й группы представлена в таблице 1.

Таблица 1

Частота осложнений вирусно-бактериальной пневмонии, ассоциированной вирусом гриппа $A(H 1 N 1) p d m 09$ (n=96)

\begin{tabular}{|l|c|c|}
\hline \multicolumn{1}{|c|}{ Осложнение } & Абс. & Р $\pm \mathrm{m} \%$ \\
\hline ОДН (II-III степени) & 71 & $74 \pm 11,3 \%$ \\
\hline ОРДС & 63 & $65,6 \pm 13,4 \%$ \\
\hline Септический шок & 49 & $51 \pm 14,8 \%$ \\
\hline Плевральный выпот & 21 & $22 \pm 10,2 \%$ \\
\hline Деструкция легочной ткани & 11 & $11,5 \pm 6 \%$ \\
\hline Инфекционно-токсический миокардит & 7 & $7,3 \pm 4 \%$ \\
\hline
\end{tabular}

Обращает на себя внимание частая комбинация различных осложнений: два осложнения выявлено у $43(44,8 \pm 5,1$ $\%)$ пациентов, три - у $25(26 \pm 4,5 \%)$ пациентов, а вот четыре осложнения (ОДН + ОРДС + плевральный выпот/деструкция легочной ткани + септический шок) - у 13 (13,5 $\pm 3,5$ \%) пациентов. Только одно осложнение регистрировалось у 15 $(15,7 \pm 3,7 \%)$ пациентов.

При поступлении у больных с тяжелым течением пневмонии были выявлены различные изменения в гемограмме (табл. 2).

Таблица 2

Показатели клинического анализа крови больных внебольничными пневмониями на фоне гриппа A(H1N1)pdm09

\begin{tabular}{|l|c|c|c|c|}
\hline \multicolumn{1}{|c|}{ Показатели } & $\begin{array}{c}\text { Значения } \\
\mathrm{N}\end{array}$ & $\begin{array}{c}\text { Тяжелые } \\
\text { пневмонии } \\
(\mathrm{n}=96)\end{array}$ & $\begin{array}{c}\text { Нетяжелые } \\
\text { пневмонии } \\
(\mathrm{n}=73)\end{array}$ & $\begin{array}{c}\text { Статист-ая } \\
\text { значимость } \\
(\mathrm{p})\end{array}$ \\
\hline $\mathrm{L}, 10^{9} /$ л & $4,0-8,0$ & $10,2 \pm 0,14$ & $8,6 \pm 0,37$ & $<0,05$ \\
\hline Эритроциты,1012/л & $3,8-5,0$ & $4,3 \pm 0,53$ & $4,5 \pm 0,62$ & $>0,05$ \\
\hline Hb, г/л & $120-160$ & $143,72 \pm 1,67$ & $143,03 \pm 2,26$ & $>0,05$ \\
\hline Тромбоциты,10\%/л & $180-320$ & $198,9 \pm 64,61$ & $224 \pm 69,47$ & $>0,05$ \\
\hline СОЭ, мм/час & $1-15$ & $35,4 \pm 1,5$ & $23,7 \pm 0,6$ & $<0,05$ \\
\hline Лимфоциты, \% & $19-37$ & $14,38 \pm 0,91$ & $21,89 \pm 1,19$ & $<0,05$ \\
\hline П/я, \% & $1-6$ & $10,79 \pm 0,88$ & $11,24 \pm 1,26$ & $>0,05$ \\
\hline С/я, \% & $47-67$ & $65,99 \pm 1,42$ & $56,46 \pm 1,42$ & $<0,05$ \\
\hline Эозинофилы, \% & $0,5-5$ & $0,46 \pm 0,08$ & $0,70 \pm 0,17$ & $<0,05$ \\
\hline Моноциты, \% & $3-11$ & $8,34 \pm 0,48$ & $9,70 \pm 0,66$ & $>0,05$ \\
\hline
\end{tabular}




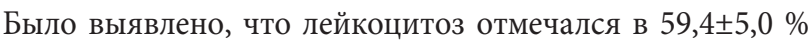

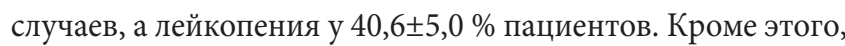
следует отметить, что количество больных с лекоцитозом нарастает в зависимости от дня поступления - чаще лейкоцитоз отмечается при поздней госпитализации (6-ой и более поздний день), а лейкопения была диагностирована у пациентов, которые поступали в первые дни болезни. Тромбоцитоз регистрировался в $31,2 \pm 4,7$ \% случаев, а тром-

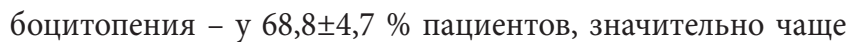
тромбоцитопения выявлялась у пациентов, поступающих в более поздние сроки от начала заболевания. В отличие от группы с тяжелым течением пневмонии, при нетяжелой пневмонии отмечался нормоцитоз у 23,3 $\pm 4,9 \%$ пациентов, а лейкоцитоз преобладал в 57,5 $\pm 5,8$ \% случаев, лейкопения выявлена у 19,2 $\pm 4,6$ \% пациентов. Показатели тромбоцитов в $80,8 \pm 4,6$ \% случаев были в пределах нормы. Преобладание лейкоцитоза и тромбоцитопении у пациентов с тяжелым течением пневмонии при позднем поступлении в стационар (более 6 дней от начала заболевания) связано с присоединением бактериальной флоры.

Общим изменением клинико-лабораторных показателей для всех групп больных при поступлении, вне зависимости от тяжести течения заболевания, явился палочкоядерный сдвиг формулы.

При тяжелом течении вирусно-бактериальной пневмонии было выявлено повышение СОЭ и незначительное повышение лейкоцитов в сравнении с нетяжелым течением $(\mathrm{p}<0,05)$. Анализ изменений клинических показателей крови в группе тяжелой пневмонии выявил выраженную лимфопению $(14,38 \pm 3,6 \%)$ в сравнении с группой нетяжелой пневмонии $(\mathrm{p}<0,05)$.

Анализируя биохимические показатели, был выявлен ряд осбенностей (табл. 3).

Таблииа 3

Показатели биохимического анализа крови больньх внебольничными пневмониями на фоне гриппа A(H1N1)pdm09

\begin{tabular}{|c|c|c|c|c|}
\hline Показатели & $\begin{array}{c}\text { Значения } \\
\mathrm{N}\end{array}$ & $\begin{array}{c}\text { Тяжелые } \\
\text { пневмонии } \\
\text { (n=96) }\end{array}$ & $\begin{array}{c}\text { Нетяжелые } \\
\text { пневмонии } \\
(n=73)\end{array}$ & $\begin{array}{c}\text { Статист-ая } \\
\text { значимость } \\
\text { (р) }\end{array}$ \\
\hline Общий белок, г/л & $66-87$ & $61,3 \pm 4,36$ & $74,8 \pm 3,26$ & $<0,05$ \\
\hline СРБ, г/л & $0-5$ & $12,8 \pm 2,03$ & $10,3 \pm 1,16$ & $>0,05$ \\
\hline $\begin{array}{l}\text { Креатинин, } \\
\text { мкмоль/л, }\end{array}$ & 59-104 & $107,5 \pm 5,18$ & $91,2 \pm 5,24$ & $<0,05$ \\
\hline Мочевина, моль/л, & $1,7-8,3$ & $6,5 \pm 0,89$ & $4,8 \pm 0,87$ & $<0,05$ \\
\hline $\mathrm{K}^{+}$, ммоль/л & $3,5-5,0$ & $4,3 \pm 0,08$ & $4,7 \pm 0,18$ & $>0,05$ \\
\hline $\mathrm{Na}^{+}$, моль/л, & $135-145$ & $137,2 \pm 0,34$ & $143,1 \pm 0,21$ & $>0,05$ \\
\hline $\begin{array}{l}\text { Общий билирубин, } \\
\text { мкмоль/л }\end{array}$ & $3,4-20,5$ & $18,7 \pm 0,19$ & $12,3 \pm 0,16$ & $<0,05$ \\
\hline АлT, ME/ת & до 41 & $30,4 \pm 1,72$ & $19,3 \pm 1,65$ & $<0,05$ \\
\hline AcT, ME/ת & до 38 & $77,3 \pm 1,53$ & $35,1 \pm 1,23$ & $<0,05$ \\
\hline КФК, МЕ/л & $10-195$ & $202,3 \pm 3,34$ & $164,7 \pm 3,55$ & $<0,05$ \\
\hline
\end{tabular}

У пациентов в обеих группах наблюдалось повышение содержания СРБ в периферической крови $(12,8 \pm 2,03$ г/л и 10,3 $\pm 1,16$ г/л, соответственно). В динамике заболевания содержание СРБ имело тенденцию к снижению с нормализацией показателей к 10 дню госпитализации, статистических отличий между группами не было.

При тяжелых пневмониях показатель АсТ в периферической крови превышал референсные значения в среднем в 2 раза. Во 2-й группе показатели АсТ регистрировалась в пределах нормы. Показатели АлТ у обследуемых пациентов находились в нормальных пределах. Кроме этого у пациентов с тяжелой пневмонией отмечалось повышение пока-

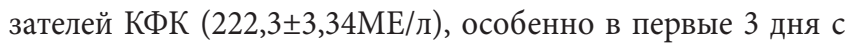
момента госпитализации, в период реконвалесценции достигли уровня нормы.

Значительное повышение КФК, а также АсТ и коэффициента де Ритиса, вероятнее всего, может свидетельствовать о повреждении мышечной ткани при тяжелом течении внебольничной пневмонии на фоне гриппа $\mathrm{A}(\mathrm{H} 1 \mathrm{~N} 1) \mathrm{pdm} 09$, что подтверждается клиническими наблюдениями - именно в группе с тяжелым течением наиболее часто регистрировались изменения в миокарде с нарушением процессов реполяризации по данным ЭКГ, кроме этого, в 7,3 $\pm 2,7$ \% случаев диагностирован инфекционно-токсический миокардит.

Вместе с тем, при тяжелой пневмонии отмечалось снижение общего белка $(61,3 \pm 4,36$ г/л) в разгар заболевания.

Таким образом, выявленные изменения биохимических показателей крови у пациентов с тяжелым течением вирусно-бактериальной пневмонии можно расценить как проявление полиорганной недостаточности на фоне эндогенной интоксикации. У пациентов с нетяжелым течением вирусно-бактериальной пневмонией биохимические показатели крови были в пределах нормы, за исключением СРБ. Изменения гематологических и биохимических показателей крови в группе тяжелых пневмоний подтверждают тяжесть течения заболевания, которые согласуются с клиническими проявлениями.

\section{Заключение}

Течение внебольничных пневмоний, ассоциированных вирусом гриппа A(H1N1)pdm09, у обследованных нами пациентов характеризовалось острым началом и проявлялось выраженным интоксикационным синдромом и поражением дыхательных путей, степень проявления которых зависела от тяжести заболевания.

В $73 \pm 4,5$ \% случаях тяжелое течение пневмонии диагностировались у молодых людей, имеющих отягощенный преморбидный фон, среди которого преобладали ожирение и избыточная масса тела $(79,1 \pm 4,1 \%)$, что повышало вероятность развития тяжелой внебольничной пневмонии на фоне гриппа $\mathrm{A}(\mathrm{H} 1 \mathrm{~N} 1) \mathrm{pdm} 09$ в 3 раза.

По данным рентгенологического обследования выявлено, что у пациентов с тяжелыми пневмониями чаще всего диагностировались двусторонние пневмонии $(64,6 \pm 4,9 \%$ ) с 
полисегментарным и долевым поражением, в группе пациентов с нетяжелым течением пневмонии, напротив, преоб-

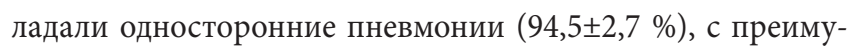

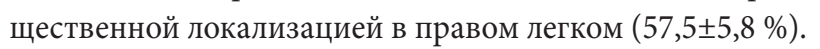

Особенностью гематологических параметров у больных с тяжелым течением пневмонии стало выявление лейкопении у пациентов, поступивших в первые 3 дня от начала заболевания, и незначительного лейкоцитоза с тромбоцитопенией при госпитализации позднее 6 дня от начала заболевания.

Изменения биохимических показателей сыворотки крови в группе пациентов с тяжелым течением пневмонии выявили повышение маркеров клеточного повреждения (креатинин, АсТ, КФК), снижение общего белка и повышение СРБ, что расценивается как проявление полиорганной недостаточности на фоне эндогенной интоксикации.

Таким образом, совокупность вышеперечисленных факторов обуславливало тяжелое течение внебольничной пневмонии на фоне гриппа A(H1N1)pdm09 с увеличением периода разрешения инфильтрации $(18 \pm 0,65$ дня) и длительностью госпитализации до $23,7 \pm 7,3$ дня.

\section{Литература}

1. Цыбалова ЛМ, Покровский ВИ, ред. Грипп: эпидемиология, диагностика, лечение, профилактика. М.: Медицинское Информационное агентство; 2012. 496 с.

2. Малый ВП, Андрейчин МА. Грипп и другие ОРВИ. М.: ГЭОТАР-Медиа; 2012. 320 с.

3. Чучалин АГ, Черняев АЛ, Зайратьянц ОВ, Келли ЕИ, Рогов КА, Михалева ЛМ, Трусов АЕ, Самсонова МВ, Чарторижская НН. Патологическая анатомия легких при гриппе A(H1N1), по данным аутопсий. Пульмонология. 2010;1:5-11.

4. Хамитов РФ, Пальмова ЛЮ, Сулбаева КР. Тяжелые пневмонии в клинической практике. Казанский медицинский журнал. 2016;97(6):994-99. DOI: 10.17750/KMJ2016994.

5. Хамитов РФ, Малова АА, Григорьева ИВ. Лечение внебольничных пневмоний: передикторы летальных исходов. Казанский медииинский журнал. 2014;95(3):356-61.

6. Чучалин АГ. Пневмония: актуальная проблема медицины XXI века. Пульмонология. 2015;25(2):133-42.

7. Говорин АВ, Серебрякова ОМ, Филев АП, Романова ЕН. Клинические особенности внебольничной пневмонии у больных гриппом А/Н1N1. Пульмонология. 2010;(5):27-9.

8. Бун НА. Пульмонология. М.: Рид Элсивер; 2009. 140 с.

9. Мизерницкий ЮЛ. Место макролидов в современной терапии внебольничной пневмонии у детей. Consilium medicum. 2011;13(4):18-21.

10. Горбунов ВВ, Говорин АВ, Лукьянов СА, Романова ЕН. Ранняя диагностика и этиотропная терапия пневмонии во время пандемии гриппа $\mathrm{A}(\mathrm{H} 1 \mathrm{~N} 1)$. Сибирский медииинский журнал. 2011;(7):79-82.

11. Зильбер ЭК. Неотложная пульмонология: руководство. М.: ГЭОТАР-Медиа; 2009. 264 с.
12. Колосов ВП. Внебольничная пневмония (клиническое течение, прогнозирование исходов). Благовещенск; 2012. 124 c.

13. Авдеев СН. Пневмония и острый респираторный дистресс-синдром, вызванные вирусом гриппа A/H1N1. Пульмонология. 2010; Приложение «Грипп А/H1N1: уроки пандемии»:32-46.

14. Лещенко ИВ, Кривоногов АВ. Особенности течения пневмонии при пандемическом гриппе А/H1N1/09. Пульмонология. 2011;(6):62-8.

15. Cunha BA. Swine influenza (H1N1) pneumonia: clinical considerations. Clinical Infectious Diseases. 2010;(24):203-28.

\section{References}

1. Tsybalova LM, Pokrovsky VI, eds. Flu: epidemiology, diagnostics, treatment, prevention. M.: Meditsinskoye informatsionnoye agentstvo; 2012. 496 p. (In Russian)

2. Malyi VP. Andreychin MA. Gripp and other SARS. M.: GEOTAR-Media; 2012. 320 p. (In Russian)

3. Chuchalin AG, Chernyaev AL, Zayratyants OV, Kelly EI, Rogov KA, Mikhaleva LM, Trusov AE, Samsonova MV, Chartorizhskaya NN. Pathological anatomy of lungs at flu A (H1N1), according to autopsies. Pulmonology. 2010;1:5-11. (In Russian)

4. Khamitov RF, Pal'mova LYu, Sulbayeva KR. Heavy pneumonia in clinical practice. Kazan medical journal. 2016;97(6):99499. (In Russian)

5. Khamitov RF, Malova AA, Grigorieva IV. Treatment of extra hospital pneumonia: reannouncers of lethal outcomes. $\mathrm{Ka}$ zan medical journal. 2014;95(3):356-61. (In Russian).

6. Chuchalin AG. Pneumonia: an urgent problem of medicine of the XXI century. Pulmonology. 2015;25(2):133-42. (In Russian)

7. Govorin AV, Serebryakova OM, Filev AP, Romanova EN. Clinical features of community-acquired pneumonia in patients with influenza A / H1N1. Pulmonology. 2010;(5):27-9. (In Russian).

8. Boon HA. Pulmonology. M.: Reed Elsiver; 2009. 140 p. (In Russian)

9. Mizernitsky Yul. Place of macrolides in modern therapy of community-acquired pneumonia in children. Consilium medicum. 2011;13 (4):18-21. (In Russian)

10. Gorbunov VV, Govorin AB, Lukyanov SA, Romanova EN. Early diagnosis and etiotropic therapy of pneumonia during influenza A (H1N1) pandemic. Siberian Medical Journal. 2011;(7):79-82. (In Russian)

11. Zil'ber EC. Emergency pulmonology : guide. M.: GEOTAR-Media; 2009. 264 p. (In Russian)

12. Kolosov VP. Community-acquired pneumonia (clinical course, prognosis of outcomes). Blagoveshchensk; $124 \mathrm{p}$. (In Russian)

13. Avdeev CH. Pneumonia and acute respiratory distress syndrome caused by the influenza A / H1N1 virus. Pulmonology. 2010; Appendix Influenza A / H1N1: Pandemic Lessons:32-46. (In Russian) 
14. Leshchenko IV, Krivonogov AV. Features of the course of pneumonia in pandemic influenza A / H1N1 / 09. Pulmonology. 2011;(6):62-8. (In Russian)

15. Cunha BA. Swine influenza (H1N1) pneumonia: clinical considerations. Clinical Infectious Diseases. 2010;(24):203-28.

\section{Сведения об авторах}

Сергеева Ирина Владимировна, Красноярский государственный медиинский университет имени профессора В.Ф. Войно-Ясенеикого; адрес: Российская Федеращия, 660022, г. Красноярск, ул. Партизана Железняка, д. 1; тел.: +7(391)2469375; e-mail: sergeevaiv-1979@mail.ru

Демко Ирина Владимировна, Красноярский государственный медииинский университет имени профессора В.Ф. Войно-Ясенеиякого; адрес: Российская Федерация, 660022, г. Красноярск, ул. Партизана Железняка, д. 1; тел.: +7(391)2283469; e-mail: demko64@mail.ru

Корчагин Егор Евгеньевич, Краевая клиническая больнииа; адрес: Российская Федера иия, 660022, г. Красноярск, ул. Партизана Железняка, д. 3a; тел.: +7(391)2201623; е-таil: eekor@medgorod.ru

\section{Information about the authors}

Sergeeva Irina V., Professor V. F. Voino-YasenetskyKrasnoyarsk State Medical University; Address: 1, Partizan Zheleznyak Str., Krasnoyarsk, Russian Federation 660022; Phone: $+7(391)$ 2469375; e-mail: sergeevaiv-1979@mail.ru

Demko Irina V., Professor V. F. Voino-YasenetskyKrasnoyarsk State Medical University; Address: 1, Partizan Zheleznyak Str., Krasnoyarsk, Russian Federation 660022; Phone: $+7(391)$ 2283469; e-mail:demko64@mail.ru

Korchagin Egor. E., Krasnoyarsk Regional clinical hospital; Address: 3a, Partizan Zheleznyak Str., Krasnoyarsk, Russian Federation 660022; Phone:+7(391)2201623; e-mail:eekor@medgorod.ru

( ) НАРКЕВИЧ А. Н., ВИНОГРАДОВ К. А., КОРЕЦКАЯ Н. М.

УДК 616-093/-098

DOI: 10.20333/2500136-2017-5-53-59.

\section{ПАРАМЕТРИЗАЦИЯ ОБЪЕКТОВ НА ЦИФРОВЫХ МИКРОСКОПИЧЕСКИХ ИЗОБРАЖЕНИЯХ МОКРОТЫ, ОКРАШЕННОЙ ПО МЕТОДУ ЦИЛЯ-НИЛЬСЕНА}

А. Н. Наркевич ${ }^{1}$, К. А. Виноградов ${ }^{1}$, Н. М.Корецкая ${ }^{2}$

${ }^{1}$ Красноярский государственный медицинский университет имени профессора В.Ф. Войно-Ясенецкого, Красноярск 660022, Российская Федерация

${ }^{2}$ Медико-санитарная часть № 24, Красноярск 660036, Российская Федерация

Цель исследования. Изучение различий объектов, являющихся кислотоустойчивыми микобактериями и иными объектами, и их параметризация для использования при распознавании таких объектов на цифровых микроскопических изображениях мокроты, окрашенной по методу ЦиляНильсена.

Материал и методы. Использовались данные о 343687 объектах, выделенных с использованием разработанных нами алгоритмов на цифровых изображениях микроскопических препаратов мокроты, окрашенной по методу Циля-Нильсена: 6708 объектов кислотоустойчивых микобактерий, 336979 объектов - иные объекты. Сравнение данных объектов производилось по 240 цветовым и морфометрическим параметрам, разделенным на 3 группы: основные морфометрические параметры объектов, радиальные размеры объектов и их соотношения и цветовые параметры объектов.

Результаты. Установлено, чтонаибольшие различия между кислотоустойчивыми микобактериями и иными объектами имеются по основным морфометрическим параметрам, таким как попиксельная площадь, размеры по оси Х и Ү, а также по цветовым параметрам объектов. Показано, что разделение объектов на классы по отдельным изучаемым параметрам довольно затруднительно.

Заключение. Результаты изучения различий кислотоустойчивых микобактерий и иных объектов свидетельствуют о довольно существенных отличиях по основным морфометрическим параметрам объектов: попиксельная площадь и размеры объектов по оси X и $\mathrm{Y}$, а также по различным цветовым параметрам объектов. Существенных отличий изучаемых классов объектов по радиальным размерам объектов и их соотношениям не установлено, однако, различия по данным параметрам требуют дальнейшего изучения с использованием многомерных математических методов анализа.

Ключевые слова: параметризация, бактериоскопическое исследование, кислотоустойчивые микобактерии, выявление, туберкулез легких, анализ изображений.

Для цитирования: Наркевич АН, Виноградов КА, Корецкая НМ. Параметризация объектов на цифровых микроскопических изображениях мокроты, окрашенной по методу Циля-Нильсена. Сибирское медииинское обозрение. 2017;(5): 53-59.DOI: 10.20333/2500136-2017-5-53-59.

\section{PARAMETERIZATION OF OBJECTS ON DIGITAL MICROSCOPIC IMAGES OF SPUTUM,STAINED BY THE ZIEHL-NEELSEN METHOD}

A. N. Narkevich ${ }^{1}$, K. A. Vinogradov ${ }^{1}$, N. M. Koretskaya ${ }^{2}$

${ }^{1}$ Krasnoyarsk State Medical University, Krasnoyarsk 660022, Russian Federation

${ }^{2}$ Medical-sanitary Department № 24, Krasnoyarsk 660036, Russian Federation

The aim of the research. To study the differences in objects that are acid-fast mycobacteria and other objects, and their parametrization for use in the recognition of such objects on digital microscopic images of sputum stained by the Ziehl-Neelsenmethod. 
Material and methods. Data on 343687 objects isolated using the methods developed by us on digital images of microscopic sputum preparations stained using the Ziehl-Neelsenmethod were used: 6708 objects of acid-fast mycobacteria, 336,979 objects - other objects. Comparison of these objects was carried out for 240 color and morphometric parameters, divided into 3 groups: the basic morphometric parameters of objects, the radial dimensions of objects and their relationships and color parameters of objects.

Results. It was found that the greatest differences between acid-fast mycobacteria and other objects are in the main morphometric parameters, such as the pixel area, the $\mathrm{X}$ and $\mathrm{Y}$ axis dimensions, and also the color parameters of the objects. It is shown that the separation of objects into classes according to the individual parameters is rather difficult.

The conclusion. The results of studying the differences in acid-fast mycobacteria and other objects indicate quite significant differences in the main morphometric parameters of objects: the per-pixel area and the size of the objects along the $\mathrm{X}$ and $\mathrm{Y}$ axes, as well as the different color parameters of the objects. There are no significant differences between the studied classes of objects by the radial dimensions of objects and their relationships, however, differences in these parameters require further study using multidimensional mathematical methods of analysis.

Key words: parametrization, bacterioscopy, acid-fast mycobacteria, detection, pulmonary tuberculosis, image analysis.

Citation: Narkevich AN, Vinogradov KA, Koretskaya NM. Parameterization of objects on digital microscopic images of sputum, stained by the ZiehlNeelsen method. Siberian Medical Review. 2017; (5): 53-59.DOI: 10.20333/2500136-2017-5-53-59.

\section{Введение}

В настоящее время микроскопические исследования используются в диагностике большого числа заболеваний. Так, данные исследования используются в диагностике онкологических, эндокринных и инфекционных заболеваний $[1,2,3]$. Одним из инфекционных заболеваний, для диагностики которого также применяется микроскопическое исследование, является туберкулез легких [4]. Микроскопическое или бактериоскопическое исследование, на предмет наличия в мокроте пациентов кислотоустойчивых микобактерий, является практически единственным доступным для общей лечебной сети методом выявления бактериовыделителей больных туберкулезом $[5,6]$.

Качество бактериоскопической диагностики туберкулеза в клинико-диагностических лабораториях общей лечебной сети остается не на должном уровне. Это связано, во-первых, с недостаточной укомплектованностью кадрами клинико-диагностических лабораторий в учреждениях общей лечебной сети. Так,общая укомплектованность кадрами таких лабораторий, по данным некоторых авторов, составляет $63 \%$, а врачами-бактериологами - чуть более 50 \% [7]. Во-вторых, отсутствие должного качества бактериоскопической диагностики туберкулеза связано с довольно длительной и рутинной методикой просмотра микроскопических препаратов, согласно которой необходимо на одном препарате мокроты просмотреть от 100 до 300 полей зрения, при этом у каждого пациента с подозрением на туберкулез необходимо провести данное обследование трехкратно.

Данные обстоятельства приводят к тому, что учреждения общей лечебной сети постепенно перестают осуществлять бактериоскопические исследования мокроты пациентов с подозрением на туберкулез, что подтверждается статистическими данными. Так, удельный вес больных туберкулезом, выявленных бактериоскопическим методом от впервые выявленных бактериовыделителей составляет лишь 0,23 \% [8]. Вместе с тем, даже при выполнении бактериоскопического исследования мокроты пациентам с подозрени- ем на туберкулез в клинико-диагностических лабораториях общей лечебной сети определяется большое числоложных результатов [9].

Использование автоматизированного анализа цифровых микроскопических изображений препаратов мокроты, окрашенной по методу Циля-Нильсена, позволит свести к минимуму перечисленные выше недостатки. Во-первых, путем исключения необходимости наличия квалифицированногоспециалиста при проведении бактериоскопического обследования, во-вторых, путем увеличения скорости проведения данного обследования и, в-третьих, путем исключения человеческого фактора из процесса диагностики.

Как правило, процесс автоматизированного анализа изображений представляет собой два этапа: сегментация изображения и идентификация или распознавание объектов, находящихся на изображении $[10,11,12]$. Основной целью сегментации изображения является исключение тех участков изображения, которые не имеют ценности для дальнейшего анализа $[13,14,15]$. В последующем производится идентификация или распознавание оставшихся после сегментации частей изображения с использованием различных математических моделей и алгоритмов $[16,17,18,19]$.

Для распознавания объектов на изображении, оставшихся после его сегментации, с использованием математических моделей, необходимо описание данных объектов в виде конкретных измеримых параметров. Так, для анализа цифровых изображений используются габариты, гистограммы плотности объектов, характеристики цветовых каналов, а также другие параметры [20, 21, 22, 23, 24]. Таким образом, для осуществления перехода от сегментации начального цифрового изображения к распознаванию находящихся на нем объектов необходимо определение параметров, с помощью которых данные объекты будут описываться и которые станут входными параметрами математических моделей или алгоритмов, осуществляющих распознавание. В связи с этим, целью настоящего исследования явилось изучение различий объектов, являющихся кислотоустойчивыми микобактериями и иными объектами, и их пара- 
метризация для использования при распознавании таких объектов на цифровых микроскопических изображениях мокроты, окрашенной по методу Циля-Нильсена.

\section{Материал и методы}

Материалом исследования явились 343687 объектов, выделенных с использованием разработанных нами алгоритмов на цифровых изображениях микроскопических препаратов мокроты, окрашенной по методу Циля-Нильсена [25], полученных с помощью тринокулярного микроскопа Микромед 1 вар. 3-20 при увеличении 10х60 с установленной цифровой камерой ToupCam UCMOS01300KPA с разрешением 0,3 МР. Каждое изображение имело разрешение 572 х 422 пикселей. Среди выделенных объектов 6708 объектов, являются кислотоустойчивыми микобактериями (КУМ), а 336979 объектов - иные объекты (артефакты, скопления мокроты, части клеток и т.д.).

Анализ данных объектов производился по 240 цветовым и морфометрическим параметрам. Данные параметры разделены на 3 группы, которые подразделяется на подгруппы. Для более удобного анализа сформирована следующая классификация данных параметров:

1. Основные морфометрические параметры объектов:

а) попиксельная площадь объектов (в пикселях);

б) размер объектов по оси X (в пикселях);

в) размер объектов по оси Y (в пикселях).

2. Радиальные размеры объектов и их соотношения:

a) размеры от центра объекта до его края

(всего 72 параметра);

б) соотношения противолежащих размеров

от центра объекта до его края (всего 36 параметров);

в) соотношения перпендикулярных размеров

от центра объекта до его края (всего 72 параметра);

г) соотношения перпендикулярных размеров

от одного края объекта до его противоположного края (всего 36 параметров).

3. Цветовые параметры объектов:

а) характеристики цвета объектов в цветовой

схеме RGB (всего 9 параметров);

б) характеристики цвета объектов в цветовой

схеме HSV (всего 9 параметров);

в) характеристики цвета объектов в оттенках

серого (всего 3 параметра).

Основные морфометрические параметры объектов, радиальные размеры объектов и их соотношения измеряются в пикселях. Измерение цветовых параметров осуществлялось в безразмерных единицах, однако интервал возможных значений отличался в зависимости от цветовой схемы. Так, характеристики цвета объектов в цветовой схеме RGB и в оттенках серого измеряются в интервале от 0 до 255, параметры характеризующие составляющее Н в цветовой схеме HSV измеряются в интервале от 0 до 359, а параметры характеризующие составляющие $\mathrm{S}$ и $\mathrm{V}$ в интервале от 0 до 100.

Для сравнения объектов КУМ с иными объектами применялось два следующих подхода. Первый - классический статистический подход с использованием непараметрического критерия Манна-Уитни. Непараметрический критерий Манна-Уитни применялся в связи с тем, что все изучаемые параметры имеют количественную шкалу и по результатам проверки на подчинение закону нормального распределения с использованием критерия Шапиро-Уилка имеют распределение, отличающееся от нормального.

Для осуществления второго подхода по каждому изучаемому параметру у группы объектов КУМ определялись минимальное и максимальное значение. Дальнейшим этапом являлось определение числа объектов, не являющихся КУМ, которые по значению своих параметров входят в интервал между минимальным и максимальным значениями параметров объектов группы КУМ. Чем меньше таких объектов определялось, тем больше по данному параметру объекты группы КУМ отличались от иных объектов. Так, основным показателем, оцениваемым при использовании данного подхода по каждому из изучаемых параметров, являлась доля объектов среди не КУМ, которые не входили в интервал между минимальным и максимальным значениями у объектов КУМ.

\section{Результаты и обсуждение}

На первом этапе изучаемые группы объектов сравнивались по каждому из анализируемых параметров с использованием непараметрического критерия Манна-Уитни. Как и ожидалось использование данного критерия не позволяет оценить различия между группами объектов КУМ и иных объектов, а тем более определить параметры, по которым данные группы отличаются в наибольшей степени, так как по всем параметрам были получены отличия с высокой степенью статистической значимости $(\mathrm{p}<0,001)$.

Данные результаты связаны с большими объемами данных в сравниваемых группах, что дает даже при минимальных отличиях групп объектов по какому-либо параметру довольно высокую статистическую значимость отличий.

Для оценки различий групп объектов КУМ и иных объектов производили оценку с применением второго подхода с использованием минимальных и максимальных значений параметров объектов КУМ. Результаты данной оценки приведены на рисунке 1, на котором представлена доля объектов среди не КУМ, которые не входили в интервал между минимальным и максимальным значениями у КУМ по первым 15 параметрам, имеющим данный показатель более 1 \%.В таблице представлены минимальные и максимальные значения объектов по данным параметрам.

Данные, представленные на рисунке 1 и в таблице, свидетельствуют о том, что наибольшие различия между объектами КУМ и иными объектами имеются по попиксельной площади данных объектов. Далее по мере снижения степени различия объектов находятся такие цветовые характеристики объектов, как среднее значение параметров В и $\mathrm{G}$ цветовой схемы RGB, максимальное значение параметра B и максимальное значение параметра Н цветовой схемы HSV. 


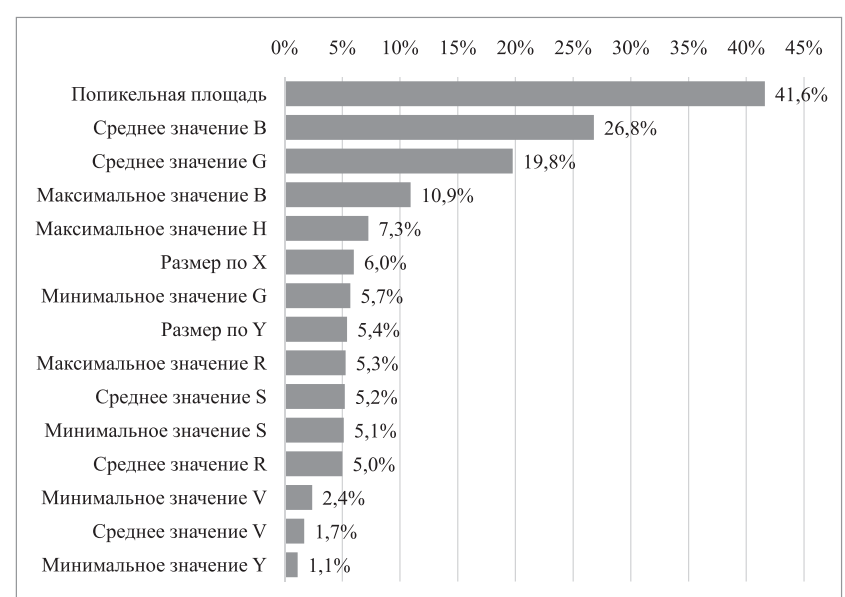

Рисунок 1.Результаты оценки различий групп объектов с использованием минимальных и максимальных значений параметров объектов КУМ.

Как видно из данных, приведенных в таблице, интервалы значений у объектов не КУМ шире, чем у КУМ-объектов, причем интервалы значений изучаемых параметров КУМ всегда входит в интервал значений данных параметров у иных объектов.

Данное обстоятельство существенно затрудняет разделение объектов на классы по изучаемым параметрам. Однако, полученные результаты оценки доли не КУМ объектов не входящих в интервал значений у объектов КУМ свидетельствует о возможности использования предложенных параметров для идентификации объектов на цифровых изобра- жениях микроскопических препаратов мокроты, окрашенной по методу Циля-Нильсена.

\section{Заключение}

Таким образом, результаты проведенного исследования свидетельствуют о том, что использование классических статистических подходов для оценки параметров на предмет возможного разделения объектов, выделяемых на цифровых изображениях, на классы практически невозможно. Это связано с большими объемами изучаемых выборок, которые потенциально могут быть неограниченными, так как, как правило, набор и изучение цифровых объектов менее затруднительно, чем реальных. Используемый подход к оценке различий между цифровыми объектами разных классов с оценкой доли объектов одного класса, которые не входят в интервал между минимальным и максимальным значениями другого класса, показал, что он может быть использован как альтернатива классическим статистическим методам для оценки степени различий больших выборок между собой.

Результаты изучения различий КУМ и иных объектов свидетельствуют о довольно существенных отличиях по основным морфометрическим параметрам объектов, таким как попиксельная площадь и размеры объектов по оси X и Y, a также по различным цветовым параметрам объектов. Существенных отличий изучаемых классов объектов по радиальным размерам объектов и их соотношениям не установлено, однако, различия по данным параметрам требуют дальнейшего изучения с использованием многомерных математических методов анализа.

Минимальные и максимальнье значения изучаемых параметров

\begin{tabular}{|c|c|c|c|c|}
\hline Показатель & $\begin{array}{c}\text { Интервал значений у } \\
\text { объектов КуМ }\end{array}$ & $\begin{array}{c}\text { Интервал значений у } \\
\text { иных объектов }\end{array}$ & $\begin{array}{c}\text { Доля не КУМ объектов } \\
\text { входящих в интервал } \\
\text { значений у объектов } \\
\text { КУМ }\end{array}$ & $\begin{array}{c}\text { Доля не КУМ объектов } \\
\text { не входящих в интервал } \\
\text { значений у объектов } \\
\text { КУМ }\end{array}$ \\
\hline Попиксельная площадь & $4-162$ & $0-1230$ & $58,4 \%$ & $41,6 \%$ \\
\hline Среднее значение В & $74-233$ & $0-240$ & $73,2 \%$ & $26,8 \%$ \\
\hline Среднее значение G & $73-225$ & $0-255$ & $80,2 \%$ & $19,8 \%$ \\
\hline Максимальное значение В & $178-255$ & $0-255$ & $89,1 \%$ & $10,9 \%$ \\
\hline Максимальное значение H & 203-359 & $0-359$ & $92,7 \%$ & $7,3 \%$ \\
\hline Размер по X & $3-86$ & $0-148$ & $94,0 \%$ & $6,0 \%$ \\
\hline Минимальное значение G & $25-206$ & $0-255$ & $94,3 \%$ & $5,7 \%$ \\
\hline Размер по Y & $1-83$ & $0-114$ & $94,6 \%$ & $5,4 \%$ \\
\hline Максимальное значение R & $5-255$ & $0-255$ & $94,7 \%$ & $5,3 \%$ \\
\hline Среднее значение S & $17-99$ & $0-100$ & $94,8 \%$ & $5,2 \%$ \\
\hline Минимальное значение S & $1-98$ & $0-100$ & $94,9 \%$ & $5,1 \%$ \\
\hline Среднее значение R & $1-240$ & $0-248$ & $95,0 \%$ & $5,0 \%$ \\
\hline Минимальное значение V & $54-100$ & $0-100$ & $97,6 \%$ & $2,4 \%$ \\
\hline Среднее значение V & $67-100$ & $0-100$ & $98,3 \%$ & $1,7 \%$ \\
\hline Минимальное значение Y & $46-150$ & $6-255$ & $98,9 \%$ & $1,1 \%$ \\
\hline
\end{tabular}




\section{Литература}

1. Мордык АВ, Пузырева ЛВ, Аксютина ЛП. Современные международные и национальные концепции борьбы с туберкулезом. Дальневосточный журнал инфекиионной патологии. 2013;22:92-7.

2. Филимонова ЕС, Тарасенко СЛ, Дыхно ЮА, Хлебникова ФБ. Оценка эффективности цитологической диагностики злокачественных новообразований легких. Сибирское медицинское обозрение. 2014;3:65-9. DOI: 10.20333/250001362014-3-65-69.

3. Xu Z, Bagci U, Mansoor A, Kramer-Marek G, Luna B, Kubler A, Dey B, Foster B, Papadakis GZ, Camp JV, Jonsson CB, Bishai WR, Jain S, Udupa JK, Mollura DJ. Computer-aided pulmonary image analysis in small animal models. Medical Physics. 2015;7:3896-910.

4. Барбова АИ. Сравнительный анализ современных бактериологических и некоторых генетических методов диагностики туберкулеза. Туберкулез, легочные болезни, ВИЧинфекиия. 2010;2:024-028.

5. Пунин АА, Гусева ИИ, Короткова ЕА, Пунин ДА, Гуляева СА, Пикалова ОС, Хоруженко ОМ, Стрелков АН, Сахаритова ЕА. Выявление туберкулеза среди больных общесоматического стационара. Вестник Смоленской государственной медииинской академии. 2016;4:58-63.

6. ДанцевВВ, Голота АС, Карпущенко ВГ, Крассий АБ, Кузин АА. Современное состояние и перспективы совершенствования дифференциальной диагностики внебольничной пневмонии и туберкулеза легких. Военно-медицинский журнал. 2015;5:29-36.

7. Чередниченко АГ, Ревякина ОВ, Петренко ТИ. Состояние лабораторной службы по диагностике туберкулеза в Сибирском и Дальневосточном федеральных округах.Tyберкулез и болезни легких. 2014;5:16-20.

8. Еремеева НИ, Вахрушева ДВ. Эффективность выявления больных туберкулезом с бактериовыделением в клинико-диагностических лабораториях учреждений первичной медико-санитарной помощи Урала в 2010-2012 гг. Туберкулез и болезни тегких. 2015; 7: 40-42.

9. Мезенцева НИ, Евгущенко ГВ, Пузанов ВА, Попов СА Фрейман ГЕ. Оценка качества диагностики туберкулеза методами микроскопии в РФ за 2011-2014 гг. по результатам ФСВОК. Туберкулез и болезни легких. 2015;6:96-97.

10. Косых НЭ, Смагин СИ, ГостюшкинВВ, Савин СЗ, Литвинов КА. Система автоматизированного компьютерного анализа медицинских изображений. Информационные технологии и вычислительные системы. 2011;3:51-6.

11. Порев ВН. Компьютерная графика. СПб.: БХВПетербург; 2002. 432 с.

12. Agoston MK. Computer graphics and geometric modeling: implementation and algorithms. London: Springer; 2005. 907 p.

13. Ерусланов РВ, Орехова МН, Дубровин ВН. Сегментация изображений органов забрюшинного пространства по компьютерным томографическим изображениям на основе функции уровня. Компьютерная оптика. 2015;4:592-99.
14. Марьянова АВ. Исследование качества алгоритмов сегментации в зависимости от размера объектов на изображении. Современные проблемы математики и её приложений: труды 46-й Международной молодежной школы-конференции. Екатеринбург: Институт математики и механики УрО РАН; 2015:129-34.

15. Prakash A, Hewko MD, Sowa M, Sherif SS. Обнаружение атеросклеротических бляшек по изображениям оптической когерентной томографии с использованием метода структурной сегментации. Современные технологии в медищине. 2015;1:21-8.

16. Сойфер ВА. Компьютерная обработка изображений. Часть 2. Методы и алгоритмы. Соросовский образовательный журнал. 1996;3:110-21.

17. Liu D, Wang S, Huang D, Deng G, Zeng F, Chen H. Medical image classification using spatial adjacent histogram based on adaptive local binary patterns. Computers in Biology and Medicine. 2006;72:185-200. DOI: 10.1016/j.compbiomed. 2016.03.010.

18. Кораблев ДС, Никитаев ВГ, Проничев АН. Система по автоматическому распознаванию и классификации лейкоцитов по изображению. Научная сессия НИЯУ МИФИ2013: аннотации докладов. М.: Национальный исследовательский ядерный университет «МИФИ»; 2013. 271 с.

19. Пивторацкая СВ, Кулябичев ЮП. Об особенностях структурного подхода к распознаванию образов на цифровых изображениях. Вестник Национального исследовательского ядерного университета МИФИ. 2012;1:125.

20. Лиманова НИ, Атаев СГ. Программная параметризация объектов компьютерной томографии. Информационные технологии в науке, управлении, социальной сфере и медицине: сборник научных трудов II Международной конференции. Томск: Национальный исследовательский Томский политехнический университет; 2015:870-71.

21. Дороничева АВ, Бурков СМ, Савин С3. Кроссбраузерные веб-технологии для задач распознавания малоконтрастных объектов на медицинских изображениях. Информационные технологии XXI века: сборник научных трудов. Хабаровск: Тихоокеанский государственный университет; 2017:378-89.

22. Новиков ИА, Махотин СС, Сурнина ЗВ. Вычисление коэффициентов анизотропии и симметричности направленности нервов роговицы на основе автоматизированного распознавания цифровых конфокальных изображений. Медииинская техника. 2015;3:23-5.

23. Дмитриев ГА, Кирсанова АВ, Альбахели Васел Ахмед Ахмед. Автоматизация распознавания границ инсультов головного мозга на основе пороговой обработки магнитно-резонансных изображений. Медииинская техника. 2015;3:31-3.

24. Самородов АВ. Автоматизированный морфологический анализ цитологических препаратов. Биомедицинская радиоэлектроника. 2009;10:35-40.

25. Наркевич АН. Алгоритмы сегментации цифровых микроскопических изображений мокроты, окрашенной по 
методу Циля-Нильсена. World Science: Proceedings of articles the international scientific conference. Киров: MCNIP LLC; 2017:431-36.

\section{References}

1. Mordyk AV, Puzyreva LV, Aksyutina LP. Modern international and national concept of TB. Dal'nevostochnyy zhurnal infektsionnoy patologii. 2013;22:92-97. (InRussian)

2. Filimonova ES, Tarasenko SL, DykhnoYuA, Khlebnikova FB. Evaluation of the effectiveness of cytological diagnosis of malignant tumors of the lungs. Siberian medical review. 2014;3:65-9. DOI: 10.20333/25000136-2014-3-65-69 (In Russian)

3. Xu Z, Bagci U, Mansoor A, Kramer-Marek G, Luna B, Kubler A, Dey B, Foster B, Papadakis GZ, Camp JV, Jonsson CB, Bishai WR, Jain S, Udupa JK, Mollura DJ. Computer-aided pulmonary image analysis in small animal models. Medical Physics. 2015;7:3896-910.

4. Barbova AI. A comparative analysis of some modern bacteriological and genetic methods of diagnostics of tuberculosis. Tuberkulez, legochnye bolezni, VICh-infektsiya. 2010;2:024-028. (InRussian)

5. Punin AA, Guseva II, Korotkova EA, Punin DA, Gulyaeva SA, Pikalova OS, Khoruzhenko OM, Strelkov AN, Sakharitova EA. The detection of tuberculosis among General patients of the hospital. Vestnik Smolenskoy gosudarstvennoy meditsinskoy akademii. 2016;4:58-63. (InRussian)

6. Dantsev VV, Golota AS, Karpushchenko VG, Krassiy AB, Kuzin AA. Current status and prospects for improving the differential diagnosis of community-acquired pneumonia and pulmonary tuberculosis. Voenno-meditsinskiy zhurnal. 2015;5:29-36. (InRussian)

7. Cherednichenko AG, Revyakina OV, Petrenko TI. The state laboratory service for the diagnosis of tuberculosis in the Siberian and far Eastern Federal districts. Tuberkulez $i$ bolezni legkikh. 2014;5:16-20. (InRussian)

8. Eremeeva NI, Vakhrusheva DV. The efficiency of detection of tuberculosis with bacterial excretion in clinical diagnostic laboratories of the primary health-care services in the Urals in 20102012. Tuberkulez i bolezni legkikh. 2015;7:40-42. (InRussian)

9. Mezentseva NI, Evgushchenko GV, Puzanov VA, Popov SA, Freyman GE. Assessment of the quality of TB diagnosis by microscopy in Russia in 2011-2014 at the Federal system of quality control results. Tuberkulez i bolezni legkikh. 2015;6:9697. (InRussian)

10. Kosykh NE, Smagin SI, Gostyushkin VV, Savin SZ, Litvinov KA. Automated computer analysis of medical images. Informatsionnye tekhnologii i vychislitel'nye sistemy. 2011;3:51-6. (InRussian)

11. Porev VN. Computer graphics. SPb.:BKhV-Peterburg; 2002.432 p. (In Russian)

12. Agoston MK. Computer graphics and geometric modeling: implementation and algorithms. London: Springer; 2005.907 p.

13. Eruslanov RV, Orekhova MN, Dubrovin VN. Image segmentation of the retroperitoneum on computed tomographic
Parameterization of objects on digital microscopic images of sputum, stained by the Ziehl-Neelsen method

images based on a function level. Komp'yuternaya optika. 2015;4:592-599. (In Russian)

14. Mar'yanova AV. Study on the quality of segmentation algorithms depending on the size of the objects in the image. Sovremennyeproblemymatematikiieeprilozheniy: trudy 46-y Mezhdunarodnoymolodezhnoyshkoly-konferentsii. Ekaterinburg: Institut matematiki i mekhaniki UrO RAN; 2015:129-34. (In Russian)

15. Prakash A, Hewko MD, Sowa M, Sherif SS. Detection of atherosclerotic plaques in images of optical coherence tomography using the method of structural segmentation. Sovremennye tekhnologii v meditsine. 2015;1:21-8. (InRussian)

16. Soyfer VA. Computer processing of images. Part 2. Methods and algorithms. Sorosovskiy obrazovatelnyy zhurnal. 1996;3:110-21. (InRussian)

17. Liu D, Wang S, Huang D, Deng G, Zeng F, Chen H. Medical image classification using spatial adjacent histogram based on adaptive local binary patterns. Computersin Biologyand Medicine. 2016;72:185-200. DOI: 10.1016/j.compbiomed.2016.03.010.

18. Korablev DS, Nikitaev VG, Pronichev AN. The system for automatic recognition and classification of white blood cells in the image. NauchnayasessiyaNIYaU MIFI-2013: annotatsiidokladov. M.: Natsional'nyy issledovatel'skiy yadernyy universitet «MIFI»; 2013:271. (InRussian)

19. Pivtoratskaya SV, KulyabichevYuP. About the features of the structural approach to pattern recognition on digital images. Vestnik Natsional'nogo issledovatel'skogo yadernogo universiteta MIFI. 2012;1:125. (InRussian)

20. Limanova NI, Ataev SG. Software parameterization of the objects computed tomography. Informatsionnyetekhnologii v nauke, upravlenii, sotsial'noy sfere i meditsine: sbornik nauchnykh trudov II Mezhdunarodnoy konferentsii. Tomsk: Natsional'nyy issledovatel'skiy Tomskiy politekhnicheskiy universitet; 2015: 870-871. (InRussian)

21. Doronicheva AV, Burkov SM, Savin SZ. Cross-browser web technologies for pattern recognition of low contrast objects in medical images. Informatsionnye tekhnologii v nauke, upravlenii, sotsial'noy sferei meditsine: sbornik nauchnykh trudov II Mezhdunarodnoy konferentsii. Tomsk: Natsional'nyy issledovatel'skiy Tomskiy politekhnicheskiy universitet; 2017:378-89. (InRussian)

22. Novikov IA, Makhotin SS, Surnina ZV. Calculation of coefficients of anisotropy and the symmetry orientation of the nerves of the cornea based on the automated recognition of digital confocal images. Biomedical Engineering. 2015;3:23-5. (InRussian)

23. Dmitriev GA, Kirsanova AV, Al'bakheliVaselAkhmedAkhmed. Automation edge detection of brain stroke on the basis of threshold processing for magnetic resonance imaging. Biomedical Engineering. 2015;3:31-3. (InRussian)

24. Samorodov AV. Automated morphological analysis of cytologic preparations. Biomeditsinskaya radioelektronika. 2009; 10:35-40. (InRussian) 
25. Narkevich AN. Algorithms for segmenting digital microscopic images of sputum stained by the method of ZiehlNielsen. World Science: Proceedings of articles the international scientific conference. Kirov: MCNIP LLC; 2017:431-36. (InRussian)

\section{Сведения об авторах}

Наркевич Артем Никотаевич, Красноярский государственный медииинский университет имени профессора В.Ф. Войно-Ясенецкого; адрес: Российская Федерачия, 660022, г. Красноярск, ул. Партизана Железняка, д. 1; тел.: +7(391)2200389; e-mail: narkevichart@gmail.com

Виноградов Константин Анатольевич, Красноярский государственный медииинский университет имени профессора В.Ф. Войно-Ясенеикого; адрес: Российская Федерачия, 660022, г. Красноярск, ул. Партизана Железняка, д. 1; тел.: +7(391)2200389; e-mail:vinogradov16@yandex.ru

Корецкая Наталия Михайловна, Медико-санитарная часть № 24 Федеральной службь исполнения наказаний; адрес: 660036, г. Красноярск, ул. Академгородок, д. 56а, стр. 1; тел.: +7(391)2205048; e-mail: fkuzmsch24@mail.ru

\section{Information about the authors}

Narkevich Artem N., Professor V. F. Voino-Yasenetsky Krasnoyarsk State Medical University; Address: 1, Partizan Zheleznyak Str., Krasnoyarsk, Russian Federation 660022; Phone: +7(391)2200389; e-mail: narkevichart@gmail.com

Vinogradov Konstantin A., Professor V.F. Voino-YasenetskyKrasnoyarsk State Medical University; Address: 1, Partizan Zheleznyak Str., Krasnoyarsk, Russian Federation 660022; Phone: +7(391)2200389; e-mail:vinogradov16@yandex.ru

Koretskaya Nataliya M., Medical-sanitary Department № 24; Address: 56a, Akademgorodok str., Krasnoyarsk, Russian Federation 660036; Phone:+7(391)2205048; e-mail: fkuzmsch24@mail.ru

Поступила 24.08.2017 2. Принята к печати 13.09.20172

( С САВЧЕНКО А. А., ГРИНШТЕЙН Ю. И., ГРИНШТЕЙН И. Ю., ГВОЗДЕВ И. И., ПЕТРОВА М. М.

УДК $616.12: 577.1: 547.587 .11$

DOI: $10.20333 / 2500136-2017-5-59-66$.

\section{ЗАВИСИМОСТЬ МЕТАБОЛИЗМА ТРОМБОЦИТОВ ОТ ХЕМИЛЮМИНЕСЦЕНТНОЙ АКТИВНОСТИ НЕЙТРОФИЛОВ ПРИ ОСТРОМ КОРОНАРНОМ СИНДРОМЕ}

А. А. Савченко ${ }^{1},{ }^{2}$ Ю. И. Гринштейн ${ }^{1}$, И. Ю. Гринштейн ${ }^{1}$, И. И. Гвоздев ${ }^{2}$, М. М. Петрова ${ }^{1}$

${ }^{1}$ Красноярский государственный медицинский университет имени профессора В.Ф. Войно-Ясенецкого, Красноярск 660022, Российская Федерация

${ }^{2}$ Федеральный исследовательский центр «Красноярский научный центр Сибирского отделения Российской академии наук» обособленное подразделение «Научно-исследовательский институт медицинских проблем Севера», Красноярск 660022, Российская Федерация

Цель исследования. Изучение особенностей взаимосвязи между показателями гемостаза и функциональной активности нейтрофилов у больных с разной чувствительностью к ацетилсалициловой кислоте (АСК) при остром коронарном синдроме (ОКС).

Материал и методы. Обследованы пациенты в первые 24 часа от развития ОКС. Все пациенты до начала лечения и реваскуляризации были обследованы на резистентность к АСК и разделены на группы чувствительных (АЧ) и резистентных к АСК (АР). Оценка резистентности/чувствительности к АСК осуществлялась in vitro путем последовательного инкубирования обогащенной тромбоцитами плазмы с АСК. Контрольная группа сформирована из 50 относительно здоровых добровольцев. Исследование активности дегидрогеназ в тромбоцитах проводили биолюминесцентным методом. Состояние респираторного взрыва нейтрофилов исследовали хемилюминесцентным методом.

Результаты. Метаболизм тромбоцитов у АЧ больных ОКС характеризуется ингибированием начальных реакций цикла трикарбоновых кислот и снижением НАДФ-зависимого субстратного обмена между реакциями аминокислотного обмена и лимонным циклом. У АР больных более выражен субстратный поток по циклу Кребса, но при ингибировании малатдегидрогеназной реакции. У АЧ пациентов выявляются минимальные изменения кинетики хемилюминесценции, которые определяются ускоренным синтезом первичных активных форм кислорода (АФК) при антигенной индукции и замедлением синтеза вторичных АФК. У АР больных ОКС состояние респираторного взрыва определяется понижением скорости синтеза первичных АФК, замедлением синтеза вторичных АФК и снижением индекса активации нейтрофилов. У АЧ пациентов уровни синтеза первичных и вторичных АФК зависят от интенсивности энергетических и антиоксидантных процессов, а также субстратными потоками на пентозофосфатный цикл и гликолиз. У АЧ больных ОКС интенсивность респираторного взрыва нейтрофилов сонаправленно меняется только активности энергетических процессов в тромбоцитах.

Заключение. Механизм недостаточного ответа на АСК обусловлен не только метаболическим состоянием тромбоцитов в условиях острой ишемии, но и формированием узкого спектра взаимосвязей в системе тромбоцитарно-нейтрофильной ассоциации.

Ключевые слова: острый коронарный синдром, ацетилсалициловая кислота, тромбоциты, нейтрофилы, НАД(Ф)-зависимые дегидрогеназы, респираторный взрыв.

Для ицтирования: Савченко АА, Гринштейн ЮИ, Гринштейн ИЮ, Гвоздев ИИ, Петрова ММ. Зависимость метаболизма тромбоцитов от хемилюминесцентной активности нейтрофилов при остром коронарном синдроме. Сибирское медицинское обозрение. 2017;(5): 59-66. DOI: 10.20333/2500136-2017-5-59-66.

\section{DEPENDENCE OF THROMBOCYTES METABOLISM FROM THE CHEMILUMINES- CENT ACTIVITY OF NEUTROPHILES IN PATIENTS WITH DIFFERENT SENSITIVITY TO ACETYLSALICYLIC ACID IN ACUTE CORONARY SYNDROME}


A. A. Savchenko ${ }^{12}$, Yu. I. Grinshtein ${ }^{1}$, I. Yu. Grinshtein ${ }^{1}$, I. I. Gvozdev' ${ }^{2}$, M. M. Petrova ${ }^{1}$

${ }^{1}$ Professor V. F. Voino-Yasenetsky Krasnoyarsk State Medical University, Krasnoyarsk 660022, Russian Federation

${ }^{2}$ Federal Research Center «Krasnoyarsk Science Center» of the Siberian Branch of the Russian Academy of Sciences,

Scientific Research Institute of medical problems of the North, Krasnoyarkk 660022, Russian Federation

The aim of the research. To study the peculiarities of the relationship between the parameters of hemostasis and the functional activity of neutrophils in patients with different sensitivity to acetylsalicylic acid (ASA) in acute coronary syndrome (ACS).

Material and methods. Patients were examined in the first 24 hours from the development of ACS. All patients before the start of treatment and revascularization were examined for resistance to ASA and divided into groups of sensitive (AC) and resistant to ASA (AR). Assessment of resistance / sensitivity to ASA was carried out in vitro by sequential incubation of platelet-rich plasma with ASA. The control group is formed from 50 healthy volunteers. The activity of dehydrogenases in platelets was studied by bioluminescent method. The state of respiratory explosion of neutrophils was investigated by the chemiluminescent method

Results. Metabolism of platelets in AC patients with ACS is characterized by inhibition of initial reactions of the tricarboxylic acid cycle and a decrease in NADP-dependent substrate metabolism between amino acid exchange reactions and the lemon cycle. In AP patients, the substrate flow through the Krebs cycle is more pronounced, but with the inhibition of the malate dehydrogenase reaction. At AC patients, minimal changes in the chemiluminescence kinetics are detected, which are determined by the accelerated synthesis of primary active oxygen species (ROS) with antigenic induction and slowing down the synthesis of secondary ROS. In AR patients with ACS, the state of respiratory explosion is determined by a decrease in the rate of synthesis of primary ROS, a slowdown in the synthesis of secondary ROS and a decrease in the activation index of neutrophils. In AC patients, the levels of synthesis of primary and secondary ROS depend on the intensity of energy and antioxidant processes, as well as substrate flows to the pentose phosphate cycle and glycolysis. In AC patients with ACS, the intensity of respiratory explosion of neutrophils co-directs only in the activity of energy processes in platelets.

The conclusion. The mechanism of an inadequate response to ASA is caused not only by the metabolic state of thrombocytes in the conditions of acute ischemia, but also by the formation of a narrow spectrum of interrelations in the system of platelet-neutrophil association.

Key words: acute coronary syndrome, acetylsalicylic acid, platelets, neutrophils, NAD (F) -dependent dehydrogenases, respiratory burst.

Citation: Savchenko AA, Grinshtein YuI, Grinshtein IYu, Gvozdev II, Petrova MM. Dependence of thrombocytes metabolism from the chemiluminesent activity of neutrophils in patients with different sensitivity to acetylsalicylic acid in acute coronary syndrome. Siberian Medical Review. 2017; (5): 59-66. DOI: 10.20333/2500136-2017-5-59-66.

\section{Введение}

Несмотря на развитие новых технологий диагностики и терапии, острый коронарный синдром (ОКС) остается основной причиной смертности, как в России, так и за рубежом. В настоящее время хорошо известно, что атеротромбоз - это результат хронического воспалительного процесса в атеромах при атеросклерозе [1]. Изменения в гемостазе и активация воспалительных процессов тесно ассоциированы между собой, вследствие чего тромбоцитарно-лейкоцитарное взаимодействие становится ведущим в патогенезе ОКС. Функциональная активность нейтрофилов во многом зависят от интенсивности респираторного взрыва, которая определяется уровнем хемилюминесценции клеток $[2,3,4,5]$. Функциональная активность тромбоцитов значительно зависит от состояния их метаболических процессов [6]. При этом взаимодействие тромбоцитов и нейтрофильных гранулоцитов реализуется различными механизмами: контактным путем (формирование агрегатов) и гуморальным (сигнальные коммуникации при участии различных биологически активных веществ).

Назначенная антитромбоцитарная терапия при ОКС предотвращает возможность активного тромбообразования, но зачастую имеет место недостаточный ответ на дезагреганты. Повышенная резистентность к ацетилсалициловой кислоте (АСК) наиболее часто наблюдается у больных инфарктом миокарда с подъемом сегмента
$\mathrm{ST}$, что объясняет высокий риск развития ишемических осложнений у пациентов ОКС по сравнению со стабильной ишемической болезнью сердца [7].

В связи с этим, целью исследования явилось изучение особенностей взаимосвязи между показателями гемостаза и функциональной активности нейтрофилов у больных с разной чувствительностью к ацетилсалициловой кислоте (АСК) при остром коронарном синдроме (ОКС).

\section{Материал и методы}

В исследование включено 53 пациентов в первые 24 часа от развития ОКС (средний возраст $61,1 \pm 1,1$ лет) из них 25 мужчин и 28 женщин. Критерии включения в исследование: ОКС у пациентов обоего пола в возрасте от 35 до 75 лет в первые 24 часа поступления в стационар от начала заболевания, не принимавших до госпитализации антиагреганты и антикоагулянты, подписавшие информированное согласие. Диагноз ОКС, а в дальнейшем острого инфаркта миокарда с элевацией или депрессией сегмента ST и положительным тропонином Т, устанавливался в соответствии с критериями Европейского общества кардиологов [8]. Критерии исключения: сопутствующий сахарный диабет, тяжелая сопутствующая патология (почечная недостаточность, последствия инсульта), сердечная недостаточность III стадии, кардиогенный шок при поступлении в стационар, отсутствие информированного согласия. Всем 
пациентам была проведена реперфузионная терапия в виде чрескожного коронарного вмешательства или тромболитической терапии. В дальнейшем пациенты получали терапию антитромбоцитарными препаратами (АСК, клопидогрел), $\beta$-адреноблокаторами, ингибиторами ангиотензин-превращающего фермента, статинами. Контрольная группа сформирована из 50 относительно здоровых добровольцев без сердечно-сосудистых заболеваний (все испытуемые были обследованы на наличие сердечно-сосудистых заболеваний), сопоставимых по

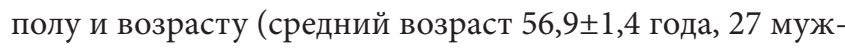
чин, 23 женщины).

Все пациенты были обследованы на резистентность к АСК до начала лечения и реваскуляризации. В связи с чем были разделены на группы чувствительных (АЧ) и резистентных (АР) к АСК. Оценка резистентности/ чувствительности к АСК осуществлялась in vitro путем последовательного инкубирования обогащенной тромбоцитами плазмы с 5 мкМ аденозиндифосфата (АДФ) и 3,36 мМ АСК и определения уровня агрегации тромбоцитов после каждого инкубирования [9].

Исследование активности НАД(Ф)-зависимых дегидрогеназ в тромбоцитах проводили с помощью биолюминесцентного метода [10]. Метаболизм клеток оценивали по активности следующих ферментов: глюкозо-6-фосфатдегидрогеназы (ГбФДГ), глицерол3-фосфатдегидрогеназы (ГЗФДГ), малик-фермента (НАДФМДГ), НАД- и НАДН-зависимой реакции лактатдегидрогеназы (ЛДГ и НАДН-ЛДГ), НАД- и НАДНзависимой реакции малатдегидрогеназы (МДГ и НАДНМДГ), НАДФ- и НАДФН-зависимой глутаматдегидрогеназы (НАДФГДГ и НАДФН-ГДГ), НАД- и НАДНзависимой глутаматдегидрогеназы (НАДГДГ и НАДНГДГ), НАД- и НАДФ-зависимых изоцитратдегидрогеназ (НАДИЦДГ и НАДФИЦДГ, соответственно) и глутатионредуктазы (ГР). Исследование проводили на ферментативном препарате NAD(P): FMNоксидоредуктазалюцифераза из Photobacterium leiognathi (получен в ФГБНУ «НИИ биофизики», Красноярск). Активность оксидоредуктаз выражали в ферментативных единицах (E) на 1 мг белка (1 E=1 мкмоль/мин). Содержание белка определяли по методу Брэдфорда.

Нейтрофилы выделяли из цельной гепаринизированной крови центрифугированием в двойном градиенте плотности фиколл-урографина: $\rho=1,077$ г/ $\mathrm{cm}^{3}-$ для от-

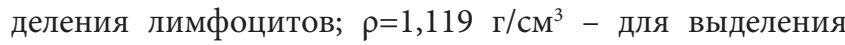
нейтрофилов. Состояние респираторного взрыва нейтрофильных гранулоцитов исследовали с помощью хемилюминесцентного анализа [3]. В качестве индикаторов хемилюминесценции использовали люминол и люцигенин. Оценка спонтанной и зимозан-индуцированной хемилюминесценции осуществлялась в течение 90 минут на 36-канальном хемилюминесцентном анализаторе “CL3606” (Россия). Определяли следующие характеристики: время выхода на максимум (Tmax), максимальное значение интенсивности (Imax), а также площадь под кривой (S) хемилюминесценции. Усиление хемилюминесценции, индуцированной зимозаном, оценивали отношением площади индуцированной хемилюминесценции (Хинд.) к площади спонтанной (Sспонт.) и определяли как индекс активации (Хинд./Sспонт.).

Данные представлены в виде медиан и перцентилий Me [25;75]. Две независимые группы по количественному признаку оценивались по Mann-Whitney U test. Для исследования силы взаимосвязей показателей вычислялся коэффициент ранговой корреляции по Спирмену. Статистический анализ проводился с использованием пакета прикладных программ Statistica 7.0 (StatSoft Inc., 2004).

\section{Результаты и обсуждение}

При исследовании активности НАДФ-зависимых дегидрогеназ в тромбоцитах у больных ОКС в зависимости от чувствительности к АСК обнаружено, что активность ГбФДГ в сравнении с контрольными значениями снижена в тромбоцитах как у АЧ пациентов, так и у АР (табл. 1). Однако у АР пациентов активность данного фермента понижена более выражено, чем у АЧ больных ОКС. Обратная зависимость наблюдается при определении активности НАДФГДГ. Активность фермента у больных ОКС снижена относительно контрольного диапазона, но у АЧ пациентов понижение активности НАДФГДГ более выражено, чем у АР больных. Независимо от чувствительности к АСК у больных ОКС в тромбоцитах снижена активность ГР. Только у АЧ пациентов с ОКС в тромбоцитах снижена активность НАДФН-ГДГ, как относительно контрольного диапазона, так и значений, выявленных у АР больных. При исследовании активности НАД-зависимых дегидрогеназ в тромбоцитах установлено, что независимо от чувствительности к АСК у больных ОКС снижены уровни активности ГЗФДГ, ЛДГ, МДГ, НАДН-МДГ и НАДН-ГДГ, а также повышена активность НАДН-ЛДГ (табл. 2). Только в тромбоцитах АЧ пациентов с АСК снижена активность НАДИЦДГ, как относительно контрольного уровня, так и значений, выявленных у АР больных ОКС.

При исследовании люцигенин-зависимой хемилюминесценции нейтрофильных гранулоцитов обнаружено снижение площади под кривой спонтанной хемилюминесценции у АР пациентов относительно показателей, выявленных у АЧ пациентов при ОКС (табл. 3). Также у АР пациентов снижена площадь под кривой зимозаниндуцированной люцигенин-зависимой хемилюминесценции как относительно контрольного диапазона, так и значений, выявленных у АЧ пациентов. Особенностями люцигенин-зависимой хемилюминесценции у АЧ пациентов является сокращение времени выхода на максимум индуцированной хемилюминесценции. Исследование люминол-зависимой хемилюминесценции 
позволило обнаружить, что независимо от чувствительности к АСК у пациентов ОКС увеличивается время выхода на максимум спонтанной и зимозан-индуцированной хемилюминесценции относительно контрольных значений (табл. 4). У АР по сравнению с АЧ пациентами и контролем снижен индекс активации люминол-зависимой хемилюминесценции.

Табтииа 1

Активность НАДФ-зависимьх дегидрогеназ тромбоцитов у чувствительных и резистентных к АСК пациентов ОКС $\left(\mathrm{Me},\left(\mathrm{C}_{25}-\mathrm{C} \mathrm{F}_{5}\right)\right)$

\begin{tabular}{|c|c|c|c|}
\hline Показатели & $\begin{array}{c}\text { Контроль } \\
\text { n=50 } \\
1\end{array}$ & $\begin{array}{c}\text { Чувствительные } \\
\text { к АСК пациенты } \\
\text { n=34 } \\
2\end{array}$ & $\begin{array}{c}\text { Резистентные к } \\
\text { АСК пациенты } \\
\text { n=19 } \\
3\end{array}$ \\
\hline ГбФДГ & $\begin{array}{c}58,32 \\
(14,37-114,03)\end{array}$ & $\begin{array}{c}13,12 \\
(3,21-20,38) \\
p_{1}=0,016\end{array}$ & $\begin{array}{c}0,44 \\
(0,02-1,96) \\
p_{1}<0,001 \\
p_{2}=0,017\end{array}$ \\
\hline НАДФМДГ & $\begin{array}{c}2,49 \\
(0,12-6,35)\end{array}$ & $\begin{array}{c}4,31 \\
(0,06-11,22)\end{array}$ & $\begin{array}{c}1,08 \\
(0,10-3,37)\end{array}$ \\
\hline НАДФГДГ & $\begin{array}{c}1,21 \\
(0,22-2,61)\end{array}$ & $\begin{array}{c}0,07 \\
(0,01-0,29) \\
p_{1}=0,027\end{array}$ & $\begin{array}{c}0,45 \\
(0,27-0,76) \\
p_{1}=0,040 \\
p_{2}=0,048\end{array}$ \\
\hline НАДФИЦДГ & $\begin{array}{c}36,36 \\
(13,68-95,66)\end{array}$ & $\begin{array}{c}30,52 \\
(0,86-98,17)\end{array}$ & $\begin{array}{c}16,48 \\
(3,41-55,28)\end{array}$ \\
\hline$\Gamma P$ & $\begin{array}{c}3,90 \\
(1,34-10,07)\end{array}$ & $\begin{array}{c}14,87 \\
(1,81-21,90) \\
p_{1}=0,037\end{array}$ & $\begin{array}{c}15,53 \\
(1,99-26,40) \\
p_{1}=0,034\end{array}$ \\
\hline НАДФН-ГДГ & $\begin{array}{c}62,53 \\
(29,72-79,86)\end{array}$ & $\begin{array}{c}1,17 \\
(0,01-2,61) \\
p_{1}<0,001\end{array}$ & $\begin{array}{c}55,18 \\
(9,98-104,31) \\
p_{2}<0,001\end{array}$ \\
\hline
\end{tabular}

Примечание: $p_{1}$ - статистически значимье различия с контролем, $p_{2}$ - статистически значимые различия между АЧ и АР пациентами.

С помощью корреляционного анализа исследованы особенности взаимосвязи между активностью НАД(Ф)зависимых дегидрогеназ тромбоцитов и показателями респираторного взрыва нейтрофилов. Обнаружено, что у лиц контрольной группы активность ГбФДГ отрицательно коррелирует с величиной индекса активации люминол-зависимой хемилюминесценции нейтрофилов $(\mathrm{r}=-0,39, \mathrm{p}=0,017)$.

Кроме того, у лиц контрольной группы активность НАДФИЦДГ положительно взаимосвязана с максимумом интенсивности спонтанной люцигенин-зависимой хемилюминесценции нейтрофилов ( $\mathrm{r}=0,37, \mathrm{p}=0,025)$, тогда как активность ГР - отрицательно коррелирует с максимумом интенсивности зимозан-индуцированной люминол-зависимой хемилюминесценции ( $\mathrm{r}=-0,32$, $\mathrm{p}=0,045)$. У АЧ больных ОКС активность ГбФДГ поло- жительно взаимосвязана с площадью под кривой индуцированной люцигенин-зависимой хемилюминесценции нейтрофилов $(\mathrm{r}=0,52, \mathrm{p}=0,032)$, активность ГЗФДГ также положительно коррелирует с величиной индекса активации люцигенин-зависимой хемилюминесценции $(\mathrm{r}=0,63, \mathrm{p}=0,011)$.

Таблица 2

Активность НАД-зависимьх дегидрогеназ тромбоцитов у чувствительных и резистентных к АСК пациентов ОКС $\left(\mathrm{Me},\left(\mathrm{C}_{25}-\mathrm{C}_{75}\right)\right)$

\begin{tabular}{|c|c|c|c|}
\hline Показатели & $\begin{array}{c}\text { Контроль } \\
\text { n=50 }\end{array}$ & $\begin{array}{c}\text { Чувствительные к } \\
\text { АСК пациенты } \\
\text { n=34 }\end{array}$ & $\begin{array}{c}\text { Резистентные к } \\
\text { АСК пациенты } \\
\text { n=19 }\end{array}$ \\
\hline ГЗФДГ & $\begin{array}{c}45,93 \\
(30,53-115,86)\end{array}$ & $\begin{array}{c}14,80 \\
(6,92-25,87) \\
p_{1}=0,005\end{array}$ & $\begin{array}{c}16,27 \\
(8,45-28,11) \\
p_{1}=0,012\end{array}$ \\
\hline лдГ & $\begin{array}{c}2354,59 \\
(956,66-3276,58)\end{array}$ & $\begin{array}{c}532,84 \\
(17,70-1129,03) \\
p_{1}=0,031\end{array}$ & $\begin{array}{c}171,84 \\
(29,68-720,57) \\
p_{1}=0,005\end{array}$ \\
\hline МДГ & $\begin{array}{c}862,92 \\
(333,18-2097,39)\end{array}$ & $\begin{array}{c}26,14 \\
(3,16-93,33) \\
p_{1}=0,035\end{array}$ & $\begin{array}{c}199,48 \\
(11,55-520,50) \\
p_{1}=0,030\end{array}$ \\
\hline НАДГДГ & $\begin{array}{c}642,77 \\
(43,48-1184,95)\end{array}$ & $\begin{array}{c}464,44 \\
(16,60-804,75)\end{array}$ & $\begin{array}{c}229,48 \\
(151,63-373,42)\end{array}$ \\
\hline НАДИЦДГ & $\begin{array}{c}12,15 \\
(0,85-30,92)\end{array}$ & $\begin{array}{c}1,66 \\
(0,01-7,52) \\
p_{1}=0,029\end{array}$ & $\begin{array}{c}7,67 \\
(0,23-41,79) \\
p_{2}=0,046\end{array}$ \\
\hline НАДН-ЛДГ & $\begin{array}{c}0,10 \\
(0,01-7,56)\end{array}$ & $\begin{array}{c}106,46 \\
(29,86-207,32) \\
p_{1}<0,001\end{array}$ & $\begin{array}{c}50,68 \\
(40,84-115,89) \\
p_{1}<0,001\end{array}$ \\
\hline НАДН-МДГ & $\begin{array}{c}317,29 \\
(112,12-537,16)\end{array}$ & $\begin{array}{c}113,41 \\
(30,95-270,07) \\
p_{1}=0,035\end{array}$ & $\begin{array}{c}50,69 \\
(42,75-141,34) \\
p_{1}=0,045\end{array}$ \\
\hline НАДН-ГДГ & $\begin{array}{c}88,65 \\
(40,90-205,55)\end{array}$ & $\begin{array}{c}27,21 \\
(7,67-35,47) \\
p_{1}=0,019\end{array}$ & $\begin{array}{c}33,47 \\
(12,36-55,10) \\
p_{1}=0,038\end{array}$ \\
\hline
\end{tabular}

Примечание: то же, что и для табл. 1.

У пациентов данной группы, активность МДГ взаимосвязана с максимумом интенсивности люминол-зависимой хемилюминесценции нейтрофилов ( $\mathrm{r}=0,50$, $\mathrm{p}=0,046)$, а активность ГР - с индексом активации люминол-зависимой хемилюминесценции $(\mathrm{r}=0,56, \mathrm{p}=0,012)$. У АР больных ОКС активность НАДН-ЛДГ положительно коррелирует с максимумом интенсивности спонтанной люминол-зависимой хемилюминесценции ( $\mathrm{r}=0,60$, $\mathrm{p}=0,011)$ и площадью под кривой индуцированной хемилюминесценции нейтрофилов $(\mathrm{r}=0,73, \mathrm{p}<0,001)$. Также у лиц данной группы обнаружены положительные корреляционные связи активности ГЗФДГ тромбоцитов с максимумом интенсивности зимозан-индуцированной 
люцигенин-зависимой хемилюминесценции нейтрофилов $(\mathrm{r}=0,63, \mathrm{p}=0,022)$ и активности МДГ с индексом активации люминол-зависимой хемилюминесценции $(\mathrm{r}=0,58, \mathrm{p}=0,039)$.

Таблииа 3

Люцигенин-зависимая хемилюминесиентная активность нейтрофильных гранулоцитов у чувствительных и резистентных к АСК пациентов ОКС $\left(\mathrm{Me},\left(\mathrm{C}_{25}-\mathrm{C}_{75}\right)\right)$

\begin{tabular}{|c|c|c|c|}
\hline Показатели & $\begin{array}{c}\text { Контроль } \\
\mathrm{n}=50 \\
1\end{array}$ & $\begin{array}{c}\text { Чувствительные } \\
\text { к АСК пациенты } \\
\text { n=34 } \\
2\end{array}$ & $\begin{array}{c}\text { Резистентные к } \\
\text { АСК пациенты } \\
\text { n=19 } \\
3 \\
\end{array}$ \\
\hline \multicolumn{4}{|c|}{ Спонтанная хемилюминесценция } \\
\hline Tmax, сек. & $\begin{array}{c}2246,5 \\
(1538,0-3418,2)\end{array}$ & $\begin{array}{c}1902,5 \\
(1563,5-3248,0)\end{array}$ & $\begin{array}{c}2821,8 \\
(2113,0-4223,5)\end{array}$ \\
\hline Imax, o.e. $\times 10^{3}$ & $\begin{array}{c}7,38 \\
(2,58-15,61)\end{array}$ & $\begin{array}{c}11,98 \\
(7,00-20,00)\end{array}$ & $\begin{array}{c}10,70 \\
(5,48-14,70)\end{array}$ \\
\hline S, o.e. 'сек.' $10^{6}$ & $\begin{array}{c}4,28 \\
(0,44-24,78)\end{array}$ & $\begin{array}{c}6,25 \\
(1,15-20,34)\end{array}$ & $\begin{array}{c}3,52 \\
(1,01-15,77) \\
p_{2}=0,045\end{array}$ \\
\hline \multicolumn{4}{|c|}{ Зимозан-индуцированная хемилюминесценция } \\
\hline Tmax, сек. & $\begin{array}{c}1830,9 \\
(1489,0-2439,1)\end{array}$ & $\begin{array}{c}1535,5 \\
(1262,5-1755,5) \\
p_{1}=0,005\end{array}$ & $\begin{array}{c}3084,0 \\
(2887,0-3724,1) \\
p_{2}=0,020\end{array}$ \\
\hline Imax, o.e. $\times 10^{3}$ & $\begin{array}{c}14,03 \\
(7,61-28,49)\end{array}$ & $\begin{array}{c}17,45 \\
(5,12-34,21)\end{array}$ & $\begin{array}{c}17,41 \\
(14,95-20,31)\end{array}$ \\
\hline S, о.е. 'сек.' $10^{6}$ & $\begin{array}{c}10,77 \\
(7,14-43,31)\end{array}$ & $\begin{array}{c}7,11 \\
(2,70-15,68)\end{array}$ & $\begin{array}{c}4,37 \\
(0,81-12,58) \\
p_{1}=0,044 ; \\
p_{2}=0,037\end{array}$ \\
\hline Кинд./ऽспонт. & $\begin{array}{c}1,80 \\
(1,17-3,19)\end{array}$ & $\begin{array}{c}1,16 \\
(0,84-2,41)\end{array}$ & $\begin{array}{c}1,35 \\
(1,41-4,02)\end{array}$ \\
\hline
\end{tabular}

Примечание: то же, что и для табл. 1.

Исследуемые оксидоредуктазы занимают ключевые позиции на основных метаболических путях клетки [11, 12]. Снижение активности ГбФДГ в тромбоцитах больных ОКС в независимости от чувствительности к АСК определяет недостаточность синтетических процессов в клетках.

Необходимо подчеркнуть, что у АР пациентов интенсивность начальных реакций пентозофосфатного цикла снижается более выражено, чем у АЧ больных. ГбФДГ также является основным конкурентом гликолиза за субстрат [11, 13]. У больных ОКС наблюдается значительное повышение активности анаэробной реакции ЛДГ, которая характеризует интенсивность терминальных реакций анаэробного гликолиза [11]. Причем высокая интенсивность терминальных реакций анаэробного гликолиза выявляется на фоне снижения активности
ГЗФДГ у больных ОКС, которая характеризует отток субстратов с реакций липидного катаболизма на окислительно-восстановительные реакции гликолиза.

Таблиияа 4

Люминол-зависимая хемилюминесиентная активность нейтрофильных гранулоцитов у чувствительньх и резистентных к АСК пациентов ОКС

$\left(\mathrm{Me},\left(\mathrm{C}_{25}-\mathrm{C}_{75}\right)\right)$

\begin{tabular}{|l|c|c|c|}
\hline Показатели & $\begin{array}{c}\text { Контроль } \\
\mathrm{n}=50 \\
1\end{array}$ & $\begin{array}{c}\text { Чувствительные } \\
\text { к АСК пациенты } \\
\mathrm{n}=34 \\
2\end{array}$ & $\begin{array}{c}\text { Резистентные к } \\
\text { АСК пациенты } \\
\mathrm{n}=19 \\
3\end{array}$ \\
\hline \multicolumn{3}{|c|}{ Спонтанная хемилюминесценция } \\
\hline Tmax, сек. & $\begin{array}{c}634,0 \\
(506,5-1332,5)\end{array}$ & $\begin{array}{c}1913,0 \\
(1092,0-2594,0) \\
\mathrm{p}_{1}=0,049\end{array}$ & $\begin{array}{c}1957,0 \\
(1595,0-2137,0) \\
\mathrm{p}_{1}=0,014\end{array}$ \\
\hline Imax, 0.е. $\times 10^{3}$ & $\begin{array}{c}45,21 \\
(12,60-61,59)\end{array}$ & $\begin{array}{c}31,73 \\
(17,85-56,16)\end{array}$ & $\begin{array}{c}52,04 \\
(35,39-68,58)\end{array}$ \\
\hline S, 0.е.' сек. '106 & $\begin{array}{c}3,21 \\
(1,43-8,51)\end{array}$ & $\begin{array}{c}5,23 \\
(3,28-70,70)\end{array}$ & $\begin{array}{c}5,46 \\
(4,02-14,98)\end{array}$ \\
\hline
\end{tabular}

Зимозан-индуцированная хемилюминесценция

\begin{tabular}{|l|c|c|c|}
\hline Tmax, сек. & $\begin{array}{c}664,0 \\
(580,0-1285,5)\end{array}$ & $\begin{array}{c}1091,0 \\
(987,0-1819,0) \\
p_{1}=0,041\end{array}$ & $\begin{array}{c}1559,0 \\
(1374,0-1692,0) \\
p_{1}=0,041\end{array}$ \\
\hline Imax, 0.e. $\times 10^{3}$ & $\begin{array}{c}64,69 \\
(23,01-118,70)\end{array}$ & $\begin{array}{c}81,12 \\
(31,53-118,15)\end{array}$ & $\begin{array}{c}61,95 \\
(30,43-109,96)\end{array}$ \\
\hline S, 0.е.' сек. ' 106 & $\begin{array}{c}6,74 \\
(1,23-23,50)\end{array}$ & $\begin{array}{c}8,52 \\
(5,71-170,80)\end{array}$ & $\begin{array}{c}5,52 \\
(4,42-34,61)\end{array}$ \\
\hline Sинд./Sспонт. & $\begin{array}{c}2,17 \\
(1,61-3,63)\end{array}$ & $\begin{array}{c}2,19 \\
(1,45-2,78)\end{array}$ & $\begin{array}{c}1,36 \\
(1,19-1,84) \\
p_{1,2}=0,040\end{array}$ \\
\hline
\end{tabular}

Примечание: то же, что и для табл. 1.

У АЧ больных ОКС снижена активность НАДИЦДГ ключевого фермента лимонного цикла, лимитирующего субстратный поток [10]. При этом активность МДГ (второй НАД-зависимой дегидрогеназы цикла Кребса) в тромбоцитах больных ОКС также снижена, что позволяет заключить об ингибировании субстратного потока по циклу трикарбоновых кислот. У АЧ пациентов данное ингибирование более выражено, чем у АР. Недостаточность интенсивности лимонного цикла может определяться низкой активностью аэробной реакции ЛДГ. Кроме того, у больных ОКС наблюдается снижение активности НАДФГДГ - вспомогательной НАДФ-зависимой дегидрогеназной реакции, которая осуществляет перенос интермедиатов аминокислотного обмена на реакции цикла трикарбоновых кислот [14]. У АЧ больных ОКС данная метаболическая реакция снижена более выра- 
жено, чем у АР пациентов. Кроме того, в тромбоцитах у больных ОКС также снижен и уровень субстратного оттока с реакций цикла трикарбоновых кислот на реакции аминокислотного обмена. Причем, если интенсивность НАД-зависимого оттока (через НАДН-ГДГ) понижена при ОКС независимо от чувствительности, то уровень НАДФ-зависимого оттока (через НАДФН-ГДГ) снижен только у АЧ пациентов. Недостаточность кислород-зависимого дыхания тромбоцитов у больных ОКС также определяется ингибированием НАДН-зависимой реакции малатдегидрогеназы, которая является ключевой в системе малат-аспартатного шунта митохондрий, определяющего уровень водородного градиента [15].

Активность респираторного взрыва в нейтрофилах определяется уровнями синтеза первичных и вторичных АФК $[2,4,5]$. У АЧ больных ОКС выявляются минимальные отличия кинетики люцигенин-зависимой хемилюминесценции нейтрофилов, которые определяются только снижением времени выхода на максимум индуцированной хемилюминесценции. Данный показатель характеризует скорость развития респираторного взрыва от момента регуляторного или антигенного воздействия на клетку до максимальной активации ферментов, синтезирующих АФК. У АР больных ОКС особенность синтеза первичных АФК нейтрофилами характеризуется снижением площади под кривой спонтанной и индуцированной люцигенин-зависимой хемилюминесценции. Подобное состояние хемилюминесцентной активности клеток отражает снижение активности НАДФН-оксидазы в синтезе супероксид-радикала. Особенность респираторного взрыва в нейтрофилах у АЧ больных ОКС определяется увеличением времени активации синтеза вторичных АФК. У АР пациентов особенность синтеза вторичных АФК в фагоцитирующих клетках определяется также определяется ускоренной активацией ферментов, но при снижении величины индекса активации, который характеризует уровень активации респираторного взрыва при антигенной стимуляции нейтрофилов.

При исследовании взаимосвязей между активностью ферментов тромбоцитов и показателями хемилюминесцентной активности нейтрофилов установлено, что у здоровых людей обнаружены только отрицательные корреляционные связи, тогда как у больных ОКС независимо от чувствительности к АСК - только положительно. Данное изменение знака корреляционных связей характеризует формирование патогенетической сонаправленности изменений метаболизма тромбоцитов и интенсивности респираторного взрыва нейтрофилов при ОКС. У больных ОКС показатели респираторного взрыва нейтрофилов взаимосвязаны с уровнями активности ферментов тромбоцитов, участвующих в метаболических процессах энергетического и пластического типа. Интенсивность зимозан-индуцированного синте- за вторичных АФК у больных данной группы положительно взаимосвязано с активностью МДГ и ГР тромбоцитов. Можно предположить, что функциональная активация нейтрофилов крови у АЧ больных ОКС сопровождается повышением интенсивности субстратного потока по циклу трикарбоновых кислот и активацией перекисных процессов в тромбоцитах.

У АЧ больных ОКС показателя дыхательного взрыва нейтрофилов взаимосвязаны с тромбоцитарными ферментами только энергетического профиля. Спонтанный и индуцированный синтез вторичных АФК в нейтрофилах крови положительно взаимосвязан с активностью МДГ и анаэробной реакции ЛДГ. Следовательно, у АЧ больных ОКС интенсивность респираторного взрыва нейтрофилов сонаправленно меняется активности энергетических процессов в тромбоцитах.

\section{Заключение}

У больных ОКС в зависимости от чувствительности к АСК выявляются характерные особенности состояния внутриклеточного метаболизма тромбоцитов и интенсивности респираторного взрыва нейтрофилов. Метаболизм тромбоцитов у АЧ больных ОКС характеризуется ингибированием начальных реакций цикла трикарбоновых кислот и снижением НАДФ-зависимого субстратного обмена между реакциями аминокислотного обмена и лимонным циклом. У АР больных более выражен субстратный поток по циклу Кребса, но при ингибировании малатдегидрогеназной реакции. Независимо от чувствительности к АСК в тромбоцитах больных ОКС выявляется ингибирование пентозофосфатного цикла и переноса продуктов липидного катаболизма на реакции гликолиза, но при увеличении активности терминальных реакций анаэробного гликолиза. У АЧ пациентов выявляются минимальные изменения кинетики респираторного взрыва, которые определяются ускоренной активацией синтеза первичных АФК в клетках при антигенной индукции, а также замедлением синтеза вторичных АФК. У АР больных ОКС состояние респираторного взрыва определяется понижением скорости синтеза первичных АФК, замедлением синтеза вторичных АФК и снижением индекса активации нейтрофилов по люминол-зависимой хемилюминесцентной реакцией. При резистентности к АСК отмечается понижение функциональной активности нейтрофилов, что представляет интерес при изучении межклеточных взаимоотношений формирования тромба. С помощью корреляционного анализа установлено, что при ОКС формируется сонаправленность изменений активности НАД(Ф)-зависимых дегидрогеназ в тромбоцитах и показателей респираторного взрыва нейтрофилов. При этом у АЧ пациентов уровни синтеза первичных и вторичных АФК зависят от интенсивности энергетических и антиоксидантных процессов, а также субстратными потоками на пентозофосфатный цикл и гликолиз. У АЧ 
больных ОКС интенсивность респираторного взрыва нейтрофилов сонаправленно меняется только активности энергетических процессов в тромбоцитах. Таким образом, механизм недостаточного ответа на АСК обусловлен не только метаболическим состоянием тромбоцитов в условиях острой ишемии, но и формированием узкого спектра взаимосвязей в системе тромбоцитарнонейтрофильной ассоциации.

\section{Литература}

1. Bae MH, Lee JH, Yang DH, Park HS, Cho Y, Chae SC. White blood cell, hemoglobin and platelet distribution width as short-term prognostic markers in patients with acute myocardial infarction. Journal of Korean Medical Science. 2014;29(4):519-26. DOI: 10.3346/jkms.2014.29.4.519.

2. Савченко АА, Здзитовецкий ДЭ, Борисов АГ, Лузан НА. Хемилюминесцентная активность нейтрофильных гранулоцитов и уровни концентрации цитокинов у больных распространенным гнойным перитонитом. Цитокины и воспаление. 2013;12(1-2):115-9.

3. Шкапова ЕА, Куртасова ЛМ, Савченко АА. Показатели люцигенин - и люминолзависимой хемилюминесценции нейтрофилов крови у больных раком почки. Бюллетень экспериментальной биологии и медицины. 2010;149(2):201-3.

4. El-Benna J, Hurtado-Nedelec M, Marzaioli V, Marie JC, Gougerot-Pocidalo MA, Dang PM. Priming of the neutrophil respiratory burst: role in host defense and inflammation. Immunological Reviews. 2016;273(1):180-93. DOI: 10.1111/ imr.12447.

5. Parenti A, Indorato B, Paccosi S. Minocycline affects human neutrophil respiratory burst and transendothelial migration. Inflammation Research. 2017;66(2):107-109. DOI: 10.1007/s00011-016-0999-x.

6. Moschos MM, Chatziralli IP, Stamatakis G, Papakonstantinou VD, Tsatsos M, Demopoulos CA. In Vitro Effects of Anti-Glaucomatous Eye Drops on Platelet-Activating Factor and its Metabolism. Seminars in Ophthalmology. 2017;32(2):198-203. DOI: 10.3109/08820538.2015.1053622.

7. Гринштейн ЮИ, Косинова АА, Гринштейн ИЮ. Возможные причины и механизмы развития вторичной резистентности к ацетилсалициловой кислоте. Российские медиинские вести. 2013;2:4-13.

8. ESC Guidelines For the management of acute coronary syndromes in patients presenting without persistent STsegment elevation. The Task Force for the management of acute coronary syndromes (ACS) in patients presenting without persistent ST-segment elevation of the European Society of Cardiology (ESC). European Heart Journal. 2011;32:2999-3054. DOI:10.1093/eurheartj/ehr236.

9. Гринштейн ЮИ, Филоненко ИВ, Савченко АА, Савченко ЕА, Гринштейн ИИ. Способ диагностики резистентности к ацетилсалициловой кислоте. Патент
№ 2413953 РФ, МПК G01N 33/86 (2006.01). Опубл. 10.03.2009, Бюл. № 7: 8 с.

10. Савченко ЕА, Савченко АА, Герасимчук АИ, Грищенко ДА. Оценка метаболического статуса тромбоцитов в норме и при ишемической болезни сердца. Клиническая лабораторная диагностика. 2006;5:33-6.

11. Куртасова ЛМ, Савченко АА, Манчук ВТ. Метаболические аспекты иммунореабилитации детей с атопическими заболеваниями. Новосибирск: Наука, 2006; 222 с.

12. Engel PC. Glutamate dehydrogenases: the why and how of coenzyme specificity. Neurochemical Research. 2014;39(3):426-32. DOI: 10.1007/s11064-013-1089-x.

13. Rostami-Far Z, Ghadiri K, Rostami-Far M, ShaveisiZadeh F, Amiri A, Rahimian Zarif B. Glucose-6-phosphate dehydrogenase deficiency (G6PD) as a risk factor of male neonatal sepsis. Journal of Medicine and Life. 2016;9(1):3438.

14. Sharkey MA, Oliveira TF, Engel PC, Khan AR. Structure of $\mathrm{NADP}(+)$-dependent glutamate dehydrogenase from Escherichia coli--reflections on the basis of coenzyme specificity in the family of glutamate dehydrogenases. Federation of European Biochemical Societies Journal. 2013;280(18):4681-92. DOI: 10.1111/febs.12439.

15. Wang C, Chen H, Zhang J, Hong Y, Ding X, Ying W. Malate-aspartate shuttle mediates the intracellular ATP levels, antioxidation capacity and survival of differentiated PC12 cells. International Journal of Physiology, Pathophysiology and Pharmacology. 2014;6(2):109-14.

\section{References}

1. Bae MH, Lee JH, Yang DH, Park HS, Cho Y, Chae SC. White blood cell, hemoglobin and platelet distribution width as short-term prognostic markers in patients with acute myocardial infarction. Journal of Korean Medical Science. 2014;29(4):519-26. DOI: 10.3346/jkms.2014.29.4.519.

2. Savchenko AA, Zdzitoveckij DJe, Borisov AG, Luzan NA. Chemiluminescent activity of neutrophils and concentration levels of cytokines in patients with widespread purulent peritonitis. Cytokines and inflammation. 2013;12(1-2):115-9. (In Russian)

3. Shkapova EA, Kurtasova LM, Savchenko AA. Lucigenin- and luminol-dependent chemiluminescence of blood neutrophils in patients with renal cancer. Bulletin of Experimental Biology and Medicine. 2010;149(2):201-3. (In Russian)

4. El-Benna J, Hurtado-Nedelec M, Marzaioli V, Marie JC, Gougerot-Pocidalo MA, Dang PM. Priming of the neutrophil respiratory burst: role in host defense and inflammation. Immunological Reviews. 2016;273(1):180-93. DOI: 10.1111/ imr.12447.

5. Parenti A, Indorato B, Paccosi S. Minocycline affects human neutrophil respiratory burst and transendothelial migration. Inflammation Research. 2017;66(2):107-109. DOI: 10.1007/s00011-016-0999-x. 
6. Moschos MM, Chatziralli IP, Stamatakis G, Papakonstantinou VD, Tsatsos M, Demopoulos CA. In Vitro Effects ofAnti-GlaucomatousEyeDropson Platelet-Activating Factor and its Metabolism. Seminars in Ophthalmology. 2017;32(2):198-203. DOI: 10.3109/08820538.2015.1053622.

7. Grinshtein YuI, Kosinova AA, Grinshtein IYu. Possible causes and mechanisms of development of secondary resistance to acetylsalicylic acid. Russian medical news. 2013;2:4-13. (In Russian)

8. ESC Guidelines For the management of acute coronary syndromes in patients presenting without persistent STsegment elevation. The Task Force for the management of acute coronary syndromes (ACS) in patients presenting without persistent ST-segment elevation of the European Society of Cardiology (ESC). European Heart Journal. 2011;32:2999-3054. DOI:10.1093/eurheartj/ehr236

9. Grinshtein YuI, Filonenko IV, Savchenko AA, Savchenko EA, Grinshtein IYu. A method for diagnosing resistance to acetylsalicylic acid. Patent № 2413953 Russia, MPK G01N 33/86 (2006.01). Published 10.03.2009, Bul. № 7: 8 p. (In Russian)

10. Savchenko EA, Savchenko AA, Gerasimchuk AI, Grishchenko DA. Evaluation of the metabolic status of platelets in normal and ischemic heart disease. Klinichescheskaya Laboratornaya Diagnostika. 2006;5:33-6. (In Russian)

11. Kurtasova LM, Savchenko AA, Manchuk VT. Metabolic aspects immunorehabilitation of children with atopic diseases. Novosibirsk: Nauka, 2006; 222 p. (In Russian)

12. Engel PC. Glutamate dehydrogenases: the why and how of coenzyme specificity. Neurochemical Research. 2014;39(3):426-32. DOI: 10.1007/s11064-013-1089-x.

13. Rostami-Far Z, Ghadiri K, Rostami-Far M, ShaveisiZadeh F, Amiri A, Rahimian Zarif B. Glucose-6-phosphate dehydrogenase deficiency (G6PD) as a risk factor of male neonatal sepsis. Journal of Medicine and Life. 2016;9(1):3438 .

14. Sharkey MA, Oliveira TF, Engel PC, Khan AR. Structure of $\mathrm{NADP}(+)$-dependent glutamate dehydrogenase from Escherichia coli--reflections on the basis of coenzyme specificity in the family of glutamate dehydrogenases.
Federation of European Biochemical Societies Journal. 2013;280(18):4681-92. DOI: 10.1111/febs.12439.

15. Wang C, Chen H, Zhang J, Hong Y, Ding X, Ying W. Malate-aspartate shuttle mediates the intracellular ATP levels, antioxidation capacity and survival of differentiated PC12 cells. International Journal of Physiology, Pathophysiology and Pharmacology. 2014;6(2):109-14.

\section{Сведения об авторах}

Савченко Андрей Анатольевич, Красноярский государственный медицинский университет имени профессора В.Ф. Войно-Ясенеикого; адрес: Российская Федерация, 660022, 2. Красноярск, ул. Партизана Железняка, д. 1;Федеральный исследовательский иентр «Красноярский научныцй иентр Сибирского отделения Российской академии наук» обособленное подразделение «Научно-исследовательский институт медицинских проблем Севера»; адрес: Российская Федерация, 660022, г. Красноярск, ул. Партизана Железняка, д. 3Г; тел.: +7(905)9713715; e-mail: aasavchenko@yandex.ru

Гринштейн Юрий Исаевич, Красноярский государственный медицинский университет имени профессора В.Ф. Войно-Ясенеиякого; адрес: Российская Федерация, 660022, г. Красноярск, ул. Партизана Железняка, д. 1; тел.:+7(902)9904664;e-mail:grinstein.yi@mail.ru

Гринштейн Игорь Юрвевич, Красноярский государственный медицинский университет имени профессора В.Ф. Войно-Ясенеикого; адрес: Российская Федерация, 660022, г. Красноярск, ул. Партизана Железняка, д. 1; тел.:+7(913)5321820; e-mail: grinst@rambler.ru

Гвоздев Иван Игоревич, Федеральный исследовательский иентр «Красноярский научный иентр Сибирского отделения Российской академии наук» обособленное подразделение «Научно-исстедовательский институт медицинских проблем Севера»; адрес: Российская Федеращия, 660022, г. Красноярск, ул. Партизана Железняка, д. 3Г; тел.: +7(963)2558482; e-mail: leshman-mult@mail.ru

Петрова Марина Михайловна, Красноярский государственный медицинский университет имени профессора В.Ф. Войно-Ясенеикого; адрес: Российская Федерация, 660022, 2. Красноярск, ул. Партизана Железняка, д. 1; тел.:+7(902)9230211; e-mail: stk99@yandex.ru

\section{Information about the authors}

Savchenko Andrei A., Professor V. F. Voino-Yasenetsky Krasnoyarsk State Medical University; Address: 1, Partizan Zheleznyak Str., Krasnoyarsk, Russian Federation 660022; Federal Research Center "Krasnoyarsk Science Center» of the Siberian Branch of the Russian Academy of Sciences, Scientific Research Institute of medical problems of the North; Address: 3G, Partizan Zheleznyak Str., Krasnoyarsk, Russian Federation 660022; Phone: $+7(905) 9713715$; e-mail:aasavchenko@yandex.ru

Grinshtein Yury I., Professor V. F. Voino-Yasenetsky Krasnoyarsk State Medical University; Address: 1, Partizan Zheleznyak Str., Krasnoyarsk, Russian Federation 660022; Phone: +7(902)9904664; e-mail:grinstein.yi@mail.ru

Grinshtein Igor Yu., Professor V. F. Voino-Yasenetsky Krasnoyarsk State Medical University; Address: 1, Partizan Zheleznyak Str., Krasnoyarsk, Russian Federation 660022; Phone:+7(913)5321820; e-mail: grinst@rambler.ru

Gvozdev Ivan I., Federal Research Center "Krasnoyarsk Science Center» of the Siberian Branch of the Russian Academy of Sciences, Scientific Research Institute of medical problems of the North; Address: 3G, Partizan Zheleznyak Str., Krasnoyarsk, Russian Federation 660022; Phone: +7(963)2558482; e-mail: leshman-mult@mail.ru

Petrova Marina M., Professor V. F. Voino-Yasenetsky Krasnoyarsk State Medical University; Address: 1, Partizan Zheleznyak Str., Krasnoyarsk, Russian Federation 660022; Phone:+7(902)9230211; e-mail:stk99@yandex.ru

\section{ПОКАЗАТЕЛИ ТРЕДМИЛ-ТЕСТА У БОЛЬНЫХ ОСТРЫМ КОРОНАРНЫМ СИНДРОМОМ И ТРЕВОЖНО-ДЕПРЕССИВНЫМИ РАССТРОЙСТВАМИ}

\section{Н. Ю. Шимохина ${ }^{1}$, М. М. Петрова ${ }^{1}$, А. А. Савченко ${ }^{1,2}$}

${ }^{1}$ Красноярский Государственный Медицинский Университет имени профессора В.Ф. Войно-Ясенецкого,

Красноярск 660022, Российская Федерация

${ }^{2}$ Научно-исследовательский институт медицинских проблем Севера, лаборатория молекулярно-клеточной физиологии и патологии, г. Красноярск 660022, Российская Федерация 
Цель исследования. Оценить функциональные показатели сердечно-сосудистой системы по данным пробы с дозированной физической нагрузкой у больных острым коронарным синдромом в сочетании с тревожно-депрессивными расстройствами.

Материал и методы. Обследовано 315 пациентов в первые 24 часа после развития острого коронарного синдрома (ОКС). В первые 72 часа после перевода из реанимационной палаты с целью определения тревожно-депрессивных расстройств (ТДР) всем пациентам было проведено психометрическое обследование. На 7-10 сутки к выписке из стационара проводилась проба с дозированной физической нагрузкой. Анализировались следующие показатели: общая продолжительность нагрузки, пороговая мощность выполненной работы, метаболический эквивалент, продолжительность нагрузки, исходные артериальное давление и ЧСС, максимальная ЧСС, максимальное систолическое и диастолическое артериальное давление.

Результаты. Положительный результат тредмил-теста наблюдался чаще у больных ОКС в сочетании с ТДР в сравнении с пациентами без аффективных нарушений. Возникновение болевого стенокардитического синдрома чаще наблюдалось у больных с ОКС в сочетании с ТДР. У больных ОКС и ТДР чаще наблюдалась косонисходящая депрессия сегмента ST. Порог толерантности к физической нагрузке, а также пороговая мощность нагрузки в группе ОКС с сопутствующими ТДР были ниже как показателей контроля, так и результатов больных ОКС без аффективных нарушений. Продолжительность нагрузки в группе ОКС и ТДР была существенно ниже показателей пациентов с ОКС без аффективных нарушений. Заключение. У пациентов с ОКС наличие сопутствующих ТДР оказывает негативное влияние на функциональные показатели сердечно-сосудистой системы, что может быть одной из причин высокого риска повторных сердечно-сосудистых катастроф.

Ключевые слова: ишемическая болезнь сердца, острый коронарный синдром, проба с физической нагрузкой, тредмил-тест, тревога, депрессия. Для иитирования: Шимохина НЮ, Петрова ММ, Савченко АА. Показатели тредмил-теста у больных острым коронарным синдромом и тревожно-депрессивными расстройствами. Сибирское медииинское обозрение. 2017;(5): 66-72. DOI: 10.20333/2500136-2017-5-66-72.

\section{TREADMILL TEST INDICATORS IN PATIENTS WITH ACUTE CORONARY SYNDROME AND ANXIETY-DEPRESSIVE DISORDERS}

N. Yu. Shimohina ${ }^{1}$, M. M. Petrova ${ }^{1}$, A. A. Savchenko ${ }^{1,2}$

${ }^{1}$ Professor V. F. Voino-Yasenetsky Krasnoyarsk State Medical University, Krasnoyarsk 660022, Russian Federation

${ }^{2}$ Institute for scientific research of medical problems of the North, laboratory of molecular and cellular physiology and pathology,

Krasnoyarsk 660022, Russian Federation

The aim of the research. To evaluate the functional parameters of the cardiovascular system according to the sample with the measured physical activity in patients with acute coronary syndrome in combination with anxiety-depressive disorders.

Material and methods. 315 patients were examined in the first 24 hours after the development of acute coronary syndrome (ACS). In the first 72 hours after the transfer from the reanimation chamber to determine anxiety-depressive disorders (TDR), all patients underwent psychometric examination. On the 7-10th day to the hospital discharge, a sample with a measured physical activity was made. The following parameters were analyzed: the total duration of the activity, the threshold power of the work performed, the metabolic equivalent, the duration of the activity, the initial blood pressure and heart rate, the maximum heart rate, maximum systolic and diastolic blood pressure.

Results. A positive result of treadmill test was observed more often in patients with ACS in combination with TDR in comparison with patients without affective disorders. The occurrence of pain angina pectoris was more common in patients with ACS in combination with TDR. In patients with ACS and TDR, obliquely downward depression of the ST segment was more common. The threshold of exercise tolerance, as well as the threshold load power in the ACS group with concomitant TDRs, were lower both in the control indicators and in the results of ACS patients without affective disorders. The duration of the load in the ACS and TDR group was significantly lower than that of patients with ACS without affective disorders.

The conclusion. In patients with ACS, the presence of concomitant DDR has a negative effect on the functional parameters of the cardiovascular system, which may be one of the reasons for the high risk of repeated cardiovascular disasters.

Key words: ischemic heart disease, acute coronary syndrome, exercise test, treadmill test, anxiety, depression.

Citation: Shimohina NYu, Petrova MM, Savchenko AA. Treadmill test indicators in patients with acute coronary syndrome and anxiety-depressive disorders. Siberian Medical Review. 2017; (5): 66-72. DOI: 10.20333/2500136-2017-5-66-72.

\section{Введение}

Ежегодно в Российской Федерации возникает около 520000 случаев острого коронарного синдрома (ОКС), который по-прежнему является основной причиной смертности во всем мире [1]. Этот термин включает в себя такие заболевания, как нестабильная стенокардия и острый инфаркт миокарда. Данные последних исследований свидетельствуют о том, что депрессия и тревога связаны с прогрессирующим течением ишемической болезни сердца (ИБС) $[2,3]$. Так, риск сердечно-сосудистой смертности у больных ОКС и тревожно-депрессивными расстройствами (ТДР) в 2-2,6 раза выше, чем у пациентов без аффективных нарушений $[4,5,6]$. Можно предположить, что у пациентов с ОКС наличие сопутствующих тревожно-депрессивных расстройств оказывает негативное влияние на функциональные показатели сердечно-сосудистой системы, что может быть одной из причин неблагоприятного прогноза у этой категории больных $[7,8,9]$.

В связи с этим, целью исследования явилась оценка функциональных показателей сердечно-сосудистой системы по 
данным пробы с дозированной физической нагрузкой у больных ОКС в сочетании с тревожно-депрессивными расстройствами.

\section{Материал и методы}

Обследовано 315 больных в первые 24 часа после развития ОКС (60,0 [52,0;67,0] лет, 150 женщин, 165 мужчин). Критериями включения в исследование являлись: ОКС у пациентов обоего пола в возрасте от 35 до 75 лет в первые 24 часа поступления в стационар от начала заболевания и подписавших информированное согласие. Диагноз ОКС, а в дальнейшем нестабильной стенокардии или острого ин- фаркта миокарда (ОИМ), устанавливался согласно рекомендациям ВНОК [10].

В первые 72 часа после перевода из реанимационной палаты всем пациентам было выполнено психометрическое обследование. ТДР были выявлены у $161(51,1 \%)$ человека. У 154 (48,9\%) пациентов расстройств аффективного спектра не обнаружено. Были сформированы две группы: первая - больные ОКС с ТДР и вторая - больные ОКС без ТДР. В таблице представлены клинико-анамнестические характеристики пациентов, значимых различий между группами не обнаружено.

Характеристика пациентов с ОКС

\begin{tabular}{|c|c|c|c|}
\hline \multirow{2}{*}{ Показатели } & \multicolumn{2}{|c|}{ Больные ОКС } & \multirow{2}{*}{$\mathrm{p}$} \\
\hline & СТДР, $n=161$ & Без ТДР, $n=154$ & \\
\hline \multicolumn{4}{|l|}{ Возраст (число больных, \%) } \\
\hline Мужчины $\geq 55$ лет & $32(19,9)$ & $31(20,1)$ & 0,907 \\
\hline Женщины $\geq 65$ лет & $23(14,8)$ & $21(13,6)$ & 0,905 \\
\hline Курение (число больных, \%) & $81(50,3)$ & $75(48,7)$ & 0,923 \\
\hline \multicolumn{4}{|l|}{ Уровень липидов крови, (Ме; С25-С75) } \\
\hline Общий холестерин & 4,$86 ; 3,77-5,24$ & 4,17; 3,45-5,49 & 0,964 \\
\hline Холестерин липопротеидов высокой плотности & 0,$98 ; 0,79-1,23$ & 0,$96 ; 0,84-1,13$ & 0,121 \\
\hline Холестерин липопротеидов низкой плотности & 3,$37 ; 2,9-3,92$ & 3,$01 ; 2,14-3,80$ & 0,822 \\
\hline Триглицериды & 2,$15 ; 1,71-2,87$ & 1,$95 ; 1,54-2,62$ & 0,539 \\
\hline Семейный анамнез ранних ССЗ (число больных, \%) & $54(33,5)$ & $43(27,9)$ & 0,582 \\
\hline $\begin{array}{l}\text { Абдоминальное ожирение: окружность талии } \\
>102 \text { см для мужчин и > } 88 \text { см для женщин (число больных, \%) }\end{array}$ & $33(20,5)$ & $28(18,2)$ & 0,124 \\
\hline \multicolumn{4}{|l|}{ Сопутствующие заболевания (число больных, \%) } \\
\hline Гипертоническая болезнь & $148(91,9)$ & $134(87,0)$ & 0,260 \\
\hline Инфаркт миокарда & $46(28,6)$ & $33(21,4)$ & 0,546 \\
\hline Инсульт/ТИА & $25(15,5)$ & $20(13,0)$ & 0,670 \\
\hline Ангиопластика и стентирование коронарных артерий & $22(13,7)$ & $19(12,3)$ & 0,372 \\
\hline Аортокоронарное шунтирование & $4(2,5)$ & $3(1,9)$ & 0,670 \\
\hline Подъем сегмента ST на ЭКГ (число больных,\%) & $40(24,8)$ & $29(18,8)$ & 0,366 \\
\hline Тропонин I нг/мл (Ме; С25-С75) & 0,$1 ; 0,0-2,2$ & 0,$1 ; 0,0-1,9$ & 0,099 \\
\hline Риск по шкале GRACE в баллах (Me; C25-C75) & $\begin{array}{c}125,3 ; \\
108,9-144,6\end{array}$ & $\begin{array}{c}120,6 ; \\
109,4139,3\end{array}$ & 0,670 \\
\hline СРБ, мг/л, (Me; С25-С75) & 12,$9 ; 1,8-35,0$ & 8,$95 ; 2,35-25,85$ & 0,537 \\
\hline \multicolumn{4}{|l|}{ Класс ОСН по Killip (число больных, \%) } \\
\hline 0 & $57(35,4)$ & $60(39,0)$ & 0,845 \\
\hline 1 & $50(31,1)$ & $52(33,8)$ & 0,934 \\
\hline 2 & $35(21,7)$ & $31(20,1)$ & 0,398 \\
\hline 3 & $19(11,8)$ & $11(7,1)$ & 0,250 \\
\hline Нестабильная стенокардия (число больных,\%) & $72(44,7)$ & $67(43,2)$ & 0,904 \\
\hline Острый инфаркт миокарда (число больных,\%) & $89(55,3)$ & $87(56,5)$ & 0,537 \\
\hline Инфаркт миокарда передней стенки левого желудочка (число больных,\%) & $43(48,3)$ & $41(47,1)$ & 0,367 \\
\hline Инфаркт миокарда нижней стенки левого желудочка (число больных,\%) & $29(32,6)$ & $27(31,1)$ & 0,769 \\
\hline Инфаркт миокарда другой локализации (число больных,\%) & $17(19,1)$ & $19(21,8)$ & 0,281 \\
\hline
\end{tabular}


Проведение пробы с дозированной физической нагрузкой на аппарате «Astrocard FS 2012-332» (Россия) выполнялось перед выпиской пациентов из стационара, на 7-10 сутки. Нагрузочный ЭКГ-тест проводили с использованием беговой дорожки, применяя модифицированноый протокол Брюса (Mod. R. Bruce) $[11,12]$. Анализ эффективности тредмил-теста был выполнен по следующим переменным: общая продолжительность нагрузки (в секундах), пороговая мощность выполненной работы (в Ваттах), метаболический эквивалент (в METs), продолжительность нагрузки до момента возникновения приступа стенокардии и/или до появления горизонтальной или косонисходящей депрессии или элевации сегмента ST с амплитудой $\geq 1$ мм, локализующейся в точке 0,06 мс от конца желудочкового комплекса, регистрировавшейся хотя бы в одном стандартном отведении, в течение или после прекращения нагрузки (в секундах), исходные артериальное давление и ЧСС, максимальная ЧСС (уд/мин), максимальное систолическое артериальное давление (САД, мм рт. ст.), максимальное диастолическое артериальное давление (ДАД, мм рт. ст.).

Группу контроля составили 55 относительно здоровых

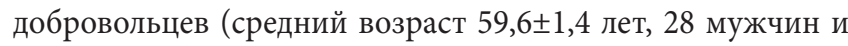
27 женщин).

Статистический анализ осуществляли в пакете программ Statistica 7.0 (StatSoft Inc. 2004). Описательная статистика для качественных признаков представлена в виде абсолютных значений и процентных долей. Описание количественных признаков производили с помощью подсчета медианы (Mе) и интерквартильного размаха в виде 25 и 75 процентилей (С25 и С75). Для определения характера распределения переменных использовали критерий КолмогороваСмирнова. Статистическая значимость различий между показателями независимых выборок оценивали по непараметрическому U-критерию Манна-Уитни. Статистическую значимость различий между показателями зависимых выборок оценивали по непараметрическому Т-критерию Вилкоксона. Различия считали значимыми при $\mathrm{p}<0,05$.

\section{Результаты и обсуждение}

Положительный результат тредмил-теста (ТT) у больных ОКС в сочетании с ТДР наблюдался достоверно чаще в сравнении с пациентами без нарушений аффективного спектра - у $87(54,0 \pm 3,9 \%$ ) и у $60(39,0 \pm 3,2 \%)$ обследованных соответственно (p=0,001). У $23(14,3 \pm 2,0 \%)$ человек из группы ОКС в сочетании с ТДР результаты ТТ были отрицательными, а у $51(31,7 \pm 3,0$ \%) больного - сомнительными. В группе больных ОКС без сопутствующих расстройств аффективного спектра отрицательный результат ТТ наблюдался у $31(20,1 \pm 2,3 \%)$ обследованного, сомнительный - у

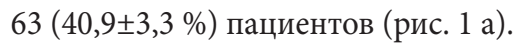

Возникновение болевого стенокардитического синдрома во время ТТ и потребовавшего её прекращения достоверно чаще наблюдалось у больных с ОКС в сочетании с ТДР - 92 $(57,1 \pm 4,0 \%)$ в сравнении с $62(40,3 \pm 3,2 \%)$ обследованными в группе ОКС без аффективных нарушений $(\mathrm{p}=0,001)$.
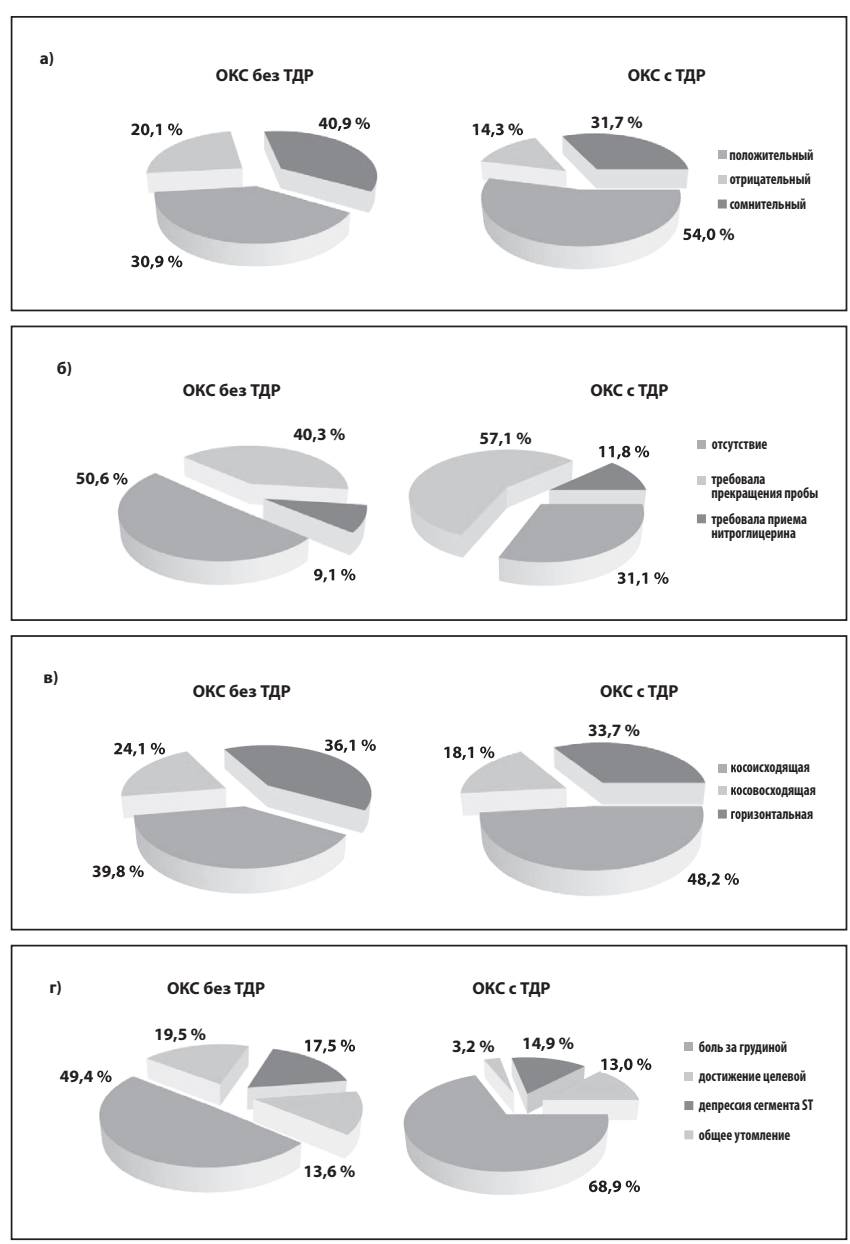

Рисунок 1. Результаты ТТ у больных ОКС в зависимости от наличия или отсутствия ТДР.

Приступ стенокардии, развившийся при проведении ТТ и потребовавший приема нитроглицерина, был отмечен у $19(11,8 \pm 1,8 \%)$ больных ОКС в сочетании с ТДР и у 14 $(9,1 \pm 1,5 \%)$ пациентов с ОКС без ТДР. У $50(31,1 \pm 3,0 \%)$ че-

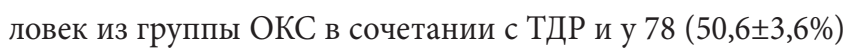
больных ОКС без аффективных нарушений болевой синдром во время ТТ не зарегистрирован (p=0,001) (рис. 1 б).

При возникновении смещения сегмента ST на высоте пробы с физической нагрузкой различали горизонтальный, косонисходящий и косовосходящий её типы. В группе больных ОКС в сочетании с ТДР чаще наблюдался косо-

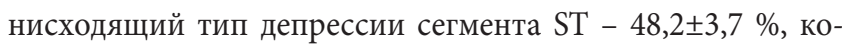
совосходящая депрессия сегмента ST отмечена в $18,1 \pm 2,3 \%$

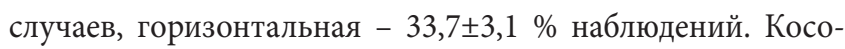
нисходящее смещение сегмента ST отмечено в $39,8 \pm 3,2 \%$ случаев в группе больных с ОКС без ТДР, косовосходящая депрессия сегмента ST зарегистрирована у $24,1 \pm 2,5 \%$, гори-

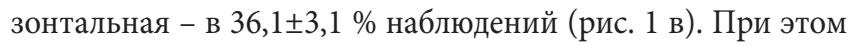
ни у кого из обследованных не отмечалось подъема сегмента ST во время ТT. Частота встречаемости косонисходящей депрессии сегмента ST достоверно чаще отмечена в группе больных ОКС в сочетании с ТДР в сравнении с пациентами без аффективных нарушений $(\mathrm{p}=0,001)$.

Основной причиной прекращения пробы с дозированной физической нагрузкой у больных ОКС в сочетании с 


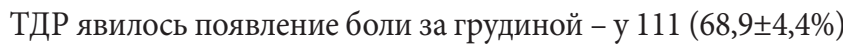
обследованных, у $24(14,9 \pm 2,1 \%)$ пациентов - возникновение депрессии сегмента ST, у 21 (13,0土1,9\%) больного - общее утомление и у $5(3,2 \pm 1,0 \%)$ человек - достижение целевых значений ЧСС. В группе больных ОКС без ТДР у $76(49,4 \pm 3,6 \%)$ человек причиной прекращения ТТ послу-

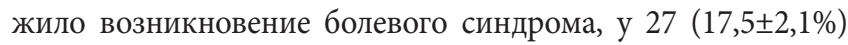
- депрессия сегмента ST, у 21 (13,6士1,9\%) больного - общее

a)

Пороговая мощность, Вт
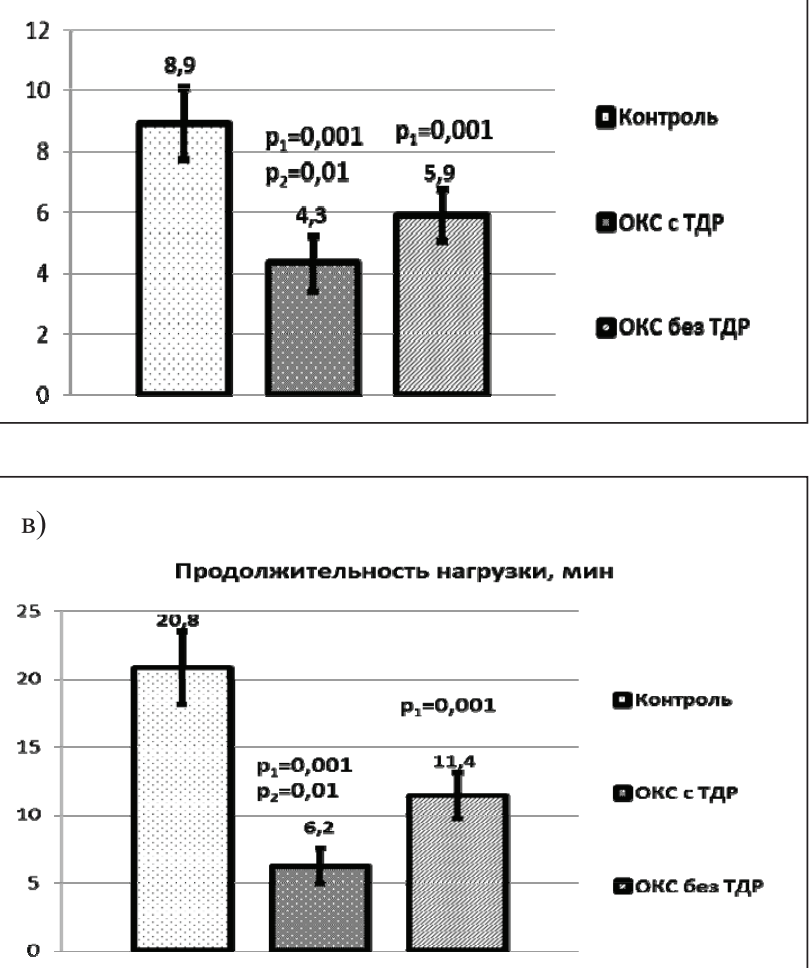

б)

Метаболический эквивалент потребления кислорода, МЕ

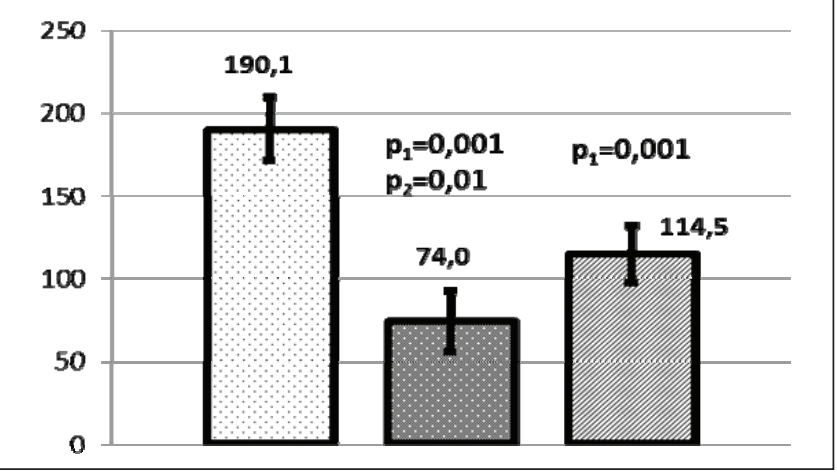

Рисунок 2. Результаты ТТ у больных ОКС в зависимости от наличия или отсутствия ТДР.

Примечание: $p 1$ - достоверное отличие от показателей контроля; 22 - достоверное отличие от показателей больных без ТДР. утомление и у $30(19,5 \pm 2,3 \%)$ человек - достижение целевого уровня ЧСС (рис. 1 г). Среди больных ОКС без аффективных нарушений достоверно чаще отмечалось достижение целевых цифр ЧСС в ходе проведения ТТ в сравнении с пациентами с ОКС и сопутствующими ТДР ( $\mathrm{p}=0,001)$.

Порог толерантности к нагрузке в группе ОКС с сопутствующими ТДР составил 74,0 (56,1-87,3) Вт и был достоверно ниже как показателей контроля, так и результатов больных группы ОКС без аффективных нарушений - 114,5 (101,6-129,2) Вт (p=0,001 и p=0,01 соответственно) (рис. 2 a). Кроме того, пороговая мощность нагрузки в METS у пациентов с ОКС и сопутствующими ТДР, составившая 4,3 (2,9-5,4) ME, была достоверно ниже показателей как группы ОКС без ТДР - 5,9 (5,4-6,2) МЕ, так и значений контрольной группы ( $\mathrm{p}=0,001$ и $\mathrm{p}=0,01$ соответственно) (рис. 2 б).

Продолжительность нагрузки у больных ОКС в сочетании с ТДР, составившая 6,2 $(4,5-8,1)$ минут, так же была существенно ниже показателей контроля и пациентов с ОКС без аффективных нарушений - 11,4 (9,8-14,2) минут ( $\mathrm{p}=0,001$ и $\mathrm{p}=0,01$ соответственно) (рис. 2 г).

В результате проведения тредмил-теста установлено, что в группе больных ОКС исходные значения ЧСС были несколько ниже в сравнении с контрольными, по-видимому, за счет медикаментозного эффекта, однако результаты не достигли достоверной значимости и составили 66,2 (59,3-70,4) уд/мин в группе ОКС без ТДР и 68,7 $(60,5-72,6)$ уд/мин в группе ОКС с сопутствующими нарушениями аффективного спектра. Однако пациентам в группе ОКС без ТДР на высоте пробы с физической нагрузкой удалось достигнуть более высоких значений ЧСС - 132,1 $(118,6-145,4)$ уд/мин в сравнении с пациентами группы ОКС с сопутствующими ТДР - 113,6 (98,2$121,8)$ уд/мин (p=0,01) (рис. 3 a).

Как и в предыдущем случае, исходные показатели САД значимо не различались в обеих группах больных, составляя 124,5 (115,6-130,2) мм рт. ст. в группе ОКС без ТДР и 129,4 $(118,3-134,1)$ мм рт. ст. у пациентов с ОКС и сопутствующими аффективными нарушениями (рис. 3 б). При этом в обеих группах больных исходные показатели ДАД так же значимо не отличались как между собой, так и в сравнении с показателями контроля, составляя 86,3 $(76,4-89,2)$ мм рт. ст. у пациентов ОКС без ТДР и 88,4 (77,5-92,4) мм рт. ст. в группе больных ОКС и сопутствующими аффективными нарушениями.

На высоте пробы с физической нагрузкой максимальные значения ДАД достоверно превышали показатели контроля как в группе больных ОКС с сопутствующими ТДР, составляя 105,6 (99,4-112,8) мм рт. ст., так и в группе пациентов с ОКС без аффективных нарушений 104,8 (97,5-110,2) мм рт. ст. ( $\mathrm{p}=0,01$ в обоих случаях). Максимальные показатели САД в обеих группах больных так же превысили результаты контроля, составляя $160,9(147,8-164,5)$ мм рт. ст. в группе ОКС без ТДР и 165,4 (151,2-171,5) мм рт. ст. у больных ОКС с сопутствующими расстройствами аффективного спектра, но только в последнем случае различия достигли статистической значимости $(\mathrm{p}=0,05)$ (рис. 3 в). 

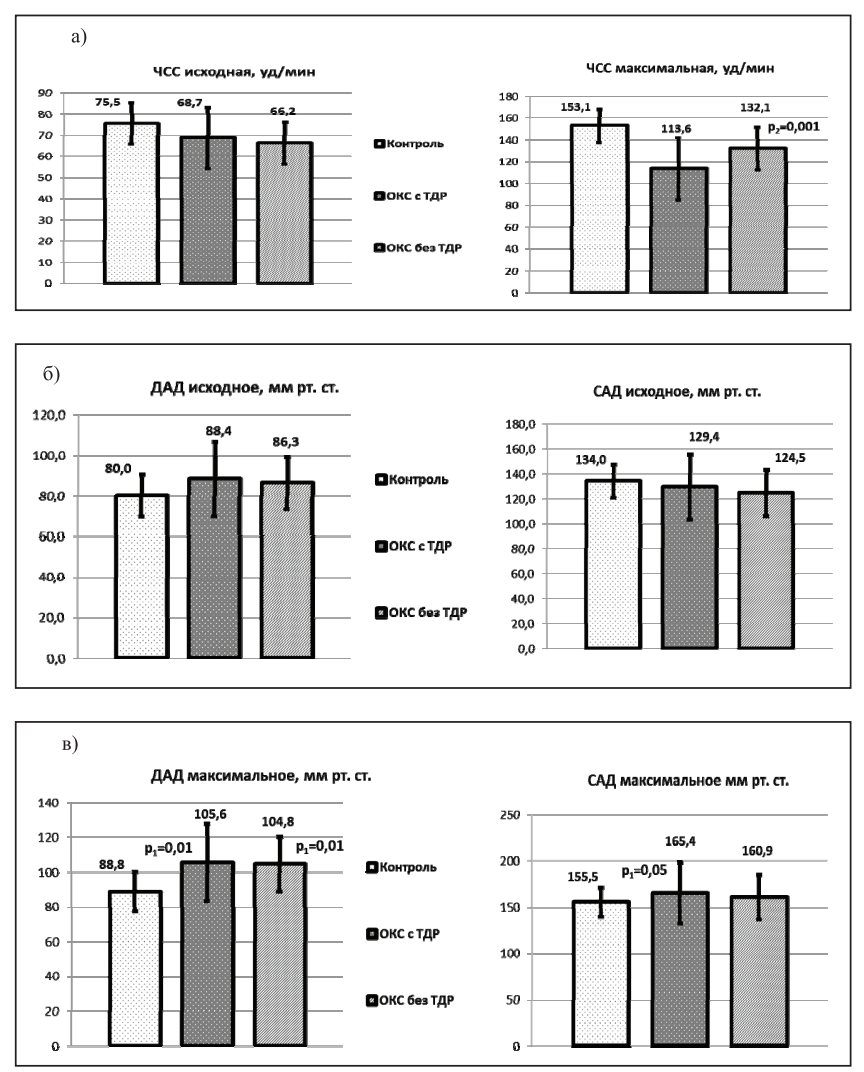

Рисунок 3. Результаты ТТ у больных ОКС в зависимости от наличия или отсутствия ТДР.

Примечание: 1 - достоверное отличие от показателей контроля; 22 - достоверное отличие от показателей больных без ТДР.

\section{Заключение}

При анализе пробы с дозированной физической нагрузкой у больных ОКС обнаружено, что положительный результат тредмил-теста наблюдался достоверно чаще у больных ОКС в сочетании с ТДР в сравнении с пациентами без нарушений аффективного спектра. Возникновение болевого стенокардитического синдрома во время ТТ, потребовавшего её прекращения, также достоверно чаще наблюдалось у больных с ОКС в сочетании с ТДР в сравнении с группой ОКС без аффективных нарушений. В группе больных ОКС в сочетании с ТДР при проведении пробы достоверно чаще наблюдалась косонисходящая депрессия сегмента ST в сравнении с пациентами без ТДР. В ходе проведения ТT среди больных ОКС без аффективных нарушений достоверно чаще отмечалось достижение целевых цифр ЧСС в сравнении с пациентами с ОКС и сопутствующими ТДР. Порог толерантности к физической нагрузке, а также пороговая мощность нагрузки в группе ОКС с сопутствующими ТДР был достоверно ниже как показателей контроля, так и результатов больных группы ОКС без аффективных нарушений. Продолжительность нагрузки у больных ОКС в сочетании с ТДР так же была существенно ниже показателей контроля и пациентов с ОКС без аффективных нарушений.

В ряде исследований установлено, что наличие ише- мических изменений у больных ИБС с сопутствующими ТДР связано с неблагоприятным прогнозом течения заболевания $[13,14,15]$. Одним из возможных механизмов более частого появления ишемических изменений на ЭКГ в ходе проведения ТТ у больных ОКС в сочетании с ТДР могут быть гемодинамические нарушения в виде высокого артериального давления, а также изменения в гемостазе, наличие эндотелиальной дисфункции и диастолической дисфункции миокарда. В частности, максимальные показатели САД на высоте нагрузки только у больных ОКС с сопутствующими расстройствами аффективного спектра были значимо выше показателей контроля. Можно предположить, что достоверно более частое появление признаков ишемии миокарда по ЭКГ в ходе проведения пробы с физической нагрузкой у больных ОКС с сопутствующими ТДР, служит одним из возможных объяснений неблагоприятной ассоциации между расстройствами аффективного спектра и прогнозом у больных ИБС.

\section{Литература}

1. Самородская ИВ, Кондрикова НВ, Казачек ЯВ, Барбараш ОЛ, Бойцов СА. Нозологическая структура смертности от болезней системы кровообращения в 2006 и 2013 годах. Комплексные проблемы сердечно-сосудистых заболеваний. 2015;4:67-72.

2. Пилюгина М, Шимохина $\mathrm{H}$, Петрова М, Савченко А, Павлова Н. Депрессия как фактор риска тромботических осложнений при остром коронарном синдроме. Врач. 2014;12:60-3.

3. Черняева МС, Петрова ММ, Савченко АА, Шимохина НЮ, Каскаева ДС, Пронина ЕА. Острый инфаркт миокарда и расстройства аффективного спектра. Сибирское медицинское обозрение. 2015;(3):5-14

4. Погосова ГВ. Депрессия - фактор риска развития ишемической болезни сердца и предиктор коронарной смерти: 10 лет научного поиска. Кардиология. 2012;52(12):4-11.

5. Пинчук АФ. Депрессивные расстройства и риск кардиоваскулярных событий. Медицинский журнал. 2015;1(51):34-8.

6. Batelaan NM, Seldenrijk A, Bot M, van Balkom AJ, Penninx BW. Anxiety and new onset of cardiovascular disease: critical review and meta-analysis. The British journal of psychiatry. 2016;208(3):223-31. DOI: 10.1192/bjp.bp.114.156554.

7. Celano CM, Millstein RA, Bedoya CA, Healy BC, Roest AM, Huffman JC. Association between anxiety and mortality in patients with coronary artery disease: A meta-analysis. American Heart Journal. 2015;170(6):1105-15. DOI: 10.1016/j. ahj.2015.09.013.

8. Шимохина НЮ, Пилюгина МС, Петрова ММ, Савченко АА, Еремина НП. Особенности эхокардиографических показателей у больных острым коронарным синдромом с сопутствующими тревожно-депрессивными расстройствами. Бюллетень сибирской медииины. 2014;6:34-39.

9. Кожокарь КГ, Урванцева ИА, Николаев КЮ. Влияние психосоциальных факторов на развитие ишемической бо- 
лезни сердца и острого коронарного синдрома. Кардиоваскулярная терапия и пробилактика. 2016;15(3):58-62.

10. Диагностика и лечение больных острым инфарктом миокарда с подъемом сегмента ST ЭКГ. Национальные клинические рекомендации. М.: Силицея-Полиграф; 2009:416-500.

11. Лупанов ВП, Нуралиев ЭЮ. Функциональные нагрузочные пробы в диагностике ишемической болезни сердца. M; 2012. 224 c.

12. Sharma K, Kohli P, Gulati M. An update on exercise stress testing. Current problems in cardiology. 2012;37(5):177-202. DOI: 10.1016/j.cpcardiol.2011.11.004.

13. Boyle SH, Samad Z, Becker RC, Williams R, Kuhn C, Ortel TL, Kuchibhatla M, Prybol K, Rogers J, O’Connor C, Velazquez EJ, Jiang W. Depressive symptoms and mental stress-induced myocardial ischemia in patients with coronary heart disease. Psychosomatic medicine. 2013;75(9): 822-31. DOI: 10.1097/ PSY.0b013e3182a893ae.

14. Wei J, Rooks C, Ramadan R, Shah AJ, Bremner JD, Quyyumi AA, Kutner M, Vaccarino V. Meta-analysis of mental stress-induced myocardial ischemia and subsequent cardiac events in patients with coronary artery disease. The American Journal of Cardiology. 2014;114(2):187-92. DOI: 10.1016/j. amjcard.2014.04.022.

15. Carney RM, Freedland KE. Depression and coronary heart disease. Nature Reviews Cardiology. 2017;14(3):145-155. DOI: $10.1038 /$ nrcardio.2016.181.

\section{References}

1. Samorodskaya IV, Kondrikova NV, Kazachek YaV, Barbarash OL, Boitsov SA. The Nosological structure of mortality circulatory system in 2006 and 2013. Kompleksnye problemy serdechnososudistykh zabolevanii. 2015;4:67-72. (In Russian)

2. Pilyugina M, Shimokhina N, Petrova M, Savchenko A, Pavlova N. Depression as a risk factor for thrombotic events in acute coronary syndrome. Vrach. 2014;12:60-63. (In Russian)

3. Chernyaeva MS, Petrova MM, Savchenko AA, Shimokhina NYu, Kaskaeva DS, Pronina EA. Acute myocardial infarction and affective spectrum disorders. Siberian Medical Review. 2015;(3):5-14. (In Russian)

4. Pogosova GV. Depression - a Risk Factor for Coronary Heart Disease and a Predictor of Coronary Death: 10 Years of Scientific Research. Kardiologiya. 2012;52(12):4-11. (In Russian)

5. Pinchuk AF. Depressive disorders and risk of cardiovascular events among patients after myocardial infarction. Meditsinskij zhurnal. 2015;1(51):34-38. (In Russian)

6. Batelaan NM, Seldenrijk A, Bot M, van Balkom AJ, Penninx BW. Anxiety and new onset of cardiovascular disease: critical review and meta-analysis. The British journal of psychiatry. 2016;208(3):223-31. DOI: 10.1192/bjp.bp.114.156554.

7. Celano CM, Millstein RA, Bedoya CA, Healy BC, Roest AM, Huffman JC. Association between anxiety and mortality in patients with coronary artery disease: A meta-analysis. American Heart Journal. 2015;170(6):1105-15. DOI: 10.1016/j. ahj.2015.09.013.

8. Shimokhina NYu, Pilyugina MS, Petrova MM, Savche- nko AA, Eremina NP. Peculiarities of parameters of echocardiographic in patients with acute coronary syndrome with comorbid anxiety and depressive disorders. Bulletin of Siberian Medicine. 2014;6:34-39. (In Russian)

9. Kozhokar' KG, Urvantseva IA, Nikolaev KYu. The influence of psychosocial factors on the development of ischemic heart disease and acute coronary syndrome. Kardiovaskulyar. terapiya i profilaktika. 2016;15(3):58-62. (In Russian)

10. Diagnosis and treatment of patients with acute myocardial infarction with ST-segment elevation ECG. National clinical guidelines. M.: Silitseya-Polygraph Publ.; 2009:416-500. (In Russian).

11. Lupanov VP, Nuraliev EYu. Functional loading tests in the diagnosis of coronary heart disease. M.; 2012. 224 p. (In Russian)

12. Sharma K, Kohli P, Gulati M. An update on exercise stress testing. Current problems in cardiology. 2012;37(5):177-202. DOI: 10.1016/j.cpcardiol.2011.11.004

13. Boyle SH, Samad Z, Becker RC, Williams R, Kuhn C, Ortel TL, Kuchibhatla M, Prybol K, Rogers J, O’Connor C, Velazquez EJ, Jiang W. Depressive symptoms and mental stress-induced myocardial ischemia in patients with coronary heart disease. Psychosomatic medicine. 2013;75(9): 822-31. DOI: 10.1097/ PSY.0b013e3182a893ae.

14. Wei J, Rooks C, Ramadan R, Shah AJ, Bremner JD, Quyyumi AA, Kutner M, Vaccarino V. Meta-analysis of mental stress-induced myocardial ischemia and subsequent cardiac events in patients with coronary artery disease. The American Journal of Cardiology. 2014;114(2):187-92. DOI: 10.1016/j. amjcard.2014.04.022.

15. Carney RM, Freedland KE. Depression and coronary heart disease. Nature Reviews Cardiology. 2017;14(3):145-155. DOI: $10.1038 /$ nrcardio.2016.181.

\section{Сведения об авторах}

Шимохина Наталья Юрвевна, Красноярский государственный медииинский университет имени профессора В.Ф. Войно-Ясенеияког; адрес: Российская Федераиия, 660022, г. Красноярск, ул. Партизана Железняка, д. 1; тел.: +7(391)2200628; e-mail:doctorkardiolog99@rambler.ru

Петрова Марина Михайловна, Красноярский государственный медицинский университет имени профессора В.Ф. Войно-Ясенеикого; адрес: Российская Федерация, 660022, г. Красноярск, ул. Партизана Железняка, д. 1; тел.: +7(391)2200628; e-mail: stk99@yandex.ru

Савченко Андрей Анатольевич, Красноярский государственный медииинский университет имени профессора В.Ф. Войно-Ясенеикого; адрес: Российская Федерация, 660022, 2. Красноярск, ул. Партизана Железняка, д. 1; Научно-исследовательский институт медицинских проблем Севера, лаборатория молекулярно-клеточной физиологии и патологии; адрес: Российская Федерация, 660022, г. Красноярск, ул. Партизана Железняка, д. 32; тел.: +7 (905)9713715; e-mail: aasavchenko@yandex.ru

\section{Information about the authors}

Shimohina Natalia Yu., Professor V. F. Voino-Yasenetsky Krasnoyarsk State Medical University; Address: 1, Partizan Zheleznyak Str., Krasnoyarsk, Russian Federation 660022; Phone: +7(391)2200628; e-mail: doctorkardiolog99@rambler.ru

Petrova Marina M., Professor V. F. Voino-Yasenetsky Krasnoyarsk State Medical University; Address: 1, Partizan Zheleznyak Str., Krasnoyarsk, Russian Federation 660022; Phone: +7(391)2200628; e-mail: stk99@yandex.ru

Savchenko Andrey A., Professor V. F. Voino-Yasenetsky Krasnoyarsk State Medical University Address: 1, Partizan Zheleznyak Str., Krasnoyarsk, Russian Federation 660022; Institute for scientific research of medical problems of the North, laboratory of molecular and cellular physiology and pathology; Address: 3g, Partizan Zheleznyak Str., Krasnoyarsk, Russian Federation 660022; e-mail: aasavchenko@yandex.ru 


\title{
КОРРЕЛЯЦИОННЫЙ АНАЛИЗ СКРУЧИВАНИЯ ЛЕВОГО ЖЕЛУДОЧКА И ПОКАЗАТЕЛЕЙ ГЕМОДИНАМИКИ ПРИ БЛОКАДЕ ЛЕВОЙ НОЖКИ ПУЧКА ГИСА
}

Е. Н. Павлюкова ${ }^{1}$, Д. А. Кужель ${ }^{2}$, Г. В. Матюшин ${ }^{2}$, Е. И. Яковлев ${ }^{4}$, О. В. Новоселов ${ }^{4}$

${ }^{1}$ Научно-исследовательский институт кардиологии Томский национальный исследовательский медицинский центр Российской академии наук, Томск 634012, Российская Федерация

${ }^{2}$ Красноярский государственный медицинский университет имени профессора В. Ф. Войно-Ясенецкого, Красноярск 660022, Российская Федерация.

${ }^{3}$ Красноярская краевая больница №2, Красноярск 660049, Российская Федерация

${ }^{4}$ Сибирский государственный аэрокосмический университет имени академика М. Ф. Решетнёва, Красноярск 660037, Российская Федерация

Цель исследования. Изучить взаимосвязь скручивания ЛЖ и показателей гемодинамики у пациентов с БЛНПГ и систолической дисфункцией. Материал и методы. Обследовано 30 пациентов с БЛНПГ с ишемической и дилатационной кардиомиопатиями и фракцией выброса ЛЖ менее 40 \%. Все больные были разделены на две группы по 15 человек: с физиологическим разнонаправленным вращением базальных отделов и верхушки (группа 1) и аномальным однонаправленным (группа 2). Всем больным была выполнена эхокардиография с определением показателей гемодинамики, деформации миокарда и скручивания. Корреляционные связи между парами количественных признаков проводилась с использованием непараметрического рангового коэффициента Спирмена.

Результаты. В группе БЛНПГ и физиологическим (разнонаправленным) вращением наблюдалась корреляция между скручиванием и вращением на уровне верхушки и базальных отделов. В группе аномального (однонаправленного) вращения подобная связь отсутствовала. При анализе корреляционных связей апикального и базального вращения, а также результирующего скручивания с показателями гемодинамики в группе физиологического вращения были выявлены связи с ЧСС, фракцией выброса ЛЖ, индексом локальной сократимости, показателями диастолической функции, глобальной циркулярной деформацией на апикальном уровне. В группе с аномальным вращением корреляционные связи вращения и скручивания с показателями гемодинамики были представлены только с циркулярной деформацией на уровне базальных отделов и показателями потока тегочных вен.

Заключение. Слабые связи вращения и скручивания с показателями гемодинамики в группе аномального вращения могут указывать на отсутствие существенной их взаимной зависимости и утрату физиологической роли скручивания в сокращении левого желудочка.

Ключевые слова: систолическая дисфункция, эхокардиография, деформация миокарда, ротация, скручивание, полная блокада левой ножки пучка Гиса.

Для цитирования: Павлюкова ЕН, Кужель ДА, Матюшин ГВ, Яковлев ЕИ, Новоселов ОВ. Корреляционный анализ скручивания левого желудочка и показателей гемодинамики при блокаде левой ножки пучка Гиса. Сибирское медищинское обозрение. 2017;(5): 73-79. DOI: 10.20333/25001362017-5-73-79.

\section{CORRELATION ANALYSIS OF LEFT VENTRICLE TWISTING AT BLOCKADE OF VENTRICULONECTOR LEFT LEG}

\author{
E. N. Pavlyukova ${ }^{1}$, D. A. Kuzhel ${ }^{2}$, G. V. Matyushin², E. I. Yakovlev', O. V. Novoselov ${ }^{4}$ \\ ${ }^{1}$ Research Institute of Cardiology, Siberian Branch of Russian Academy of Medical Sciences, Tomsk 634012, Russian Federation \\ ${ }^{2}$ Professor V. F. Voino-YasenetskyKrasnoyarsk State Medical University; 660022, Russian Federation \\ ${ }^{3}$ Regional State Hospital №2, Krasnoyarsk 660049, Russian Federation \\ ${ }^{4}$ M. F. Reshetnev Krasnoyarsk State Aerospace University. Krasnoyarsk 660037, Russian Federation
}

The aim of the research. To study the relationship between LV twisting and hemodynamic parameters in patients with BLNGH and systolic dysfunction. Material and methods. Thirty patients with BLNGH with ischemic and dilated cardiomyopathies and LV ejection fraction less than $40 \%$ were examined. All patients were divided into two groups of 15 people: with physiological multidirectional rotation of the basal sections and apex (group 1) and anomalous unidirectional (group 2). All patients underwent echocardiography with determination of hemodynamic parameters, myocardial deformation and twisting. Correlation connections between pairs of quantitative characteristics were carried out using the nonparametric Spearman rank coefficient.

Results. In the group of BLNPH and physiological (multidirectional) rotation, a correlation was observed between twisting and rotation at the level of the apex and basal sections. In the group of anomalous (unidirectional) rotation, such connection was absent. When analyzing the correlation of the apical and basal rotation, as well as the resulting twisting with the parameters of hemodynamics in the group of physiological rotation, connections with heart rate, LV ejection fraction, local contractility index, diastolic function indices, global circular deformation at the apical level were revealed. In the group with anomalous rotation, the correlations of rotation and twisting with hemodynamic parameters were presented only with circular deformation at basal level and with pulmonary veins. 
The conclusion. Weak connections of rotation and twisting with indices of hemodynamics in the group of anomalous rotation may indicate a lack of significant mutual dependence and loss of the physiological role of twisting in contraction of the left ventricle.

Key words: systolic dysfunction, echocardiography, deformation of the myocardium, rotation, twisting, complete blockage of the ventriculonector left leg. Citation: Pavlyukova EN, Kuzhel DA, Matyushin GV, Yakovlev EI, Novoselov OV. Correlation analysis of left ventricle twisting at blockade of ventriculonector left leg. Siberian Medical Review. 2017;(5):73-79. DOI: 10.20333/2500136-2017-5-73-79.

\section{Введение}

Скручивание левого желудочка (ЛЖ) играет ведущую роль в нормальном функционировании его систолической и диастолической функции, однако этот движение может быть подвержено негативному влиянию различных процессов, в том числе и болезней системы проведения [1-3]. Известно, что блокада левой ножки пучка Гиса (БЛНПГ) уменьшает скручивание среди лиц с кардиопатиями и систолической дисфункцией. Это отрицательное влияние может в значительной степени ухудшать состояние гемодинамики ЛЖ $[4,5]$. Несмотря на активное изучение влияния БЛНПГ на функцию ЛЖ, многое в понимании механизмов негативного эффекта этого нарушения проведения остается неясным.

Целью нашей работы было изучение корреляционных связей разных вариантов скручивания с показателями гемодинамики среди лиц с блокадой левой ножки пучка Гиса и систолической дисфункцией.

\section{Материал и методы}

Исследование было выполнено у 30 лиц с полной БЛНПГ (средняя продолжительность QRS 153,1 \pm 24,5 мс, $(\mathrm{M} \pm \mathrm{SD}))$, имеющих выраженную систолическую дисфункцию ЛЖ ишемического или неишемического генеза в возрасте 30-60 лет с признаками хронической сердечной недостаточности III-IV функционального класса согласно NYHA. Критерием включения было наличие синусового ритма на ЭКГ, снижение сократительной способности ЛЖ с фракцией выброса (ФВ) менее $40 \%$, конечный диастолический объем (КДО) ЛЖ более 180 мл. Всем больным была выполнена коронаровентрикулография. Под ишемической кардиомиопатией понималась систолическая дисфункция ЛЖ с развитием застойной сердечной недостаточности при наличии одного или более из перечисленных признаков: наличие в анамнезе инфаркта миокарда или реваскуляризации миокарда, стеноз ствола левой коронарной артерии, передней нисходящей коронарной артерии или двух и более коронарных сосудов со стенозом более 75 \% [6]. Диагноз дилатационной кардиомиопатии устанавливался на основании критериев, предложенных L. Mestroni et al. [7]. Критериями исключения служили: ФВ ЛЖ $\geq 40 \%$, органическое поражение клапанов сердца, перенесенный инфаркт миокарда и/или инсульт менее 6 месяцев. У всех включенных в исследование пациентов было подписано информированное согласие на проведение эхокардиографии (ЭхоКГ) и анализ исследования в режиме off-line. Исследование сердца производилось на ультразвуковом аппарате «Vivid 7 Dimention» и «Vivid-S6» (GE Healthcare). Определялись стандартные ЭхоКГ-показатели в общепринятых доступах. В апикальной позиций на уровне 4-х и 2-х камер оценивался конечный диастолический и конечный систолический объемы, рассчитывалась ФВ ЛЖ по методике Simpson $\left(\mathrm{KДО}_{4 \mathrm{C}}, \mathrm{KCO}_{4 \mathrm{C}}, \mathrm{KДО}_{2 \mathrm{C}}, \mathrm{KCO}_{2 \mathrm{C}}\right.$, $\Phi \mathrm{B}_{4 \mathrm{C}}, \Phi \mathrm{B}_{2 \mathrm{C}}$ ), объем левого предсердия (ЛП), определялся индекс сферичности (IS), индекс локальной сократимости, оценивалось систолическое давление в легочной артерии (СДЛА) [8]. Оценка деформации (strain) миокарда ЛЖ проводилась по двухмерным изображениям, зарегистрированным из парастернального доступа в позиции короткой оси и апикального доступа, позиции 4-х и 2-х камер. Серошкальные изображения (при частоте кадров (frame rate) 36 и более в секунду), автоматически «замораживались» в конце систолы с последующим оконтурированием границ эндокарда и автоматическим определением глобальной продольной деформации (GS \%), а также циркулярной деформации на уровне базальных и апикальных отделов $\left(\mathrm{GS}_{\mathrm{MV}}\right.$, \%, GSAp, \%). С целью изучения вращательного движения ЛЖ выполнялась ЭхоКГ в двухмерном режиме по стандартной методике из парастернального доступа по короткой оси ЛЖ на уровне фиброзного кольца митрального клапана и верхушки. В режиме кинопетли регистрировались три кардиоцикла, затем выполнялась оценка ротации и скручивания ЛЖ с помощью ультразвуковой технологии Speckle Tracking Imaging с использованием soft-программы (Echopac PC, GE Healthcare). По кривым, полученным на уровне митрального клапана и верхушки, рассчитывалось вращение ЛЖ в конце систолы на базальном $\left(\operatorname{Rot}_{\mathrm{MV}}\right)$ и апикальном уровнях $\left(\operatorname{Rot}_{\text {арех }}\right)$, выраженное в градусах. Нормальное движение верхушки в систолу подразумевает движение против часовой стрелки и изображается на графике в виде кривой, направленной вверх от изолинии, и оценивается как положительная величина. Тогда как нормальное вращение базальных отделов связано с движением по часовой стрелке, что показывается на графике как кривая направленная вниз и оценивается в отрицательных значениях. Результирующее скручивание ЛЖ (torsion) оценивалось количественно как выраженная в градусах ротация верхушки минус значение ротации на базальном уровне [9]. Диастолическая функция ЛЖ оценивалась по трансмитральному кровотоку из апикальной 4-х камерной позиции в 
режиме импульсно-волнового Допплера [10]. Определялась максимальная скорость $(\operatorname{Vmax})$ раннего $\left(\mathrm{E}_{\text {mitr }}\right)$ и позднего $\left(\mathrm{A}_{\text {mitr }}\right)$ наполнения, их отношение $\left(\mathrm{E}_{\text {mitr }} / \mathrm{A}_{\text {mitr }}\right)$, время изоволюмического расслабления (IVRT), время замедления пика Е (DT). В режиме импульсно-волновой тканевой допплерографии регистрировалась усредненная скорость движения базального сегмента боковой стенки и межжелудочковой перегородки в период раннего наполнения ЛЖ (Av. e'), отношение $\mathrm{E}_{\text {mitr }}$ / Av. e.' С помощью импульсно-волнового Допплера по динамике потока в легочных венах также определялись дополнительные показатели диастолической функции ЛЖ: скорость систолического потока (S PV), скорость диастолического потока (D PV), их отношение (S/D). Кроме того, оценивался скоростно-временной интеграл систолической (VTI S PV) и диастолической (VTI D PV) волны потока легочных вен, фракция систолического наполнения левого предсердия (SEF), временная разница между продолжительностью пика $\mathrm{Ar}$ потока легочных вен в систолу предсердий и продолжительности пика А диастолического трансмитрального потока (Ar-A), временной интервал от начала пика Е трансмитрального потока и пика е' тканевого Допплера (Т Е-е'), отношение времени изоволюмического расслабления и разницы между началом пика Е и е' (IVRT/T E-e'). Наличие внутрижелудочковой диссинхронии оценивалось как выраженная в миллисекундах (мс) задержка между пиком S (систолического сокращения) базаль-

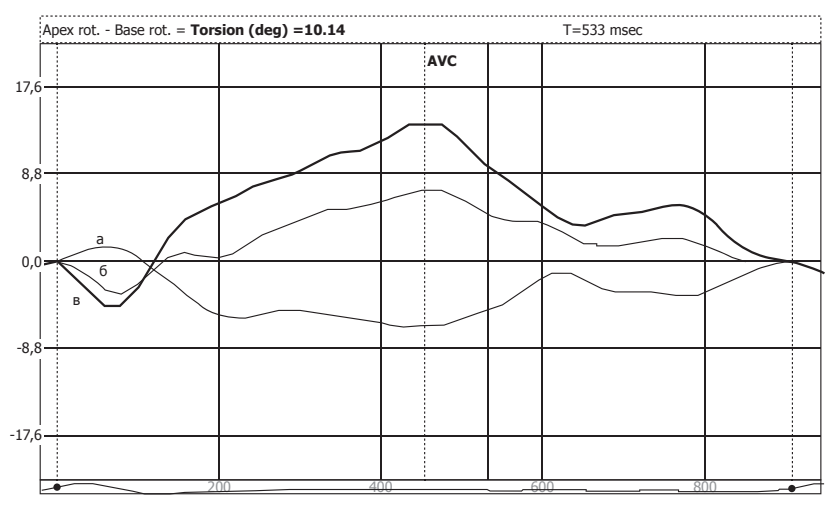

Рисунок 1. Нормальное физиологическое вращение базальных отделов (а) и верхушки (б). Результирующее скручивание (в).

ного септального сегмента и пиком $\mathrm{S}$ базального сегмента боковой или задней стенки в режиме цветового тканевого допплеровского картирования (DelS(CTD)).

По итогам ультразвукового исследования все пациенты были разделены на две группы. В 1-ю группу вошли 15 пациентов (53,7 \% мужчин) с физиологическим, то есть разнонаправленным вращением апикаль-

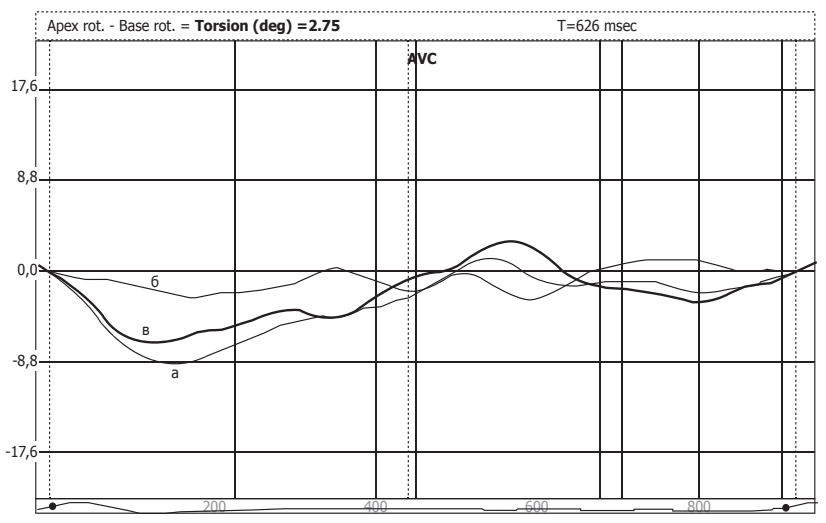

Рисунок 2. Аномальное (по часовой стрелке) вращение верхушки (а). Верхушка и базальные отдель врашаются в одном направлении - "rigid body rotation" $(6,8)$.

ных и базальных отделов (рис. 1), во 2-ю группу - 15 пациентов (60\% мужчин) с аномальным, то есть с их однонаправленным вращением (рuc. 2). Средний возраст пациентов в 1-й группе составил $63,0 \pm 10,1$ лет (медиана 63 года, нижняя квартиль - 55 лет, верхняя квартиль - 73 года), тогда как во 2-й группе - $62,7 \pm 13,5$ лет (медиана 63 года, нижняя квартиль - 51 год, верхняя квартиль - 71 год) ( $\mathrm{p}=0,75)$. В 1-й группе у 12 (80 \%) человек была диагностирована ишемическая и у 3 (20 \%) - дилатационная кардиомиопатия. Во 2-й группе у 11 (73,3 \%) была диагностирована ишемическая и у 4 (26,7 \%) - дилатационная кардиомиопатия.

Гипотеза о гауссовском распределении по критериям Колмогорова-Смирнова в форме Лиллиефорса (Lilliefors) и Шапиро-Уилка (Shapiro-Wilk) была отвергнута, поэтому оценка корреляционных связей между парами количественных признаков осуществлялась с использованием непараметрического рангового коэффициента Спирмена. Во всех процедурах статистического анализа критический уровень значимости р принимался равным 0,05 .

\section{Результаты и обсуждение}

При оценке корреляционных связей в первую очередь изучалась взаимная зависимость вращения на апикальном и базальном уровне, а также результирующего скручивания (см. таб. 1). Оказалось, что в 1-й группе (физиологическое вращение) наблюдалась зависимость скручивания от вращения на уровне верхушки и базальных отделов, тогда как взаимная зависимость отсутствовала. Напротив, во 2-й группе (аномальное вращение) результирующее скручивание не зависело от вращения на апикальном и базальном уровне, при этом присутствовала взаимная зависимость вращения апикальных и медиальных отделов.

Следующим этапом была оценка зависимости вращения на апикальном и базальном уровнях, а также результирующего скручивания от основных показателей 
Корреляционные связи между вращением на уровне базальных отделов, верхушки и итогового скручивания в 1-й группе

Таблиия 1 (физиологическое вращение) и 2-й группе (аномальное вращение)

\begin{tabular}{|c|c|c|c|c|c|c|}
\hline \multirow[t]{2}{*}{ Группа 1} & \multicolumn{2}{|c|}{ RotMV } & \multicolumn{2}{|c|}{ RotAp } & \multicolumn{2}{|c|}{ Torsion } \\
\hline & $\begin{array}{c}\text { Уровень } \\
\text { корреляции }\end{array}$ & $\begin{array}{c}\text { Уровень } \\
\text { значимости }\end{array}$ & $\begin{array}{c}\text { Уровень } \\
\text { корреляции }\end{array}$ & $\begin{array}{c}\text { Уровень } \\
\text { значимости }\end{array}$ & $\begin{array}{c}\text { Уровень } \\
\text { корреляции }\end{array}$ & $\begin{array}{c}\text { Уровень } \\
\text { значимости }\end{array}$ \\
\hline RotMV & & & $-0,066152$ & 0,822223 & $-0,784141$ & 0,000901 \\
\hline RotAp & $-0,066152$ & 0,822223 & & & 0,601985 & 0,022737 \\
\hline Torsion & $-0,784141$ & 0,000901 & 0,601985 & 0,022737 & & \\
\hline \multirow[t]{2}{*}{ Группа 2} & \multicolumn{2}{|c|}{ RotMV } & \multicolumn{2}{|c|}{ RotAp } & \multicolumn{2}{|c|}{ Torsion } \\
\hline & $\begin{array}{c}\text { Уровень } \\
\text { корреляции }\end{array}$ & $\begin{array}{c}\text { Уровень } \\
\text { значимости }\end{array}$ & $\begin{array}{c}\text { Уровень } \\
\text { корреляции }\end{array}$ & $\begin{array}{c}\text { Уровень } \\
\text { значимости }\end{array}$ & $\begin{array}{c}\text { Уровень } \\
\text { корреляции }\end{array}$ & $\begin{array}{c}\text { Уровень } \\
\text { значимости }\end{array}$ \\
\hline RotMV & & & 0,830306 & 0,000020 & 0,141969 & 0,574156 \\
\hline RotAp & 0,830306 & 0,000020 & & & 0,388803 & 0,110799 \\
\hline Torsion & 0,141969 & 0,574156 & 0,388803 & 0,110799 & & \\
\hline
\end{tabular}

Примечание: RotAp - ицркулярная деформация левого желудочка на уровне верхушки, RotMV - ииркулярная деформация левого желудочка на уровне базальньх отделов, Torsion - результирующее скручивание левого желудочка.

гемодинамики. Как видно из представленных данных в таблице 2 в группе с физиологическим вращением наблюдались множественные корреляционные связи вращения на апикальном и базальном уровне, а также итогового скручивания с показателями гемодинамики. Была выявлена зависимость от показателей, характе- ризующих глобальную функцию ЛЖ, в частности ЧСС, фракции выброса ЛЖ и индекса локальной сократимости.

Также была выявлена взаимосвязь с показателями, характеризующими диастолическую функцию - отношение скорости раннего трансмитрального наполне-

Таблица 2

Корреляционные связи между вращением на уровне базальных отделов, верхушки и итогового скручивания с показателями гемодинамики в 1-й группе (физиологическое вращение) и 2-й группе (аномальное вращение)

\begin{tabular}{|c|c|c|c|c|c|c|}
\hline \multirow[b]{2}{*}{ Группа 1} & \multicolumn{2}{|c|}{ RotMV } & \multicolumn{2}{|c|}{ RotAp } & \multicolumn{2}{|c|}{ Torsion } \\
\hline & $\begin{array}{c}\text { Уровень } \\
\text { корреляции }\end{array}$ & $\begin{array}{c}\text { Уровень } \\
\text { значимости }\end{array}$ & $\begin{array}{c}\text { Уровень } \\
\text { корреляции }\end{array}$ & $\begin{array}{c}\text { Уровень } \\
\text { значимости }\end{array}$ & $\begin{array}{c}\text { Уровень } \\
\text { корреляции }\end{array}$ & $\begin{array}{c}\text { Уровень } \\
\text { значимости }\end{array}$ \\
\hline $4 C C$ & 0,5318 & 0,034 & 0,690882 & 0,003 & 0,5621 & 0,0234 \\
\hline ФВ ЛЖ & & & & & 0,5456 & 0,0192 \\
\hline ИЛС & 0,54 & 0,0207 & 0,472727 & 0,048 & & \\
\hline$E_{\text {mitr }} / A v \cdot e^{\prime}$ & 0,6383 & 0,0058 & & & & \\
\hline SEF & 0,678 & 0,022 & & & & \\
\hline GSAp & & & & & 0,5178 & 0,04 \\
\hline \multirow[t]{2}{*}{ Группа 2} & \multicolumn{2}{|c|}{ RotMV } & \multicolumn{2}{|c|}{ RotAp } & \multicolumn{2}{|c|}{ Torsion } \\
\hline & $\begin{array}{c}\text { Уровень } \\
\text { корреляции }\end{array}$ & $\begin{array}{c}\text { Уровень } \\
\text { значимости }\end{array}$ & $\begin{array}{c}\text { Уровень } \\
\text { корреляции }\end{array}$ & $\begin{array}{c}\text { Уровень } \\
\text { значимости }\end{array}$ & $\begin{array}{c}\text { Уровень } \\
\text { корреляции }\end{array}$ & $\begin{array}{c}\text { Уровень } \\
\text { значимости }\end{array}$ \\
\hline Ar-A & & & & & 0,971 & 0,001 \\
\hline $\mathrm{GS}_{\mathrm{MV}}$ & 0,762435 & 0,0015 & & & 0,585903 & 0,0277 \\
\hline
\end{tabular}

Примечание: ИЛС - индекс локальной сократимости, ЧСС - частота сердечных сокрашений, ФВ ЛЖ - фракиия выброса левого желудочка, Аr-A - разница в продолжительности пика Аr (систола предсердий при регистрации потока легочных вен) и пика А трансмитрального потока, GSMV - ииркулярная дебормачия левого желудочка на уровне базальных отделов, Emitr / Av. e' - отночение пиковой ранней диастолической скорости трансмитрального потока к усредненной пиковой ранней диастолической скорости базальных сегментов левого желудочка в импульсно-волновом тканевом режиме, GSAp - ииркулярная деформация на уровне верхушки тевого желудочка, SEF - фракиия систолического потока легочных вен в наполнении тевого предсердия, RоtАр - ииркулярная дебормачия левого желудочка на уровне верхушки, RotMV - ииркулярная деформация левого желудочка на уровне базальных отделов, Тогsion - результирующее скручивание левого желудочка. 
ния к усредненной скорости импульсного тканевого допплера в фазу ранней диастолы ( $\mathrm{E}_{\text {mitr }}$ / Av. e'), а также с систолической фракцией потока легочных вен (SEF). Наконец, была выявлена зависимость результирующего скручивания ЛЖ от циркулярной деформации на апикальном уровне.

С другой стороны, в группе с аномальным вращением корреляционные связи вращения и скручивания были крайне скупыми. Зависимость от диастолической функции была продемонстрирована корреляцией итогового скручивания с разницей в продолжительности предсердного пика Ar потока легочных вен и пика A трансмитрального потока (Ar-A). Кроме того, в этой группе обращает на себя внимание зависимость итогового скручивания от циркулярной деформации, но уже на базальном уровне.

Скручивание ЛЖ имеет неоспоримое физиологическое значение для нормального обеспечения систолической и диастолической функции сердца [3]. Этот процесс может быть подвержен негативному влиянию различных заболеваний, в том числе и нарушения проведения по ЛЖ $[1,5,11]$. Как один из наиболее неблагоприятных с точки зрения физиологии сценариев систолического движения ЛЖ, описано, так называемое, однонаправленное («ригидное») движение верхушки и базальных отделов, которые в физиологических условиях должны вращаться в противоположных направлениях $[11,12]$. В этой связи представляется интересным определение взаимных зависимостей вращения на апикальном и базальном уровнях и результирующего скручивания. Анализ этого процесса показал, что в группе с физиологическим (разнонаправленным) вращением верхушки и основания наблюдалась зависимость итогового скручивания от этих ротаций, что представляется вполне закономерным, поскольку в нормальных условиях этот параметр является результатом алгебраической суммы этих показателей. В группе с аномальным (однонаправленным) вращением такой зависимости не наблюдалось, что вероятно также является закономерным, однако присутствовала взаимная зависимость вращений на апикальном и базальном уровне. В этой связи представляется интересным зависимость вращений и скручивания от деформационных свойств миокарда в изучаемых группах.

Принято считать, что в норме сократительная способность ЛЖ в значительной степени зависит от вращения на апикальном уровне. Поэтому, при развитии кардиопатий изменения в сократимости и вращении в наибольшей степени затрагивают именно апикальные отделы, а уменьшение результирующего скручивания лЖ происходит, главным образом, из-за снижения апикального вращения [13]. Неудивительно, что в ис- следовании, проведенном нами, в группе физиологического вращения наблюдалась зависимость скручивания от циркулярной деформации именно на апикальном уровне. С другой стороны, в группе аномального вращения наблюдалась зависимость скручивания уже от циркулярной деформации на базальном уровне. Этот факт подтверждает ранее высказанное предположение о доминирующей роли базальных отделов, когда постепенная инверсия вращения верхушки заканчивается переходом в движение, повторяющее вращение основания ЛЖ [13].

Тесная взаимосвязь вращения и скручивания с диастолической функцией ЛЖ была продемонстрирована в обеих группах. Однако в группе с физиологическим вращением такая связь представляется более сильной, так как наблюдалась по двум параметрам - отношению скорости раннего трансмитрального наполнения к усредненной скорости импульсного тканевого допплера в фазу ранней диастолы ( $\mathrm{E}_{\text {mitr }} /$ Av. e') и с систолической фракцией потока легочных вен (SEF). В группе с аномальным вращением была выявлена только одна зависимость скручивания от разницы в продолжительности предсердного пика Ar потока легочных вен и пика А трансмитрального потока (Ar-A). Все вышеперечисленные показатели используются для определения высокого давления наполнения ЛЖ, более того, они зависимы от параметров вращения и скручивания.

Наконец, в группе с физиологическим вращением наблюдалась зависимость вращения и скручивания от показателей, характеризующих глобальную функцию ЛЖ, в частности с фракцией выброса, ЧСС и индексом локальной сократимости, поскольку большинство пациентов, в основе заболевания, имело ишемическую кардиомиопатию.

Как известно, спиральная архитектура миокарда и скручивание облегчает однородное распределение стресса во время сокращения волокон миокарда на стенку ЛЖ. Устранение скручивания может увеличить стресс эндокардиальных волокон и потребление кислорода, что уменьшит эффективность систолической функции ЛЖ. Не просто утолщение или сокращение продольных и циркулярных волокон, а вращательное движение спиральных волокон, является фундаментальным механизмом сокращения ЛЖ, и обеспечивает эффективную его работу вплоть до 40 \% ударного объёма ЛЖ. Наконец, скручивание, деформируя матрикс миокарда, сохраняет потенциальную энергию сокращения, которая впоследствии используется в качестве диастолической отдачи и облегчает всасывание $[14,15]$.

Таким образом, слабые связи вращения и скручивания с показателями гемодинамики в группе аномального вращения, вероятно, могут указывать на отсутствие 
существенной их взаимной зависимости, а также на то, что эти движения утрачивают значимую физиологическую роль в работе сердца. Возможно, это является свидетельством своеобразной физиологической перестройки в работе ЛЖ и перехода на качественно иной, вероятно, более энергозатратный уровень функционирования сердца.

\section{Литература}

1. Павлюкова EH, Кужель ДА, Матюшин ГВ, Савченко ЕА, Филиппова СА. Ротация, скручивание и раскручивание левого желудочка: физиологическая роль и значение в клинической практике. Рациональная бармакотерапия в кардиологии. 2015;11(1):68-78.

2. Beladan CC, Calin A, Rosca M, Ginghina C, Popescu BA. Left ventricular twist dynamics: principles and applications. Heart. 2014;100:731-40. DOI: 10.1136/ heartjnl-2012-302064.

3. Sengupta PP, Tajik AJ, Chandrasekaran K, Khandheria BK. Twist Mechanics of the Left Ventricle. JACC: Cardiovascular Imaging. 2008;1:366-76. DOI: 10.1016/j. jcmg.2008.02.006.

4. Павлюкова ЕН, Кужель ДА, Матюшин ГВ, Лыткина ВС. Блокада левой ножки пучка Гиса и скручивание левого желудочка при низкой фракции выброса. Клиническая медииина. 2015;93(11):15-21.

5. Bertini M, Sengupta P, Nucifora G, Delgado V, Ng A, Marsan N, Shanks M, van Bommel R, Schalij M, Narula J, Bax J. Role of Left Ventricular Twist Mechanics in the Assessment of Cardiac Dyssynchrony in Heart Failure. JACC: Cardiovascular Imaging. 2009;2(12):1425-35. DOI: 10.1016/j.jcmg.2009.09.013.

6. Briceno N, Schuster A, Lumley M, Perera Ischaemic cardiomyopathy: pathophysiology, assessment and the role of revascularization. Heart. 2016;102:397-406. DOI: 10.1136/heartjnl-2015-308037.

7. Mestroni L, Maisch B, McKenna WJ, Sshwartz K, Charron P, Rocco C, Tesson F, Richter A, Wilke A, Komajda M. Guidelines for the study of familial dilated cardiomyopathies. Collaborative Research Group of the European Human and Capital Mobility Project on Familial Dilated Cardiomyopathy. European Heart Journal. 1999;20:93-102. DOI: org/10.1053/euhj.1998.1145

8. Lang R, Badano L, Mor-Avi V, Afilalo J, Armstrong A, Ernande L, Flachskampf F, Foster E, Goldstein S, Kuznetsova T, Lancellotti P, Muraru D, Picard M, Rietzschel E, Rudski L, Spencer K, Tsang W, Voigt J. Recommendations for Cardiac Chamber uantification by Echocardiography in Adults: An Update from the American Society hocardiography and the European Association of Cardiovascular Imaging. Journal of the American Society of Echocardiography. 2015;28:1-39. DOI: 10.1016/j.echo.2014.10.003.

9. Helle-Valle T, Crosby J, Edvardsen T, Lysseggen E,
Amundsen BH, Smith HJ, Rosen BD, Lima JA, Torp H, Ihlen $\mathrm{H}$, Smiseth OA. New noninvasive method for assessment of left ventricular rotation: speckle tracking echocardiography. Circulation. 2005;112:3149-56. DOI: 10.1161/ circulationaha.104.531558.

10. Nagueh SF, Smiseth OF, Appleton CP, Byrdn BF, Dokainish H, Edvardsen T, Flachskampf FA, Gillebert TC, Klein AL, Lancellotti P, Marino P, Oh JK, Popescu BA, Waggoner AD. Recommendations for the Evaluation of Left Ventricular Diastolic Function by Echocardiography: an update from the American Society of Echocardiography and the European Association of Cardiovascular imaging. Journal of the American Society of Echocardiography. 2016;29:277-314. DOI:10.1016/j.echo.2016.01.011.

11. Karaahmet T, Gürel E, Tigen K, Guler A, Dundar C, Fotbolcu H, Basaran Y. The effect of myocardial fibrosis on left ventricular torsion and twist in patients with non-ischemic dilated cardiomyopathy. Cardiology Journal. 2013;20(3):276-86. DOI: 10.5603/cj.2013.0073.

12. van Dalen BM, Caliskan K, Soliman OI, Nemes A, Vietter WB, Ten Cate FJ, Geleijnse ML. Left ventricular solid body rotation in non-compaction cardiomyopathy: a potential new objective and quantitative functional diagnostic criterion? European Journal Heart Failure. 2008;10(11):1088-93. DOI: 10.1016/j.ejheart.2008.08.006.

13. Setser RM, Kasper JM, Lieber ML, Starling RC, McCarthy PM, White RD. Persistent abnormal left ventricular systolic torsion in dilated cardiomyopathy after partial left ventriculectomy. The Journal of Thoracic and Cardiovascular Surgery. 2003;126:48-55. DOI: org/10.1016/S00225223(03)00050-3.

14. Partridge JB, Smerup MH, Petersen SE. Linking left ventricular function and mural architecture: what does the clinician need to know? 2014;100:1289-1298. DOI: 10.1136/ heartjnl-2013-304571.

15. Song J-K. How Does the Left Ventricle Work? Ventricular Rotation as a New Index of Cardiac Performance. Korean Circulation Journal. 2009;39:347-351. DOI: 10.4070/ kcj.2009.39.9.347.

\section{References}

1. Pavlyukova EN, Kuzhel DA, Matyushin GV, Savchenko EA, Filippova SA. Left ventricular rotation, twist and untwist: physiological role and clinical relevance. Rational Pharmacotherapy in Cardiology. 2015;11(1):68-78. (In Russian)

2. Beladan CC, Calin A, Rosca M, Ginghina C, Popescu BA. Left ventricular twist dynamics: principles and applications. Heart. 2014;100:731-40. DOI: 10.1136/ heartjnl-2012-302064.

3. Sengupta PP, Tajik AJ, Chandrasekaran K, Khandheria BK. Twist Mechanics of the Left Ventricle. JACC: 
Cardiovascular Imaging. 2008;1:366-76. DOI: 10.1016/j. jcmg.2008.02.006.

4. Pavlukova EN, Kuzhel DA, Matyushin GV, Lytkina VS. Left His bundle branch block associated with left ventricular torsion and reduced ejection fraction. Klinicheskaya Meditsina (Mosk). 2015;.93(11):15-21. (In Russian)

5. Bertini M, Sengupta P, Nucifora G, Delgado V, Ng A, Marsan N, Shanks M, van Bommel R, Schalij M, Narula J, Bax J. Role of Left Ventricular Twist Mechanics in the Assessment of Cardiac Dyssynchrony in Heart Failure. JACC: Cardiovascular Imaging. 2009;2(12):1425-35. DOI: 10.1016/j.jcmg.2009.09.013.

6. Briceno N, Schuster A, Lumley M, Perera Ischaemic cardiomyopathy: pathophysiology, assessment and the role of revascularization. Heart. 2016;102:397-406. DOI: 10.1136/heartjnl-2015-308037.

7. Mestroni L, Maisch B, McKenna WJ, Sshwartz K, Charron P, Rocco C, Tesson F, Richter A, Wilke A, Komajda M. Guidelines for the study of familial dilated cardiomyopathies. Collaborative Research Group of the European Human and Capital Mobility Project on Familial Dilated Cardiomyopathy. European Heart Journal. 1999;20:93-102. DOI: org/10.1053/euhj.1998.1145.

8. Lang R, Badano L, Mor-Avi V, Afilalo J, Armstrong A, Ernande L, Flachskampf F, Foster E, Goldstein S, Kuznetsova T, Lancellotti P, Muraru D, Picard M, Rietzschel E, Rudski L, Spencer K, Tsang W, Voigt J. Recommendations for Cardiac Chamber uantification by Echocardiography in Adults: An Update from the American Society hocardiography and the European Association of Cardiovascular Imaging. Journal of the American Society of Echocardiography. 2015;28:1-39. DOI: 10.1016/j.echo.2014.10.003.

9. Helle-Valle T, Crosby J, Edvardsen T, Lysseggen E, Amundsen BH, Smith HJ, Rosen BD, Lima JA, Torp H, Ihlen H, Smiseth OA. New noninvasive method for assessment of left ventricular rotation: speckle tracking echocardiography. Circulation. 2005;112:3149-56. DOI: 10.1161/ circulationaha. 104.531558

10. Nagueh SF, Smiseth OF, Appleton CP, Byrdn BF, Dokainish H, Edvardsen T, Flachskampf FA, Gillebert TC, Klein AL, Lancellotti P, Marino P, Oh JK, Popescu BA, Waggoner AD. Recommendations for the Evaluation of Left Ventricular Diastolic Function by Echocardiography: an update from the American Society of Echocardiography and the European Association of Cardiovascular imaging. Journal of the American Society of Echocardiography. 2016;29:277-314. DOI:10.1016/j.echo.2016.01.011.

11. Karaahmet T, Gürel E, Tigen K, Guler A, Dundar C, Fotbolcu H, Basaran Y. The effect of myocardial fibrosis on left ventricular torsion and twist in patients with non-ischemic dilated cardiomyopathy. Cardiology Journal. 2013;20(3):276-86. DOI: 10.5603/cj.2013.0073.
12. van Dalen BM, Caliskan K, Soliman OI, Nemes A, Vietter WB, Ten Cate FJ, Geleijnse ML. Left ventricular solid body rotation in non-compaction cardiomyopathy: a potential new objective and quantitative functional diagnostic criterion? European Journal Heart Failure. 2008;10(11):1088-93. DOI: 10.1016/j.ejheart.2008.08.006.

13. Setser RM, Kasper JM, Lieber ML, Starling RC, McCarthy PM, White RD. Persistent abnormal left ventricular systolic torsion in dilated cardiomyopathy after partial left ventriculectomy. The Journal of Thoracic and Cardiovascular Surgery. 2003;126:48-55. DOI: org/10.1016/S00225223(03)00050-3.

14. Partridge JB, Smerup MH, Petersen SE. Linking left ventricular function and mural architecture: what does the clinician need to know? 2014;100:1289-1298. DOI: 10.1136/ heartjnl-2013-304571.

15. Song J-K. How Does the Left Ventricle Work? Ventricular Rotation as a New Index of Cardiac Performance. Korean Circulation Journal. 2009;39:347-351. DOI: 10.4070/ kcj.2009.39.9.347.

\section{Сведения об авторах}

Павлюкова Елена Николаевна, Научно-исследовательский институт кардиологии Федерального государственного бюджетного научного учреждения Томский национальный исстедовательский медииинский иентр Российской академии наук; адрес: Российская Федеращия, 634012, г. Томск, ул. Киевская, д. 111a; e-mail:pavlyukovaelena@yandex.ru

Кужель Дмитрий Анатольевич, Красноярский государственный медицинский институт имени профессора В.Ф.Войно-Ясенецкого, г. Красноярск, ул. Партизана Железняка, д. 1 Красноярская краевая больнииа №2; адрес: Российская Федерация, 660049, г. Красноярск, ул. Карла Маркса, д. 43; тел.: +7(391)2026772; e-mail: dakushel@yandex.ru

Матюшин Геннадий Васильевич, Красноярский государственный медицинский институт имени профессора В.Ф.Войно-Ясенеи,кого; адрес: Российская Федерация, 660022, г. Красноярск, ул. Партизана Железняка, д. 1; тел.: +7(391)2201550; e-mail: matyushin1@yandex.ru

Яковлев Евгений Иосифович, Сибирский государственный аэрокосмический университет имени академика М. Ф. Решетнёва; адрес: Российская Федеращия, 660037, г. Красноярск, ул. Красноярский рабочий, д. 31; тел.: +7(391)2919119; e-mail: yei@nт.ru

Новоселов Олег Вадимович, Сибирский государственный аэрокосмический университет имени академика М. Ф. Решетнёва; адрес: Российская Федерация, 660037, г. Красноярск, ул. Красноярский рабочий, д. 31; тел.: +7(391)2919119; e-mail:novoselov_oleg_v@mail.ru

\section{Information about the authors}

Pavlyukova Elena N., Scientific-Research Institute of Cardiology Federal state budgetary scientific institution Tomsk National Research Medical Center of the Russian Academy of Sciences; Address: 111a, Kievskaya str., Tomsk, Russian Federation, 634012; e-mail:pavlyukovaelena@yandex.ru

Kuzhel Dmity A., Professor V. F. Voino-Yasenetsky Krasnoyarsk State Medical University; Address: 1, Partizan Zheleznyakstr., Krasnoyarsk, Address: 43, Karl Marx str., Krasnoyarsk, Russian Federation 660049; Phone:+7(391)2026772, e-mail: dakushel@yandex.ru.

Matyushin Gennady V., Professor V. F. Voino-Yasenetsky Krasnoyarsk State Medical University; Address: 1, Partizan Zheleznyak str., Krasnoyarsk, Russian Federation 660022; Phone:+7(391)2201550; e-mail: matyushin1@yandex.ru

Yakovlev Evgeny I., Reshetnev Siberian State University of Science and Technology; Address: Krasnoyarsky Rabochy Av., 31, Krasnoyarsk, Russian Federation 660037; Phone: +7(391)2919119; e-mail:yei@nm.ru

Novoselov Oleg V., Reshetnev Siberian State University of Science and Technology; Address: Krasnoyarsky Rabochy Av., 31, Krasnoyarsk, Russian Federation 660037; Phone: +7(391)2919119; e-mail: novoselov_oleg_v@mail.ru 


\title{
ОСОБЕННОСТИ ВАРИАБЕЛЬНОСТИ РИТМА СЕРДЦА У БЕРЕМЕННЫХ С ИДИОПАТИЧЕСКОЙ ЖЕЛУДОЧКОВОЙ ЭКСТРАСИСТОЛИЕЙ
}

Е. А. Припачкина, А. П. Филёв, А. В. Говорин, Н. В. Муха, П. В. Василенко, Н. А. Соколова

Читинская государственная медицинская академия, Чита 672000, Российская Федерация

Цель исследования. Оценить особенности вегетативного статуса по данным вариабельности ритма сердца у беременных с идиопатической желудочковой экстрасистолией.

Материал и методы. Для изучения вариабельности сердечного ритма суточная запись ЭКГ проведена 40 беременным женщинам с желудочковыми нарушениями сердечного ритма. Группы контроля составили соматически здоровые беременные и небеременные женщины без нарушений сердечного ритма. Холтеровское мониторирование ЭКГ проводилось по стандартной методике с использованием комплекса суточного мониторирования электрокардиограмм «Кардиотехника-4000». Статистическая обработка полученных в исследовании данных осуществлялась с использованием пакета программ STATISTICA 10.0.

Результаты. Установлено, что для беременных женщин характерно снижение основных временных и спектральных показателей вариабельности ритма сердца. Отмечены более низкие показатели вариабельности ритма сердца, отвечающие за общую мощность спектра (SDNN, TP), а также параметры, характеризующие влияние симпатического отдела вегетативной нервной системы на регуляцию сердечного ритма (SDNNi, LF, VLF) и парасимпатической иннервации (RMSSD, pNN50, HF). Данные изменения выражены в большей степени при наличии идиопатических желудочковых аритмий IV-V градации по Rуan. Кроме того, у данной категории пациенток отмечен больший вклад центральных нейрогуморальных влияний (VLF \%) и, напротив, меньший-периферических вагусных влияний (HF \%).

Заключение. У беременных пациенток с идиопатической желудочковой экстрасистолией IV-V градации по Rуап выявлено перенапряжение адаптационных процессов в виде преобладающего влияния на регуляцию ритма сердца высших вегетативных центров, а также умеренная гиперсимпатикотония; определен меньший вклад периферических вагусных влияний на фоне более низкой общей мощности вариабельности ритма сердца. Ключевые слова: беременность, нарушения сердечного ритма, желудочковая экстрасистолия, холтеровское мониторирование ЭКГ, вариабельность ритма сердца, гиперсимпатикотония.

Для иитирования: Припачкина ЕА, Филёв АП, Говорин АВ, Муха НВ, Василенко ПВ, Соколова. НА. Особенности вариабельности ритма сердца у беременных с идиопатической желудочковой экстрасистолией. Сибирское медицинское обозрение. 2017;(5): 80-84. DOI: 10.20333/2500136-2017-580-84.

\section{PECULIARITIES OF VARIABILITY OF HEART RHYTHM IN PREGNANT WOMEN WITH IDIOPATHIC VENTRICULAR EXTRASYSTOLE}

\author{
E. A. Pripachkina, A. P. Filev, A. V. Govorin, N. V. Mukha, P. V. Vasilenko, N. A. Socolova \\ Chita State Medical Academy, Chita 672000, Russian Federation
}

The aim of the research. To assess the features of the vegetative status according to the heart rate variability in pregnant women with idiopathic ventricular extrasystole.

Material and methods. To study the variability of the heart rate, 24-hour ECG recording was made in 40 pregnant women with ventricular arrhythmias. Control groups consisted of somatically healthy pregnant and non-pregnant women with no heart rhythm disturbances. Holter monitoring of the ECG was carried out according to a standard procedure using the 24-hour cardiovascular monitoring complex "Cardiotechnics-4000". Statistical processing of the obtained data in the study was carried out using the STATISTICA 10.0 software package.

Results. It was found that for pregnant women, the main temporal and spectral indices of cardiac rhythm variability are typically. The lower cardiac rhythm variability parameters, responsible for the total spectrum power (SDNN, TP), as well as the parameters characterizing the influence of the sympathetic part of the vegetative nervous system on the regulation of the heart rhythm (SDNNi, LF, VLF) and parasympathetic innervation (RMSSD, pNN50, HF ) were noted. These changes are more pronounced in the presence of idiopathic ventricular arrhythmias IV-V gradation by Ryan. In addition, in this category of patients it was noted a greater contribution of central neurohumoral influences (VLF \%) and, on the contrary, less-peripheral vagal influences (HF\%).

The conclusion. In pregnant patients with idiopathic ventricular extrasystole of IV-V gradation by Ryanit was revealed overstrain of adaptation processes in the form of a predominant influence on the regulation of the heart rhythm of higher vegetative centers, as well as moderate hypersympathicotonia; it was noted smaller contribution of peripheral vagal influences against the background of a lower total cardiac rhythm variability.

Key words: pregnancy, cardiac rhythm disturbances, ventricular extrasystole, holter ECG monitoring, heart rate variability, hypersympathicotonia.

Citation: Pripachkina EA, Filev AP, Govorin AV, Mukha NV, Vasilenko PV, Socolova NA. Peculiarities of variability of heart rhythm in pregnant women with idiopathic ventricular extrasystole. Siberian Medical Review. 2017; (5): 80-84. DOI: 10.20333/2500136-2017-5-80-84. 


\section{Введение}

Различные нарушения сердечного ритма в период беременности при отсутствии органической патологии сердца встречаются в 10-15 \% случаев. Чаще они протекают бессимптомно и носят доброкачественный характер $[1,2,3,4,5]$. Значительная роль в развитии аритмий у данной группы пациенток отводится гиперсимпатикотонии, как адаптационной реакции организма к новым условиям функционирования системы «мать-плацентаплод» $[5,6,7,8,9]$. Важная роль в регуляции адаптационных процессов, направленных на поддержание гомеостаза на протяжении всего периода гестации, принадлежит вегетативной нервной системе $[10,11,12,13,14]$.

Анализ вариабельности ритма сердца является методом оценки механизмов регуляции физиологических функций в организме. Прежде всего речь идет об оценке общей активности регуляторных механизмов, нейрогуморальной регуляции сердца, соотношения между симпатическим и парасимпатическим отделами вегетативной нервной системы $[15,16,17,18,19,20]$. Вариабельность сердечного ритма отражает степень напряжения регуляторных систем в ответ на любое стрессовое воздействие [21, 22]. Этот ответ выражается активацией системы «гипофиз - надпочечники» и реакцией симпатоадреналовой системы. Таким образом, ритм сердца является отражением интегративного взаимодействия проводящей системы сердца, вегетативной нервной системы, центральной нервной системы и регулирующих гуморальных влияний $[23,24,25,26]$.

Цель исследования: оценить особенности вегетативного статуса по данным вариабельности ритма сердца у беременных с идиопатической желудочковой экстрасистолией.

\section{Материал и методы}

Проведено обследование 82 женщин. Основную группу составили 40 беременных с выявленной в ходе холтеровского мониторирования электрокардиографии (ХМЭКГ) желудочковой экстрасистолией 2-5 градации по Ryan на сроке гестации 20-26 недель, средний возраст которых составил 31 [25;37] год. Перед включением в исследование у женщин исключены возможные кардиальные и внекардиальные причины развития нарушений ритма сердца. Ocновная группа ретроспективно была разделена на 2 подгруппы. В первую подгруппу (IA) было включено 24 беременных с экстрасистолией 2-3 градации по Ryan, вторая подгруппа (ІБ) представлена 16 беременными с 4-5 классом желудочковой экстрасистолии. Вторую группу (группу контроля) составили 22 соматически здоровые беременные без нарушений сердечного ритма, сопоставимые по возрасту и сроку гестации с основной группой. В III группу включены 20 небеременных женщин без соматической патологии и нарушений ритма сердца, средний возраст которых составил 27,5 [24;30] лет. Этический комитет одобрил протокол исследования. Критерии включения: беременные женщины в возрасте от 24 до 37 лет, давшие согласие на участие в исследовании, проведение необходимых обследований, использование результатов исследования при публикации научных работ. Наличие сердечных аритмий при проведении ХМЭКГ (для пациенток основной группы). Критерии исключения: женщины с имеющимися до беременности нарушениями ритма сердца, заболеваниями сердечно-сосудистой системы, органическим поражением ЦНС, эндокринными заболеваниями, ожирением, электролитным дисбалансом, злокачественными новообразованиями, патологией органов дыхания и пищеварения (способной вызвать аритмии), заболеваниями крови.

Для оценки вариабельности сердечного ритма использовалась суточная запись ЭКГ, полученная при помощи монитора «Кардиотехника-4000», 3АО «ИНКАРТ», СанктПетербург, Россия. Обработка результатов проводилась с использованием одноименного программного обеспечения. На основании результатов холтеровского мониторирования ЭКГ проводился автоматизированный анализ спектральных и временных показателей вариабельности ритма сердца.

Во временной области оценивались следующие параметры: SDNN, SDANN, SDNNindex, RMSSD, pNN50. Для обработки спектральных индексов сердечного ритма использовался анализ Фурье для 5-минутного окна записи. Оценивались следующие характеристики: TP, LF, HF, VLF. Для оценки вагосимпатического баланса оценивалось соотношение LF/HF, которое подчеркивает контролируемое и сбалансированное симпато-парасимпатическое влияние этих двух звеньев вегетативной нервной системы. Кроме того, оценивался вклад каждой составляющей в процентах в общую структуру спектра.

Статистическая обработка полученных в ходе исследования данных осуществлялась с использованием пакета программ STATISTICA 10.0. Данные в таблицах представлены в виде медиан и перцентилий Ме [25;75]. Две независимые группы по количественному признаку сравнивались с помощью критерия Манна-Уитни. Статистически значимым считали различия при $\mathrm{p}<0,05$.

\section{Результаты и обсуждение}

При анализе вариабельности ритма сердца было зарегистрировано снижение основных временных и спектральных показателей у всех беременных по сравнению с группой небеременных пациенток.

Параметр SDNN, отражающий общий тонус вегетативной нервной системы, был выше у здоровых небеременных пациенток на 16,8 \% и 18,7 \%, соответственно, по сравнению c IA и II группой и на 45,8 \% в сравнении с пациентками с желудочковой экстрасистолией IV-V градации по Ryan $(\mathrm{p}<0,05)$ (табл. 1). У всех беременных пациенток зарегистрировано снижение мощности показателей, отражающих парасимпатическую активность во временной областиRMSSD и pNN50. В большей степени снижение параметров RMSSD и pNN50 в сравнении с III группой зафиксировано y беременных пациенток с желудочковой экстрасистолией 
Табтииа 1

Сравнительньй анализ временных показателей ВРС

\begin{tabular}{|c|c|c|c|c|}
\hline \multirow{2}{*}{ Показатель } & \multicolumn{2}{|c|}{1 группа (n=42) } & \multirow{2}{*}{$\begin{array}{c}\text { II группа } \\
(\mathrm{n}=22)\end{array}$} & \multirow{2}{*}{$\begin{array}{c}\text { III группа } \\
(\mathrm{n}=20)\end{array}$} \\
\hline & IA, $n=24$ & I5, $n=16$ & & \\
\hline SDNN & $\begin{array}{c}129 \\
{[112 ; 147]} \\
p_{3}=0,02\end{array}$ & $\begin{array}{c}84 \\
{[73 ; 111]} \\
p_{1}=0,00012\end{array}$ & $\begin{array}{c}126 \\
{[121 ; 139]} \\
p_{2}=0,0002\end{array}$ & $\begin{array}{c}155 \\
{[128 ; 161]} \\
p_{4}=0,00002 \\
p_{5}=0,02\end{array}$ \\
\hline SDANN & $\begin{array}{c}118 \\
{[102 ; 133]} \\
p_{3}=0,009\end{array}$ & $\begin{array}{c}97,5 \\
{[65 ; 115]} \\
p_{1}=0,01\end{array}$ & $\begin{array}{c}120 \\
{[109 ; 125]} \\
p_{2}=0,0005\end{array}$ & $\begin{array}{c}134 \\
{[129 ; 149]} \\
p_{4}=0,00003 \\
p_{5}=0,006\end{array}$ \\
\hline SDNNi & $\begin{array}{c}55 \\
{[50 ; 58]} \\
p_{3}=0,0003\end{array}$ & $\begin{array}{c}33,5 \\
{[26 ; 45]} \\
p_{1}=0,00001\end{array}$ & $\begin{array}{c}54 \\
{[44 ; 65]} \\
p_{2}=0,0003\end{array}$ & $\begin{array}{c}75 \\
{[58 ; 80]} \\
p_{4}=0,000003 \\
p_{5}=0,001\end{array}$ \\
\hline RMSSD & $\begin{array}{c}32 \\
{[23 ; 39]} \\
p_{3}=0,0007\end{array}$ & $\begin{array}{c}18,3 \\
{[13 ; 25]} \\
p_{1}=0,00007\end{array}$ & $\begin{array}{c}28 \\
{[24 ; 41]} \\
p_{2}=0,0009\end{array}$ & $\begin{array}{c}48 \\
{[39 ; 55]} \\
p_{4}=0,00002 \\
p_{5}=0,002\end{array}$ \\
\hline pNN50 & $\begin{array}{c}10,5 \\
{[6 ; 15]} \\
p_{3}=0,00008\end{array}$ & $\begin{array}{c}1 \\
{[0 ; 5]} \\
p_{1}=0,00007\end{array}$ & $\begin{array}{c}8 \\
{[5 ; 19]} \\
p_{2}=0,0008\end{array}$ & $\begin{array}{c}17 \\
{[12 ; 20]} \\
p_{4}=0,00001\end{array}$ \\
\hline
\end{tabular}

Примечание: данные в таблице представлены в виде медиан и периентилей [25;75].

n-число наблюдений; $p_{1}$ - сравнение IА группы с группой IБ; р2 - сравнение IБ группы со II группой; р3 -группа IА в сравнении с небеременными; р4 - сравнение IБ и III групnы; р5 - сравнение групп II и III.

IV-V градации по Ryan; на 61,9 \% и 94,2 \%, соответственно $(\mathrm{p}<0,05)$ (табл. 1).

При анализе спектральных показателей было выявлено, что у женщин ІБ подгруппы отмечалось статистически более низкие следующие показатели: общая мощность вариабельности ритма сердца-ТР (на 53,1 \%), параметр в диапазоне очень низких частот-VLF (на 50 \%), мощность LF на $62 \%$ и мощность спектра в диапазоне высоких частот-НF на 80 \% по сравнению с женщинами III группы $(\mathrm{p}<0,05)$ (табл. 2). У женщин с желудочковой экстрасистолией II-III градации по Ryan снижение мощности спектра во всех частотных диапазонах было не столь выражено, как в ІБ подгруппе; зарегистрировано статистически значимо низкие показатели в диапазонах TP, VLF, HF на 24,3 \%, 10 \%, и 16,4 $\%$, соответственно, по сравнению со здоровыми небеременными женщинами $(\mathrm{p}<0,05)$. При сравнении подгруппы ІБ с группой здоровых беременных выявлены следующие особенности: показатели общей мощности спектра-ТР и очень низкочастотный компонент-VLF у пациенток ІБ подгруппы были ниже в сравнении с пациентками II группы на 43 \% и $36,6 \%$, соответственно $(\mathrm{p}<0,05)$ (табл. 2). Отмечалось снижение показателя $\mathrm{HF}$ на 37,2 \% у пациенток IA подгруппы и на 69 \% у пациенток ІБ подгруппы в сравнении со здоровыми беременными $(\mathrm{p}<0,05)$. В группе пациенток с желудочковой экстрасистолией IV-V градации по Ryan был вы-
Табтииа 2

Сравнительный анализ спектральных показателей ВРС

\begin{tabular}{|c|c|c|c|c|}
\hline \multirow{2}{*}{ Показатели } & \multicolumn{2}{|c|}{1 группа (n=42) } & \multirow{2}{*}{$\begin{array}{c}\text { II группа } \\
(\mathrm{n}=22)\end{array}$} & \multirow{2}{*}{$\begin{array}{c}\text { III группа } \\
(\mathrm{n}=20)\end{array}$} \\
\hline & $I A, n=24$ & $\mathrm{IE}, \mathrm{n}=16$ & & \\
\hline VLF, MC & $\begin{array}{c}2127 \\
{[1817 ; 2431]}\end{array}$ & $\begin{array}{c}1183 \\
{[1081 ; 1361]} \\
p_{1}=0,0065\end{array}$ & $\begin{array}{c}1865 \\
{[1737 ; 2023]} \\
p_{2}=0,0016\end{array}$ & $\begin{array}{c}2368 \\
{[1869 ; 2598]} \\
p_{5}=0,002\end{array}$ \\
\hline $\mathrm{LF}, \mathrm{MC}$ & $\begin{array}{c}1308 \\
{[1194 ; 1527]}\end{array}$ & $\begin{array}{c}505 \\
{[438 ; 514]} \\
p_{1}=0,0022\end{array}$ & $\begin{array}{c}1147 \\
{[1072 ; 1190]} \\
p_{2}=0,0016 \\
p_{3}=0,009\end{array}$ & $\begin{array}{c}1329 \\
{[1137 ; 1692]} \\
p_{5}=0,002 \\
p_{6}=0,042\end{array}$ \\
\hline$H F, M C$ & $\begin{array}{c}642 \\
{[554 ; 700]} \\
p_{4}=0,0066\end{array}$ & $\begin{array}{c}150 \\
{[128 ; 237]} \\
p_{1}=0,001\end{array}$ & $\begin{array}{c}601 \\
{[492 ; 685]} \\
p_{2}=0,0007\end{array}$ & $\begin{array}{c}768 \\
{[702 ; 838]} \\
p_{5}=0,001 \\
p_{6}=0,012\end{array}$ \\
\hline TP, MC & $\begin{array}{c}3487 \\
{[3305 ; 3889]} \\
p_{4}=0,001\end{array}$ & $\begin{array}{c}1980 \\
{[1662 ; 2239]} \\
p_{1}=0,0022\end{array}$ & $\begin{array}{c}3473 \\
{[3273 ; 4073]} \\
p_{2}=0,0016\end{array}$ & $\begin{array}{c}4610 \\
{[3898 ; 4787]} \\
p_{5}=0,002 \\
p_{6}=0,0017\end{array}$ \\
\hline$L F / H F$ & $\begin{array}{c}1,85 \\
{[1,5 ; 2,2]}\end{array}$ & $\begin{array}{c}2,6 \\
{[2,1 ; 3]} \\
p_{1}=0,03\end{array}$ & $\begin{array}{c}1,6 \\
{[1,5 ; 2,2]} \\
p_{2}=0,029\end{array}$ & $\begin{array}{c}1,9 \\
{[1,7 ; 2,0]} \\
p_{5}=0,004\end{array}$ \\
\hline VLF\% & $\begin{array}{c}51 \\
{[45 ; 58]}\end{array}$ & $\begin{array}{c}66 \\
{[65 ; 69]} \\
p_{1}=0,012\end{array}$ & $\begin{array}{c}52 \\
{[51 ; 58]} \\
p_{2}=0,008\end{array}$ & $\begin{array}{c}51 \\
{[48 ; 53]} \\
p_{5}=0,006\end{array}$ \\
\hline LF\% & $\begin{array}{c}30 \\
{[27 ; 35]}\end{array}$ & $\begin{array}{c}26 \\
{[25 ; 26]}\end{array}$ & $\begin{array}{c}27 \\
{[23 ; 34]}\end{array}$ & $\begin{array}{c}34 \\
{[30 ; 35]} \\
p_{5}=0,026\end{array}$ \\
\hline $\mathrm{HF} \%$ & $\begin{array}{c}17 \\
{[15 ; 21]}\end{array}$ & $\begin{array}{c}9 \\
{[9 ; 11]} \\
p_{1}=0,002\end{array}$ & $\begin{array}{c}16 \\
{[15 ; 18]} \\
p_{2}=0,0015\end{array}$ & $\begin{array}{c}16 \\
{[14 ; 17]} \\
p_{5}=0,002\end{array}$ \\
\hline
\end{tabular}

Примечание: данные в таблице представлены в виде медиан и периентилей [25;75].

n-число наблюдений; $p_{1}$-сравнение IА группы с группой IБ; 2 -сравнение групп IБ и II; 33 - сравнение IA группы со II группой; р4-сравнение групп IA и III; $p 5$-сравнение IБ и III группь;; р6 - сравнение групп II и III.

явлен достоверно высокий параметр LF/HF, характеризующий вагосимпатический баланс, в 1,5 раза по сравнению с пациентками IA подгруппы, II и III групп ( $<00,05)$.

При оценке относительного вклада каждой составляющей в общую мощность спектра зарегистрировано снижение показателя HF\% у женщин с желудочковой экстрасистолией IV-V градации по Ryan на 43,7 \% по сравнению c IA, II и III группами $(\mathrm{p}<0,05)$. Мощность VLF \%, напротив, была выше у пациенток ІБ подгруппы (66 \%) и превышала на 22,7 \% аналогичный показатель в группах здоровых беременных и небеременных женщин, и женщин с желудочковой экстрасистолией II-III градации по Ryan $(\mathrm{p}<0,05)$ (табл. 2).

Таким образом, было установлено, что у беременных пациенток ІБ подгруппы большинство спектральных и временных показателей вариабельности ритма сердца существенно отличались от аналогичных параметров женщин 
с желудочковой экстрасистолией II-III градации по Ryan и лиц контрольных групп (II и III). При изучении параметров вариабельности ритма сердца, оцененных как при суточной записи ЭКГ, так и на коротких участках; у беременных женщин с желудочковой экстрасистолией IV-V градации по Ryan выявлено снижение основных временных и спектральных показателей с одновременным увеличением коэффициента LF/HF и уменьшением параметра HF\%, что свидетельствует о преобладании симпатических влияний на сердечный ритм и снижении защитного вагусного контроля сердечной деятельности. Кроме того, выявлено превалирование VLF-компонента в общей структуре мощности вариабельности ритма сердца у пациенток подгруппы IБ (VLF\% - 66 \%), что свидетельствует о преимущественном влиянии на регуляцию сердечного ритма высших надсегментарных центров.

\section{Заключение}

У беременных пациенток зарегистрировано снижение основных показателей вариабельности ритма сердца. В большей степени вагусно-симпатический дисбаланс в сторону преобладания активности симпатического отдела вегетативной нервной системы был выражен у беременных пациенток с идиопатической желудочковой экстрасистолией IV-V градации по Rуan. Таким образом, проведенный анализ нейровегетативного статуса у беременных пациенток с желудочковой экстрасистолией IV-V класса по Ryan, позволяет сделать вывод о перенапряжении у них адаптационных процессов в виде более низких показателей общей мощности вариабельности ритма сердца, преобладающего влияния на регуляцию ритма сердца высших вегетативных центров, а также умеренной гиперсимпатикотонии. Возможно, выявленные изменения вегетативного статуса, могут способствовать развитию желудочковых нарушений ритма сердца у данной категории беременных пациенток.

\section{Литература}

1. Бухонкина ЮМ. Нарушения сердечного ритма у беременных - современное состояние проблемы. Здравоохранение Дальнего Востока. 2014;4:76-83.

2. Апресян СВ. Беременность и роды при экстрагенитальных заболеваниях. М.: ГЭОТАР - Медиа; 2009. 464 с.

3. Мравян СР, Петрухин ВА. Нарушения ритма сердца и проводимости у беременных. М.: Миклюш; 2011. 128 с.

4. Шехтман ММ. Руководство по экстрагенитальной патологии у беременных. М.: Триада-Х; 2013. 896 с.

5. Экстрагенитальная патология и беременность / Под ред. Лоскутова ЛС, ред. Экстрагенитальная патология и беременность. М.: Литтера; 2012. 544 с.

6. Gowda MR, Khan IA, Mehta NJ, Vasavada BC, Sacchi TJ. Cardiac arrhythmias in pregnancy: clinical and therapeutic considerations. Journal of Cardiology. 2003;88:129-133.

7. Стрюк РИ, Бухонкина ЮМ, Шоикиемова ДУ. Возможные причины и характер нарушений сердечного ритма при беременности. Проблемы женского здоровья. 2008;2:37-41.
8. Стрюк РИ. Диагностика и лечение сердечно - сосудистых заболеваний при беременности: национальные рекомендации (разработаны Комитетом экспертов Всероссийского научного общества кардиологов, секция «Заболевания сердечно-сосудистой системы у беременных»). М.; 2013. 40 c.

9. Стрюк РИ. Заболевания сердечно - сосудистой системы и беременность. М.: ГЭОТАР - Медиа; 2010. 280 с.

10. Pagani M. Heart rate variability and pregnancy. Editorial commentaries. Journal of Hypertension. 2002;20:2125-126.

11. Клещеногов СА, Флейшман АН. Спектральный компьютерный анализ кардиоритма беременных: оценка течения и прогнозирование осложнений беременности: метод. Пособие для практикующих врачей. Новокузнецк; 2003. 40с.

12. Ревина НЕ. Вариабельность ритма сердца как показатель вегетативного регулирования сердца при эмоциональном напряжении человека. Вестник Российской АMH. 2006;2:41-5.

13. Вейн АМ. Вегетативные расстройства. Клиника, диагностика, лечение. М.: Медицина; 2003. 752 с.

14. Аксельрод АС, Чомахидзе ПШ, Сыркин АЛ. Холтеровское мониторирование ЭКГ: возможности, трудности, ошибки. М.: МИА; 2007.187 с.

15. Баевский РМ, Иванов ГГ. Вариабельность сердечного ритма: теоретические аспекты и возможности клинического применения. М.: Медицина; 2000.240 с.

16. Михайлов ВМ. Вариабельность ритма сердца. Опыт практического применения. Иваново; 2000. 200 с.

17. Захарова НЮ, Михайлов ВП. Физиологические особенности вариабельности ритма сердца в разных возрастных группах. Вестник аритмологии. 2003;31:37-40.

18. Вариабельность сердечного ритма. Стандарты измерения, физиологической интерпретации и клинического использования. Рабочая группа Европейского Кардиологического Общества и Северо - Американского общества стимуляции и электрофизиологии.СПб.: АООТ Типография «Правда»; 2000. 65с.

19. Шубик ЮВ. Суточное мониторирование ЭКГ при нарушениях ритма и проводимости сердца. СПб.: ИНКАРТ; 2001. 216c.

20. Соколова НА, Говорин АВ, Хышиктуев БС, Горбунов BВ. Предсказующие возможности некоторых электрофизиологических показателей у больных нестабильной стенокардией. Деп. В ВИНИТИ; 2004:84-В.

21. Соболев АВ. Методы анализа вариабельности сердечного ритма на длительных промежутках времени. М.: Медпрактика - М.; 2009. 172 с.

22. Рябыкина ГВ. Мониторирование ЭКГ с анализом вариабельности ритма сердца. М.: Медпрактика-М; 2005. 222 с.

23. Рябыкина ГВ, Соболев АВ. Вариабельность ритма сердца. М.: Старко; 1998. 200 с.

24. Chamchad D, Horrow JC, Nakhamchik L. Heart rate variability changes during pregnancy: an observational study. International Journal of Obstetric Anesthesia. 2007;16:1069. DOI: 10.1016/j.ijoa.2006.08.008. 
25. Huikuri HV, Stein PK. Heart rate variability in risk stratification of cardiac patients. Cardiovascular Disease.2013;56(2):153-59. DOI: 10.1016/j.pcad. 2013.07.003.

26. Sookan T, McKune AJ. Heart rate variability in physically active individuals: reliability and gender characteristics. Cardiovascular Journal. 2012;23(2):67-72. DOI: 10.5830/CVJA-2011.108.

\section{References}

1. Bukhonkina YuM. Cardiac arrhythmias in pregnant women - the current state of the problem. Zdravookhranenie Dal'nego Vostoka. 2014;4:76-83. (In Russian)

2. Apresyan SV. Pregnancy and childbirth with extragenital diseases. M.: GEOTAR Media; 2009. 464 p. (In Russian)

3. Mravyan SR, Petrukhin VA. Cardiac arrhythmias and conduction disturbance in pregnant women. Moscow: Miklyush; 2011. 128 p. (In Russian)

4. Shekhtman MM. Guide extragenital pathology in pregnant women. M.: TriadaKh; 2013. 896 p. (In Russian)

5. Logutova LS, ed. Extragenital pathology and pregnancy. M. : Littera; 2012. 544 p. (In Russian))

6. Gowda MR, Khan IA, Mehta NJ, Vasavada BC, Sacchi TJ. Cardiac arrhythmias in pregnancy: clinical and therapeutic considerations. Journal of Cardiology. 2003;88:129-133.

7. Stryuk RI. Possible causes and character of cardiac arrhythmias during pregnancy. Problemy zhenskogo zdorov'ya. 2008;2:37-41 (In Russian).

8. Stryuk RI. Diagnosis and treatment of cardiovascular disease in pregnancy: national guidelines. Moscow; 2013.40 p. (In Russian)

9. Stryuk RI. Diseases of the cardio - vascular system and pregnancy. M.: GEOTAR Media; 2010.280 p. (In Russian).

10. Pagani M. Heart rate variability and pregnancy. Editorial commentaries. Journal of Hypertension. 2002;20:2125-126.

11. Kleshchenogov SA, Fleyshman AN. Spectral computer analysis of the cardiac rhythm of pregnant women: assessment of the course and prediction of complications of pregnancy: method. A manual for practicing doctors. Novokuznetsk; 2003. 40 p. (In Russian)

12. Revina NE. The variability of heart rhythm as an indicator of vegetative regulation of the heart with emotional stress of a person. Bulletin of the Russian Academy of Medical Sciences. 2006;2: 415. (In Russian)

13. Veyn AM. Vegetative disorders. Clinic, diagnosis, treatment. M.: Meditsina; 2003. 752 (In Russian).

14. Aksel'rod AS, Chomakhidze PSh, Syrkin AL. Holter monitoring of ECG: possibilities, difficulties, errors. M.: MIA; 2007.187. (In Russian)

15. Baevskiy, RM, Ivanov GG.Heart rate variability: theoretical aspects and possibilities of clinical application. M.: Medicine, 2000. 240 p. (In Russian)

16. Mikhaylov VM. The variability of the rhythm of the heart. Practical experience. Ivanovo; 2000. 200 p. (In Russian)

17. Zakharova NYu, Mikhaylov VP. Physiological features of the variability of the rhythm of the heart in different age groups. Vestnik aritmologii. 2003;31:37-40. (In Russian)

18. Heart rate variability. Standards of measurement, physi- ological interpretation and clinical use. Working Group of the European Society of Cardiology and the North American Society of Stimulation and Electrophysiology. SPb.: AOOT Tipografiya «Pravda»; 2000. 65 p. (In Russian)

19. Shubik YuV. Daily monitoring of ECG in cases of heart rhythm and conduction disorders. SPb.: INKART; 216 p. (In Russian)

20. Sokolova NA, Govorin AV, Khyshiktuev BS, Gorbunov VV. Predicting capabilities of some electrophysiological indices in patients with unstable angina. In VINITI; 2004. 84-B. (In Russian)

21. Sobolev AV. Methods for analyzing heart rate variability over long periods of time. M.: Medpraktika - M; 2009. 172 p. (In Russian)

22. Ryabykina GV. ECG monitoring with heart rate variability analysis. M.: Medpraktika-M; 2005.222 p. (In Russian)

23. Ryabykina GV, Sobolev AV. The variability of the rhythm of the heart. M.: Starko; 1998. 200 p. (In Russian)

24. Chamchad D, Horrow JC, Nakhamchik L. Heart rate variability changes during pregnancy: an observational study. International Journal of Obstetric Anesthesia. 2007;16:106-9. DOI: 10.1016/j.ijoa.2006.08.008.

25. Huikuri HV, Stein PK. Heart rate variability in risk stratification of cardiac patients. Cardiovascular Disease. 2013;56 (2):153-59. DOI: 10.1016/j.pcad.2013.07.003.

26. Sookan T, McKune AJ. Heart rate variability in physically active individuals: reliability and gender characteristics. Cardiovascular Journal. 2012; 23(2):67-72. DOI: 10.5830/CVJA-2011.108.

\section{Сведения об авторах}

Припачкина Екатерина Александровна, Читинская государственная медицинкая академия; адрес: Российская Федерация, 672000, г. Чита, ул. Горького, д. 39А; тел: +7(3022)354324; e-mail: ekaterinapripachkina@mail.ru

Филёв Андрей Петрович, Читинская государственная медииинская академия; адрес: Российская Федерация, 672000, г. Чита, ул. Горького, д. 39A; тел.: +7(3022)354324; е-таil: andfilev@mail.ru

Говорин Анатолий Васильевич, Читинская государственная медицинская академия; адрес: Российская Федерация, 672000, г. Чита, ул. Горького, д. 39A; тел.: +7(3022)354324; e-mail:govorav@mail.ru

Муха Наталья Вячеславовна, Читинская государственная медицинская академия; адрес: Российская Федерация, 672000, г. Чита, ул. Горького, д. 39А; тел.: +7(3022)354324; e-mail: mushanatasha@inbox.ru

Василенко Павел Владимирович, Читинская государственная медицинская академия; адрес: Российская Федерация, 672000, г. Чита, ул. Горького, д. 39A; тел.: +7(3022)354324; e-mail:pavelvasilenkochita@mail.ru

Соколова Наталья Анатольевна, Читинская государственная медицинская академия; адрес: Российская Федерация, 672000, г. Чита, ул. Горького, д. 39A; тел.: +7(3022)354324; e-mail:natalasocolova@mail.ru

\section{Information about authors}

Pripachkina Ekaterina A., Chita State Medical Academy; Address: 39-A Gorky St., Chita 672000, Russian Federation; Phone: +7(3022)354324; e-mail: ekaterinapripachkina@mail.ru

Filev Andrey P., Chita State Medical Academy; Address: 39-A Gorky St., Chita 672000, Russian Federation; Phone:+7(3022)354324; e-mail: andfile@@mail.ru

Govorin Anatoliy V., Chita State Medical Academy; Address: 39-A Gorky St., Chita 672000, Russian Federation; Phone: +7(3022)354324; e-mail: govorav@mail.ru

Mukha Natalia V., Chita State Medical Academy; Address: 39-A Gorky St., Chita 672000, Russian Federation; Phone: +7(3022)354324; e-mail:mushanatasha@inbox.ru Vasilenko Pavel V., Chita State Medical Academy; Address: 39-A Gorky St., Chita 672000, Russian Federation; Phone: +7(3022)354324; e-mail: pavelvasilenkochita@mail.ru

Socolova Natalia A., Chita State Medical Academy; Address: 39-A Gorky St., Chita 672000, Russian Federation; Phone: +7(3022)354324; e-mail: natalasocolova@mail.ru 
๑ ДОЧКИНА Е. С., УСТИНОВА А. В., ТАРАНУШЕНКО Т. Е.

УДК 616.831-009.11-053.2-071.1-02:616.83-053.13

DOI: $10.20333 / 2500136-2017-5-85-90$.

\section{ОСОБЕННОСТИ АНАМНЕЗА ДЕТЕЙ С ДЕТСКИМ ЦЕРЕБРАЛЬНЫМ ПАРАЛИЧОМ}

Е. С. Дочкина ${ }^{1}$, А. В. Устинова 2 , Т. Е. Таранушенко ${ }^{3}$

${ }^{1} \mathrm{OOO}$ «Профмед» Клиника Элайф, Красноярск 660135, Российская Федерация

${ }^{2}$ Красноярская краевая детская больница, Красноярск 660051, Российская Федерация

${ }^{3}$ Красноярский государственный медицинский университет им. проф. В.Ф. Войно-Ясенецкого, Красноярск 660022, Российская Федерация

Цель исследования. Проанализировать особенности анамнеза детей с детским церебральным параличом, сформировавшимся на фоне перинатального гипоксического и гипоксически-геморрагического поражения центральной нервной системы (ЦНС).

Материал и методы. В статье представлен анализ анамнестических сведений 81 ребенка с ДЦП, из которых у 50 детей в раннем неонатальном периоде диагностировано гипоксически-ишемическое поражение ЦНС и у 31 ребенка в этом же возрасте установлен диагноз гипоксическигеморрагического поражения ЦНС. Выполнена оценка семейного анамнеза с учетом ряда факторов, которые могут повлиять на формирование рассматриваемой патологии.

Результаты. Анализ исследования показал значимое преобладание более тяжелого поражения ЦНС (гипоксически-геморрагического) у детей, матери которых были старше 35 лет (45,2 \%). Вредные привычки отца отмечены в 95,3% случаев при гипоксическически-ишемическом поражении и в 77,8 \% при гипоксически-геморрагическом поражении ЦНС ( $<0,025)$. Установлен отягощенный соматический анамнез у матерей, родивших детей с перинатальным поражением ЦНС (заболевания органов пищеварения, патология мочеполовой системы, болезни системы кровообращения, которые выявлялись чаще у женщин, дети которых имели гипоксически-ишемическое поражение ЦНС). Выявлены отягощенный анамнез по ОРВИ в первой половине беременности 64,4 \% случаев при гипоксически-ишемическом поражении и в 60 \% при гипоксическигеморрагическом поражении ЦНС, патология беременности в виде гестозов 1-ой половины 76 \% случаев в группе с гипоксически-ишемическим поражением ЦНС, а также наличие хронической фетоплацентарной недостаточности (ХФН) в обоих группах с одинаковой частотой (100 \%).

Заключение. Полученные данные подтверждают важность планирования беременности, необходимость эффективного акушерско-гинекологического контроля, профилактики и своевременного лечения ОРВИ у беременных, хронических заболеваний у женщин, планирующих беременность, для предупреждения тяжелых перинатальных поражения ЦНС, на фоне которых может сформироваться детский церебральный паралич. Ключевые слова: дети, новорожденные, детский церебральный паралич, перинатальное поражение ЦНС, семейный анамнез.

Для изитирования: Дочкина ЕС, Устинова АВ, Таранушенко ТЕ. Особенности анамнеза детей с детским церебральным параличом. Сибирское медицинское обозрение. 2017;(5): 85-90. DOI: 10.20333/2500136-2017-5-85-90.

\section{PECULIARITIES OF ANAMNESIS IN CHILDREN WITH INFANTILE CEREBRAL PALSY}

E. S. Dochkina ${ }^{1}$, A.V. Ustinova ${ }^{2}$, T. E. Taranushenko ${ }^{3}$

${ }^{1}$ Profmed Ltd. Clinic Elife, Krasnoyarsk 660135, Russian Federation

${ }^{2}$ Krasnoyarsk Regional Children`s Hospital, Krasnoyarsk 660051, Russian Federation

${ }^{3}$ Professor V. F. Voino-Yasenetsky Krasnoyarsk State Medical University, Krasnoyarsk 660022, Russian Federation

The aim of the research. To analyze the features of anamnesis of children with cerebral palsy, formed against a background of perinatal hypoxic and hypoxichemorrhagic damage of the central nervous system (CNS).

Material and methods. The article presents an analysis of anamnestic information of 81 children with cerebral palsy, 50 of them were diagnosed in the early neonatal period with hypoxic-ischemic involvement of the CNS and 31 children were diagnosed a hypoxic-hemorrhagic CNS lesion at the same age. The family history was assessed taking into account a number of factors that could affect to the formation of the pathology.

Results. Analysis of the study showed a significant predominance of more severe lesion of the central nervous system (hypoxic-hemorrhagic) in children whose mothers were older than 35 years (45.2\%). Bad habits of the father were noted in $95.3 \%$ of cases with hypoxic-ischemic lesions and in $77.8 \%$ with hypoxic-hemorrhagic CNS lesion ( $\mathrm{p}<0.025)$. A burdened somatic anamnesis was established in mothers who gave birth to children with perinatal CNS lesions (diseases of the digestive system, pathology of the genitourinary system, circulatory system diseases, which were detected more often in women whose children had hypoxic-ischemic lesions of the central nervous system). The burdened anamnesis in ARVI in the first half of pregnancy $64.4 \%$ of cases with hypoxic-ischemic lesions and in $60 \%$ with hypoxic-hemorrhagic CNS lesion, pregnancy pathology in the form of gestosis of the first half of $76 \%$ of cases in the group with hypoxic-ischemic lesions of the central nervous system, as well as the presence of chronic fetoplacental insufficiency (CFN) in both groups with the same frequency $(100 \%)$.

The conclusion. The data confirm the importance of pregnancy planning, the need for effective obstetric-gynecological control, prevention and timely treatment of acute respiratory viral infection in pregnant women, chronic diseases in women planning pregnancy, to prevent severe perinatal CNS lesions, against which cerebral palsy can form.

Key words: children, newborns, infantile cerebral palsy, perinatal CNS lesion, family anamnesis.

Citation: Dochkina ES, Ustinova AV, Taranushenko TE. Peculiarities of anamnesis in children with infantile cerebral palsy. Siberian Medical Review. 2017; (5): 85-90. DOI: 10.20333/2500136-2017-5-85-90. 


\section{Введение}

Несмотря на современные достижения в области медицины, распространенность ДЦП продолжает оставаться высокой. Частота встречаемости данной патологии в развитых странах составляет от 1,5 до более 4-х на 1000 детей. И последние 50 лет эта цифра остается в тех же пределах, несмотря на улучшения акушерско-гинекологического контроля [1].

Свыше половины больных не имеют точно установленных этиологий, хотя очевидно, причины формирования патологии относятся преимущественно к анте-, интра- или неонатальному периодам жизни [2]. Гипоксия занимает особое место среди причин поражения ЦНС. Она определяет характер церебральных расстройств, которые могут приводить к необратимым процессам и стать основанием для формирования патологии ЦНС: нарушение координации, речи, движений, задержки в интеллектуальном развитии, дисфункции мышечной и двигательной систем [3]. По данным зарубежных авторов, гипоксическое поражение ЦНС встречается с частотой 2,5 на 1000 новорожденных, из этого числа до 70 \% формируются неврологические заболевания [4]. Новорожденные недоношенные дети, перенесшие хроническую гипоксию плода, подвержены внутрижелудочковым (ВЖК) или субэпендимальным (СЭК) кровоизлияниям. ВЖК являются основной причиной летальных исходов у недоношенных новорожденных (70 \%), поэтому данная проблема по-прежнему остается социально-значимой [5].

\section{Материал и методы}

Нами проанализированы данные анамнеза у 81 ребенка с диагностированным ДЦП, из которых были сформированы 2 группы: первая группа - 50 детей с диагнозом гипоксически-ишемическое поражение (ГИП) ЦНС и вторая группа - 31 ребенок с гипоксически-геморрагическим поражением (ГГП) ЦНС в неонатальном периоде. На момент включения в исследования дети находились в отделении восстановительного лечения детского санатория «Ласточка», который является структурным подразделением центра реабилитации при Красноярском краевом клиническом центре охраны материнства и детства.

Критерии включения: диагностированный ДЦП и добровольное согласие родителей на участие в исследовании.

Оценка анамнеза выполнялась по протоколу, который включал паспортные данные (возраст родителей, место жительства), семейный анамнез (вредные привычки родителей, профвредности и перенесенные заболевания), а также заключения нейросонографических исследований детей с ДЦП. Все данные анамнеза собирались по традиционной схеме опроса родителей и уточнялись на основе медицинской документации (выписка из родильного дома, выкопировка данных медицинской формы 112, результаты выписных эпикризов из стационаров и т.д.). Расчет статистических данных проводился при помощи критерия Хи-квадрат для таблиц сопряженности 2х2 (без поправки Иэйтса на непрерывность) и точного критерия Фишера (двусторонний).

\section{Результаты и обсуждение}

Известно, что возраст матери может оказывать существенное влияние на развитие антенатальной патологии, особенно с поражением ЦНС. Матери юного возраста (менее 20 лет) не всегда планируют беременность, что существенно повышает риск рождения детей с различной патологией. У таких матерей в $21 \%$ рождаются дети с задержкой внутриутробного развития плода (ЗВУР) [6]. У позднородящих же женщин (старше 35 лет) чаще рождаются дети с генетической патологией, хромосомными заболеваниями и другими патологическими состояниями [7].

В настоящем исследовании основная доля женщин $(69,1$ \%) находилась в возрастном интервале 21-34 года (табл.1). В группе детей с ГИП ЦНС преобладали женщины в возрасте 21-34 года - 78 \%, нежели 54,8 \% в группе с ГГП ЦНС $(\mathrm{p}<0,05)$. Матери в возрасте менее 20 лет не зарегистриро-

\section{Особенности семейного анамнеза}

\begin{tabular}{|c|c|c|c|c|c|}
\hline \multirow[t]{2}{*}{ Признак } & \multicolumn{2}{|c|}{$\begin{array}{l}\text { Гипоксически- } \\
\text { ишемические } \\
\text { поражения } \\
\text { ЦНС (n=50) }\end{array}$} & \multicolumn{2}{|c|}{$\begin{array}{c}\text { Гипоксически- } \\
\text { геморрагические } \\
\text { поражения } \\
\text { ЦНС }(n=31)\end{array}$} & \multirow[t]{2}{*}{$p$} \\
\hline & abc. & $\%$ & абс. & $\%$ & \\
\hline Матери младше 20 лет & 0 & 0 & 0 & 0 & - \\
\hline Матери старше 35 лет & 11 & 22 & 14 & 45,2 & $p<0,05$ \\
\hline $\begin{array}{l}\text { Матери в возрасте } \\
\text { от } 21 \text { до } 34 \text { лет }\end{array}$ & 39 & 78 & 17 & 54,8 & $p<0,05$ \\
\hline $\begin{array}{l}\text { Наличие вредных } \\
\text { привычек у матерей }\end{array}$ & 6 & 12,5 & 4 & 13,3 & $p>0,05$ \\
\hline $\begin{array}{l}\text { Отсутствие вредных } \\
\text { привычек у матерей }\end{array}$ & 42 & 87,5 & 26 & 86,7 & $p>0,05$ \\
\hline $\begin{array}{l}\text { Данные о вредных привычках } \\
\text { у матерей неизвестны }\end{array}$ & 2 & 4,2 & 1 & 3,3 & - \\
\hline Профвредности матерей & 4 & 8,2 & 2 & 6,5 & $p>0,05$ \\
\hline $\begin{array}{l}\text { Отсутствие профвредностей } \\
\text { у матерей }\end{array}$ & 45 & 91,8 & 29 & 93,5 & $p>0,05$ \\
\hline $\begin{array}{l}\text { Данные о профвредностях } \\
\text { у матерей неизвестны }\end{array}$ & 1 & 2 & 0 & 0 & - \\
\hline $\begin{array}{l}\text { Наличие вредных привычек } \\
\text { у отцов }\end{array}$ & 41 & 95,3 & 21 & 77,8 & $p<0,025$ \\
\hline $\begin{array}{l}\text { Отсутствие вредных привычек } \\
\text { у отцов }\end{array}$ & 2 & 4,7 & 6 & 22,2 & $p<0,025$ \\
\hline $\begin{array}{l}\text { Данные о вредных привычках } \\
\text { у отцов неизвестны }\end{array}$ & 7 & 16,3 & 4 & 14,8 & - \\
\hline Про Профвредности отцов & 29 & 67,4 & 19 & 67,9 & $p>0,05$ \\
\hline $\begin{array}{l}\text { Отсутствие профвредностей } \\
\text { у отцов }\end{array}$ & 15 & 34,9 & 8 & 28,6 & $p>0,05$ \\
\hline
\end{tabular}

Примечание: р - критический уровень значимости, $n$ - общее количество детей в группе, абс.- абсолютное количество детей в группе по каждому признаку. Сравнение показателей, измеренных в номинальной шкале, проводилось при помощи критерия Хи-квадрат для таблии, сопряженности $2 \times 2$ (без поправки Иэйтса на непрерывность) и точного критерия Фишера (двусторонний). 
ваны в рассматриваемых группах. Важно, что женщины, у которых дети страдали ГГП ЦНС, имели возраст старше 35 лет $(45,2 \%)$, в сравнении с женщинами из группы детей с ГИП ЦНС (22\%) (p<0,05).

При сборе анамнеза особое внимание было уделено вредным привычкам родителей (курение, алкоголизм) (табл.1). Вредные привычки матерей регистрировались при различных поражениях ЦНС в среднем у 13 \% женщин без существенных различий в группах. Вредные привычки отца отмечались в 95,3 \% случаев при ГИП ЦНС, против 77,8 \% в группе с ГГП ЦНС ( $<20,025)$. Вредные привычки могут оказать отрицательное влияние на половые клетки как женские, так и мужские, и приводить к рождению детей с различными пороками и дефектами развития $[8,9]$.

Нами не получено убедительных данных о влиянии профессиональных вредностей отцов и матерей на характер поражения ЦНС (табл. 1).

Болезни родителей могут оказывать влияние на внутриутробное развитие ребенка. В период беременности у женщины нередко обостряется хроническая патология, приводящая к ФПН, нарушению питания плода, формированию внутриутробной патологии [10].

\section{Соматическая патология у родителей в рассматриваемьх группах}

\begin{tabular}{|c|c|c|c|c|c|}
\hline \multirow{2}{*}{ Признак } & $\begin{array}{c}\text { Гипоксически- } \\
\text { ишемические } \\
\text { поражения } \\
\text { ЦНС }(\mathrm{n}=50)\end{array}$ & $\begin{array}{c}\text { Гипоксически- } \\
\text { геморрагические } \\
\text { поражения } \\
\text { ЦНС }(\mathrm{n}=31)\end{array}$ & $\mathrm{p}$ \\
\cline { 2 - 6 } & $\mathrm{a \sigma c.}$ & $\%$ & абс. & $\%$ & \\
\hline
\end{tabular}

Данные матерей

\begin{tabular}{|l|c|c|c|c|c|}
\hline $\begin{array}{l}\text { Заболевания органов } \\
\text { кровообращения }\end{array}$ & 5 & 10,4 & 1 & 3,4 & $\mathrm{p}>0,05$ \\
\hline Заболевания эндокринные & 0 & 0 & 1 & 3,4 & $\mathrm{p}>0,05$ \\
\hline Заболевания цНС & 1 & 2,1 & 1 & 3,4 & $\mathrm{p}>0,05$ \\
\hline Заболевания ЖКТ & 13 & 27,1 & 7 & 24,1 & $\mathrm{p}>0,05$ \\
\hline $\begin{array}{l}\text { Хронические геникологические } \\
\text { заболевания }\end{array}$ & 11 & 23 & 6 & 20,7 & $\mathrm{p}>0,05$ \\
\hline Заболевания отрицают & 22 & 45,8 & 9 & 31 & $\mathrm{p}>0,05$ \\
\hline Данные неизвестны & 2 & 4,2 & 2 & 6,9 & - \\
\hline
\end{tabular}

Данные отцов

\begin{tabular}{|l|c|c|c|c|c|}
\hline Заболевания ЦНС & 2 & 5 & 0 & 0 & $\mathrm{p}>0,05$ \\
\hline Заболевания ЖКТ & 5 & 12,5 & 6 & 22,2 & $\mathrm{p}>0,05$ \\
\hline $\begin{array}{l}\text { Заболевания позвоночника и } \\
\text { опорно-двигательного аппарата }\end{array}$ & 7 & 17,5 & 1 & 3,7 & $\mathrm{p}>0,05$ \\
\hline Отрицают заболевания & 5 & 12,5 & 6 & 22,2 & $\mathrm{p}>0,05$ \\
\hline Данные неизвестны & 10 & 25 & 4 & 14.8 & - \\
\hline
\end{tabular}

Примечание: такое же как в табл. 1.
При анализе семейного анамнеза нами изучен характер соматической патологии родителей (табл. 2). Установлено, что у матерей, родивших детей с перинатальным поражением ЦНС, самыми частыми патологиями в обеих группах стали заболевания органов пищеварения (гастриты, язвы, холециститы, панкреатиты), которые составили 27,1 \% и 24,1 \% соответственно; другой частой патологией были болезни мочеполовой системы 23 \% и 20,7 \% случаев - это невоспалительные (эндометриоз, эрозии шейки матки, кисты яичников), воспалительные (аднекситы, эндометриты) и доброкачественные новообразования. Болезни системы кровообращения статистически значимых различий между группами не показали, несмотря на то, что у женщин, дети которых страдали ГИП ЦНС они выявлялись чаще (10,4 \% против 3,4 \%). В структуре соматических проблем отца преобладали болезни нервной системы и патология ЖКТ также без статистически значимых различий в обеих группах.

Нами рассмотрен вклад ОРВИ, переносимых женщиной в период беременности и способных увеличивать риск поражения ЦНС. В 1-ой половине беременности 64,4 \% и 60 \% женщин в обеих группах перенесли ОРВИ. Восприимчивость к гриппу беременных высока, что провоцирует пороки развития и преждевременные прерывание беременности.[11]. Во 2-ой половине беременности доля женщин с ОРВИ существенно снижалась и составила всего 8,9\% и 12 $\%$ соответственно.

Наличие гинекологических заболеваний у беременных может также приводить к поражению ЦНС ребенка, вплоть до грубых неврологических нарушений, исходом которых может стать ДЦП [12]. Выполненный анализ гинекологического анамнеза женщин показал (табл.3): в рассматриваемых группах наиболее частыми невоспалительными заболеваниями женских половых органов были эндометриоз (8,3 \% при ГИП ЦНС) и эрозия шейки матки $(4,2 \%$ при ГИП ЦНС), воспалительными - эндометриты (6,3 \% при ГИП ЦНС) и аднекситы (6,3 при ГИП ЦНС), а также доброкачественные новообразования - миомы (17,2 \% при ГГП ЦНС). Указанная патология регистрировалась без достоверных различий.

Из акушерского анамнеза - в группе детей с ГИП ЦНС преобладала доля матерей с 1-ой по счету беременностью (28\%), что практически в три раза превысило показатель в группе детей с ГГП ЦНС 9,7 \% ( $<<0,05)$. Наряду с этим в группе детей с ГИП ЦНС преобладал процент женщин в возрасте 21-34 года, для которых настоящая беременность была 1-ой по счету - 78 \%, против 54,8 \% (p<0,05). У первородящих чаще отмечается затяжной потужный период и слабость родовой деятельности, что может быть связано с узким тазом и слабостью его мышечного каркаса, в результате - травматизация костей, мышц и связок тазового кольца [13]. При рассмотрении 2-ой, 3-ей и последующего числа беременностей достоверных различий между рассматриваемыми группами не установлено.

Факт экстракорпорального оплодотворения и много- 


\section{Особенности семейного анамнеза}

\begin{tabular}{|c|c|c|c|c|c|}
\hline \multirow[t]{2}{*}{ Признак } & \multicolumn{2}{|c|}{$\begin{array}{c}\text { Гипоксически- } \\
\text { ишемические } \\
\text { поражения } \\
\text { ЦНС }(n=50)\end{array}$} & \multicolumn{2}{|c|}{$\begin{array}{c}\text { Гипоксически- } \\
\text { геморрагические } \\
\text { поражения } \\
\text { ЦНС }(n=31) \\
\end{array}$} & \multirow[t]{2}{*}{ p } \\
\hline & abc. & $\%$ & абс. & $\%$ & \\
\hline Миомы & 3 & 6,3 & 5 & 17,2 & $p>0,05$ \\
\hline Эндометриоз & 4 & 8,3 & 0 & 0 & $p>0,05$ \\
\hline Эндометрит & 3 & 6,3 & 0 & 0 & $p>0,05$ \\
\hline Эрозии шейки матки & 2 & 4,2 & 1 & 3,4 & $p>0,05$ \\
\hline Аднекситы & 3 & 6,3 & 1 & 3,4 & $p>0,05$ \\
\hline Отрицают заболевания & 33 & 68,8 & 22 & 75,9 & $p>0,05$ \\
\hline Данные неизвестны & 2 & 4,2 & 2 & 6,9 & - \\
\hline Беременность по счету 1 & 14 & 28 & 3 & 9,7 & $p<0,05$ \\
\hline Беременность по счету 2 & 18 & 36 & 10 & 32,3 & $p>0,05$ \\
\hline $\begin{array}{l}\text { Беременность по счету } \\
3 \text { и более }\end{array}$ & 20 & 40 & 16 & 51,6 & $p>0,05$ \\
\hline Многоплодная беременность & 4 & 8 & 5 & 16,1 & $p>0,05$ \\
\hline Одноплодная беременность & 46 & 92 & 26 & 83,9 & $p>0,05$ \\
\hline Беременность ЭКО & 3 & 6 & 1 & 3,2 & $p>0,05$ \\
\hline $\begin{array}{l}\text { Беременность } \\
\text { естественным путем }\end{array}$ & 47 & 94 & 30 & 96,8 & $p>0,05$ \\
\hline $\begin{array}{l}\text { Гестозы I половины } \\
\text { беременности }\end{array}$ & 38 & 76 & 16 & 51,6 & $p<0,025$ \\
\hline $\begin{array}{l}\text { Гестозы II половины } \\
\text { беременности }\end{array}$ & 9 & 18 & 9 & 29 & $p>0,05$ \\
\hline Гестозы отрицают & 4 & 8 & 5 & 16,1 & $p>0,05$ \\
\hline $\mathrm{XФH}$ & 41 & 100 & 26 & 100 & $p>0,05$ \\
\hline Данные неизвестны о ХФН & 9 & 22 & 5 & 19,2 & - \\
\hline $\begin{array}{l}\text { Угроза выкидыша } \\
\text { 1-ой половины беременности }\end{array}$ & 9 & 18,8 & 5 & 17,2 & $p>0,05$ \\
\hline $\begin{array}{l}\text { Угроза выкидыша } \\
\text { 2-ой половины беременности }\end{array}$ & 34 & 70,8 & 24 & 82,8 & $p>0,05$ \\
\hline Угрозу выкидыша отрицают & 5 & 10,4 & 0 & 0 & $p>0,05$ \\
\hline $\begin{array}{l}\text { Данные об угрозе выкидыша } \\
\text { неизвестны }\end{array}$ & 2 & 4,2 & 2 & 6,9 & - \\
\hline
\end{tabular}

Примечание: такое же как в табл. 1.

плодной беременности также не выявил значимых различий между исследуемыми группами.

Одними из главных факторов риска развития патологии ЦНС у детей являются гестозы. Нами проанализирована частота выявления гестозов 1-ой и 2-ой половины беременности. Матери, с гестозом 1-ой половины беременности, чаще встречались в группе детей с ГИП ЦНС - 76 \%, нежели в группе детей с ГГП ЦНС - 51,6 \% (p<0,025). Гестозы 2-ой половины беременности встречались с частотой 18 \% и 29 $\%$ соответственно, отмечен более высокий процент поздних гестозов у женщин, родивших детей с ГГП ЦНС (29\%). Известно, что гестозы могут приводить к ФПН, наступает задержка роста и формирования плода. Отдельные авторы указывают на взаимосвязь между патологией плацент и формированием ДЦП в дальнейшем $[14,15]$. По нашим данным, ФПН у беременных женщин в анамнезе регистрировалась в $100 \%$ случаев как при рождении детей с ГИП ЦНС, так и с ГГП ЦНС.

Угроза выкидыша первой половины беременности не имела существенных различий в группах и составила 18,8 $\%$ и $17,2 \%$. Течение 2 -ой половины беременности у женщин обеих групп характеризовалось $4 \mathrm{x}$ кратным повышением числа случаев угрозы выкидыша (14 женщин, против 58); при этом сравнение между группами с ГИП и ГГП ЦНС не выявило достоверных различий и составило 70,8 \% и 82,8 \% соответственно (табл. 3).

\section{Заключение}

Выполненный анализ особенностей семейного анамнеза детей с ДЦП, на фоне ГИП и ГГП ЦНС, показал значимое преобладание более тяжелого ГГП ЦНС у детей, матери которых были старше 35 лет (45,2 \%, против $22 \%)$ и отягощенный соматический анамнез (заболевания органов пищеварения, хронические гинекологические заболевания и частые ОРВИ в первой половине беременности $64,4 \%$ и $60 \%)$.

В группе детей, с ДЦП на фоне ГИП ЦНС, обращает внимание высокая частота встречаемости вредных привычек со стороны отца (до 95,3 \% случаев), преобладание матерей с 1-ой по счету беременностью (28 \%), неблагоприятные факторы антенатального анамнеза (гестозы первой половины беременности до 76 \%, наличие ХФН до 100 \% в обеих группах и угрозу выкидыша во 2-ой половине беременности - в группе с ГГП ЦНС преобладание случаев в четыре раза, нежели в группе с ГГП ЦНС).

Представленные данные определяют необходимость пристального внимания к вопросам планирования беременности и проведения комплекса мер, направленных на своевременное лечение хронических заболеваний, предупреждение развития острой патологии в период беременности и эффективного акушерско-гинекологического наблюдения.

\section{Литература}

1. O'Callaghan ME, MacLennan AH, Gibson CS, McMichael GL, Haan EA, Broadbent JL, Baghurst PA, Goldwater PN, Dekker GA. Australian Collaborative Cerebral Palsy Research Group. Genetic and clinical contributions to cerebral palsy: a multi-variable analysis. Journal of paediatrics and child health. 2013;49(7):575-81.

2. Студеникин ВМ, Букш АА, Кузенкова ЛМ, Куренков АЛ. Детский церебральный паралич и эпилепсия: эпидемиология и этиология. Лечащий врач. 2016;3:68-72.

3. Ледяйкина ЛВ, Балыкова ЛА, Гарина СВ, Солдатова $\mathrm{OH}$, Толкунова АA, Страдина АA, Герасименко АВ. Некоторые аспекты патогенеза ишемически-гипоксических поражений центральной нервной системы у новорожденных. Самарский научный вестник. 2015;2(11):112-15.

4. Chen Chien-Yi, Sun Wei-Zen, Kang Kai-Hsiang, Chou 
Hung-Chieh, Tsao Po-Nien, Hsieh Wu-Shiun, Fu Wen-Mei. Hypoxic Preconditioning Suppresses Glial Activation and Neuroinflammation in Neonatal Brain Insults. Hindawi Publishing Corporation Mediators of Inflammation. 2015;2015:1-11.

5. Брыксина ЕЮ, Брыксин ВС, Буштырева ВА, Ониангет ЕП. Патогенетические аспекты перинатального поражения центральной нервной системы и особенности неврологического статуса недоношенных детей. Современные проблемы науки и образования. 2015;4:410.

6. Ситникова ЛН, Лавлинская ЛИ. Организация медицинской помощи беременным групп высокого риска. Вестник новых медицинских технологий. 2014;1:65.

7. Xue J, Chen LZ, Xue L, Zhou Q. Meta-analysis of risk factors for childhood cerebral palsy during pregnancy. Zhongguo Dang Dai Er Ke Za Zhi. 2013; 15(7):535-40.

8. Ahlin K, Himmelmann K, Hagberg G, Kacerovsky M, Cobo T, Wennerholm UB, Jacobsson B. Non-infectious risk factors for different types of cerebral palsy in term-born babies: a population-based, case-control study. BJOG. 2013;120(6):724-31.

9. Семенова ТВ, Аржанова ОН, Беспалова ОН, Милютина ЮП, Прокопенко ВМ, Зубжицкая ЛБ, Арутюнян АВ. Особенности течения беременности и исходов родов при табакокурении. Журнал акушерства и женских болезней. 2014;LXIII (2):50-8.

10. Ковалев ЕВ, Занько ЮВ, Трубкина ТЮ. Факторы риска задержки роста плода, связанные с состоянием здоровья и образом жизни беременной женщины. Мать и дитя в Кузбacce. 2014;4:24-8.

11. Попов АФ, Киселев ОИ. Грипп у беременных. Эпидемиология и инфекиионные болезни. 2013;3:40-3.

12. Созаева ДИ, Бережанская СБ. Иммунопатогенетические механизмы формирования двигательных нарушений у детей грудного возраста, родившихся от матерей с осложненным течением беременности и родов. Современные проблемы науки и образования. 2013;5:336.

13. Miller JM, Low LK, Zielinski R. Evaluating maternal recovery from labor and delivery: bone and levator and injuries. American journal of obstetrics and gynecology. 2015;21(188):1-11.

14. Гулая ВС. Роль активности протеолитических ферментов в развитии задержки роста плода на фоне хронической плацентарной недостаточности. Альманах современной науки и образования. 2014;9(87):42-5.

15. Устинова СИ, Таранушенко ТЕ, Устинова АВ, Карпова ЛН. Патология плаценты - как фактор риска реализации детского церебрального паралича. Сибирское медицинское обозрение. 2010;6:72-5.

\section{References}

1. O'Callaghan ME, MacLennan AH, Gibson CS, McMichael GL, Haan EA, Broadbent JL, Baghurst PA, Goldwater PN, Dekker GA. Australian Collaborative Cerebral Palsy Research Group. Genetic and clinical contributions to cerebral palsy: a multi-variable analysis. Journal of paediatrics and child health. 2013;49 (7):575-81.

2. Studenikin VM, Buksh AA, Kuzenkova LM, Kurenkov AL.
Children's cerebral palsy and epilepsy: epidemiology and etiology. The treating doctor. 2016;3:68-72. (In Russian)

3. Ledyaykina LV, Balykova LA, Garina SV, Soldatova ON, Tolkunova AA, Stradina AA, Gerasimenko AV. Some aspects of the pathogenesis of ischemic-hypoxic lesions of the central nervous system in newborns. Samara Scientific Bulletin. 2015;2(11):112-15. (In Russian)

4. Chen Chien-Yi, Sun Wei-Zen, Kang Kai-Hsiang, Chou Hung-Chieh, Tsao Po-Nien, Hsieh Wu-Shiun, Fu Wen-Mei. Hypoxic Preconditioning Suppresses Glial Activation and Neuroinflammation in Neonatal Brain Insults. Hindawi Publishing Corporation Mediators of Inflammation. 2015;2015:1-11.

5. Bryksina EYu, Bryksin VS, Bushtyreva VA, Onianget EP. Pathogenetic aspects of perinatal involvement of the central nervous system and features of neurological state of premature babies. Modern problems of science and education. 2015;4:4106. (In Russian)

6. Sitnikova LN, Lavlinskaya LI. Organization of medical care for pregnant high-risk groups. Bulletin of new medical technologies. 2014;1:65. (In Russian)

7. Xue J, Chen LZ, Xue L, Zhou Q. Meta-analysis of risk factors for childhood cerebral palsy during pregnancy. Zhongguo Dang Dai Er Ke Za Zhi. 2013;15(7):535-40.

8. Ahlin K, Himmelmann K, Hagberg G, Kacerovsky M, Cobo T, Wennerholm UB, Jacobsson B. Non-infectious risk factors for different types of cerebral palsy in term-born babies: a population-based, case-control study. BJOG. 2013;120(6):724-31.

9. Semenova TV, Arzhanova ON, Bespalova ON, Milutina Yu.P., Prokopenko VM, Zubzhitskaya LB, Arutyunyan AV. Features of the course of pregnancy and the outcome of labor during tobacco smoking. Journal of Obstetrics and Women's Diseases. 2014;LXIII(2):50-8. (In Russian)

10. Kovalev EV, Zanko YuV, Trubkina TYu. Risk factors for fetal growth retardation associated with the state of health and lifestyles of a pregnant woman. Mother and child in Kuzbass. 2014;4:24-8. (In Russian)

11. Popov AP, Kiselev OI. Influenza in pregnant women. Epidemiology and infectious diseases. 2013;3:40-3. (In Russian)

12. Sozaeva DI, Berezhanskaya SB. Immunopathogenetic mechanisms of formation of motor disorders in infants born from mothers with complicated course of pregnancy and childbirth. Modern problems of science and education. 2013;5:336. (In Russian)

13. Miller JM, Low LK, Zielinski R. Evaluating maternal recovery from labor and delivery: bone and levator and injuries. American journal of obstetrics and gynecology. 2015; 21(188):1-11.

14. Gulaya VS. The role of proteolytic enzyme activity in the development of delayed fetal growth against a background of chronic placental insufficiency. Almanac of modern science and education. 2014;9(87):42-5. (In Russian)

15. Ustinova SI, Taranushenko TE, Ustinova AV, Karpova L.N. Pathology of the placenta - as a risk factor for the realization of infantile cerebral palsy. Siberian Medical Review. 2010;6:72-5. (In Russian) 


\section{Сведения об авторах}

Дочкина Елена Семеновна, ООО «Профмед» Клиника Элайф; адрес: Российская Федерация, 660135, г. Красноярск, ул. Алексеева, д. 115; тел.: +7(391)2214010 e-mail:helenad.73@mail.ru

Устинова Алена Васильевна, Красноярская краевая детская больница; адрес: Российская Федеращия, 660051, г. Красноярск, ул. Академика Киренского, д. 2A; тел.: +7(391)2435673; e-mail:2956959@mail.ru

Таранушенко Татьяна Евгеньевна, Красноярский государственный медицинский университет им. проф. В.Ф. Войно-Ясенеикого; адрес: Российская Федеращия, 660022, г Красноярск, ул. Партизана Железняка, д.1; тел.: +7(391)2433952; e-mail: tetar@rambler.ru

\section{Information about the authors}

Dochkina Elena S., Profmed Ltd. Clinic Elife; Address: 115, Alekseeva Str., Krasnoyarsk 660135 Russian Federation, Phone: +7(391)2214010; e-mail: helenad.73@mail.ru

Ustinova Alena V., Krasnoyarsk Regional Children's Hospital; Address: 2A, Acad. Kirenski Str., Krasnoyarsk 660051, Russian Federation; Phone: +7(391)2435673; e-mail: 2956959@mail.ru Taranushenko Tatyana E., Professor V. F. Voino-Yasenetsky Krasnoyarsk State Medical University; Address: 1, Partizan Zheleznyak Str., Krasnoyarsk 660022, Russian Federation; Phone:+7(391)2433952; e-mail: tetar@rambler.ru

\section{Практическая медицина / Problems of practical health care}

( ) БЕЗДЕНЕЖНЫХ А. В., СУМИН А. Н.

УДК 616.1-07

DOI: $10.20333 / 2500136-2017-5-90-105$.

\section{ОЦЕНКА РИСКА СЕРДЕЧНО-СОСУДИСТЫХ ОСЛОЖНЕНИЙ ПРИ ВНЕСЕРДЕЧНЫХ ОПЕРАТИВНЫХ ВМЕШАТЕЛЬСТВАХ: КОМОРБИДНОСТЬ И ПРИМЕНЕНИЕ ШКАЛ КЛИНИЧЕСКОЙ ОЦЕНКИ}

А. В. Безденежных, А. Н. Сумин

Научно-исследовательский институт комплексных проблем сердечно-сосудистых заболеваний, Кемерово 650002, Российская Федерация

Резюме. Сердечно-сосудистые осложнения при внесердечных оперативных вмешательствах являются актуальной проблемой современной медицины. Для управления риском таких осложнений создан ряд национальных и международных рекомендаций. В качестве основы для принятия решения лечащим врачом в таких руководствах предлагаются алгоритмы, существенную часть которых составляет клиническая оценка периоперационного риска кардиальных осложнений. Для оптимизации работы врача или мультидисциплинарной команды специалистов предложен ряд шкал и индексов, позволяющий у постели больного оценить вероятность сердечно-сосудистых осложнений и помочь в принятии решения. В настоящей статье рассматриваются практические аспекты применения шкал клинической оценки риска, дается их сравнительная характеристика и особенности применения, а также обсуждаются практические подходы к управлению периоперационным кардиальным риском внесердечной хирургии при выявлении у пациента отдельных коморбидных состояний, оставшихся за пределами алгоритмов рекомендаций.

Ключевые слова: некардиальные оперативные вмешательства, сердечно-сосудистые осложнения, клиническая оценка риска.

Для иитирования: Безденежных АВ, Сумин АН. Оценка риска сердечно-сосудистых осложнений при внесердечных оперативных вмешательствах: коморбидность и применение шкал клинической оценки. Сибирское медицинское обозрение. 2017;(5): 90-105. DOI: 10.20333/2500136-2017-5-90-105.

\section{EVALUATION OF CARDIAC-VASCULAR COMPLICATIONS RISK IN OUT-OF-CARDIAC SURGERY: COMORBIDITY AND USE OF CLINICAL EVALUATION SCALE}

A. V. Bezdenezhnykh, A. N. Sumin

Research Institute for Complex Issues of Cardiovascular Diseases, Kemerovo 650002, Russian Federation

Abstract. Cardiovascular complications with out-of-cardiac surgery are an urgent problem of modern medicine. A number of national and international recommendations have been established to manage the risk of such complications. As a basis for the decision of the physician in such guidelines algorithms are proposed, a significant part of which is the clinical evaluation of the perioperative risk of cardiac complications. To optimize the work of a doctor or a multidisciplinary team of specialists, a series of scales and indices have been proposed that allow to assess the probability of cardiovascular complications and help in making a decision. In this article practical aspects of the use of the scales of clinical risk assessment are considered, their comparative characteristics and application peculiarities are given, and practical approaches to management of perioperative cardiac risk of out-of-cardiac surgery are discussed in case of detection of individual comorbid conditions in the patient outside the recommendations algorithms.

Key words: noncardial operative interventions, cardiovascular complications, clinical assessment of risk.

Citation: Bezdenezhnykh AV, Sumin AN. Evaluation of cardiac-vascular complications risk in out-of-cardiac surgery: comorbidity and use of clinical evaluation scale. Siberian Medical Review. 2017; (5): 90-105. DOI: 10.20333/2500136-2017-5-90-105. 


\section{Введение}

Внесердечная хирургия занимает существенное место в объемах оказания медицинской помощи по всему миру. Проблема сердечно-сосудистых осложнений (ССО) остается весьма актуальной не только в связи с высокой распространенностью такой патологии $[1,2]$, но и в связи с тем, что эти осложнения обладают максимальным неблагоприятным прогностическим влиянием. Попытки управления риском кардиальных осложнений после хирургических вмешательств предпринимаются уже достаточно давно. Первые согласительные документы были выпущены около 10 лет назад: в 2007 г. Американская ассоциация сердца (АНА) совместно с Американской коллегией кардиологов (АСС) опубликовала рекомендации по оценке и управлению риском кардиальных осложнений при внесердечной хирургии [3], а в 2009 г. аналогичный документ был выпущен и Европейским обществом кардиологов (ESC) [4]. В 2014 г. оба документа были пересмотрены и доработаны [5, 6]. В России рекомендации ESC были переведены и адаптированы в 2011 г. [7]. Однако это были рекомендации 2009 г., претерпевшие с тех пор ряд существенных изменений. Тем не менее мы можем, с некоторыми оговорками, применять современные рекомендации ESC и в российской действительности.

Основой для принятия решения лечащим врачом, готовящим пациента к оперативному вмешательству, является пошаговый алгоритм, основанный на стратификации риска как собственно оперативного вмешательства, так и индивидуального риска для каждого пациента. Первый его раздел касается неотложных состояний, которые требуют либо экстренного или срочного внесердечного оперативного вмешательства, либо являются неотложным кардиологическим состоянием (острый коронарный синдром). В настоящей статье мы не будем касаться этого раздела, так как он настолько многогранен, что принимать решение в такой ситуации может только мультидисциплинарная команда специалистов различного профиля («heart team»), которая рассмотрит возможные варианты подготовки, коррекции гомеостаза, определит необходимость того или иного вмешательства. Собственно, такой подход и нашел свое отражение в последних рекомендациях ESC и ACC/AHA $[5,6]$.

Рекомендации по оценке и управлению периоперационным риском ССО содержат достаточно большой объем информации, касающийся обследований пациентов перед некардиальной хирургией, интра- и послеоперационного анестезиологического пособия, особенностей медикаментозной терапии и водной нагрузки в зависимости от той или иной коморбидности. Мы постараемся осветить лишь раздел, связанный с клинической оценкой риска и функциональным состоянием пациента, которому уделено существенное внимание в рекомендациях. Так, при низком клиническом риске и высоком функциональном статусе оперативное лечение предполагается без дополнительного обследования. При худших характеристиках пациента - углубленное обследование сердечно-сосудистой системы, в т.ч. с проведением неинвазивного тестирования, коронарной ангиографии (КАГ) и, возможно, превентивной реваскуляризации миокарда.

Для оценки клинического риска используется ряд шкал и индексов, позволяющих достаточно оперативно у постели больного оценить его перспективу и принять решение. Кроме того, существует ряд коморбидных состояний, которые не вошли в алгоритм предоперационной оценки, однако могут оказать существенное влияние на принятие решений о проведении как некардиального, так и кардиохирургического вмешательства у пациента. В настоящей статье мы рассмотрим эти коморбидные состояния, а также приведем существующие шкалы клинической оценки риска ССО перед внесердечной хирургией.

Функииональный статус: оценка, клиническое и прогностическое значение при некардиальной хирургии

Функциональный статус принято оценивать в метаболических эквивалентах (MET). 1 МЕТ - это базальное потребление кислорода сорокалетним мужчиной с массой тела 70 кг. Количество эквивалентов существенно отражается как на результатах хирургии [8], так и на прогнозе для жизни пациента в целом $[9,10]$. Самым объективным методом для оценки является спироэргометрия, однако ввиду ее неполной доступности европейские и американские рекомендации предлагают достаточно простые шкалы ориентировочной оценки функционального статуса [11]. Функциональный статус может быть плохим ( $\leq 4 \mathrm{MET})$, средним (4-10 MET) и хорошим (>10 MET). Известно, что наиболее неблагоприятным является низкий функциональный статус с невозможностью выполнить более 4 MET [8]. Кроме того, невозможность выполнения пациентом определенного объема нагрузки, например, при периферическом атеросклерозе или неврологическом дефиците [12], может маскировать проявления ишемической болезни сердца (ИБС) или хронической сердечной недостаточности (ХCH). Таким образом, у пациента с низким функциональным статусом клинический риск оперативного вмешательства будет существенно выше. Следует также упомянуть, что в рекомендациях АCC/AНА присутствует такая характеристика как «неизвестный» функциональный статус [5]. При появлении такого показателя пациент автоматически рассматривается как лицо, неспособное выполнить 5 MET и требующее тщательного неинвазивного тестирования с возможной КАГ и реваскуляризацией, либо как неоперабельное.

Оценка функционального статуса проводится в европейских и американских рекомендациях на разных этапах алгоритма, кроме того, в тесной связи с ней проводится определение клинического риска.

Клинические шкалы оценки риска

Раздел, касающийся оценки риска оперативного вмешательства, имеет некоторые отличия в рекомендациях ESC и AНА. Так, если рекомендации АНА разделяют пациентов на подлежащих операциям низкого и повышенного риска, то 
Стратификация риска оперативньх вмешательств по рекомендациям ESC [6]

\begin{tabular}{|c|c|c|}
\hline $\begin{array}{c}\text { Низкий риск } \\
(<1 \%)\end{array}$ & $\begin{array}{c}\text { Промежуточный риск } \\
(1-5 \%) \\
\end{array}$ & $\begin{array}{c}\text { Высокий риск } \\
(>5 \%)\end{array}$ \\
\hline $\begin{array}{l}\text { · Вмешательства на молочной железе } \\
\text { · Стоматологическая хирургия } \\
\text { · Операции на щитовидной железе } \\
\text { · Хирургия глаза } \\
\text { · Вмешательства на бессимптомных каротидных } \\
\text { стенозах (открытое или чрескожное) } \\
\text { · Малые гинекологические операции } \\
\text { · Малые ортопедические операции } \\
\text { · Малые урологические операции }\end{array}$ & $\begin{array}{l}\text { · Интраперитонеальные вмешательства } \\
\text { (грыжесечение, холецистэктомия) } \\
\text { · Вмешательства на симптомных каротидных } \\
\text { стенозах (открытое или чрескожное) } \\
\text { · Периферическая ангиопластика } \\
\text { · Эндоваскулярные вмешательства } \\
\text { на брюшной аорте } \\
\text { · Большие урологические и гинекологические } \\
\text { операции } \\
\text { · Трансплантация почки } \\
\text { · Малая торакальная хирургия }\end{array}$ & $\begin{array}{l}\text { · Хирургия брюшной аорты и ее основных ветвей } \\
\text { · Открытое вмешательство на артериях нижних } \\
\text { конечностей, ампутация или тромбэмболэктомия } \\
\text { · Хирургия дуодено-панкреатической зоны } \\
\text { · Хирургия печени и желчных протоков } \\
\text { · Эзофагэктомия } \\
\text { · Восстановление перфорации кишечника } \\
\text { · Пневмонэктомия } \\
\text { · Трансплантация печени или легкого } \\
\text { · Адреналэктомия }\end{array}$ \\
\hline
\end{tabular}

ESC предполагает наличие операций низкого, промежуточного и высокого риска. В Таблице 1 представлена стратификация риска оперативных вмешательств в соответствии с рекомендациями ESC, т.е. определенные вмешательства заранее считаются операциями низкого, промежуточного или высокого риска с соответствующим процентом вероятности возникновения кардиальных осложнений.

Клиническая оценка необходима только для пациентов, планирующихся на оперативное вмешательство высокого риска, в то время как АНА рекомендует стратифицировать риск операции собственно по шкалам оценки риска, представленным ниже.

RCRI (Revised Cardiac Risk Index) определяет риск инфаркта миокарда (ИМ), отека легких, фибрилляции желудочков, остановки сердца или полной атриовентрикулярной блокады. Разработан в 1999 г. T. Lee et al. [13] как дополнение индексов L. Goldman [14] и A. Detsky [15]. Это, пожалуй, наиболее часто используемый клинический индекс. Он включен в алгоритмы рекомендаций по предоперационной оценке сердечно-сосудистого риска, кроме того, его зачастую используют для описания тяжести той или иной когорты оперируемых пациентов $[16,17]$. Суть применения данного индекса в выявлении у пациента, планирующегося на внесердечное вмешательство, шести факторов риска, каждому из которых присваивается 1 балл. Рассмотрим эти факторы ниже:

1. Внесердечная хирургия высокого риска. К таковой относятся любое полостное вмешательство и сосудистая хирургия выше паховой складки.

2. Наличие у пациента клиники ИБС. Данный фактор риска рассматривается не как простое упоминание о какомлибо клиническом проявлении коронарной патологии, а как определенное указание на перенесенный ранее ИМ, имеющуюся клинику стенокардии, наличие патологического зубца Q на электрокардиограмме (ЭКГ), положительный результат нагрузочного теста. Проведенная ранее реваскуляризация миокарда (открытая или чрескожная) является нивелирующим обстоятельством. Т.е. если у пациента, перенесшего коронарную хирургию, нет клиники стенокар- дии, то при использовании RCRI пациент учитывается как не имеющий ИБС.

3. Застойная сердечная недостаточность. Балл за этот пункт присваивается при наличии застойной сердечной недостаточности, отека легких, приступов сердечной астмы в анамнезе, ритма галопа или двусторонних хрипов в легких, застой в малом круге кровообращения (МКК), выявленный при рентгенологическом исследовании.

4. Цереброваскулярное событие в анамнезе - перенесенные ранее острое нарушение мозгового кровообращения (ОНМК) или транзиторная ишемическая атака (ТИА).

5. Наличие сахарного диабета (СД) на фоне проводимой инсулинотерапии. Этот пункт RCRI в 2007 г. был пересмотрен и в индекс был включен СД независимо от типа проводимой терапии.

6. Уровень креатинина более 177 мкмоль/л. Следует отметить, что в индекс включается именно значение креатинина, а не расчетная скорость клубочковой фильтрации, причем пороговый уровень креатинина достаточно высок.

Какую же информацию получает кардиолог, оценивающий риск периоперационных сердечно-сосудистых осложнений по шкале RCRI? В результате получается разделение пациентов на классы: отсутствие факторов риска - первый класс, 1 фактор - второй класс, 2 фактора - третий класс и 3 и более факторов риска - четвертый класс. Для каждого из них определен уровень риска указанных выше осложнений: 0,$4 ; 0,9 ; 6,6$ и $11 \%$, соответственно. Пациентам первого и второго классов можно проводить оперативное вмешательство без дополнительного углубленного обследования. Третий класс требует уже более пристального внимания с оценкой данных ЭКГ и эхокардиографии. Четвертый предполагает достаточно высокий риск осложнений, а значит и требует углубленного предоперационного обследования, в т.ч. с проведением коронарографии и, возможно, превентивной реваскуляризации.

Несмотря на то, что данная клиническая шкала позволяет быстро оценить риск кардиальных осложнений перед внесердечным вмешательством, она подвергается активной критике с ряда позиций. Во-первых, в когортах, использо- 
ванных для получения и валидации индекса было относительно мало пациентов, подвергавшихся некоронарной сосудистой хирургии [18]. Это нашло отражение и в работах нашей научной группы. Так, у пациентов, подвергшихся некоронарной сосудистой хирургии, гемодинамически значимое поражение трех коронарных артерий и/или стеноз ствола левой коронарной артерии имелись у 15,6 \% больных с отсутствием клинических факторов риска кардиальных осложнений, у 19,0 \% больных - с одним таким фактором, у 28,5 \% - с двумя факторами риска и у 42,8 \% пациентов - с тремя и более факторами риска [12]. И именно у таких пациентов шкала RCRI недооценивает риск осложнений, поскольку пациенты с некоронарным атеросклерозом имеют высокую распространенность ИБС, в том числе и бессимптомных ее вариантов. Критике подвергается этот индекс и при его использовании в большой ортопедической хирургии [19].

Данный индекс охватывает достаточно большое количество кардиальных осложнений, включая острые сосудистые события, нарушения ритма и декомпенсацию ХСН. Вероятно, тот факт, что его прогностическая значимость подвергается сомнению, связан не только с методологическими особенностями проведенного исследования, но и с тем, что в течение прошедших двадцати лет изменилась хирургическая и анестезиолоическая техника, а также усовершенствовались подходы к выявлению послеоперационных осложнений.

National Surgical Quality Improvement Program (NSQIP) Myocardial Infarction and Cardiac Arrest (MICA). NSQIP MICA достаточно удобный индекс, позволяющий рассчитать риск наиболее опасных осложнений. Следует внести определенные уточнения в определения составляющих индекса. Сердечный арест определялся в случае отсутствия сокращений сердца или хаотичного ритма, приводящего к потере сознания, требующее начала сердечно-легочной реанимации. Пациенты с имплантированным кардиовертером при его срабатывании, но при отсутствии потери сознания, к этой категории не относятся [20]. Таким образом, это понятие включает гемодинамически значимые наджелудочковые и желудочковые аритмии, электромеханическую диссоциацию и асистолию. Диагноз инфаркта миокарда устанавливается при подъеме сегмента ST в двух и более смежных отведениях, полной блокаде левой ножки пучка Гиса, появлении нового зубца Q в двух и более смежных отведениях, повышении уровня тропонина более чем в три раза от верхней границы нормы. Для автоматического расчета риска необходимы следующие показатели: возраст; уровень креатинина сыворотки более 133 мкмоль/л; характеристика функционального состояния пациента по классификации Американского общества анестезиологов (ASA); предоперационное функциональное состояние: полностью независим, частично зависим, полностью зависим; тип хирургического вмешательства: аноректальная хирургия; аорта; мозг; бариатрическая хирургия; кардиохирур- гия; эндокринная хирургия; двенадцатиперстная кишка и печеночная и панкреатобилиарная хирургия; желчный пузырь, надпочечник, аппендикс, селезенка; кишечник; шея; акушерство/гинекология; прочая абдоминальная хирургия; сосудистая хирургия; ортопедия и несосудистые вмешательства на конечностях; кожа; позвоночник; грудная хирургия; вены; урологические вмешательства.

Следует также привести использованную в индексе классификацию ASA в пересмотре 2014 г. Все пациенты, ожидающие оперативного лечения, делятся на следующие классы:

Класс I - здоровый пациент без органических, физиологических или психических расстройств, т.е. здоровый с хорошей переносимостью физической нагрузки;

Класс II - пациент с контролируемыми сопутствующими заболеваниями без значительных системных эффектов: контролируемая гипертензия или диабет без поражения органов-мишеней, курение, легкая хроническая обструктивная болезнь легких (ХОБЛ), ожирение с индексом массы тела (ИМТ) менее 40 кг/м², возраст менее 1 года и более 70 лет, беременность;

Класс III - пациент, имеющий сопутствующие заболевания с выраженными системными нарушениями, периодически приводящими к значительной функциональной недостаточности: контролируемая застойная сердечная недостаточность, стабильная стенокардия, плохо контролируемый СД, ХОБЛ или артериальная гипертензия (АГ), морбидное ожирение, активный гепатит, имплантированный электрокардиостимулятор (ЭКС), умеренное снижение фракции выброса левого желудочка (ФВ ЛЖ), хроническая болезнь почек (ХБП) на фоне гемодиализа, ИМ, коронарная реваскуляризация или цереброваскулярное событие, перенесенное более чем 3 месяца назад;

Kласс IV - пациент с плохо контролируемым состоянием, что связано со значительной органной дисфункцией и потенциальной угрозой жизни: нестабильная стенокардия, недавний (менее 3 месяцев) ИМ, ОНМК/ТИА или коронарная реваскуляризация менее чем 3 месяца назад, тяжелая клапанная дисфункция, тяжелое снижение ФВ ЛЖ, сепсис, конечная стадия ХБП без постоянного диализа;

Kласс $V$ - пациент в критическом физическом состоянии, которое дает мало шансов на выживание даже при отсутствии хирургического вмешательства: полиорганная недостаточность, сепсис с гемодинамической нестабильностью, гипотермия, плохо контролируемая коагулопатия, разрыв аневризмы аорты любой локализации, массивная травма, внутричерепное кровоизлияние с масс-эффектом;

Класс VI - пациент со смертью мозга, выступающий в роли донора органов.

Индекс NSQIP MICA был разработан на основе анализа более чем 200000 случаев внесердечных операций, и помимо клинического удобства, обладает достаточной доказательностью. Тем не менее авторы отмечают и наличие его ограничений. Например, в анализ не включались данные о результатах неинвазивных стресс-тестов, эхокардиогра- 
фии, исходные данные об аритмиях и поражении аортального клапана. Также и ИБС, существующая или анамнестическая, за исключением проведенного ранее чрескожного коронарного вмешательства (ЧКВ) или коронарного шунтирования (КШ), также не была включена в многофакторный анализ. Но, несмотря на это, предсказательные возможности калькулятора достаточно высоки - 0,88 (88 \%), и значительно превышают таковые у приведенного выше RCRI. Однако с учетом включенной в анализ классификации ASA, эти ограничения могли бы быть сняты, если бы не высокая вариабельность в оценке функционального состояния различными специалистами $[21,22]$. Так, по данным S. Theivanayagam et al. (2017) показана средняя согласованность в установлении класса по ASA между специалистами, направлявшими пациента на эндоскопическую хирургию [22]. Кроме того, степень несогласованности оценки между анестезиологами также высока и может зависеть от сложности заболевания [21]. Также следует отметить и то, что неблагоприятные исходы, а именно ИМ и сердечный арест, не отражают полного набора возможных сердечно-сосудистых осложнений, в т.ч. и при сравнении этого индекса с RCRI [23].

American College of Surgeons (ACS) National Surgical Quality Improvement Program (NSQIP). Еще одна объемная шкала NSQIP ACS описывает как кардиальные, так и внесердечные осложнения. Факторами риска являются: тип оперативного вмешательства, возраст, пол, предоперационное функциональное состояние, ASA класс, прием стероидов, асцит в течение 30 дней до операции, сепсис в течение 48 часов до операции, ИВЛ, диссеминированный рак, сахарный диабет, АГ, требующая лекарственной терапии, ХСН в течение 30 дней до операции, ХОБЛ, диализ, острая почечная недостаточность, ИМТ [24]. Для работы специалистов создан он-лайн калькулятор (http://riskcalculator.facs.org/ RiskCalculator/), в результате использования которого врач получает расчетный риск для данного пациента и сравнение его со средним риском для каждого вида оперативного вмешательства. Расчетный риск зависит от примененного кода оперативного вмешательства для групп осложнений: смерть, кардиальные осложнения, почечные, пневмония, раневые, серьезные осложнения и др. Очевидно, что данный калькулятор имеет те же ограничения, что и указанный выше NSQIP MICA. Однако большое количество вводных данных, а также возможность субъективно утяжелить риск позволяет получить результат, пригодный для рассмотрения в качестве вспомогательного инструмента. Именно этот факт авторы и отмечают - калькулятор лишь помогает принять решение, но не является основополагающим. Следует отметить, что в РФ применение этого калькулятора может быть несколько затруднено тем, что врачу необходимо ввести так называемый СРТ код (Current Procedural Terminology), позволяющий оценить специфичный для данного вмешательства риск. Однако понимание предстоящего объема оперативного вмешательства и достаточно скромные знания английского языка позволяют без труда найти код требующейся процедуры.

Vascular Quality Initiative Cardiac Risk Index (VQI-CRI). Специфический индекс клинической оценки риска, разработаны для пациентов, подвергающихся некоронарной сосудистой хирургии [18]. Именно эти пациенты рассматриваются в качестве группы высокого риска ССО, что связано как с высокой распространенностью среди них коронарного атеросклероза, так и с плохим функциональным статусом, что делает клиническое выявление ИБС затруднительным [25]. Данный индекс разрабатывался при прямом сравнении с RCRI и в качестве осложнений учитывались те же состояния, что и в RCRI. Также в VQI-CRI прослеживается специфичность полученного значения индекса для того или иного типа сосудистой хирургии. Рассмотрим вводные данные для этого индекса ниже.

Каротидная эндартерэктомия. Факторы риска: возраст; креатинин более 159 мкмоль/л или проводимый диализ; сахарный диабет и вид его лечения (пероральные препараты или инсулин); ИБС симптомная (клиника стабильной или нестабильной стенокардии или ИМ в течение 6 мес.) или бессимптомная (ИМ в анамнезе более чем 6 мес. назад, отсутствие симптомов стенокардии); выраженность ХСН: бессимптомная, легкая (ФК 2 по NYHA), умеренная или тяжелая ХCH (3-4 ФК по NYHA); предшествующая реваскуляризация миокарда (КШ или ЧКВ); результат стресс-теста в течение 2 лет; любая предшествующая некоронарная сосудистая хирургия или большая ампутация.

Эндоваскулярное вмешательство при аневризме брюшной аорты. Факторы риска: возраст; креатинин более 159 мкмоль/л или проводимый диализ; срочность процедуры; максимальный размер аневризмы: <55 мм, 55-60 мм, >60 мм; ИБС - симптомная (клиника стабильной или нестабильной стенокардии или ИМ в течение 6 мес.) или бессимптомная (ИМ в анамнезе более чем 6 мес. назад, отсутствие симптомов стенокардии); выраженность ХСН: бессимптомная, легкая (ФК 2 по NYHA), умеренная или тяжелая ХCH (3-4 ФК по NYHA); результат стресс-теста в течение 2 лет; ХОБЛ и ее лечение; факт наличия сахарного диабета; предшествующая периферическая сосудистая хирургия.

Инфраингвинальная сосудистая хирургия. Факторы риска: возраст; раса; показания к операции: перемежающая хромота, боль в покое, острая ишемия, трофические нарушения; креатинин более 159 мкмоль/л или проводимый диализ; курение (в анамнезе или в настоящее время); ИБС симптомная (клиника стабильной или нестабильной стенокардии или ИМ в течение 6 мес.) или бессимптомная (ИМ в анамнезе более чем 6 мес. назад, отсутствие симптомов стенокардии); артериальная гипертензия; результат стресстеста в течение 2 лет; сахарный диабет и вид его лечения (пероральные препараты или инсулин); планирующийся уровень дистального анастомоза.

Открытое вмешательство при аневризме брюшной аорmы. Факторы риска: возраст; раса; индекс массы тела; креа- 
тинин более 159 мкмоль/л; ХОБЛ и ее лечение; ХСН любого ФК; результат стресс-теста в течение 2 лет; предшествующая реваскуляризация миокарда (КШ или ЧКВ); предшествующая сосудистая хирургия, планируемый проксимальный уровень пережатия по отношению к чревному стволу и почечным артериям, планируемый уровень дистального анастомоза.

В результате работы калькулятора, доступного он-лайн (www.qxmd.com/calculate/calculator_323) или в офф-лайн приложении для мобильных устройств, врач получает значение риска ССО для пациента. Валидизация данного калькулятора неоднократно проводилась как для различных процедур $[26,27]$, так и для отдельных неблагоприятных исходов [28]. Шкала VQI-CRI представляется весьма специфичным клиническим инструментом для сосудистых пациентов, однако она не была включена в рекомендации по управлению риском некардиальной хирургии. Очевидно, требуются дополнительные исследования (возможно многоцентровые) на внешних выборках для дополнительного подтверждения работоспособности предложенной модели.

Помимо индексов в клинической оценке пациента важную роль играют коморбидные состояния. В то время как сердечная недостаточность, почечная дисфункция и сахарный диабет нашли свое отражение в шкалах и диагностическом алгоритме, пороки клапанов сердца и некоронарный атеросклероз рассматриваются за его пределами. Далее в настоящей статье мы постараемся кратко рассмотреть основные состояния, которые могут сказаться на риске возникновения ССО.

\section{Коморбидные состояния}

Сердечная недостаточность. Несмотря на то, что сердечная недостаточность входит в состав многих шкал риска как напрямую (RCRI, VQI-CRI), так и опосредованно через шкалу ASA, при оценке периоперационного риска ХCH уделяется отдельное внимание.

Диагноз ХСН требует наличия симптомов и наличия сниженной ФВ ЛЖ или нормальной систолической функции ЛЖ [29]. ХСН хорошо известный фактор риска некардиальной хирургии, который активно используется в шкалах риска $[13,18,30]$. В то же время роль ХСН с сохранной ФВ ЛЖ в развитии периоперационных осложнений некардиальной хирургии недостаточно изучена [31, 32]. У пациентов с сохранной ФВ ЛЖ чаще выявляется ФП, АГ и менее часто ИБС $[33,34]$. Ввиду отсутствия доказательной базы рекомендации для ХСН со сниженной и сохранной ФВ одинаковы: необходима оценка симптомов, признаков перегрузки кругов кровообращения, или уровней натрийуретических пептидов. Эхокардиография (ЭхоКГ) - ключевой элемент в предоперационной оценке пациентов с известной или предполагаемой ХСН. У таких пациентов важна оценка не только систолической, но и диастолической функции [35]. Таким образом, рутинная ЭхоКГ должна предполагаться у пациентов высокого риска хирургии, однако в большом канадском когортном исследовании предоперационная ЭхоКГ не была связана с улучшением послеоперационных результатов [36]. Предоперационные уровни натрийуретических пептидов сильно коррелируют с прогнозом ХCH, послеоперационной смертностью и осложненностью $[37,38]$. По сравнению с единичным определением пептидов, серийное улучшает риск-стратификацию по композитным точкам (смерть, нефатальный ИМ) [39]. Таким образом, оценка уровней натрийуретических пептидов может быть частью рутинного предоперационного обследования, в случае, когда дисфункция миокарда известна или предполагается.

Клапанные пороки сердия. Очевидно, что пациенты с клапанными пороками имеют более высокий риск осложнений при некардиальной хирургии [40]. Также понятно, что всем пациентам с известной или предполагаемой клапанной болезнью необходимо проведение ЭхоКГ для уточнения ее характера и тяжести. Однако в первую очередь оценивается симптомность порока и оценка риска сердечно-сосудистых осложнений в соответствии с типом хирургии [6]. Клапанные стенозы и регургитации играют различную роль в предоперационной оценке риска. Так, стеноз аортального клапана (АК) является известным фактором риска периоперационных осложнений. В случае плановой хирургии наличие симптомов аортального стеноза является решающим моментом [41]. У симптомных пациентов протезирование аортального клапана должно быть проведено перед некардиальной хирургией [42], при невозможности протезирования - некардиальная хирургия проводится только по жизненным показаниям. У бессимптомных пациентов хирургия низкого и промежуточного риска безопасна без какой-либо дополнительной подготовки [41]. При планирующейся хирургии высокого риска дальнейшая оценка необходима для оценки риска протезирования аортального клапана [42]. У пациентов с незначимым стенозом митрального клапана или со значимым, но бессимптомным, хирургия низкого риска может быть безопасной. Основной задачей становится контроль частоты сердечных сокращений. У симптомных пациентов риск осложнений существенно выше и такие пациенты могут иметь положительное влияние протезирования митрального клапана, особенно при хирургии высокого риска.

Органическая недостаточность митрального и аотрального клапанов не является независимыми факторами риска неблагоприятных исходов некардиальной хирургии [43]. У бессимптомных пациентов с выраженной регургитацией и сохранной ФВ ЛЖ некардиальная хирургия не несет дополнительного риска. Симптомные пациенты и те, у кого ФВ ЛЖ менее $30 \%$, имеют больший риск осложнений и требуют либо оперативной коррекции порока, либо операции только по жизненным показания на фоне оптимальной медикаментозной терапии. Относительная недостаточность митрального клапана является частью ремоделирования ЛЖ и ведение таких пациентов осуществляется по сути, как и у пациентов со сниженной ФВ ЛЖ и/или ИБС. 
Пациенты с протезированными клапанами сердца при удовлетворительной функции протеза не представляют проблемы для некардиальной хирургии. Основной сложностью является модификация антикоагулянтного режима, когда оральные антикоагулянты должны временно заменяться на нефракционированный или низкомолекулярный гепарин.

Хроническая болезнь почек и почечная дисфункиия. Почечная дисфункция связана с существенным увеличением риска ССО и является их независимым фактором риска $[44,45]$. Она включена в большинство клинических шкал оценки риска, однако в них наличие почечной дисфункции определяется по уровню сывороточного креатинина. Более предпочтительной представляется оценка почечной функции по расчетной скорости клубочковой фильтрации (СКФ). Для этого может использоваться любая имеющаяся формула. Однако наиболее точной, по сравнению с Cockroft-Gault и MDRD на данный момент считается уравнение Chronic Kidney Disease Epidemiology Collaboration (CKD-EPI), в которую включены пол, возраст, раса и концентрация креатинина сыворотки. Значение расчетной СКФ менее 60 мл/мин/1.73 м² имеет сильную связь с большими ССО. Своевременное выявление пациентов с почечной дисфункцией достаточно важно для начала мероприятий по коррекции гидробаланса, своевременному началу терапии вазопрессорами [46].

Каротидный атеросклероз. Периоперационное ОНМК развивается менее чем у 1 \% пациентов, подвергающихся некардиальной хирургии, за исключением пациентов, подвергающихся некоронарной сосудистой хирургии, где встречаемость ОНМК может достигать 3 \% [47]. Как и вне хирургии, периоперационное ОНМК может быть атеротромботическим и кардиоэмболическим. Причем если во втором случае очевидной причиной является неадекватность антикоагулянтной терапии, то для первого имеет значение состояние супрааортальных сосудов. Гипотония, наличие тяжелых стенозов брахиоцефальных артерий, а также воздушная, жировая или парадоксальная эмболия являются весьма редкими причинами ОНМК [48]. Антитромбоцитарная и антикоагулянтная терапия в послеоперационном периоде должны возобновляться как можно раньше. Пациенты, перенесшие ТИА или ОНМК в предшествующие 6 месяцев, должны консультироваться неврологом и проходить нейровизуализацию. У пациентов с симптомными стенозами сонных артерий вмешательство на них должно выполняться до некардиального вмешательства. Обследование каротидного бассейна, хотя и не рекомендуется всем пациентам перед некардиальной хирургией, тем не менее, показано пациентам, планирующимся на сосудистое вмешательство. Визуализация перед некардиальной и несосудистой хирургией остается предметом спора. Важно также отметить, что цель каротидной реваскуляризации заключается не столько в уменьшении риска периоперационного ОНМК, сколько в уменьшении отдаленного риска ОНМК для пациента [49]. Также пациенты с церебральным атеросклерозом имеют весьма высокую распространенность коронарного атеросклероза, причем более $20 \%$ из них имеют трехсосудистое поражение, около $10 \%$ - значимое поражение ствола левой коронарной артерии [50, 51]. Таким образом, пациенты с выявленным поражением сонных артерий должны подвергаться дополнительному обследованию, направленному на выявление коронарного атеросклероза для оценки необходимости и выбора метода превентивной реваскуляризации миокарда [52].

Атеросклероз артерий нижних конечностей. Поражение артерий нижних конечностей чаще всего определяется при низком лодыжечно-плечевом индексе в сочетании с перемежающейся хромотой или при предшествующих вмешательствах на артериях нижних конечностей, и обычно означает наличие серьезного поражения большинства артериальных регионов [53-56] и худший прогноз, по сравнению с пациентами без периферического атеросклероза [57-59]. В то же время, наличие клиники перемежающей хромоты может маскировать проявления ИБС, затрудняя оценку периоперационного риска у таких пациентов [12]. Таким образом, периферический атеросклероз является известным фактором риска некоронарной хирургии и у таких пациентов обоснованным является пристальное внимание к анамнезу для выявления симптомов ИБС. Кроме того, у таких пациентов требуется дополнительное обследование в виде неинвазивного тестирования, КАГ с последующей превентивной реваскуляризацией миокарда.

Хроническая обструктивная болезнь легких. Сопутствующая легочная патология может увеличивать риск осложнений у пациентов, подвергающихся некардиальной хирургии. Преимущественно это собственно легочные инфекционные осложнения, причем наиболее часто они развиваются при операциях на брюшной и грудной полостях $[60,61]$. Одним из прямых осложнений, связанных с ХОБЛ, является легочное сердце и правожелудочковая недостаточность, однако ССО связаны с широкой распространенностью ИБС у пациентов с ХОБЛ [62], поэтому дополнительное обследование для выявления поражения коронарных артерий требуется таким пациентам не только в связи с бронхо-легочной патологией. Все шкалы периоперационного риска, кроме RCRI, так или иначе, включают в себя ХОБЛ. Также для больных ХОБЛ характерен низкий функциональный статус. Таким образом, эти пациенты составляют существенную долю больных, требующих углубленного предоперационного обследования сердечно-сосудистой системы. Основой предоперационной подготовки пациентов с ХОБЛ является оптимизация медикаментозной терапии, отказ от курения (по крайней мере, за 2 месяца до операции), физические тренировки.

Сахарный диабет является частым коморбидным состоянием пациентов, подвергающихся некоронарной хирургии, и существенно влияет на ближайший и отдаленный прогноз любого оперативного вмешательства [63]. Тема 
СД и оперативных вмешательств настолько обширна, что в рамках данной статьи можно коснуться ее лишь тезисно. Наличие диабета учитывается во всех описанных шкалах, в некоторых - степень контроля СД, наличие осложнений, инсулинотерапия. В настоящее время текущие национальные руководства по управлению сахарным диабетом Америки, Канады, Европы, России на основании позиций доказательной медицины достаточно четко регламентируют периоперационные цели гликемии и ведение пациентов с СД, причем следование данным рекомендациям существенно снижает периоперационный риск [64-66]. В то же время последние рекомендации Американской диабетической ассоциации 2016 года отмечают, что доказательная база по применению сахароснижающих средств при оперативных вмешательствах до сих пор недостаточна [66]. Эта группа пациентов требует значительных ресурсов как при предоперационной подготовке, так и при послеоперационном ведении.

\section{Литература}

1.Haynes AB, Weiser TG, Berry WR, Lipsitz SR, Breizat AH, Dellinger EP, Herbosa T, Joseph S, Kibatala PL, Lapitan MC, Merry AF, Moorthy K, Reznick RK, Taylor B, Gawande AA; Safe Surgery Saves Lives Study Group. A surgical safety checklist to reduce morbidity and mortality in a global population. The New England Journal of Medicine. 2009;360(5):491-9. DOI: 10.1056/ NEJMsa0810119.

2. Devereaux PJ, Chan MT, Alonso-Coello P, Walsh M, Berwanger O, Villar JC, Wang CY, Garutti RI, Jacka MJ, Sigamani A, Srinathan S, Biccard BM, Chow CK, Abraham V, Tiboni M, Pettit S, Szczeklik W, Lurati Buse G, Botto F, Guyatt G, HeelsAnsdell D, Sessler DI, Thorlund K, Garg AX, Mrkobrada M, Thomas S, Rodseth RN, Pearse RM, Thabane L, McQueen MJ, VanHelder T, Bhandari M, Bosch J, Kurz A, Polanczyk C, Malaga G, Nagele P, Le Manach Y, Leuwer M, Yusuf S. Vascular Events In Noncardiac Surgery Patients Cohort Evaluation (VISION) Study Investigators Association between postoperative troponin levels

Табтица 2

Индекс активности Дьюка [11]

\begin{tabular}{|l|c|}
\hline Активность. Можете ли вы... & Оценка в баллах \\
\hline 1. осуществлять уход за собой, т.е. самостоятельно принимать пищу, одеваться, мыться, пользоваться туалетом? & 2,75 \\
\hline 2. свободно передвигаться по дому? & 1,75 \\
\hline 3. пройти 1 или 2 дома по ровной поверхности? & 2,75 \\
\hline 4. подняться на 1 лестничный пролет или подняться на небольшой подъем? & 5,50 \\
\hline 5. пробежать короткую дистанцию? & 8,00 \\
\hline 6. делать легкую работу по дому, например, убираться или мыть посуду? & 2,70 \\
\hline 7. заниматься домашней работой средней интенсивности, например, уборка пылесосом, мытье полов? & 3,50 \\
\hline 8. заниматься тяжелой физической работой, такой как натирание полов или перемещение тяжелой мебели? & 8,00 \\
\hline 9. заниматься работой во дворе, такой как уборка листьев, прополка или работа с газонокосилкой? & 4,50 \\
\hline 10. заниматься сексом? & 5,245 \\
\hline 11. заниматься активностью средней интенсивности, например, гольф, боулинг, танцы? & 6,00 \\
\hline 12. заниматься активностью высокой интенсивности, например, плавание, футбол, баскетбол, лыжи? & 7,50 \\
\hline
\end{tabular}

\section{Заключение}

Риск периоперационных ССО при внесердечных вмешательствах зависит от исходного состояния пациента, срочности, тяжести и продолжительности хирургии. Наиболее вероятно появление ССО у пациентов с ИБС, ХCH, пороками клапанов сердца. В то же время распространенная коморбидность (некоронарный атеросклероз, почечная дисфункция, сахарный диабет) оказывают существенное влияние на решение о способе вмешательства, анестезиологическом пособии, а также об операбельности пациента.

Клинические шкалы и индексы являются полезным и наглядным инструментом, помогающим оценить индивидуальный риск операции, однако имеющиеся у них ограничения с одной стороны и ограниченный набор ССО с другой, не дают полной уверенности в правильности принимаемого решения. Видимо, дальнейшее развитие направления клинической оценки риска и появление новых калькуляторов, специфичных для каждой хирургической процедуры позволит более точно оценивать риск у постели больного. and 30-day mortality among patients undergoing noncardiac surgery. JAMA. 2012;307(21):2295-304. DOI: 10.1001/ jama.2012.5502.

3. ACC/AHA 2007 guidelines on perioperative cardiovascular evaluation and care for noncardiac surgery: a report of the American College of Cardiology/American Heart Association Task Force on Practice Guidelines (Writing Committee to Revise the 2002 Guidelines on Perioperative Cardiovascular Evaluation for Noncardiac Surgery) developed in collaboration with the American Society of Echocardiography, American Society of Nuclear Cardiology, Heart Rhythm Society, Society of Cardiovascular Anesthesiologists, Society for Cardiovascular Angiography and Interventions, Society for Vascular Medicine and Biology, and Society for Vascular Surgery. Journal of the American College of Cardiology.2007;50(17 ):e159-241. DOI:10.1016/j.jacc.2007.09.003.

4. Poldermans D, Bax JJ, Boersma E, De Hert S, Eeckhout E, Fowkes G, Gorenek B, Hennerici MG, Iung B, Kelm M, Kjeldsen KP, Kristensen SD, Lopez-Sendon J, Pelosi P, Philippe F, Pierard 
L, Ponikowski P, Schmid JP, Sellevold OF, Sicari R, Van den Berghe G, Vermassen F. Task Force for Preoperative Cardiac Risk Assessment and Perioperative Cardiac Management in Non-cardiac Surgery; European Society of Cardiology (ESC). Guidelines for pre-operative cardiac risk assessment and perioperative cardiac management in non-cardiac surgery. European Heart Journal. 2009;30(22):2769-812. DOI: 10.1093/eurheartj/ehp337.

5. Fleisher LA, Fleischmann KE, Auerbach AD, Barnason SA, Beckman JA, Bozkurt B, Davila-Roman VG, Gerhard-Herman MD, Holly TA, Kane GC, Marine JE, Nelson MT, Spencer CC, Thompson A, Ting HH, Uretsky BF, Wijeysundera DN. American College of Cardiology; American Heart Association. 2014 ACC/ AHA guideline on perioperative cardiovascular evaluation and management of patients undergoing noncardiac surgery: a report of the American College of Cardiology/American Heart Association task force on practice guidelines. Journal of the American College of Cardiology. 2014;64(22):e77-e137. DOI:10.1016/j.jacc.2014.07.944.

6. Kristensen SD, Knuuti J, Saraste A, Anker S, Bøtker HE, Hert SD, Ford I, Gonzalez-Juanatey JR, Gorenek B, Heyndrickx GR, Hoeft A, Huber K, Iung B, Kjeldsen KP, Longrois D, Lüscher TF, Pierard L, Pocock S, Price S, Roffi M, Sirnes PA, SousaUva M, Voudris V, Funck-Brentano C. Authors/Task Force Members. 2014 ESC/ESA Guidelines on non-cardiac surgery: cardiovascular assessment and management: The Joint Task Force on non-cardiac surgery: cardiovascular assessment and management of the European Society of Cardiology (ESC) and the European Society of Anaesthesiology (ESA). European Heart Journal. 2014;35(35):2383-431. DOI: 10.1093/eurheartj/ehu282.

7. Щукин ЮВ, Хохлунов СМ, Суркова ЕА, Дупляков ДВ, Вачёв АН, Германов АВ, Землянова МЕ, Круглов ВН, Кузьмин ВП, Ляс МН, Павлова ГА, Павлова ТВ, Поляков ВП, Рябов АЕ, Скуратова МА, Чомахидзе ПШ, Шварц ЮГ, Бойцов СА, Веселкова НС, Гендлин ГЕ. Прогнозирование и профилактика кардиальных осложнений внесердечных хирургических вмешательств. Кардиоваскулярная терапия и профилактика. 2011;10(6)S3:1-28.

8. Biccard BM. Relationship between the inability to climb two flights of stairs and outcome after major non-cardiac surgery: implications for the pre-operative assessment of functional capacity. Anaesthesia. 2005;60(6):588-93.

9. Salzwedel A, Reibis R, Wegscheider K, Eichler S, Buhlert H, Kaminski S, Völler H. Cardiopulmonary exercise testing is predictive of return to work in cardiac patients after multicomponent rehabilitation. Clinical Research in Cardiology. 2016;105(3):257-67. DOI: 10.1007/s00392-015-0917-1.

10.Senthong V, Wu Y, Hazen SL, Tang WH. Predicting longterm prognosis in stable peripheral artery disease with baseline functional capacity estimated by the Duke Activity Status Index. American Heart Journal. 2017;184:17-25. DOI: 10.1016/j. ahj.2016.10.009.

11.Hlatky MA, Boineau RE, Higginbotham MB, Lee KL, Mark DB, Califf RM, Cobb FR, Pryor DB.A brief self-administered questionnaire to determine functional capacity (the Duke Activity Status Index). The American Journal of Cardiology. 1989;64(10):651-4.

12.Барбараш ЛС, Сумин АН, Евдокимов ДО, Безденежных АВ, Корок ЕВ, Иванов СВ, Моисеенков ГВ, Барбараш ОЛ. Роль коронароангиографии в снижении числа кардиальных осложнений при сосудистых операциях. Ангиология и сосудистая хирургия. 2012;18(4):33-41.

13.Lee TH, Marcantonio ER, Mangione CM, Thomas EJ, Polanczyk CA, Cook EF, Sugarbaker DJ, Donaldson MC, Poss R, Ho KK, Ludwig LE, Pedan A, Goldman L. Derivation and prospective validation of a simple index for prediction of cardiac risk of major noncardiac surgery. Circulation. 1999;100(10):10439.

14.Goldman L, Caldera DL, Nussbaum SR, Southwick FS, Krogstad D, Murray B, Burke DS, O'Malley TA, Goroll AH, Caplan CH, Nolan J, Carabello B, Slater EE. Multifactorial index of cardiac risk in noncardiac surgical procedures. The New England Journal of Medicine. 1977;297(16):845-50. DOI: 10.1056/NEJM197710202971601.

15.Detsky AS, Abrams HB, Forbath N, Scott JG, Hilliard JR. Cardiac assessment for patients undergoing noncardiac surgery. A multifactorial clinical risk index. Archives of Internal Medicine. 1986;146(11):2131-4. 16. Simeoni R, Breitenstein K, Eßer D, Guntinas-Lichius O. Cardiac comorbidity in head and neck cancer patients and its influence on cancer treatment selection and mortality: a prospective cohort study. European Archives of Oto-rhinolaryngology. 2016;273(9):2765-72. DOI: 10.1007/s00405-0153836-x.

17.Roshanov PS, Walsh M, Devereaux PJ, MacNeil SD, Lam NN, Hildebrand AM, Acedillo RR, Mrkobrada M, Chow CK, Lee VW, Thabane L, Garg AX. External validation of the Revised Cardiac Risk Index and update of its renal variable to predict 30-day risk of major cardiac complications after non-cardiac surgery: rationale and plan for analyses of the VISION study. BMJ Open. 2017;7(1):e013510. DOI: 10.1136/bmjopen-2016-013510.

18.Bertges DJ, Goodney PP, Zhao Y, Schanzer A, Nolan BW, Likosky DS, Eldrup-Jorgensen J, Cronenwett JL; Vascular Study Group of New England. The Vascular Study Group of New England Cardiac Risk Index (VSG-CRI) predicts cardiac complications more accurately than the Revised Cardiac Risk Index in vascular surgery patients. Journal of Vascular Surgery. 2010;52(3):674-83:e1-683.e3. DOI: 10.1016/j.jvs.2010.03.031.

19. Waterman BR, Belmont PJ Jr, Bader JO, Schoenfeld AJ. The Total Joint Arthroplasty Cardiac Risk Index for Predicting Perioperative Myocardial Infarction and Cardiac Arrest After Primary Total Knee and Hip Arthroplasty. The Journal of Arthroplasty. 2016;31(6):1170-4. DOI: 10.1016/j. arth.2015.12.013.

20.Gupta PK, Gupta H, Sundaram A, Kaushik M, Fang X, Miller WJ, Esterbrooks DJ, Hunter CB, Pipinos II, Johanning JM, Lynch TG, Forse RA, Mohiuddin SM, Mooss AN. Development and validation of a risk calculator for prediction of cardiac risk 
after surgery. Circulation.2011;124(4):381-7. DOI:10.1161/CIRCULATIONAHA.110.015701.

21.Cuvillon P, Nouvellon E, Marret E, Albaladejo P, Fortier LP, Fabbro-Perray P, Malinovsky JM, Ripart J. American Society of Anesthesiologists' physical status system: a multicentre Francophone study to analyse reasons for classification disagreement. European Journal of Anaesthesiology. 2011;28(10):7427. DOI: 10.1097/EJA.0b013e328348fc9d.

22.Theivanayagam S, Lopez KT, Matteson-Kome ML, Bechtold ML, Asombang AW. ASA Classification Pre-Endoscopic Procedures: A Retrospective Analysis on the Accuracy of Gastroenterologists. Southern Medical Journal. 2017;110(2):7982. DOI: 10.14423/SMJ.0000000000000610.

23.Lee TH, Goldman L. Letter by Lee and Goldman regarding article, Development and validation of a risk calculator for prediction of cardiac risk after surgery. Circulation.2012;125(7):e385; author reply e386. DOI: 10.1161/ CIRCULATIONAHA.111.068999.

24.Bilimoria KY, Liu Y, Paruch JL, Zhou L, Kmiecik TE, Ko CY, Cohen ME. Development and evaluation of the universal ACS NSQIP surgical risk calculator: a decision aid and informed consent tool for patients and surgeons. Journal of the American College of Surgeons. 2013;217(5):833-42.e1-3. DOI: 10.1016/j. jamcollsurg.2013.07.385.

25.Сумин АН, Безденежных АВ, Евдокимов ДО, Иванов СВ, Моисеенков ГВ, Барбараш ОЛ. Возможности коронароангиографии в оценке риска кардиологических осложнений при некардиальных операциях. Российский кардиологический журнал. 2013;100(2):38-44.

26.Eslami MH, Rybin D, Doros G, Kalish JA, Farber A; Vascular Study Group of New England. Comparison of a Vascular Study Group of New England risk prediction model with established risk prediction models of in-hospital mortality after elective abdominal aortic aneurysm repair. Journal of Vascular Surgery. 2015;62(5):1125-33.e2. DOI: 10.1016/j.jvs.2015.06.051.

27.Eslami MH, Rybin D, Doros G, Farber A. An externally validated robust risk predictive model of adverse outcomes after carotid endarterectomy. Journal of Vascular Surgery. 2016;63(2):345-54. DOI: 10.1016/j.jvs.2015.09.003.

28.Bertges DJ, Neal D, Schanzer A, Scali ST, Goodney PP, Eldrup-Jorgensen J, Cronenwett JL; Vascular Quality Initiative. The Vascular Quality Initiative Cardiac Risk Index for prediction of myocardial infarction after vascular surgery. Journal of Vascular Surgery. 2016;64(5):1411-1421.e4. DOI: 10.1016/j. jvs.2016.04.045.

29.Ponikowski P, Voors AA, Anker SD, Bueno H, Cleland JG, Coats AJ, Falk V, González-Juanatey JR, Harjola VP, Jankowska EA, Jessup M, Linde C, Nihoyannopoulos P, Parissis JT, Pieske B, Riley JP, Rosano GM, Ruilope LM, Ruschitzka F, Rutten FH, van der Meer P; Authors/Task Force Members. 2016 ESC Guidelines for the diagnosis and treatment of acute and chronic heart failure: The Task Force for the diagnosis and treatment of acute and chronic heart failure of the European Society of Cardiology (ESC)Developed with the special contribution of the Heart
Failure Association (HFA) of the ESC. European Heart Journal. 2016;37(27):2129-200. DOI: 10.1093/eurheartj/ehw128.

30.Cho DH, Park SM, Kim MN, Kim SA, Lim H, Shim WJ. Presence of preoperative diastolic dysfunction predicts postoperative pulmonary edema and cardiovascular complications in patients undergoing noncardiac surgery. Echocardiography. 2014;31(1):42-9. DOI: 10.1111/echo.12285.

31.Xu-Cai YO, Brotman DJ, Phillips CO, Michota FA, Tang WH, Whinney CM, Panneerselvam A, Hixson ED, Garcia M, Francis GS, Jaffer AK. Outcomes of patients with stable heart failure undergoing elective noncardiac surgery. Mayo Clinic Proceedings. 2008;83(3):280-8. DOI: 10.4065/83.3.280.

32.Сумин АН, Безденежных АВ, Евдокимов ДО, Корок ЕВ, Иванов СВ, Барбараш ОЛ, Барбараш ЛС. Систолическая дисфункция левого желудочка и риск послеоперационных осложнений при вмешательствах на некоронарных артериальных бассейнах. Журнал сердечная недостаточHocms. 2010;11(6):347-54.

33.Kontogeorgos S, Thunström E, Johansson MC, Fu M. Heart failure with preserved ejection fraction has a better long-term prognosis than heart failure with reduced ejection fraction in old patients in a 5-year follow-up retrospective study.International Journal of Cardiology. 2017;232:86-92. DOI: 10.1016/j. ijcard.2017.01.048.

34.Oren O, Goldberg S. Heart Failure with Preserved Ejection Fraction - Diagnosis and Management. American Medical Journal. 2017;130(5):510-6. DOI: 10.1016/j.amjmed.2016.12.031.

35.Mor-Avi V, Lang RM, Badano LP, Belohlavek M, Cardim NM, Derumeaux G, Galderisi M, Marwick T, Nagueh SF, Sengupta PP, Sicari R, Smiseth OA, Smulevitz B, Takeuchi M, Thomas JD, Vannan M, Voigt JU, Zamorano JL. Current and evolving echocardiographic techniques for the quantitative evaluation of cardiac mechanics: ASE/EAE consensus statement on methodology and indications endorsed by the Japanese Society of Echocardiography. European Journal of Echocardiography. 2011;12(3):167-205. DOI: 10.1093/ejechocard/jer021.

36.Wijeysundera DN, Beattie WS, Karkouti K, Neuman MD, Austin PC, Laupacis A. Association of echocardiography before major elective non-cardiac surgery with postoperative survival and length of hospital stay: population based cohort study. BMJ. 2011;342:d3695. DOI: 10.1136/bmj.d3695.

37.Brecher O, Gulati H, Roistacher N, Zhang H, Shi W, Thaler HT, Amar D. Preoperative Echocardiographic Indices of Diastolic Dysfunction and Brain Natriuretic Peptide in Predicting Postoperative Atrial Fibrillation After Noncardiac Surgery. Anesthesia and Analgesia. 2016;124(4):1099-104.DOI: 10.1213/ANE.0000000000001471.

38.Malhotra AK, Ramakrishna H. N-terminal pro B type natriuretic peptide in high cardiovascular-risk patients for noncardiac surgery: What is the current prognostic evidence? Annals of Cardiac Anaesthesia. 2016;19(2):314-20. DOI: 10.4103/0971-9784.179636.

39.Rodseth RN, Biccard BM, Le Manach Y, Sessler DI, Lurati Buse GA, Thabane L, Schutt RC, Bolliger D, Cagini L, Cardinale 
D, Chong CP, Chu R, Cnotliwy M, Di Somma S, Fahrner R, Lim WK, Mahla E, Manikandan R, Puma F, Pyun WB, Radović M, Rajagopalan S, Suttie S, Vanniyasingam T, van Gaal WJ, Waliszek $\mathrm{M}$, Devereaux PJ. The prognostic value of pre-operative and postoperative B-type natriuretic peptides in patients undergoing noncardiac surgery: B-type natriuretic peptide and $\mathrm{N}$-terminal fragment of pro-B-type natriuretic peptide: a systematic review and individual patient data meta-analysis. Journal of the American College of Cardiology. 2014;63(2):170-80. DOI: 10.1016/j.jacc.2013.08.1630.

40.Raymer K, Yang H. Patients with aortic stenosis: cardiac complications in non-cardiac surgery. Canadian Journal of Anaesthesia. 1998;45(9):855-9. DOI: 10.1007/BF03012219.

41.Tarantini G, Nai Fovino L, Tellaroli P, Fabris T, Iliceto S. Asymptomatic Severe Aortic Stenosis and Noncardiac Surgery. The American Journal of Cardiology. 2016;117(3):486-8. DOI: 10.1016/j.amjcard.2015.11.020.

42.Vahanian A, Alfieri O, Andreotti F, Antunes MJ, BarónEsquivias G, Baumgartner H, Borger MA, Carrel TP, De Bonis M, Evangelista A, Falk V, Iung B, Lancellotti P, Pierard L, Price S, Schäfers HJ, Schuler G, Stepinska J, Swedberg K, Takkenberg J, Von Oppell UO, Windecker S, Zamorano JL, Zembala M. Joint Task Force on the Management of Valvular Heart Disease of the European Society of Cardiology (ESC); European Association for Cardio-Thoracic Surgery (EACTS). Guidelines on the management of valvular heart disease (version 2012). European Heart Journal. 2012;33(19):2451-96. DOI: 10.1093/eurheartj/ ehs109.

43.Bajaj NS, Agarwal S, Rajamanickam A, Parashar A, Poddar KL, Griffin BP, Catacutan T, Tuzcu EM, Kapadia SR. Impact of severe mitral regurgitation on postoperative outcomes after noncardiac surgery. American Medical Journal. 2013;126(6):52935. DOI: 10.1016/j.amjmed.2012.12.005.

44.Mases A, Sabaté S, Guilera N, Sadurní M, Arroyo R, Fau M, Rojo A, Castillo J, Bover J, Sierra P, Canet J; ANESCARDIOCAT Group. Preoperative estimated glomerular filtration rate and the risk of major adverse cardiovascular and cerebrovascular events in non-cardiac surgery. British Journal of Anaesthesia. 2014;113(4):644-51. DOI: 10.1093/bja/aeu134.

45.Cywinski JB, Mascha EJ, Kurz A, Sessler DI. Estimated glomerular filtration rate better predicts 30-day mortality after non-cardiac surgery than serum creatinine: a retrospective analysis of 92,888 patients. Canadian Journal of Anaesthesia. 2015;62(7):745-52. DOI: 10.1007/s12630-015-0398-8.

46.Wilson T, Quan S, Cheema K, Zarnke K, Quinn R, de Koning L, Dixon E, Pannu N, James MT. Risk prediction models for acute kidney injury following major noncardiac surgery: systematic review. Nephrology, dialysis, transplantation. 2016;31(2):231-40. DOI: $10.1093 / \mathrm{ndt} / \mathrm{gfv} 415$.

47.Vasivej T, Sathirapanya P, Kongkamol C. Incidence and Risk Factors of Perioperative Stroke in Noncardiac, and Nonaortic and Its Major Branches Surgery. Journal of Stroke and Cerebrovascular Diseases. 2016;25(5):1172-6. DOI: 10.1016/j.jstrokecerebrovasd is.2016.01.051.
48.NgJL, Chan MT, Gelb AW.Perioperativestrokein noncardiac, nonneurosurgical surgery. Anesthesiology. 2011;115(4):879-90. DOI: 10.1097/ALN.0b013e31822e9499.

49.Покровский АВ, Белоярцев ДФ. Значение каротидной эндартерэктомии в предупреждении ишемических повреждений головного мозга. Журнал неврологии и психиатрии им. С.С. Корсакова. 2015;(9-2):4-14. DOI:10.17116/ jnevro2015115924-14.

50.Hofmann R, Kypta A, Steinwender C, Kerschner K, Grund $\mathrm{M}$, Leisch $\mathrm{F}$. Coronary angiography in patients undergoing carotid artery stenting shows a high incidence of significant coronary artery disease. Heart. 2005;91(11):1438-41. DOI:10.1136/ hrt.2004.050906.

51.Steinvil A, Sadeh B, Arbel Y, Justo D, Belei A, Borenstein N, Banai S, Halkin A. Prevalence and predictors of concomitant carotid and coronary artery atherosclerotic disease. Journal of the American College of Cardiology. 2011;57(7):779-83. DOI: 10.1016/j.jacc.2010.09.047.

52.Illuminati G, Schneider F, Greco C, Mangieri E, Schiariti M, Tanzilli G, Barillà F, Paravati V, Pizzardi G, Calio' F, Miraldi F, Macrina F, Totaro M, Greco E, Mazzesi G, Tritapepe L, Toscano M, Vietri F, Meyer N, Ricco JB. Long-term results of a randomized controlled trial analyzing the role of systematic pre-operative coronary angiography before elective carotid endarterectomy in patients with asymptomatic coronary artery disease. European Journal of Vascular and Endovascular Surgery. 2015;49(4):366-74. DOI: 10.1016/j.ejvs.2014.12.030.

53.Барбараш ЛС, Сумин АН, Безденежных АВ, Жучкова ЕА, Барбараш ОЛ. Распространенность мультифокального атеросклероза у больных ишемической болезнью сердца. Комплексные проблемы сердечно-сосудистых заболеваний. 2013;(3):4-11. DOI:10.17802/2306-1278-2013-3-4-11.

54.Marsico F, Ruggiero D, Parente A, Pirozzi E, Musella F, Lo Iudice F, Savarese G, Losco T, Giugliano G, Rengo G, Dellegrottaglie S, Leosco D, Esposito G, Trimarco B, PerroneFilardi P. Prevalence and severity of asymptomatic coronary and carotid artery disease in patients with lower limbs arterial disease. Atherosclerosis. 2013;228(2):386-9. DOI: 10.1016/j. atherosclerosis.2013.03.025.

55.Imori Y, Akasaka T, Ochiai T, Oyama K, Tobita K, Shishido K, Nomura Y, Yamanaka F, Sugitatsu K, Okamura N, Mizuno S, Arima K, Suenaga H, Murakami M, Tanaka Y, Matsumi J, Takahashi S, Tanaka S, Takeshita S, Saito S. Co-existence of carotid artery disease, renal artery stenosis, and lower extremity peripheral arterial disease in patients with coronary artery disease. The American Journal of Cardiology. 2014;113(1):30-5. DOI 10.1016/j.amjcard.2013.09.015.

56.Marsico F, Giugliano G, Ruggiero D, Parente A, Paolillo S, Guercio LD, Esposito G, Trimarco B, Filardi PP. Prevalence and severity of asymptomatic coronary and carotid artery disease in patients with abdominal aortic aneurysm. Angiology. 2015;66(4):360-4. DOI: 10.1177/0003319714540319.

57.Carmo GA, Calderaro D1, Gualandro DM, Pastana AF, Yu PC, Marques AC, Caramelli B. The Ankle-Brachial 
Index is Associated With Cardiovascular Complications After Noncardiac Surgery. Angiology. 2016;67(2):187-92. DOI: 10.1177/0003319715589684.

58.Ishihara T, Iida O, Tosaka A, Soga Y, Sakamoto Y, Hirano K, Nanto S, Uematsu M. Severity of coronary artery disease affects prognosis of patients with peripheral artery disease. Angiology.20 13;64(6):417-22. DOI: 10.1177/0003319712452627.

59.Nakamura Y, Kunii H, Yoshihisa A, Takiguchi M, Shimizu T, Yamauchi H, Iwaya S, Owada T, Abe S, Sato T, Suzuki S, Oikawa M, Kobayashi A, Yamaki T, Sugimoto K, Nakazato K, Suzuki H, Saitoh S, Takeishi Y. Impact of peripheral artery disease on prognosis in hospitalized heart failure patients. Circulation Journal. 2015;79(4):785-93. DOI: 10.1253/circj.CJ-14-1280.

60.Ramachandran SK, Nafiu OO, Ghaferi A, Tremper KK, Shanks A, Kheterpal S. Independent predictors and outcomes of unanticipated early postoperative tracheal intubation after nonemergent, noncardiac surgery. Anesthesiology. 2011;115(1):44-53. DOI: 10.1097/ALN.0b013e31821cf6de.

61.Pasin L, Nardelli P, Belletti A, Greco M, Landoni G, Cabrini L, Chiesa R, Zangrillo A. Pulmonary Complications After Open Abdominal Aortic Surgery: A Systematic Review and MetaAnalysis. Journal of Cardiothoracic and Vascular Anesthesia. 2017;31(2):562-8. DOI: 10.1053/j.jvca.2016.09.034.

62.Liang BM, Xu ZB, Yi Q, Ou XM, Feng YL. Association of chronic obstructive pulmonary disease with coronary artery disease. Chinese Medical Journal. 2013;126(17):3205-8.

63.Сумин АН, Безденежных НА, Безденежных АВ, Иванов СВ, Барбараш ОЛ, Барбараш ЛС. Факторы риска больших сердечно-сосудистых событий в отдаленном периоде коронарного шунтирования у пациентов с ишемической болезнью сердца при наличии сахарного диабета 2 типа. Российский кардиологический журнал. 2015; 6(122):30-7.

64.Canadian Diabetes Association. 2013 Clinical Practice Guidelines for the Prevention and Management of Diabetes in Canada. Canadian Journal of Diabetes. 2013;37(1):S4-7. DOI: 10.1016/j.jcjd.2013.01.010.

65.Дедов ИИ, Шестакова МВ., ред. Клинические рекомендации «Алгоритмы специализированной медицинской помощи больным сахарным диабетом». Сахарный диабет. 2015;18(1s):1-112. DOI: 10.14341/dm20151s1-112.

66.American Diabetes Association. Standards of Medical Care in Diabetes - 2016. Diabetes Care. 2016;39(Suppl. 1):S3. DOI: 10.2337/dc16-S002.

\section{References}

1. Haynes AB, Weiser TG, Berry WR, Lipsitz SR, Breizat AH, Dellinger EP, Herbosa T, Joseph S, Kibatala PL, Lapitan MC, Merry AF, Moorthy K, Reznick RK, Taylor B, Gawande AA; Safe Surgery Saves Lives Study Group. A surgical safety checklist to reduce morbidity and mortality in a global population. The New England Journal of Medicine. 2009;360(5):491-9. DOI: 10.1056/ NEJMsa0810119.

2. Devereaux PJ, Chan MT, Alonso-Coello P, Walsh M, Berwanger O, Villar JC, Wang CY, Garutti RI, Jacka MJ, Sigamani A, Srinathan S, Biccard BM, Chow CK, Abraham V, Tiboni M,
Pettit S, Szczeklik W, Lurati Buse G, Botto F, Guyatt G, HeelsAnsdell D, Sessler DI, Thorlund K, Garg AX, Mrkobrada M, Thomas S, Rodseth RN, Pearse RM, Thabane L, McQueen MJ, VanHelder T, Bhandari M, Bosch J, Kurz A, Polanczyk C, Malaga G, Nagele P, Le Manach Y, Leuwer M, Yusuf S. Vascular Events In Noncardiac Surgery Patients Cohort Evaluation (VISION) Study Investigators Association between postoperative troponin levels and 30-day mortality among patients undergoing noncardiac surgery. JAMA. 2012;307(21):2295-304. DOI: 10.1001/ jama.2012.5502.

3. ACC/AHA 2007 guidelines on perioperative cardiovascular evaluation and care for noncardiac surgery: a report of the American College of Cardiology/American Heart Association Task Force on Practice Guidelines (Writing Committee to Revise the 2002 Guidelines on Perioperative Cardiovascular Evaluation for Noncardiac Surgery) developed in collaboration with the American Society of Echocardiography, American Society of Nuclear Cardiology, Heart Rhythm Society, Society of Cardiovascular Anesthesiologists, Society for Cardiovascular Angiography and Interventions, Society for Vascular Medicine and Biology, and Society for Vascular Surgery. Journal of the American College of Cardiology.2007;50(17):e159-241. DOI:10.1016/j. jacc.2007.09.003.

4. Poldermans D, Bax JJ, Boersma E, De Hert S, Eeckhout E, Fowkes G, Gorenek B, Hennerici MG, Iung B, Kelm M, Kjeldsen KP, Kristensen SD, Lopez-Sendon J, Pelosi P, Philippe F, Pierard L, Ponikowski P, Schmid JP, Sellevold OF, Sicari R, Van den Berghe G, Vermassen F. Task Force for Preoperative Cardiac Risk Assessment and Perioperative Cardiac Management in Non-cardiac Surgery; European Society of Cardiology (ESC). Guidelines for pre-operative cardiac risk assessment and perioperative cardiac management in non-cardiac surgery. European Heart Journal. 2009;30(22):2769-812. DOI: 10.1093/eurheartj/ ehp337.

5. Fleisher LA, Fleischmann KE, Auerbach AD, Barnason SA, Beckman JA, Bozkurt B, Davila-Roman VG, Gerhard-Herman MD, Holly TA, Kane GC, Marine JE, Nelson MT, Spencer CC, Thompson A, Ting HH, Uretsky BF, Wijeysundera DN; American College of Cardiology; American Heart Association. 2014 ACC/AHA guideline on perioperative cardiovascular evaluation and management of patients undergoing noncardiac surgery: a report of the American College of Cardiology/American Heart Association task force on practice guidelines. Journal of the American College of Cardiology. 2014;64(22):e77-e137. DOI:10.1016/j.jacc.2014.07.944.

6. Kristensen SD, Knuuti J, Saraste A, Anker S, Bøtker HE, Hert SD, Ford I, Gonzalez-Juanatey JR, Gorenek B, Heyndrickx GR, Hoeft A, Huber K, Iung B, Kjeldsen KP, Longrois D, Lüscher TF, Pierard L, Pocock S, Price S, Roffi M, Sirnes PA, Sousa-Uva M, Voudris V, Funck-Brentano C. Authors/Task Force Members. 2014 ESC/ESA Guidelines on non-cardiac surgery: cardiovascular assessment and management: The Joint Task Force on non-cardiac surgery: cardiovascular assessment and management of the European Society of Cardiology (ESC) and the 
European Society of Anaesthesiology (ESA). European Heart Journal. 2014;35(35):2383-431. DOI: 10.1093/eurheartj/ehu282.

7.Shhukin JuV, Hohlunov SM, Surkova EA, Dupljakov DV, Vachjov AN, Germanov AV, Zemljanova ME, Kruglov VN, Kuz'min VP, Ljas MN, Pavlova GA, Pavlova TV, Poljakov VP, Rjabov AE, Skuratova MA, Chomahidze PSh, Shvarc JuG, Bojcov SA, Veselkova NS, Gendlin GE. Prediction and prevention of cardiac complications of non-cardiac surgery. Cardiovascular Therapy and Prevention. 2011;10(6)S3:1-28. (In Russian)

8. Biccard BM. Relationship between the inability to climb two flights of stairs and outcome after major non-cardiac surgery: implications for the pre-operative assessment of functional capacity. Anaesthesia. 2005;60(6):588-93.

9. Salzwedel A, Reibis R, Wegscheider K, Eichler S, Buhlert H, Kaminski S, Völler H. Cardiopulmonary exercise testing is predictive of return to work in cardiac patients after multicomponent rehabilitation. Clinical Research in Cardiology. 2016;105(3):257-67. DOI: 10.1007/s00392-015-0917-1.

10. Senthong V, Wu Y, Hazen SL, Tang WH. Predicting longterm prognosis in stable peripheral artery disease with baseline functional capacity estimated by the Duke Activity Status Index. American Heart Journal. 2017;184:17-25. DOI: 10.1016/j. ahj.2016.10.009.

11. Hlatky MA, Boineau RE, Higginbotham MB, Lee KL, Mark DB, Califf RM, Cobb FR, Pryor DB.A brief self-administered questionnaire to determine functional capacity (the Duke Activity Status Index). The American Journal of Cardiology. 1989;64(10):651-4.

12.Barbarash LS, Sumin AN, Evdokimov DO, Bezdenezhnykh AV, Korok EV, Ivanov SV, Moiseenkov GB, Barbarash OL. Role of coronary angiography in decreasing cardiac complications rate during vascular operations. Angiology and Vascular Surgery. 2012;18(4):33-41. (In Russian)

13. Lee TH, Marcantonio ER, Mangione CM, Thomas EJ, Polanczyk CA, Cook EF, Sugarbaker DJ, Donaldson MC, Poss R, Ho KK, Ludwig LE, Pedan A, Goldman L. Derivation and prospective validation of a simple index for prediction of cardiac risk of major noncardiac surgery. Circulation. 1999;100(10):1043-9.

14. Goldman L, Caldera DL, Nussbaum SR, Southwick FS, Krogstad D, Murray B, Burke DS, O'Malley TA, Goroll AH, Caplan CH, Nolan J, Carabello B, Slater EE. Multifactorial index of cardiac risk in noncardiac surgical procedures. The New England Journal of Medicine. 1977;297(16):845-50. DOI: 10.1056/ NEJM197710202971601.

15. Detsky AS, Abrams HB, Forbath N, Scott JG, Hilliard JR. Cardiac assessment for patients undergoing noncardiac surgery. A multifactorial clinical risk index. Archives of Internal Medicine. 1986;146(11):2131-4.

16. Simeoni R, Breitenstein K, Eßer D, Guntinas-Lichius O. Cardiac comorbidity in head and neck cancer patients and its influence on cancer treatment selection and mortality: a prospective cohort study. European Archives of Oto-rhino-laryngology. 2016;273(9):2765-72. DOI: 10.1007/s00405-015-3836-x.

17. Roshanov PS, Walsh M, Devereaux PJ, MacNeil SD, Lam
NN, Hildebrand AM, Acedillo RR, Mrkobrada M, Chow CK, Lee VW, Thabane L, Garg AX. External validation of the Revised Cardiac Risk Index and update of its renal variable to predict 30day risk of major cardiac complications after non-cardiac surgery: rationale and plan for analyses of the VISION study. BMJ Open. 2017;7(1):e013510. DOI: 10.1136/bmjopen-2016-013510.

18. Bertges DJ, Goodney PP, Zhao Y, Schanzer A, Nolan BW, Likosky DS, Eldrup-Jorgensen J, Cronenwett JL; Vascular Study Group of New England. The Vascular Study Group of New England Cardiac Risk Index (VSG-CRI) predicts cardiac complications more accurately than the Revised Cardiac Risk Index in vascular surgery patients. Journal of Vascular Surgery. 2010;52(3):674-83:e1-683.e3. DOI: 10.1016/j.jvs.2010.03.031.

19. Waterman BR, Belmont PJ Jr, Bader JO, Schoenfeld AJ. The Total Joint Arthroplasty Cardiac Risk Index for Predicting Perioperative Myocardial Infarction and Cardiac Arrest After Primary Total Knee and Hip Arthroplasty. The Journal of Arthroplasty. 2016;31(6):1170-4. DOI: 10.1016/j.arth.2015.12.013.

20. Gupta PK, Gupta H, Sundaram A, Kaushik M, Fang X, Miller WJ, Esterbrooks DJ, Hunter CB, Pipinos II, Johanning JM, Lynch TG, Forse RA, Mohiuddin SM, Mooss AN. Development and validation of a risk calculator for prediction of cardiac risk after surgery. Circulation.2011;124(4):381-7. DOI:10.1161/ CIRCULATIONAHA.110.015701.

21. Cuvillon P, Nouvellon E, Marret E, Albaladejo P, Fortier LP, Fabbro-Perray P, Malinovsky JM, Ripart J. American Society of Anesthesiologists' physical status system: a multicentre Francophone study to analyse reasons for classification disagreement. European Journal of Anaesthesiology. 2011;28(10):742-7. DOI: 10.1097/EJA.0b013e328348fc9d.

22. Theivanayagam S, Lopez KT, Matteson-Kome ML, Bechtold ML, Asombang AW. ASA Classification Pre-Endoscopic Procedures: A Retrospective Analysis on the Accuracy of Gastroenterologists. Southern Medical Journal. 2017;110(2):79-82. DOI: 10.14423/SMJ.0000000000000610.

23. Lee TH, Goldman L. Letter by Lee and Goldman regarding article, Development and validation of a risk calculator for prediction of cardiac risk after surgery. Circulation.2012;125(7):e385; author reply e386. DOI: 10.1161/CIRCULATIONAHA.111. 068999.

24. Bilimoria KY, Liu Y, Paruch JL, Zhou L, Kmiecik TE, Ko CY, Cohen ME. Development and evaluation of the universal ACS NSQIP surgical risk calculator: a decision aid and informed consent tool for patients and surgeons. Journal of the American College of Surgeons. 2013;217(5):833-42.e1-3. DOI: 10.1016/j. jamcollsurg.2013.07.385.

25.Sumin AN, Bezdenezhnykh AV, Evdokimov DO, Ivanov SV, Moiseenkov GV, Barbarash OL. Potential of coronary angiography in the assessment of cardiac complication risk during non-cardiac interventions. Russian Journal of Cardiology. 2013;100(2):38-44 (In Russian)

26. Eslami MH, Rybin D, Doros G, Kalish JA, Farber A; Vascular Study Group of New England. Comparison of a Vascular Study Group of New England risk prediction model with es- 
tablished risk prediction models of in-hospital mortality after elective abdominal aortic aneurysm repair. Journal of Vascular Surgery. 2015;62(5):1125-33.e2. DOI: 10.1016/j.jvs.2015.06.051.

27. Eslami MH, Rybin D, Doros G, Farber A. An externally validated robust risk predictive model of adverse outcomes after carotid endarterectomy. Journal of Vascular Surgery. 2016;63(2):345-54. DOI: 10.1016/j.jvs.2015.09.003.

28. Bertges DJ, Neal D, Schanzer A, Scali ST, Goodney PP, Eldrup-Jorgensen J, Cronenwett JL; Vascular Quality Initiative. The Vascular Quality Initiative Cardiac Risk Index for prediction of myocardial infarction after vascular surgery. Journal of Vascular Surgery. 2016;64(5):1411-1421.e4. DOI: 10.1016/j. jvs.2016.04.045.

29. Ponikowski P, Voors AA, Anker SD, Bueno H, Cleland JG, Coats AJ, Falk V, González-Juanatey JR, Harjola VP, Jankowska EA, Jessup M, Linde C, Nihoyannopoulos P, Parissis JT, Pieske B, Riley JP, Rosano GM, Ruilope LM, Ruschitzka F, Rutten FH, van der Meer P; Authors/Task Force Members. 2016 ESC Guidelines for the diagnosis and treatment of acute and chronic heart failure: The Task Force for the diagnosis and treatment of acute and chronic heart failure of the European Society of Cardiology (ESC)Developed with the special contribution of the Heart Failure Association (HFA) of the ESC. European Heart Journal. 2016;37(27):2129-200. DOI: 10.1093/eurheartj/ehw128.

30. Cho DH, Park SM, Kim MN, Kim SA, Lim H, Shim WJ. Presence of preoperative diastolic dysfunction predicts postoperative pulmonary edema and cardiovascular complications in patients undergoing noncardiac surgery. Echocardiography. 2014;31(1):42-9. DOI: 10.1111/echo.12285.

31. Xu-Cai YO, Brotman DJ, Phillips CO, Michota FA, Tang WH, Whinney CM, Panneerselvam A, Hixson ED, Garcia M, Francis GS, Jaffer AK. Outcomes of patients with stable heart failure undergoing elective noncardiac surgery. Mayo Clinic Proceedings. 2008;83(3):280-8. DOI: 10.4065/83.3.280.

32. Sumin AN, Bezdenezhnykh AV, Evdokimov DO, Korok EV, Ivanov SV, Barbarash OL, Barbarash LS. Left ventricle systolic dysfunction and postoperative complications risk of non-coronary vascular surgery. Russian Heart Failure Journal. 2010;11(6):347-354. (In Russian)

33. Kontogeorgos S, Thunström E, Johansson MC, Fu M. Heart failure with preserved ejection fraction has a better longterm prognosis than heart failure with reduced ejection fraction in old patients in a 5-year follow-up retrospective study.International Journal of Cardiology. 2017;232:86-92. DOI: 10.1016/j. ijcard.2017.01.048.

34. Oren O, Goldberg S. Heart Failure with Preserved Ejection Fraction - Diagnosis and Management. American Medical Journal. 2017;130(5):510-6. DOI: 10.1016/j.amjmed.2016.12.031.

35. Mor-Avi V, Lang RM, Badano LP, Belohlavek M, Car$\operatorname{dim}$ NM, Derumeaux G, Galderisi M, Marwick T, Nagueh SF, Sengupta PP, Sicari R, Smiseth OA, Smulevitz B, Takeuchi M, Thomas JD, Vannan M, Voigt JU, Zamorano JL. Current and evolving echocardiographic techniques for the quantitative evaluation of cardiac mechanics: ASE/EAE consensus statement on methodology and indications endorsed by the Japanese Society of Echocardiography. European Journal of Echocardiography. 2011;12(3):167-205. DOI: 10.1093/ejechocard/jer021.

36. Wijeysundera DN, Beattie WS, Karkouti K, Neuman MD, Austin PC, Laupacis A. Association of echocardiography before major elective non-cardiac surgery with postoperative survival and length of hospital stay: population based cohort study. BMJ. 2011;342:d3695. DOI: 10.1136/bmj.d3695.

37. Brecher O, Gulati H, Roistacher N, Zhang H, Shi W, Thaler HT, Amar D. Preoperative Echocardiographic Indices of Diastolic Dysfunction and Brain Natriuretic Peptide in Predicting Postoperative Atrial Fibrillation After Noncardiac Surgery. Anesthesia and Analgesia. 2016;124(4):1099-104. DOI: 10.1213/ ANE.0000000000001471.

38. Malhotra AK, Ramakrishna H. N-terminal pro B type natriuretic peptide in high cardiovascular-risk patients for noncardiac surgery: What is the current prognostic evidence? Annals of Cardiac Anaesthesia. 2016;19(2):314-20. DOI: 10.4103/09719784.179636.

39. Rodseth RN, Biccard BM, Le Manach Y, Sessler DI, Lurati Buse GA, Thabane L, Schutt RC, Bolliger D, Cagini L, Cardinale D, Chong CP, Chu R, Cnotliwy M, Di Somma S, Fahrner R, Lim WK, Mahla E, Manikandan R, Puma F, Pyun WB, Radović M, Rajagopalan S, Suttie S, Vanniyasingam T, van Gaal WJ, Waliszek M, Devereaux PJ. The prognostic value of pre-operative and post-operative B-type natriuretic peptides in patients undergoing noncardiac surgery: B-type natriuretic peptide and $\mathrm{N}$ terminal fragment of pro-B-type natriuretic peptide: a systematic review and individual patient data meta-analysis. Journal of the American College of Cardiology. 2014;63(2):170-80. DOI: 10.1016/j.jacc.2013.08.1630.

40. Raymer K, Yang H. Patients with aortic stenosis: cardiac complications in non-cardiac surgery. Canadian Journal of Anaesthesia. 1998;45(9):855-9. DOI: 10.1007/BF03012219.

41. Tarantini G, Nai Fovino L, Tellaroli P, Fabris T, Iliceto S. Asymptomatic Severe Aortic Stenosis and Noncardiac Surgery. The American Journal of Cardiology. 2016;117(3):486-8. DOI: 10.1016/j.amjcard.2015.11.020.

42. Vahanian A, Alfieri O, Andreotti F, Antunes MJ, BarónEsquivias G, Baumgartner H, Borger MA, Carrel TP, De Bonis M, Evangelista A, Falk V, Iung B, Lancellotti P, Pierard L, Price S, Schäfers HJ, Schuler G, Stepinska J, Swedberg K, Takkenberg J, Von Oppell UO, Windecker S, Zamorano JL, Zembala M. Joint Task Force on the Management of Valvular Heart Disease of the European Society of Cardiology (ESC); European Association for Cardio-Thoracic Surgery (EACTS). Guidelines on the management of valvular heart disease (version 2012). European Heart Journal. 2012;33(19):2451-96. DOI: 10.1093/eurheartj/ ehs 109.

43. Bajaj NS, Agarwal S, Rajamanickam A, Parashar A, Poddar KL, Griffin BP, Catacutan T, Tuzcu EM, Kapadia SR. Impact of severe mitral regurgitation on postoperative outcomes after noncardiac surgery. American Medical Journal. 2013;126(6):52935. DOI: 10.1016/j.amjmed.2012.12.005. 
44. Mases A, Sabaté S, Guilera N, Sadurní M, Arroyo R, Fau M, Rojo A, Castillo J, Bover J, Sierra P, Canet J; ANESCARDIOCAT Group. Preoperative estimated glomerular filtration rate and the risk of major adverse cardiovascular and cerebrovascular events in non-cardiac surgery. British Journal of Anaesthesia. 2014;113(4):644-51. DOI: 10.1093/bja/aeu134.

45. Cywinski JB, Mascha EJ, Kurz A, Sessler DI. Estimated glomerular filtration rate better predicts 30 -day mortality after non-cardiac surgery than serum creatinine: a retrospective analysis of 92,888 patients. Canadian Journal of Anaesthesia. 2015;62(7):745-52. DOI: 10.1007/s12630-015-0398-8.

46. Wilson T, Quan S, Cheema K, Zarnke K, Quinn R, de Koning L, Dixon E, Pannu N, James MT. Risk prediction models for acute kidney injury following major noncardiac surgery: systematic review. Nephrology, dialysis, transplantation. 2016;31(2):231-40. DOI: 10.1093/ndt/gfv415.

47. Vasivej T, Sathirapanya P, Kongkamol C. Incidence and Risk Factors of Perioperative Stroke in Noncardiac, and Nonaortic and Its Major Branches Surgery. Journal of Stroke and Cerebrovascular Diseases. 2016;25(5):1172-6. DOI: 10.1016/j. jstrokecerebrovasdis.2016.01.051.

48. Ng JL, Chan MT, Gelb AW. Perioperative stroke in noncardiac, nonneurosurgical surgery. Anesthesiology. 2011;115(4):879-90. DOI: 10.1097/ALN.0b013e31822e9499.

49.Pokrovsky AV, Beloyartsev DF. A role of carotid endarterectomy in prevention of cerebral ischemic damage. Zhurnal nevrologii i psikhiatrii imeni S.S. Korsakova. 2015;(9-2):4-14. DOI:10.17116/jnevro2015115924-14. (In Russian)

50. Hofmann R, Kypta A, Steinwender C, Kerschner K, Grund $\mathrm{M}$, Leisch F. Coronary angiography in patients undergoing carotid artery stenting shows a high incidence of significant coronary artery disease. Heart. 2005;91(11):1438-41. DOI:10.1136/hrt.2004.050906.rt.2004.050906.

51. Steinvil A, Sadeh B, Arbel Y, Justo D, Belei A, Borenstein N, Banai S, Halkin A. Prevalence and predictors of concomitant carotid and coronary artery atherosclerotic disease. Journal of the American College of Cardiology. 2011;57(7):779-83. DOI: 10.1016/j.jacc.2010.09.047.

52. Illuminati G, Schneider F, Greco C, Mangieri E, Schiariti M, Tanzilli G, Barillà F, Paravati V, Pizzardi G, Calio' F, Miraldi F, Macrina F, Totaro M, Greco E, Mazzesi G, Tritapepe L, Toscano M, Vietri F, Meyer N, Ricco JB. Long-term results of a randomized controlled trial analyzing the role of systematic pre-operative coronary angiography before elective carotid endarterectomy in patients with asymptomatic coronary artery disease. European Journal of Vascular and Endovascular Surgery. 2015;49(4):366-74. DOI: 10.1016/j.ejvs.2014.12.030.

53. Barbarash LS, Sumin AN, Bezdenezhnykh AV, Zhuchkova EA, Barbarash OL. Prevalence of polyvascular disease in patients with ischemic heart disease. Complex Issues of Cardiovascular Diseases. 2013;(3):4-11. DOI:10.17802/2306-12782013-3-4-11. (In Russian)

54. Marsico F, Ruggiero D, Parente A, Pirozzi E, Musella F, Lo Iudice F, Savarese G, Losco T, Giugliano G, Rengo G, Del- legrottaglie S, Leosco D, Esposito G, Trimarco B, PerroneFilardi P. Prevalence and severity of asymptomatic coronary and carotid artery disease in patients with lower limbs arterial disease. Atherosclerosis. 2013;228(2):386-9. DOI: 10.1016/j. atherosclerosis.2013.03.025.

55. Imori Y, Akasaka T, Ochiai T, Oyama K, Tobita K, Shishido K, Nomura Y, Yamanaka F, Sugitatsu K, Okamura N, Mizuno S, Arima K, Suenaga H, Murakami M, Tanaka Y, Matsumi J, Takahashi S, Tanaka S, Takeshita S, Saito S. Co-existence of carotid artery disease, renal artery stenosis, and lower extremity peripheral arterial disease in patients with coronary artery disease. The American Journal of Cardiology. 2014;113(1):30-5. DOI 10.1016/j.amjcard.2013.09.015.

56. Marsico F, Giugliano G, Ruggiero D, Parente A, Paolillo S, Guercio LD, Esposito G, Trimarco B, Filardi PP. Prevalence and severity of asymptomatic coronary and carotid artery disease in patients with abdominal aortic aneurysm. Angiology. 2015;66(4):360-4. DOI: 10.1177/0003319714540319.

57. Carmo GA, Calderaro D1, Gualandro DM, Pastana AF, Yu PC, Marques AC, Caramelli B. The Ankle-Brachial Index is Associated With Cardiovascular Complications After Noncardiac Surgery. Angiology. 2016;67(2):187-92. DOI: 10.1177/0003319715589684.

58. Ishihara T, Iida O, Tosaka A, Soga Y, Sakamoto Y, Hirano K, Nanto S, Uematsu M. Severity of coronary artery disease affects prognosis of patients with peripheral artery disease. Angiology.2013;64(6):417-22. DOI: 10.1177/0003319712452627.

59. Nakamura Y, Kunii H, Yoshihisa A, Takiguchi M, Shimizu T, Yamauchi H, Iwaya S, Owada T, Abe S, Sato T, Suzuki S, Oikawa M, Kobayashi A, Yamaki T, Sugimoto K, Nakazato K, Suzuki H, Saitoh S, Takeishi Y. Impact of peripheral artery disease on prognosis in hospitalized heart failure patients. Circulation Journal. 2015;79(4):785-93. DOI: 10.1253/circj.CJ-141280 .

60. Ramachandran SK, Nafiu OO, Ghaferi A, Tremper KK, Shanks A, Kheterpal S. Independent predictors and outcomes of unanticipated early postoperative tracheal intubation after nonemergent, noncardiac surgery. Anesthesiology. 2011;115(1):44-53. DOI: 10.1097/ALN.0b013e31821cf6de.

61. Pasin L, Nardelli P, Belletti A, Greco M, Landoni G, Cabrini L, Chiesa R, Zangrillo A. Pulmonary Complications After Open Abdominal Aortic Surgery: A Systematic Review and Meta-Analysis. Journal of Cardiothoracic and Vascular Anesthesia. 2017;31(2):562-8. DOI: 10.1053/j.jvca.2016.09.034.

62. Liang BM, Xu ZB, Yi Q, Ou XM, Feng YL. Association of chronic obstructive pulmonary disease with coronary artery disease. Chinese Medical Journal. 2013;126(17):3205-8.

63.Sumin AN, Bezdenezhnykh NA, Bezdenezhnyh AV, Ivanov SV, Barbarash OL, Barbarash LS. Risk factors major cardiovascular events in the long term coronary artery bypass grafting in patients with coronary heart disease in the presence of type 2 diabetes. Russian Journal of Cardiology. 2015; 6(122):30-7. (In Russian)

64. Canadian Diabetes Association. 2013 Clinical Practice 
Guidelines for the Prevention and Management of Diabetes in Canada. Canadian Journal of Diabetes. 2013;37(1):S4-7. DOI: 10.1016/j.jcjd.2013.01.010.

65. Dedov II, Shestakova MV., eds. Standards of specialized diabetes care. 7th edition. Diabetes Mellitus. 2015;18(1s):1112. DOI: 10.14341/dm20151s1-112. (In Russian)

66. American Diabetes Association. Standards of Medical Care in Diabetes - 2016. Diabetes Care. 2016;39(Suppl. 1):S3. DOI: $10.2337 / \mathrm{dc} 16-S 002$. проблем сердечно-сосудистых заболеваний; адрес: Российская Федерация, 650002, Кемерово, ул. Сосновый бульвар, 6; тел.: +7(384)2645360; e-mail: bezdav@kemcardio.ru

Сумин Алексей Николаевич, Научно-исследовательский институт комплексных проблем сердечно-сосудистых заболеваний; адрес: Российская Федераиия, 650002, Кемерово, ул. Сосновый бульвар, 6; тел.: +7(384)2644461; e-mail: sumian@kemcardio.ru

\section{Information about the authors}

Bezdenezhnykh Andrey V., Research Institute for Complex Issues of Cardiovascular Diseases; Address:6, Sosnovy blvd., Kemerovo, 650002, Russian Federation; нa 6, Pine Boulevard, Kemerovo, Russian Federation 650002; Phone: +7(384)2645360; e-mail: bezdav@kemcardio.ru

Sumin Aleksey N., Research Institute for Complex Issues of Cardiovascular Diseases; Address: 6 , Sosnovy blvd., Kemerovo, 650002, Russian Federation; на 6, Pine Boulevard, Kemerovo, Russian Federation 650002; Phone: +7(384)2644461; e-mail: sumian@kemcardio.ru

Поступита 28.02.2017 Принята к печати 13.09.20172.

\title{
Мнение по проблеме / Opinion about the problem
}

( С КОХ Н. В., СЛЕПУХИНА А. А., ЛИФШИЦ Г. И.

УДК 616-08-039.71

DOI: 10.20333/2500136-2017-5-105-109.

\section{ПОДХОДЫ К ПРОФИЛАКТИКЕ И ЛЕЧЕНИЮ МЕТАБОЛИЧЕСКОГО СИНДРОМА: НУТРИГЕНЕТИКА}

Н. В. Кох, А. А. Слепухина, Г. И. Лифшиц

Институт химической биологии и фундаментальной медицины СО РАН, Новосибирск 630090, Российская Федерация

Резюме. В статье описаны вариации полиморфизма генов подверженности избыточной массе тела и ассоциированных с ней состояний, прежде всего предрасположенности к метаболическому синдрому: полиморфные варианты генов липидного обмена T-1131C и с.*365+359C>G ApoA5, G-75A ApoA1, E2/E3/E4 и c.526C >T ApoE, C1791G LPL, c.300C>T LPR1, полиморфные варианты генов, участвующих в формировании пищевого поведения g.87653T>A FTO, g.39272658T>C MC4R, c.178C>A GHRL; полиморфные варианты генов, влияющих на запасание жирных кислот и липолиз G2445A FABP2, с.-1073C>G ADIPOQ, C34G PPARG. Обсуждаются практические рекомендации по профилактике ожирения у пациентов, имеющих генетическую предрасположенность. Рассмотрены пути модификации факторов риска метаболического синдрома за счет коррекции негативного влияния, вызванного нарушением функции или активности белка в случаях носительства неблагоприятных аллельных вариантов. Обзорно представлены подходы к выбору нутриентов для формирования рациона с целью снизить массу тела в рамках профилактики и лечения метаболического синдрома.

Ключевые слова: метаболический синдром, полиморфные варианты генов, FTO, инсулинорезистентность, избыточный вес, гиперлипидемия, ожирение.

Для иитирования: Кох НВ, Слепухина АА, Лифшиц ГИ. Подходы к профилактике и лечению метаболического синдрома: нутригенетика. Сибирское медищинское обозрение. 2017;(5): 105-109. DOI: 10.20333/2500136-2017-5-105-109.

\section{APPROACHES TO PREVENTION AND TREATMENT OF METABOLIC SYNDROME: NUTRIGENETICS}

N. V. Kokh, A. A. Slepukhina, G. I. Lifshits

Institute of Chemical Biology and Fundamental Medicine SB RAS, Novosibirsk 630090, Russian Federation

\begin{abstract}
Variations in the polymorphism of genes for susceptibility to excess body weight and associated conditions, in particular, predispositions to the metabolic syndrome: polymorphic variants of the lipid metabolism genes T-1131C and c. * 365 + 359C> G ApoA5, G-75A ApoA1, E2 / E3 / E4 and c.526C> T ApoE, C1791G LPL, c.300C > T LPR1, polymorphic variants of genes involved in the formation of food behavior g.87653T> A FTO, g.39272658T>C MC4R, c.178C> A GHRL; polymorphic variants of genes that affect the storage of fatty acids and lipolysis G2445A FABP2, c-1073C> G ADIPOQ, C34G PPARG are described in the article. Practical recommendations on the prevention of obesity in patients with genetic predisposition are discussed. The ways of modifying the risk factors of the metabolic syndrome due to the correction of the negative effect, caused by disturbance of the function or activity of the protein in cases of carriage of adverse allelic variants are considered. A review of approaches to the selection of nutrients for the formation of a diet to reduce body weight in the prevention and treatment of metabolic syndrome is presented.

Key words: metabolic syndrome, polymorphic variants of genes, FTO, insulin resistance, overweight, hyperlipidemia, obesity.

Citation: Kokh NV, Slepukhina AA, Lifshits GI. Approaches to prevention and treatment of metabolic syndrome: nutrigenetics. Siberian Medical Review. 2017; (5): 105-109. DOI: 10.20333/2500136-2017-5-105-109.
\end{abstract}


Избыточная масса тела и ожирение не только эстетическая проблема, но и значительный фактор риска атеросклероза и ишемической болезни сердца, артериальной гипертонии и ишемического инсульта, и других многофакторных заболеваний. Также избыточный вес негативно влияет на эндокринную систему - это фактор риска сахарного диабета II (СД2), к которому приводит инсулинорезистентность тканей и нарушение утилизации глюкозы. Кроме того, может являться самостоятельной или дополнительной причиной женского и мужского бесплодия.

Все эти нарушения, к которым рано или поздно приводит ожирение, объединены в понятие Метаболический Синдром (МС) - болезнь века, связанная с погрешностями в питании и малоподвижным образом жизни. Характеризуется следующими симптомами: абдоминальное ожирение, инсулинорезистентность, повышение уровня глюкозы и липидов, а также повышение артериального давления. Помимо очевидных причин, связанных с образом жизни, вклад в развитие МС имеют и генетические факторы. Исследования полногеномного анализа ассоциаций (GWA), такие как консорциум GIANT (Genetic Investigation of ANtropometric Traits) включивший 270000 европейцев, позволили выявить конкретные полиморфные варианты генов, с высокой вероятностью влияющие на индекс массы тела $[1,2]$. Наличие генетически обусловленной склонности к избыточной массе тела или носительство полиморфных вариантов генов подверженности МС являются определенными индикаторами риска развития данных состояний. Тщательный подбор нутриентов и персонализированные на основе генетических данных рекомендации могут быть использованы в лечении МС и профилактике СД2 [3]. Характер питания и уровень физической активности являются модифицирующими факторами риска заболевания.

Избыточный вес у многих людей возникает в силу особенностей пищевого поведения: позднее насыщение, склонность к перееданию, раннее возникновение чувства голода, склонность к частым перекусам и другие. Пищевое насыщение - исчезновение чувства голода после приема пищи, отказ от дальнейшего приема пищи. Скорость насыщения зависит как от механических (растяжение, желудка), так и от нейроэндокринных (выделение активных веществ, влияющих на центр насыщения в головном мозге) факторов. Полиморфизм генов, влияющих на эти нейроэндокринные реакции, может приводить к изменению концентрации и активности кодируемых белков, и таким образом влиять на скорость возникновения чувства сытости. Однонуклеотидный полиморфизм гена FTO g.87653Т >A ассоциирован с ожирением и связан с риском переедания, т.к. участвует в процессах регуляции потребления калорий и резистентности к лептину (гормон, концентрация которого возрастает во время приема пищи и используется для контроля чувства насыщения) [4,5]. Рецептор меланокортина 4, синтезируется в головном мозге, регулирует аппетит и чувство насыщения, через лептиновый механизм. Аллельный вари- ант С гена MC4R g.39272658T>C ассоциирован с избыточным весом, из-за развивающейся резистентности к лептину и как следствие склонности к перееданию [6]. Людям с неблагоприятными (аллели риска) вариантами этих генов сложнее контролировать объем съеденного, у них позже приходит ощущение сытости, что определяет склонность к перееданию. В качестве профилактической меры рекомендуется контролировать объем порции, общую калорийность порции пищи.

Чувство голода - сложный процесс, регулируемый многими факторами: уровнем глюкозы в крови, уровнем лептина и активностью его рецептора, уровнем орексогенных белков (грелина, нейропептида У и др.). Скорость возникновения и выраженность чувства голода зависит как от образа жизни (в том числе характера физической активности), так и от генетической предрасположенности. Минорный аллель с.178C >A полиморфного гена $G H R L$ ассоциирован с ожирением, эффект возникает из-за повышения уровня грелина, формируя раннее чувство голода [7]. Другие полиморфные варианты гена грелина были ассоциированы с отдельными «компонентами» MC: индекс массы тела, окружность талии, систолическое кровяное давление, уровнями натощаковой глюкозы, триглицеридов, холестерина [8].

Определение генетических маркеров, влияющих на липидный обмен, позволяет оценить индивидуальный риск гиперлипидемии (повышения уровня холестерина ЛПНП, а также триглицеридов), которая лежит в основе атеросклероза и ишемической болезни сердца. Кроме того, нарушения всасывания, распределения и мобилизации жирных кислот из адипоцитов влияют на риск избыточной массы тела и необходимость ограничивать жиры определенного класса. Существует несколько видов жиров: насыщенные, полиненасыщенные, мононенасыщенные и гидрогенизированные жиры (трансжиры). Одним из основных методов снижения веса у пациентов с МС является использование низкожировой диеты [9].

Цель низкожировых диет - снизить потребление жирных продуктов и заменить маложирными. Соблюдение низкожировой диеты снижает риск сердечно-сосудистых заболеваний, заболеваний печени и почек. Однако резкое ограничение жиров на длительное время может иметь неблагоприятные последствия: дефицит витаминов А, D, K, Е, что ведет к физическому и умственному утомлению, сухости кожи, выпадению волос и другим нарушениям. Сокращать необходимо животные жиры и особенно рафинированные жиры (трансжиры). Полиненасыщенные жирные кислоты, содержащиеся в рыбе и нерафинированных растительных маслах, не ограничиваются. Вариации в гене переносчика жирных кислот через стенку кишечника G2445A FABP2 acсоциированы с ожирением, дислипидемией, нарушениями углеводного обмена, МС, влияют на активность белка, что отражается потерей массы тела на низкожировых диетах [10-12]. Помимо общего снижения жиров в рационе, важен также и баланс поступающих в организм жиров: на- 
сыщенных, полиненасыщенных, мононенасыщенных, гидрогенизированных. Потребление избыточного количества насыщенных жиров является фактором риска сердечно-сосудистых заболеваний, а у некоторых людей влияет на появление избыточной массы тела. В качестве оценки подверженности развитию гиперлипидемий, гипертриглицеридемии анализируется носительство полиморфных вариантов

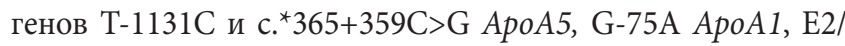
E3/E4 и с.526C > T ApoE, C1791G LPL, с.300C > T LPR1 [13-15]. Аполипопротеин А5 - белок входящий в состав липопротеинов низкой плотности (ЛПНП) и липопротеинов очень низкой плотности (ЛПОНП), стимулирует липолиз, ингибирует синтез триглицеридов в печени, влияет на регуляцию транскрипции генов, продукты которых регулируют уровень триглицеридов. Белок Аполипопротеин Е участвует в производстве, транспорте и утилизации холестерина в организме. АроЕ является лигандом для рецептора ЛПНП и обладает антиатерогенным действием, непосредственно влияя на клиренс ремнантов ЛПОНП богатых холестерином - липопротеинов промежуточной плотности, тем самым уменьшая уровень холестерина в плазме. Пациентам, носителям патологических аллельных вариантов, помимо ограничения насыщенных жиров требуется своевременное назначение терапии статинами. Другим важным фактором риска гиперлипидемий является повышенное потребление гидрогенизированных жиров. Подвергаясь метаболизму, трансжиры нарушают транспорт питательных веществ через мембраны клеток. В результате этого ухудшается процесс клеточного питания, что ведет к накоплению токсических продуктов. При повышенном генетическом риске нарушения обмена липидов особенно необходимо следить за ограничением потребления трансжиров. Среди факторов, которые следует учитывать, для оценки необходимости ограничения насыщенных жиров, полиморфизм гена $A D I P O Q$ с.-1073C $>\mathrm{G}$, носительство аллелей риска ассоциировано с инсулинорезистентностью, при снижении экспрессии этого гена или снижении функции рецептора к адипонектину происходит нарушение сигналинга для липолитических процессов [16]. Адипонектин модулирует чувствительность к инсулину и поддерживает гомеостаз глюкозы.

К полиненасыщенным жирам относят Омега-6 и Омега-3 жирные кислоты. Современная диета включает большое количество Омега-6 и недостаточное Омега-3 жирных кислот. Оптимальное соотношение 4:1, а современный человек получает из своей диеты примерно 20:1, то есть в пять раз меньше Омега-3 жирных кислот, что вызывает дисбаланс в обменных процессах. Среди рекомендаций для профилактики сердечно-сосудистых, онкологических заболеваний и $\mathrm{MC}$, актуальной для носителей аллельных вариантов риска генов FABP и FADS2, будет повышение продуктов, содержащих Омега-3 жирные кислоты: рыбий жир, льняное масло.

Рецептор активации пролиферации пероксисом гамма, играет ключевую роль в росте жировых клеток при посту- плении жирной пищи. Минорный аллель полиморфизма C34G гена PPARG является протективным, носители этого аллельного варианта менее склонны к запасанию липидов в адипоцитах. Носители мажорного аллеля склонны к избыточному весу, им рекомендовано повышать в рационе мононенасыщенные жиры (МНЖК), которые будут иметь вклад в снижение веса у таких пациентов. Недостаток МНЖК в организме приводит к ухудшению мозговой деятельности, нарушению работы сердечно-сосудистой системы. Самым известным представителем МНЖК является олеиновая кислота (Омега-9), которая в большом количестве содержится в оливковом масле. Также МНЖК содержатся в арахисовом масле, масле из фундука, многих орехах, авокадо. Потребность в мононенасыщенных жирах возрастает: при проживании в холодном регионе; для тех, кто активно занимается спортом, выполняет тяжёлую работу на производстве; для детей в период активного развития; при нарушении работы сердечно-сосудистой системы; при нахождении в экологически неблагоприятных районах (профилактика онкологических заболеваний); для больных сахарным диабетом 2 типа. Потребность в мононенасыщенных жирах снижается: при аллергических реакциях; для людей, с малоподвижным образом жизни; для старшего поколения. Также среди распространенных рекомендаций для носителей редкого аллельного варианта полиморфизма C34G гена PPARG в качестве профилактики ожирения рекомендуют разгрузочные дни.

Индивидуальная вариабельность генетического компонента в качестве причины избыточного веса колеблется от 40 до 70 \% [3,17]. Устойчивая связь избыточного веса с резистентностью к инсулину, дислипидемией находятся в глубине этиопатогенетических механизмов формирования МС. Учитывая распространенность состояний, объединяющихся в МС, всё более раннюю их выявляемость, следует уделить особое внимание профилактике этого заболевания. Приведенное описание полиморфизма генов, участвующих в липидном обмене и генов регуляции пищевого поведения в совокупности с имеющимися практическими клиническими рекомендациями, направленными на модифицирование вклада генетических факторов, может использоваться в качестве инструмента при выборе тактики снижения веса. Контроль нутриентов в рационе, вредных или полезных с точки зрения генетической обусловленности - один из подходов снижения веса для профилактики и лечения МС

\section{Литература}

1. Hebebrand J, Volckmar A-L, Knoll N, Hinney A. Chipping away the "missing heritability": GIANT steps forward in the molecular elucidation of obesity - but still lots to go. Obesity Facts. 2010;3(5):294-303. DOI:10.1159/000321537.

2. Speliotes EK, Willer CJ, Berndt SI Association analyses of 249,796 individuals reveal 18 new loci associated with body mass index. Nature Genetics. 2010;42(11):937-48. DOI:10.1038/ ng.686. 
3. Berná G, Oliveras-López MJ, Jurado-Ruíz E, Tejedo J, Bedoya F, Soria B, Martín F. Nutrigenetics and nutrigenomics insights into diabetes etiopathogenesis. Nutrients. 2014;6(11):5338-69. DOI:10.3390/nu6115338.

4. Loos RJF, Yeo GSH. The bigger picture of FTO: the first GWAS-identified obesity gene. Nature Reviews. Endocrinology. 2014;10(1):51-61. DOI:10.1038/nrendo.2013.227.

5. Tung YC, Gulati P, Liu CH, Rimmington D, Dennis R, Ma M, Saudek V, O'Rahilly S, Coll AP, Yeo GS. FTO is necessary for the induction of leptin resistance by high-fat feeding. Molecular Metabolism. 2015;4(4):287-98. DOI:10.1016/j. molmet.2015.01.011.

6. Xi B, Chandak GR, Shen Y, Wang Q, Zhou D. Association between Common Polymorphism near the MC4R Gene and Obesity Risk: A Systematic Review and Meta-Analysis. PLoS One. 2012;7(9):e45731. DOI:10.1371/journal.pone.0045731.

7. Imaizumi T, Ando M, Nakatochi M, Yasuda $Y$, Honda $H$, Kuwatsuka Y, Kato S, Kondo T, Iwata M, Nakashima T, Yasui H, Takamatsu H, Okajima H, Yoshida Y, Maruyama S. Effect of dietary energy and polymorphisms in BRAP and GHRL on obesity and metabolic traits. Obesity Research and Clinical Practice. 2016; pii: S1871-403X(16)30032-1. DOI:10.1016/j. orcp.2016.05.004.

8. You Y, Yu Y, Wu Y, Rao W, Zhang Y, Liu Y, Yang G, Fu Y, Shi J, Kou C. Association Study between Ghrelin Gene Polymorphism and Metabolic Syndrome in a Han Chinese Population. Clinical Laboratory. 2017;63(1):175-81.

9. Abete I, Astrup A, Martínez JA, Thorsdottir I, Zulet MA. Obesity and the metabolic syndrome: role of different dietary macronutrient distribution patterns and specific nutritional components on weight loss and maintenance. Nutrition Reviews. 2010;68(4):214-31. DOI:10.1111/j.1753-4887.2010.00280.x.

10. Esteves A, Knoll-Gellida A, Canclini L, Silvarrey MC, André M, Babin PJ. Fatty acid-binding proteins have the potential to channel dietary fatty acids into enterocyte nuclei. Journal of Lipid Research. 2015;57(2):jlr.M062232. DOI:10.1194/jlr.M062232.

11. Liu P, Yu D, Jin X, Li C, Zhu F, Zheng Z, Lv C, He X. The association between the FABP2 Ala54Thr variant and the risk of type 2 diabetes mellitus: a meta-analysis based on 11 casecontrol studies. International Jurnal of Clinical and Experimental Medicine. 2015;8(4):5422-9.

12. Khattab SA, Abo-Elmatty DM, Ghattas MH, Mesbah NM, Mehanna ET. Intestinal fatty acid binding protein Ala54Thr polymorphism is associated with peripheral atherosclerosis combined with type 2 diabetes mellitus. Journal of Diabetes. 2016. DOI:10.1111/1753-0407.12496

13. Bu G. Apolipoprotein E and its receptors in Alzheimer's disease: pathways, pathogenesis and therapy. Nature Reviews. Neuroscience. 2009;10(5):333-44. DOI:10.1038/nrn2620.

14. Smith CE, Tucker KL, Lai C-Q, Parnell LD, Lee Y-C, Ordovás JM. Apolipoprotein A5 and lipoprotein lipase interact to modulate anthropometric measures in Hispanics of Caribbean origin. Obesity (Silver Spring). 2010;18(2):327-32. DOI:10.1038/ oby.2009.216.
15. Кох НВ, Лифшиц ГИ, Воронина ЕН. Возможности анализа полиморфизма генов липидного обмена для выявления факторов риска атеросклероза. Российский кардиологический журнал. 2014;10(114):53-7. DOI:10.15829/15604071-2014-10-53-057.

16. Gong M, Long J, Liu Q, Deng HC. Association of the ADIPOQ rs17360539 and rs266729 polymorphisms with type 2 diabetes: A meta-analysis. Molecular and Cellular endocrinology. 2010;325(1):78-83. DOI:10.1016/j.mce.2010.05.007.

17. Neeha VS, Kinth P. Nutrigenomics research: a review. Journal of Food Science and Technology. 2013;50(3):415-28. DOI:10.1007/s13197-012-0775-z.

\section{References}

1. Hebebrand J, Volckmar A-L, Knoll N, Hinney A. Chipping away the "missing heritability": GIANT steps forward in the molecular elucidation of obesity - but still lots to go. Obesity Facts. 2010;3(5):294-303. DOI:10.1159/000321537.

2. Speliotes EK, Willer CJ, Berndt SI Association analyses of 249,796 individuals reveal 18 new loci associated with body mass index. Nature Genetics. 2010;42(11):937-48. DOI:10.1038/ ng.686.

3. Berná G, Oliveras-López MJ, Jurado-Ruíz E, Tejedo J, Bedoya F, Soria B, Martín F. Nutrigenetics and nutrigenomics insights into diabetes etiopathogenesis. Nutrients. 2014;6(11):5338-69. DOI:10.3390/nu6115338.

4. Loos RJF, Yeo GSH. The bigger picture of FTO: the first GWAS-identified obesity gene. Nature Reviews. Endocrinology. 2014;10(1):51-61. DOI:10.1038/nrendo.2013.227.

5. Tung YC, Gulati P, Liu CH, Rimmington D, Dennis R, Ma M, Saudek V, O'Rahilly S, Coll AP, Yeo GS. FTO is necessary for the induction of leptin resistance by high-fat feeding. Molecular Metabolism. 2015;4(4):287-98. DOI:10.1016/j. molmet.2015.01.011.

6. Xi B, Chandak GR, Shen Y, Wang Q, Zhou D. Association between Common Polymorphism near the MC4R Gene and Obesity Risk: A Systematic Review and Meta-Analysis. PLoS One. 2012;7(9):e45731. DOI:10.1371/journal.pone.0045731.

7. Imaizumi T, Ando M, Nakatochi M, Yasuda $Y$, Honda $H$, Kuwatsuka Y, Kato S, Kondo T, Iwata M, Nakashima T, Yasui H, Takamatsu H, Okajima H, Yoshida Y, Maruyama S. Effect of dietary energy and polymorphisms in BRAP and GHRL on obesity and metabolic traits. Obesity Research and Clinical Practice. 2016; pii: S1871-403X(16)30032-1. DOI:10.1016/j. orcp.2016.05.004.

8. You Y, Yu Y, Wu Y, Rao W, Zhang Y, Liu Y, Yang G, Fu Y, Shi J, Kou C. Association Study between Ghrelin Gene Polymorphism and Metabolic Syndrome in a Han Chinese Population. Clinical Laboratory. 2017;63(1):175-81.

9. Abete I, Astrup A, Martínez JA, Thorsdottir I, Zulet MA. Obesity and the metabolic syndrome: role of different dietary macronutrient distribution patterns and specific nutritional components on weight loss and maintenance. Nutrition Reviews. 2010;68(4):214-31. DOI:10.1111/j.1753-4887.2010.00280.x. 
10. Esteves A, Knoll-Gellida A, Canclini L, Silvarrey MC, André M, Babin PJ. Fatty acid-binding proteins have the potential to channel dietary fatty acids into enterocyte nuclei. Journal of Lipid Research. 2015;57(2):jlr.M062232. DOI:10.1194/jlr.M062232.

11. Liu P, Yu D, Jin X, Li C, Zhu F, Zheng Z, Lv C, He X. The association between the FABP2 Ala54Thr variant and the risk of type 2 diabetes mellitus: a meta-analysis based on 11 casecontrol studies. International Jurnal of Clinical and Experimental Medicine. 2015;8(4):5422-9.

12. Khattab SA, Abo-Elmatty DM, Ghattas MH, Mesbah NM, Mehanna ET. Intestinal fatty acid binding protein Ala54Thr polymorphism is associated with peripheral atherosclerosis combined with type 2 diabetes mellitus. Journal of Diabetes. 2016. DOI:10.1111/1753-0407.12496.

13. Bu G. Apolipoprotein E and its receptors in Alzheimer's disease: pathways, pathogenesis and therapy. Nature Reviews. Neuroscience. 2009;10(5):333-44. DOI:10.1038/nrn2620.

14. Smith CE, Tucker KL, Lai C-Q, Parnell LD, Lee Y-C, Ordovás JM. Apolipoprotein A5 and lipoprotein lipase interact to modulate anthropometric measures in Hispanics of Caribbean origin. Obesity (Silver Spring). 2010;18(2):327-32. DOI:10.1038/ oby.2009.216.

15 Kokh NV, Lifshits GI, Voronina EN. Approaches to the lipid metabolism genes polymorphism analysis in screening for atherosclerosis risk factors. Russian Journal of Cardiology. 2014;10(114):53-7. DOI:10.15829/1560-4071-2014-10-53-057. (In Russian).
16. Gong M, Long J, Liu Q, Deng HC. Association of the ADIPOQ rs17360539 and rs266729 polymorphisms with type 2 diabetes: A meta-analysis. Molecular and Cellular endocrinology. 2010;325(1):78-83. DOI:10.1016/j.mce.2010.05.007.

17. Neeha VS, Kinth P. Nutrigenomics research: a review. Journal of Food Science and Technology. 2013;50(3):415-28. DOI:10.1007/s13197-012-0775-z.

\section{Сведения об авторах}

Кох Наталья Викторовна, Институт химической биологии и фундаментальной медииины СО РАН; адрес: Российская Федерация, Новосибирск, 630090, проспект акад. Лаврентьева, 8; тел.: +7(383)3635150; e-mail: slepukhina_aa@cnmt.ru

Слепухина Анастасия Александровна, Институт химической биологии и фундаментальной медищины СО РАН; адрес: Российская Федеращия, Новосибирск, 630090, проспект акад. Лаврентьева, 8; тел.: +7(383)3635150; e-mail: slepukhina_aа@crmt.ru

Лифшии Галина Израилевна, Институт химической биологии и фундаментальной медищины CO РАН; адрес: Российская Федеращия, Новосибирск, 630090, проспект акад. Лаврентьева, 8; тел.: +7(383)3635150; e-mail: slepukhina_aa@cnmt.ru

\section{Information about the authors}

Kokh Natal'ya V., Institute of Chemical Biology and Fundamental Medicine SB RAS, Address: 8, Lavrentiev Avenue, Novosibirsk, Russian Federation 630090; Phone: +7(383)3635150; e-mail:slepukhina_aa@cnmt.ru

Slepukhina Anastasiya A., Institute of Chemical Biology and Fundamental Medicine SB RAS Adress: 8, Lavrentiev Avenue, Novosibirsk, Russian Federation 630090; Phone: +7(383)3635150; e-mail:slepukhina_aa@cnmt.ru

Lifshits Galina I., Institute of Chemical Biology and Fundamental Medicine SB RAS; Address: 8, Lavrentiev Avenue, Novosibirsk, Russian Federation 630090; Phone: +7(383)3635150; e-mail: slepukhina_aa@cnmt.ru

( С КОНДРИКОВА Н. В., ПОМЕШКИНА С. А., БАРБАРАШ О. Л.

УДК: 616.12-005.4-089-036.8:615.8

DOI: $10.20333 / 2500136-2017-5-109-114$

\section{ПАЦИЕНТ ПОСЛЕ КОРОНАРНОГО ШУНТИРОВАНИЯ: ФОКУС НА ВОССТАНОВЛЕНИЕ ТРУДОСПОСОБНОСТИ}

Н. В. Кондрикова, С. А Помешкина, О. Л. Барбараш

Научно-исследовательский институт комплексных проблем сердечно-сосудистых заболеваний, Кемерово 650002, Российская Федерация

Резюме. В статье представлен обзор основных причин, приводящих к низкому возврату пациентов, перенесших КШ, к своей профессиональной деятельности. А так же обзор мероприятий, изменений в нормативной базе, произошедших в период с 2009 по 2015гг, направленных на улучшение восстановления трудоспособности больных, после перенесенного коронарного шунтирования.

Ключевые слова: коронарное шунтирование, трудоспособность, инвалидность, реабилитация.

Для иитирования: Кондрикова НВ, Помешкина СА, Барбараш ОЛ. Пациент после коронарного шунтирования. Фокус на восстановление трудоспособности. Сибирское медицинское обозрение. 2017;(5): 109-114. DOI: 10.20333/2500136-2017-5-109-114.

\section{PATIENT AFTER CORONARY ARTERY BYPASS GRAFTING. FOCUS FOR RECOVERY OF LABOUR ABILITY}

N. V. Kondrikova, S. A. Pomeshkina, O. L. Barbarash

Research Institute for Complex Issues of Cardiovascular Diseases, Kemerovo 650002, Russian Federation

Abstract. The article provides an overview of the main causes leading to a low return of patients who underwent CABG to their professional activities. As well as a review of activities, changes in the regulatory base that occurred between 2009 and 2015, aimed at improving the rehabilitation of patients, after coronary artery bypass grafting.

Key words: coronary artery bypass grafting, labour ability, disability, rehabilitation. 
Citation: Kondrikova NV, Pomeshkina SA, Barbarash OL. Patient after coronary artery bypass grafting. Focus for recovery of labour ability. Siberian Medical Review. 2017; (5): 109-114. DOI: 10.20333/2500136-2017-5-109-114.

Реабилитация после коронарного шунтирования (КШ) - сложный многогранный процесс, одной из целей которого является улучшение качества жизни, включая восстановление трудоспособности пациента. В России количество проводимых кардиохирургических вмешательств постоянно увеличивается, что требует внедрения эффективных методов реабилитации. Многие аспекты реабилитации пациентов после КШ активно разрабатываются и внедряются в последние годы. Внедрение таких программ демонстрирует множество проблем, связанных с их практическим использованием. Наиболее важные отсутствие преемственности между этапами реабилитационного процесса; низкая доступность центров реабилитации; проблемы финансирования, отсутствие программ физической реабилитации и доказательно обоснованных методологических подходов к оценке эффективности этих программ; недостаточная приверженность пациентов к врачебным рекомендациям по увеличению физической активности и другим рекомендациям по модификации образа жизни. Такая ситуация снижает эффективность как самих кардиохирургических вмешательств, так и мероприятий вторичной профилактики, и ассоциируется с прогрессированием основного заболевания, увеличивает потребность в повторных операциях реваскуляризации, сопровождается ростом инвалидности, а, следовательно, высокими экономическими затратами [1].

В ранее проведенном нами исследовании на основе регистра больных, перенесших КШ (2009г.), выявлен очень низкий показатель возвращения пациентов к труду после оперативного вмешательства. Было показано, что в течение первого года после КШ уменьшилось количество пациентов, вернувшихся к своему труду: до операции процент работающих пациентов среди лиц трудоспособного возраста 61 \%, а после операции - только 36 \% [2]. Ниже приведены основные причины низкого возврата к труду после перенесенного КШ:

1. Не соблюдались сроки продления временной нетрудоспособности до и после коронарного шунтирования.

Длительность листка временной нетрудоспособности до КШ определяется патологией, по поводу которой пациент проходит лечение. В действующем на момент исследования нормативном документе, регламентирующем сроки временной утраты трудоспособности, а именно «Рекомендации для руководителей лечебно-профилактических учреждений и лечащих врачей, специалистов - врачей исполнительных органов фонда социального страхования Российской Федерации», утвержденные Минздравсоцразвития РФ от 21.08.2000г. № 2510/9362-34, представлены ориентировочные сроки временной утраты трудоспособности при различных формах ишемической болезни сердца (ИБС). При наличии у пациента стенокардии не- стабильной (впервые возникшей, прогрессирующей) срок временной утраты трудоспособности составляет 10-14 дней, стенокардии напряжения II функционального класca (ФК) - 10-15 дней; III ФК - 20-30 дней; IV ФК - до 40-60 дней, острого инфаркта миокарда от 60 до 130 дней в зависимости от развившихся осложнений [3]. В обсуждаемом документе других оснований для продления больничного листа нет.

В другом нормативном документе - Приказе N 624 н «Об утверждении порядка выдачи листков нетрудоспособности» - отражены сроки направления пациента на медико-социальную экспертизу (МСЭ) после перенесённых реконструктивных операций: на МСЭ направляются граждане, имеющие стойкие ограничения жизнедеятельности, трудоспособности и нуждающиеся в социальной защите, при очевидном неблагоприятном клиническом и трудовом прогнозе - не позднее 4 месяцев от даты ее начала; а при благоприятном клиническом и трудовом прогнозе - не позднее 10 месяцев от даты начала временной нетрудоспособности, либо гражданин выписывается к трудовой деятельности [4].

В проведенном нами исследовании (2009г.) было отмечено, что среди работающих пациентов, впервые направленных на МСЭ в первый год после КШ, были превышены сроки временной нетрудоспособности перед планируемым хирургическим вмешательством (в среднем срок продления больничного листа до КШ составил 59 дней, а максимальный срок был 225 дней). Этот факт обусловлен не тяжестью коронарной патологией (в основном это были пациенты со стабильной формой ИБС - стенокардией II ФК - 51 \%), а длительным периодом нахождения в «листе ожидания» сначала коронаровентрикулографии и затем КШ с необоснованным, в большинстве случаев, продлением листка нетрудоспособности на этот период. Также в этой группе больных отмечено сокращение срока лечения после КШ перед направлением на МСЭ. Так, средний срок лечения на листке нетрудоспособности после перенесенной операции до даты направления на МСЭ составил всего 90 дней, а минимальный срок составил всего лишь 20 дней [5].

2. Перед направлением пациентов на МСЭ после КШ необходимые обследования проводились не в полном объеме.

Так, у больных, впервые направленных на МСЭ в первый год после КШ, эхокардиография была проведена только у 56 (49 \%), велоэргометрия - у 36 (31\%), суточное мониторирование электрокардиограммы - у 42 (37 \%) пациентов и даже электрокардиография - не в 100 \% случаев, а только у 104 (91 \%) пациентов. Помимо этого, нарушались сроки проведения обследований - в направлениях на МСЭ неоднократно встречались заключения обследований, 
которые были проведены во время лечения в отделении кардиохирургии (то есть в раннем послеоперационном периоде) [6]. Таким образом, большинство пациентов после КШ были направлены на МСЭ с нарушением правил признания лица инвалидом - при незавершенных диагностических мероприятиях.

3. У пациентов после КШ имел место «феномен застывших диагнозов».

При направлении пациентов на МСЭ была отмечена закономерность - диагноз в направлении на МСЭ был полностью скопирован из выписки отделения кардиохирургии. Мы это назвали «феноменом застывших диагнозов». При этом важно отметить, что в выписных эпикризах из отделения кардиохирургии у всех пациентов указывались функциональные нарушения, в том числе ФК стенокардии и хронической сердечной недостаточности (ХCH), нарушения ритма и другие, имевшие место у пациента до операции; а затем «клеймо» стенокардии и ее функциональный класс, а так же все другие функциональные нарушения, остаются в медицинской документации и после проведения у пациента оперативного вмешательства [7]. Итогом этого является факт, что высокий ФК стенокардии, ХСН до операции предопределяет и более выраженную степень функциональных нарушений по данным медицинской документации при направлении и проведении медико-социальной экспертизы.

4. Низкая осведомленность врачей по вопросам экспертизы трудоспособности.

Для оценки уровня знаний вопросов экспертизы трудоспособности было проведено анкетирование врачей различных медицинских организаций города Кемерово. Полученные результаты показали очень низкую осведомленность по этим вопросам. Наиболее слабые знания от- мечены по вопросам, касающимся непосредственно условий и критериев определения группы инвалидности [8].

Из представленных данных следует, что проблемы реабилитации, восстановления трудоспособности среди больных ИБС после КШ очень актуальны и требуют активного многостороннего вмешательства.

На пути решения данных проблем можно отметить позитивные сдвиги.

Так как при проведении медико-социальной экспертизы основным инструментом определения характера и степени выраженности нарушенных функций органов и систем организма, приводящих к ограничениям жизнедеятельности, является клинико-функциональная диагностика, в 2012 году Федеральным бюро МСЭ разработан новый документ, регламентирующий объем направления на МСЭ. Этот документ содержит перечень необходимых обследований, проведенных не более чем за 1 месяц до направления пациента на МСЭ, что позволит объективно оценить имеющиеся функциональные нарушения и снизить процент ошибок при вынесении медико-социального экспертного решения [9].

Следует отметить, что основными принципами диагностики при проведении МСЭ являются: применение адекватных, своевременных, надежных и безопасных методов медицинской диагностики, верифицированных с позиции доказательной медицины

В декабре 2015 г. вышел новый приказ Министерства труда и социальной защиты РФ N 1024н «О классификациях и критериях, используемых при осуществлении медико-социальной экспертизы граждан федеральными государственными учреждениями медико-социальной экспертизы» (с изменениями и дополнениями), где прописаны и утверждены критерии определения той или иной

Таблииа

Перечень методов обследования граждан течебно-профилактическими учреждениями, необходимых при направлении на медико-социальную экспертизу

\begin{tabular}{|c|c|}
\hline Нозология & Необходимые методы обследования \\
\hline \multirow{10}{*}{ Ишемическая болезнь сердца } & ЭКГ в динамике \\
\hline & ВЭМ или Тредмил-тест с протоколом исследования и заключением \\
\hline & Доплер-ЭхоКГ (полный протокол, с указаниями линейных размеров) \\
\hline & Суточное мониторирование ЭКГ с протоколом и заключением \\
\hline & Суточное мониторирование АД с протоколом и заключением (по показаниям) \\
\hline & Исследование NT-proBNP \\
\hline & Коронаровентрикулография (по показаниям) \\
\hline & $\begin{array}{c}\text { Холестерин, глюкоза крови, трансаминазы, КФК, электролиты; } \\
\text { Исследование липидного спектра крови }\end{array}$ \\
\hline & Консультация кардиолога \\
\hline & Консультация кардиохирурга (по показаниям) \\
\hline
\end{tabular}

Примечание: АД - артериальное давление, ВЭМ - велоэргометрия, КФК - креатинфобокиназа, ЭКГ - электрокардиография, ЭхоКГ - эхокардиография, NT-ргоВNP-натриуретический гормон (B-типа) N-кониевой пропептид. 
групп инвалидности при различных заболеваниях, а также введена количественная система оценки степени выраженности стойких нарушений функций организма, обусловленных заболеваниями (в процентах). Такой подход позволяет объективизировать оценку функциональных нарушений органов кровообращения, имеющихся у больных после перенесенного коронарного шунтирования при осуществлении МСЭ [10]. Необходимо помнить, что количественная оценка стойких нарушений функций сердечно-сосудистой системы организма человека, обусловленных ИБС и перенесенным КШ, основывается преимущественно на оценке степени выраженности следующих клинико-функциональных проявлений: недостаточности кровообращения, болевого синдрома - стенокардии, вторичной легочной гипертензии, нарушений сердечного ритма, толерантности к физической нагрузке. Учитываются также и другие факторы патологического процесса: форма и тяжесть течения, распространенность, наличие осложнений.

Учитывая выявленную низкую осведомленность врачей медицинских организаций по вопросам медико-социальной экспертизы, сотрудниками нашего учреждения совместно с главным бюро МСЭ по Кемеровской области, разработаны методические рекомендации «Вопросы экспертизы нетрудоспособности при ИБС», в которых освещается основная нормативно-правовая база, касающаяся вопросов экспертизы как временной, так и стойкой утраты трудоспособности у больных ИБС. В данных методических рекомендациях большое внимание уделено правилам направления пациентов на МСЭ, необходимому объему обследований $[11,9]$. Сделан акцент на условиях признания гражданина инвалидом. Отмечено, что для признания гражданина инвалидом вследствие ИБС необходимо, как минимум два из трех представленных условий:

а) нарушение здоровья со стойким расстройством функций организма, обусловленное ИБС и ее осложнениями;

б) наличие как минимум двух из представленных ограничений жизнедеятельности (полная или частичная утрата гражданином способности или возможности осуществлять самообслуживание, самостоятельно передвигаться или заниматься трудовой деятельностью);

в) необходимость в мерах социальной защиты, включая реабилитацию.

В качестве несомненно позитивного факта следует отметить, что в последние годы в России увеличилась доступность высокотехнологичной медицинской помощи, в том числе коронарного шунтирования. К 2015 году существенно сократились сроки ожидания операции (максимально этот срок составляет 1,5 месяца), что укладывается в оптимальные сроки, представленные в рекомендациях европейского общества кардиологов по реваскуляризации миокарда от 29.08.2014г. [12], и, естественно, позволило расширить сроки для полноценной реабилитации больных после операции.
Участие пациентов после хирургических вмешательств на сердце в реабилитационных программах является одним из главных составляющих успеха. Россия в последние годы переживает ренессанс кардиореабилитации. На всероссийском конгрессе кардиологов в 2016 году представлен проект рекомендаций, посвященных реабилитации пациентов после КШ. В данном документе аргументируется необходимость трехэтапной программы реабилитации (кардиохирургический стационар, стационарное отделение центра реабилитации и амбулаторный этап реабилитации) [13]. Однако практическая реализация такого подхода в настоящее время имеет ряд ограничений.

Организационные преобразования, проводимые в нашем кардиохирургическом центре, позволили в 2013 году сформировать службу медицинской реабилитации, представляющую многопрофильную команду, включающую кардиохирурга, кардиолога-реабилитолога, врача лечебной физкультуры (ЛФК), инструктора ЛФК и психолога. Безусловно, полноценная многоэтапная программа послеоперационной реабилитации пока делает «первые шаги». Однако даже первые результаты ее оптимистичны [14]. Так, среди пациентов, участвующих в трехэтапной системе реабилитации, оказалось достоверно меньше больных, которые после операции были впервые направлены на медико-социальную экспертизу (15,7 \% против 34,5 \% пациентов, не участвующих в третьем этапе реабилитации), а так же большее количество пациентов $(47,1$ \% и $30,9 \%$ соответственно) вернулись к своей профессиональной деятельности в течение первого года после перенесенного КШ [15].

На сегодняшний день осуществление третьего, амбулаторного, этапа реабилитации является наиболее сложным. Этот этап реабилитации - один из самых важных, но и трудновыполнимых, ввиду отсутствия поликлинических кардиореабилитационных отделений в структуре ЛПу области, отсутствия адекватного финансирования амбулаторных программ реабилитации, обученных кадров, четкой методической базы и утвержденных рекомендаций по проведению данного этапа. Как и первые два этапа, третий - амбулаторный этап реабилитации, должен строиться на мультидисциплинарном командном подходе и включать не только контролируемые физические тренировки, но и активное внедрение психологической реабилитации, участие пациентов в «школах для больных, перенесших КШ». Именно третий этап призван закрепить достижения успешно проведенной операции на сердце, вернуть пациента к активной жизни и, что немало важно, к труду.

В настоящее время в нашем учреждении даже контролируемые физические тренировки на амбулаторном этапе реабилитации доступны далеко не всем пациентам, а только жителям города Кемерово и ближайших населенных пунктов. Отдаленность места жительства, отсутствие центров реабилитации на базе ЛПУ различных городов 
области, вне кардиохирургических клиник - одно из серьезных ограничений для внедрения третьего этапа реабилитации. Очевидно, определенную категорию пациентов целесообразно в условиях стационара обучать принципам последующей амбулаторной реабилитации, контроль за эффективностью которой возможно проводить с помощью телекоммуникационных средств.

Внедрение же полноценной программы реабилитации после КШ, направленной на достижение максимального реабилитационного эффекта, включающего восстановление трудоспособности, а также выработка единых подходов к проведению медико-социальной экспертизы и вынесению объективных экспертных решений по признанию граждан инвалидами, позволит достичь главную цель хирургического вмешательства у пациентов с ИБС улучшение качества жизни и возвращение пациентов, перенесших КШ, к своей профессиональной деятельности.

\section{Литература}

1. Барбараш ОЛ. «Нужна ли реабилитация пациентам после коронарного шунтирования?» (интервью). Русский медииинский журнал. 2016;(19):1254-56.

2. Помешкина СА, Кондрикова НВ, Барбараш ОЛ. Оценка трудоспособности пациентов, подвергшихся коронарному шунтированию. Комплексные проблемь сердечно-сосудистых заболеваний. 2014;(1):26-30. DOI: 10.17802/2306-1278-2014-1-26-30

3. Рекомендации для руководителей лечебно-профилактических учреждений и лечащих врачей, специалистов-врачей исполнительных органов Фонда социального страхования Российской Федерации [Интернет] : Утв. 18.08.2000, Минздравом РФ 21.08.2000 N 2510/9362-34, ФСС РФ 21.08.2000 N 02-08/10-1977П. Об ориентировочных сроках временной нетрудоспособности при наиболее распространенных заболеваниях и травмах : Письмо ФСС РФ от 01.09.2000 N 02-18/10-5766. Доступно: http:// www.consultant.ru/document/cons_doc_LAW_56793/ (дата обращения: 28.11.2016)

4. Об утверждении Порядка выдачи листков нетрудоспособности [Интернет] : Приказ Минздравсоцразвития России от 29.06.2011 N 624н, ред. от 02.07.2014 (Зарегистрировано в Минюсте России 07.07.2011 N 21286). Доступно: http://www.consultant.ru/document/cons_doc_ LAW_116333/ (дата обращения: 28.11.2016)

5. Барбараш ОЛ, Самородская ИВ, Эфрос ЛА, Помешкина СА, Кондрикова НВ, Бойцов СА. Вопросы определения инвалидности после коронарного шунтирования. Кардиология. 2016;(6):96-101. DOI: 10.18565/ cardio.2016.6.96-101.

6. Помешкина СА, Кондрикова НВ, Крупянко ЕВ, Каган ЕС, Барбараш ОЛ. Анализ подходов к оценке стойкой утраты трудоспособности у пациентов, подвергшихся коронарному шунтированию. Кардиология. 2013;53(7):62-6.

7. Кондрикова НВ, Симчина ЯВ, Братчикова ВА. Ана- лиз ошибок при направлении пациентов на медико-социальную экспертизу. Врач. 2016;(7):2-5.

8. Кондрикова НВ, Барбараш ОЛ. Оценка знания врачами вопросов медико-социальной экспертизы. Врач. 2015;(3):83-5.

9. Дымочка МА, Лаврова ДИ. Перечень методов обследования граждан лечебно-профилактическими учреждениями, необходимых для направления на медико-социальную экспертизу [Интернет]: Информационное письмо. Москва; 2012. Доступно: http://www.invalidnost.com/ publ/sotrudnikam_sluzhby_mseh/perechen_obsledovanij_ dlja_mseh_pri_razlichnykh_zabolevanijakh/3-1-0-484. (дата обращения 30.12.2016)

10. О классификациях и критериях, используемых при осуществлении медико-социальной экспертизы граждан федеральными государственными учреждениями медико-социальной экспертизы (с изменениями и дополнениями) [Интернет] : Приказ Министерства труда и социальной защиты РФ от 17 декабря 2015 г. N 1024н. Доступно: http://base.garant.ru/71309914/\#ixzz4QizoaVSo. (дата обращения: 09.01.2017)

11. О порядке и условиях признания лица инвалидом [Интернет] : Постановление Правительства РФ от 20.02.2006 N 95 (в ред. Постановлений Правительства РФ от 07.04.2008 N 247,от 30.12.2009 N 1121, от 06.02.2012 N 89,от 16.04.2012 N 318, от 04.09.2012 N 882,от 06.08.2015 N 805, от 10.08.2016 N 77). Доступно: http://www.studfiles. ru/preview/6212897/page:2/. (дата обращения: 28.18.2016)

12. Windecker S, Kolh Ph, Alfonso F, Collet J-P, Cremer J, Falk V. и др. Рекомендации ESC/EACTS по реваскуляризации миокарда 2014. Российский кардиологический журнал. 2015;2(118):5-81. DOI: 10.15829/1560-4071-2015-02-581

13. Бокерия ЛА, Аронов ДМ, Барбараш ОЛ, Бубнова МГ, Князева ТА, Красницкий ВБ, Лямина НП, Маликов $\mathrm{BE}$, Новикова НК, Петрунина ВE, Арзуманян МА, Сумин $\mathrm{AH}$, Чумакова ГА. Коронарное шунтирование больных ИБС - реабилитация и вторичная профилактика [Интернет] : Российские клинические рекомендации. Москва; 2016 Доступно: http://www.scardio.ru/content/Guidelines/ project/Project_Koronarnoe_shuntirovanie_pacientov_ IBS_19.07.2016.pdf. (дата обращения: 28.12.2016)

14. Белякин СА, Юдин ВЕ, Щегольков АМ, Шкарупа ОФ. Проблемы эффективности качества медицинской реабилитации больных ишемической болезнью сердца после коронарного шунтирования и пути их решения. Russian Journal of Rehabilitation Medicine. 2014;1(4):10-18.

15. Помешкина СА, Кондрикова НВ, Иноземцева АА, Панычева ЕП, Барбараш ОЛ. Влияние трехэтапной системы реабилитации после коронарного шунтирования на трудоспособность пациентов. Кардиология 2016: вызовы и пути решения : тезисы Российского национального конгресса кардиологов. С. 583. 


\section{References}

1. Barbarash OL. Do patients need rehabilitation after a coronary bypass surgery? (interview). RMJ. 2016;(19):12541256. (In Russian)

2. Pomeshkina SA, Kondrikova NV, Barbarash OL. Labour ability assessment of patients undergone by coronary artery bypass grafting. Complex Issues of Cardiovascular Diseases. 2014;(1):26-30. DOI: 10.17802/2306-1278-2014-1-26-30. (In Russian)

3. The Statement of the SIF of the RF dated 09.01.2000 N 02-18 / 10-5766 "Approximate timing of temporary disability in common diseases and injuries - Guidelines for managers of health care institutions and physicians, expert physicians of the Social Insurance Fund of the Russian Federation approved on 08.18 .2000 , by the Ministry of Healthcare of the Russian Federation on 21.08.2000 N 2510 / 9362-34, by the SIF on 21.08.2000 N 02-08 / 10-1977P. Available from: http:// www.consultant.ru/document/cons_doc_LAW_56793/. (cited 2016 Nov 28). (In Russian)

4. The Order of the Ministry of Healthcare and Social Development of the Russian Federation issued on 06.29.2011 N 624n (ed. on 02.07.2014) "On approval of the procedure for issuing sick leave" (Registered in the Ministry of Justice of the Russian Federation on 07.07.2011 N 21286). Available from: http://www.consultant.ru/document/cons_doc_ LAW_116333/ (cited 2016 Nov 28). (In Russian)

5. Barbarash OL, Samorodskaya IV, Efros LA, Pomeshkina SA, Kondrikova NV, Boitsov SA. Problems of Determination of Degree of Disability After Coronary Artery Bypass Surgery. Kardiologiia. 2016;(6):96-101.DOI: 10.18565/ cardio.2016.6.96-101. (In Russian)

6. Pomeshkina SA, Kondrikova NV, Krupyanko EV, Kagan ES, Barbarash OL. Analysis of Approaches to Assessment of Persistent Loss of Capacity to Work in Patients Who Had Undergone Coronary Bypass Surgery. Kardiologiia. 2013;53(7):62-66. (In Russian)

7. Kondrlkova NV, Simchina YV, Bratchikova VA. Analysis of errrors when referring patients to sociomedical examinatio. Vrach (The Doctor). 2016;(7):2-5. (In Russian)

8. Kondrikova NV, Barbarash OL. Assessment of physicians, awareness about sociomedical examination. Vrach (The Doctor). 2015;(3):83-85.

9. Dymochka MA, Lavrova DI. The Statement of the FSBI "Federal Bureau of Medical and Social Expertise" of the Ministry of Labor and Social Protection "List of examination methods for healthcare institutions for citizens' referral to medical and social expertise // Moscow. 2012. Available from: http://www.invalidnost.com/publ/sotrudnikam_sluzhby_ mseh/perechen_obsledovanij_dlja_mseh_pri_razlichnykh_ zabolevanijakh/3-1-0-484 (cited 2016 Dec 30). (In Russian)

10. The Order of the Ministry of Labor and Social Protection of the Russian Federation issued on December

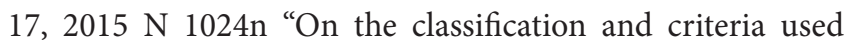
in medical and social expertise of citizens by federal government agencies for medical and social expertise" (amended and augmented). Available from: http://base. garant.ru/71309914/\#ixzz4QizoaVSo (cited 2017 Jan 09). (In Russian)

11. The Government Decree issued on 02.20.2006 N 95 (amended by the RF Government Decree issued on 04.07.2008 N 247, on 12.30.2009 N 1121, on 02.06.2012 N 89 , on $04.16 .2012 \mathrm{~N} \mathrm{318}$, on $09.04 .2012 \mathrm{~N} \mathrm{882}$, on 08.06 .2015 $\mathrm{N} 805$, on 10.08.2016 N 77) "Procedures and conditions of getting approved for disability" . Available from: http://www. studfiles.ru/preview/6212897/page:2/. (cited 2016 Dec 28). (In Russian)

12. Windecker S, Kolh Ph, Alfonso F, Collet J-P, Cremer J, Falk V. 2014 ESC/EACTS guidelines on myocardial revascularization. Russian Journal of Cardiology. 2015;2(118):5-81.DOI: 10.15829/1560-4071-2015-02-5-81

13. Bokeria LA, Aronov DM, Barbarash OL, Bubnova MG, Knyazeva TA, Krasnitskiy VB, Lyamina NP, Malikov VE, Novikova NK, Petrunina VE, Arzumanyan MA, Sumin AN, Chumakova GA. Russian clinical guidelines "Coronary artery bypass grafting in patients with coronary artery disease - rehabilitation and secondary prevention". Moscow. 2016. Available from: http://www.scardio.ru/content/Guidelines/ project/Project_Koronarnoe_shuntirovanie_pacientov_ IBS_19.07.2016.pdf. (cited 2016 Dec 28). (In Russian)

14. Belyakin SA, Yudin VE, Shchegol'kov AM, Shkarupa OF. Problems of the efficiency and quality of medical rehabilitation of coronary heart disease patients after coronary bypass surgery and solution. Russian journal of rehabilitation medicine. 2014;1(4):10-18. (In Russian)

15. Pomeshkina SA, Kondrikova NV, Inozemtseva AA, Panycheva EP, Barbarash OL. Effects of a three-stagerehabilitation program after coronary artery bypass grafting on patients' disability. Abstracts of the Russian National Congress. Cardiology 2016: Challenges and Solutions. P. 583. (In Russian)

\section{Сведения об авторах}

Кондрикова Наталья Владимировна, Научно-исследовательский институт комплексных проблем сердечно-сосудистых заболеваний; адрес: Российская Федерация, 650002, Кемерово, Сосновый бульвар, д. 6; тел.: +79039071836; е-mail: NKondrik@yandex.ru

Помешкина Светлана Александровна, Научно-исследовательский институт комплексных проблем сердечно-сосудистых заболеваний; адрес: Российская Федерация, 650002, Кемерово, Сосновый бульвар, д. 6; тел.: +73842643153; e-mail: Swetlana.sap2@mail.ru

Барбараш Ольга Леонидовна, Научно-исследовательский институт комплексных проблем сердечно-сосудистых заболеваний; адрес: Российская Федерация, 650002, г. Кемерово, Сосновый бульвар, д. 6; тел.: +73842643308; e-mail: Olb61@mail.ru

\section{Information about the authors}

Kondrikova Natalia V., Research Institute for Complex Issues of Cardiovascular Diseases; Address: 6, Pine Boulevard, Kemerovo, Russian Federation 650002; Phone: +79039071836; e-mail: NKondrik@yandex.ru

Pomeshkina Svetlana A., Research Institute for Complex Issues of Cardiovascular Diseases; Address: 6, Pine Boulevard, Kemerovo, Russian Federation 650002; Phone: +73842643153 ; e-mail:Swetlana.sap2@mail.ru

Barbarash Olga L., Research Institute for Complex Issues of Cardiovascular Diseases; Address: 6, Pine Boulevard, Kemerovo, Russian Federation 650002; Phone: +73842643308 e-mail:Olb61@mail.ru 


\title{
Защищенные дессертации / Dissertations
}

() ШТАРИК С. Ю.

\author{
ОБЗОР ТЕМАТИКИ ДИССЕРТАЦИЙ, РАССМОТРЕННЫХ В 2016 ГОДУ \\ СОВЕТОМ ПО ЗАЩИТЕ ДИССЕРТАЦИЙ НА СОИСКАНИЕ УЧЕНОЙ СТЕПЕНИ \\ КАНДИДАТА НАУК, НА СОИСКАНИЕ УЧЕНОЙ СТЕПЕНИ ДОКТОРА НАУК Д \\ 208.037.01 ПО СПЕЦИАЛЬНОСТИ 14.01.08 - ПЕДИАТРИЯ
}

С. Ю. Штарик

Красноярский государственный медицинский университет им. проф. В.Ф. Войно-Ясенецкого, Красноярск, 660022, Российская Федерация

\section{REVIEW OF DISSERTATION TOPICS THAT WERE SUBMITTED IN 2016 BY THE COMMITTEE OF DISSERTATION DEFENSE FOR THE DEGREE OF CANDIDATE OF SCIENCE, FOR THE DEGREE OF DOCTOR OF SCIENCE D 208.037.01 IN SPECIALTY 14.01.08 - PEDIATRICS}

S. Yu. Shtarik

Professor V. F. Voino-Yasenetsky Krasnoyarsk State Medical University, Krasnoyarsk 660022, Russian Federation

Диссертационный совет Д 208.037.01 утвержден при Красноярском государственном медицинском университете имени профессора В.Ф. Войно-Ясенецкого приказом Рособрнадзора от 01 декабря 2001 года № 495 - в. Диссертационному совету было разрешено принимать к защите диссертации по специальностям: 14.01.04 - внутренние болезни и 14.01 .08 - педиатрия. Приказом Рособрнадзора № 1110-142 от 18.05.2011г. совету Д 208.037.01 расширены полномочия и разрешено принимать к защите диссертации по трем специальностям (14.01.04 - внутренние болезни, 14.01 .05 - кардиология, медицинские науки и 14.01 .08 - педиатрия), утвержден новый состав совета.

В 2016 году по специальности 14.01 .08 - педиатрия диссертационным советом Д 208.037.01 рассмотрено 2 кандидатских диссертации. Все диссертации выполнены по одной специальности, с положительным решением по итогам защит.

Диссертация Кустовой Татьяны Владимировны на соискание ученой степени кандидата медицинских наук по специальности 14.01.08 - педиатрия «Клинико-эпидемиологические и нейропсихологические особенности синдрома дефицита внимания и гиперактивности у детей младшего школьного возраста» выполнена на кафедре педиатрии ИПО ГБОУ ВПО «Красноярский государственный медицинский университет имени профессора В.Ф. Войно-Ясенецкого» Минздрава России. Научный руководитель - д.м.н., профессор Таранушенко Татьяна Евгеньевна, заведующая кафедрой педиатрии ИПО ГБОУ ВПО «Красноярский государственный медицинский университет имени профессора В.Ф. Войно-Ясенецкого» Минздрава России. Научный консультант - д.м.н., профессор Салмина Алла Борисовна, заведующая кафедрой биологической химии с курсом медицинской, фармацевтической и токсикологической химии ГБОУ ВПО «Красноярский государственный медицинский университет им. проф. В.Ф. Войно-Ясенецкого» Минздрава России. Диссертационная работа выполнена по плану НИР ГБОУ ВПО «Красноярский государственный медицинский университет им. проф. В.Ф. Войно-Ясенецкого» Минздрава России (№ государственной регистрации 01201458158)

Диссертационным советом было отмечено, что на основании выполненных соискателем исследований разработана новая научная идея об участии окситоцина в патогенезе синдрома дефицита внимания и гиперактивности (СДВГ), обогащающая научную концепцию о механизмах формирования данной патологии; предложен диагностический алгоритм СДВГ, позволяющий оптимизировать врачебную тактику при СДВГ; доказано отсутствие различий в частоте СДВГ по гендерному признаку сре- ди младших школьников Красноярского края и представлены варианты течения данной патологии с учетом коморбидности, что позволило выявить клинические особенности данного расстройства преимущественно у мальчиков (возрастная группа 8-9 лет), имеющих высокую вероятность сочетания СДВГ и сопутствующих нарушений.

Теоретическая значимость исследования обоснована тем, что доказано увеличение уровня окситоцина в плазме крови у детей с СДВГ (гиперактивная и комбинированная формы), что подтверждает причастность данного нейромедиатора к патогенетическим механизмам развития изучаемой патологии и определяет необходимость дальнейшего научного поиска.

Применительно к проблематике диссертации, наряду с анамнестическими и клиническими методами, результативно использованы методы лабораторной диагностики, включая метод иммуноферментного анализа для исследования окситоцина плазмы крови, и психологическое обследование детей с оценкой уровня умственного развития, внимания и памяти.

Изложены доказательства, что наиболее частыми коморбидными состояниями у детей с СДВГ являются различные виды невротических, неврозоподобных и тревожных расстройств, второе место занимают нарушения речи и школьных навыков, третье место принадлежит оппозиционно-вызывающим вариантам поведения; к гендерным особенностям сопутствующих нарушений отнесены тики, энурез, расстройства развития речи, оппозиционно-вызывающее поведение у мальчиков и тревожность и нарушения сна у девочек; раскрыты особенности неврологического статуса у детей с СДВГ в виде редких случаев грубой очаговой неврологической симптоматики при значительной частоте «мягких» неврологических знаков, которые определяются типом рассматриваемой патологии и требуют самостоятельной оценки в диагностическом алгоритме СДВГ; изучены данные о выявляемости, гендерных и возрастных особенностях всех клинических вариантов СДВГ в популяции младших школьников Красноярского края и обоснована информативность нового доклинического скрининг-метода выявления данной патологии на основе дифференцированного подхода с уточнением высокой и низкой вероятности верификации диагноза.

Значение полученных соискателем результатов исследования для практики подтверждается тем, что разработаны и внедрены результаты проведенного исследования в работу детских лечебно-профилактических учреждений: КГБУЗ «Красноярский краевой клинический центр охраны материнства и детства» (660074, г.Красноярск, ул.акад.Киренского, д.2А), 
КГБУЗ «Красноярская межрайонная детская клиническая больница № 1» (660021, г. Красноярск, ул. Ленина 149). Материалы работы включены в программы практических занятий и лекционного курса кафедры педиатрии ИПО Красноярского государственного медицинского университета им. проф. В.Ф.Войно-Ясенецкого (660022, г. Красноярск, ул. П. Железняка, 1). Определена возможность практического использования доклинического скрининг-метода выявления СДВГ. Представлены методические рекомендации для педиатров и врачей общей практики «Диагностика и лечение синдрома дефицита внимания и гиперактивности у детей».

Оценка достоверности результатов исследования выявила, что теория построена на известных данных о роли нейрогормонов в регуляции социального поведения; идея базируется на известных данных о том, что окситоцин влияет на развитие ряда патологий, сопряженных с нарушениями социальных контактов (аутизм, депрессии, шизофрения, синдром неонатального отделения от матери и др.); использованы сравнения с данными A. Baumgaertel et al. (1996), Н.К. Сухотиной (2002), R.A. Barkley (2003), И.П. Брязгунова (2008), О.Р. Ноговициной и соавт. (2008), О.И. Романчука (2010), Е.А. Морозовой (2011), Н.Н. Заваденко (2012), Л.С. Чутко и соавт. (2012); установлено совпадение данных о распространенности СДВГ с работами А. Baumgaertel et al. (1996), предикторах (с работами Е.А. Морозовой (2011), Л.С. Чутко и соавт. (2012)) и сведениях о коморбидности рассматриваемой патологии с исследованиями Н.К. Сухотиной (2002), О.Р. Ноговициной и соавт. (2008), Н.Н. Заваденко (2012); использованы в работе современные лабораторные и инструментальные методы верификации диагноза, адекватные по объему исследуемые группы (скрининговое популяционное обследование 1731 школьников (842 мальчиков и 889 девочек) младших классов (с 1 по 4 класс, включительно) с использованием рейтинговой шкалы ADHD RS-IV, которая представлена 2 вариантами опросников (родительская и учительская версия), с выделением 3 групп: дети с отрицательным результатом скрининга (набранное количество баллов ниже 85 перцентиля), у которых отсутствуют данные за СДВГ; дети с субнормальными значениями скрининга (от 85 до 90 перцентиля); дети с вероятным диагнозом СДВГ по результатам анкетирования (от 90 перцентиля), которые составили целевую выборку по рассматриваемой патологии (229 детей, что составило 13,2 \% от всей выборки)); современные методы статистической обработки позволяют с высоким уровнем доверия относиться к полученным результатам.

Диссертация Чугуновой Татьяны Николаевны на соискание ученой степени кандидата медицинских наук по специальности 14.01.08 - педиатрия «Клинико-анамнестические особенности и диагностическое значение системы матриксных металлопротеиназ при гипоксическом поражении центральной нервной системы у детей» выполнена на кафедре пропедевтики детских болезней ГБОУ ВПО «Алтайский государственный медицинский университет» Минздрава России, г. Барнаул. Научный руководитель - доктор медицинских наук, профессор Лобанов Юрий Фёдорович, заведующий кафедрой пропедевтики детских болезней ГБОУ ВПО «Алтайский государственный медицинский университет» Минздрава России. Научный консультант - кандидат медицинский наук Кореновский Юрий Владимирович, ассистент кафедры биохимии и клинической лабораторной диагностики ГБОУ ВПО «Алтайский государственный медицинский университет» Минздрава России. Работа выполнена по плану НИР АГМУ (№ гос. регистрации 01200112706, № тем. карты 221-269).

Диссертационным советом было отмечено, что на основании выполненных соискателем исследований разработана новая научная идея об активации системы матриксных металлопротеиназ в течение первых 3-4 суток жизни новорожденных с перинатальной гипоксией, обогащающая научную концепцию о механизмах развития данной патологии; предложено использовать определение ферментов протеолитической системы матриксных металлопротеиназ в качестве диагностических маркеров тяжести перинатальной гипоксии в раннем неонатальном периоде; доказано, что исследование концентраций матриксных металлопротеиназ-1 и -9, тканевого ингибитора матриксных металлопротеиназ-1 в крови новорожденных в раннем неонатальном периоде повышает эффективность диагностики тяжести перинатального гипоксического поражения центральной нервной системы (ЦНС) и прогноза неврологических нарушений на первом году жизни.
Теоретическая значимость исследования обоснована тем, что доказана перспективность дальнейших исследований по изучению матриксных металлопротеиназ у детей с гипоксическим поражением ЦНС.

Применительно к проблематике диссертации наряду с клиническими методами (изучение анамнеза, оценка неврологического статуса) результативно использованы методы ультразвуковой диагностики (оценка нейросонографии), биохимические и иммунохимические исследования.

Изложены доказательства, что перинатальное гипоксическое поражение центральной нервной системы у новорожденных детей в раннем неонатальном периоде сопровождается нарастанием матриксных металлопротеиназ-1 и -9 на 3-4 сутки жизни и пониженным уровнем тканевого ингибитора матриксных металлопротеиназ-1; раскрыто, что изменения в системе матриксных металлопротеиназ позволяют прогнозировать тяжесть гипоксического поражения центральной нервной системы у детей и определять своевременность и длительность реабилитационного периода; изучена взаимосвязь степени выраженности клинических проявлений поражения ЦНС с концентрациями ферментов протеолитической системы матриксных металлопротеиназ.

Значение полученных соискателем результатов исследования для практики подтверждается тем, что разработаны и внедрены результаты исследования в практическую деятельность медицинского учреждения: КГБУ3 «Перинатальный центр (клинический) Алтайского края» (656019, Алтайский край, г.Барнаул, ул.Попова,29); а также в учебный процесс и научную деятельность на кафедре биохимии и клинической лабораторной диагностики ГБОУ ВПО «Алтайский государственный медицинский университет» Минздрава России (656038, Алтайский край, г. Барнаул, проспект Ленина, д. 40); определена возможность практического использования результатов исследования для повышения качества диагностики гипоксического поражения центральной нервной системы у детей.

Оценка достоверности результатов исследования выявила, что теория построена на известных данных о роли матриксных металлопротеиназ в патогенезе гипоксического поражения ЦНС у детей; идея базируется на отсутствии четких алгоритмов диагностики заболевания, эффективных подходов к лечению; использованы сравнения с результатами работ $\mathrm{S}$. Chakraborti et al. (2003); S. Sunagawa, T. Ichiyama, R. Honda et al. (2009), Y. Yang, J.W. Hill, G. A. Rosenberg (2011), Ю.В. Кореновского и соавт. (2011, 2012); установлено, что в работах S. Sunagawa, T. Ichiyama, R. Honda et al. (2009), Y. Yang, J.W. Hill, G. A. Rosenberg (2011) определено повышение концентрации матриксных металлопротеиназ в плазме венозной крови при перинатальной гипоксии; использованы в работе современные лабораторные и инструментальные методы верификации диагноза; современные биохимические методики на сертифицированном оборудовании, адекватные по объему исследуемые и контрольные группы (всего взято под наблюдение 124 новорождённых ребёнка: 74 недоношенных и 50 доношенных пациентов, из них 50 недоношенных детей и 25 доношенных - имели гипоксическое поражение центральной нервной системы и 24 недоношенных и 25 доношенных детей, не имевших поражения ЦНС и критериев исключения, составили группу клинического сравнения), современные методы статистической обработки, что позволяет с высоким уровнем доверия относиться к полученным результатам.

В заключение необходимо отметить, что по материалам рассмотренных диссертаций опубликовано 12 печатных работ, в том числе опубликованных в ведущих рецензируемых научных журналах и изданиях, определенных Высшей аттестационной комиссией, -8 статей, 2 работы опубликованы в материалах всероссийских и международных конференций и симпозиумов и 1 работа - в зарубежном научном издании; изданы 1 методические рекомендации.

\section{Сведения об авторах}

Штарик Светлана Юрьевна, Красноярский государственный медииинский университет им. проф. В. Ф. Войно-Ясенеикого; адрес: Российская Федеращия, 660022, г. Красноярск, ул. Партизана Железняка, д. 1; тел.: +7(391) 2125394; e-mail: shtarik@yandex.ru.

\section{Information about the authors}

Shtarik Svetlana. Yu., Professor V. F. Voino-Yasenetsky Krasnoyarsk State Medical University; Address: 1, Partizan Zheleznyak Str., Krasnoyarsk, Russian Federation 660022; Phone: +7 (391) 2125394; e-mail: shtarik@yandex.ru. 